\title{
Pregnancy derived products for treatment of perinatal brain injuries
}

Citation for published version (APA):

Müller, M. M. (2017). Pregnancy derived products for treatment of perinatal brain injuries. [Doctoral Thesis, Maastricht University]. Maastricht University. https://doi.org/10.26481/dis.20170224mm

Document status and date:

Published: 01/01/2017

DOI:

10.26481/dis.20170224mm

Document Version:

Publisher's PDF, also known as Version of record

\section{Please check the document version of this publication:}

- A submitted manuscript is the version of the article upon submission and before peer-review. There can be important differences between the submitted version and the official published version of record.

People interested in the research are advised to contact the author for the final version of the publication, or visit the DOI to the publisher's website.

- The final author version and the galley proof are versions of the publication after peer review.

- The final published version features the final layout of the paper including the volume, issue and page numbers.

Link to publication

\footnotetext{
General rights rights.

- You may freely distribute the URL identifying the publication in the public portal. please follow below link for the End User Agreement:

www.umlib.nl/taverne-license

Take down policy

If you believe that this document breaches copyright please contact us at:

repository@maastrichtuniversity.nl

providing details and we will investigate your claim.
}

Copyright and moral rights for the publications made accessible in the public portal are retained by the authors and/or other copyright owners and it is a condition of accessing publications that users recognise and abide by the legal requirements associated with these

- Users may download and print one copy of any publication from the public portal for the purpose of private study or research.

- You may not further distribute the material or use it for any profit-making activity or commercial gain

If the publication is distributed under the terms of Article $25 \mathrm{fa}$ of the Dutch Copyright Act, indicated by the "Taverne" license above, 
(3)

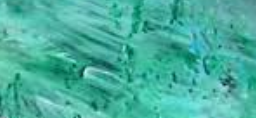

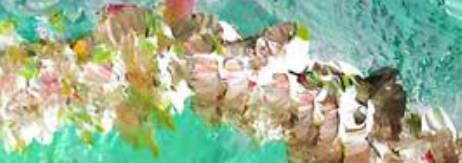

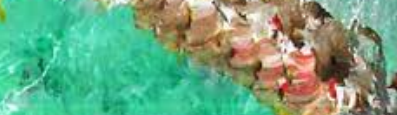

6.

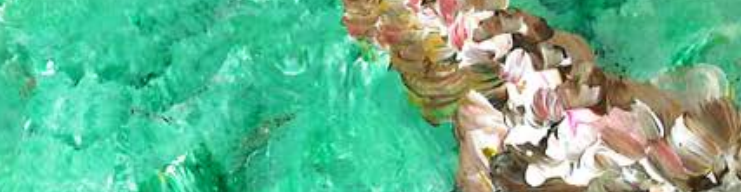

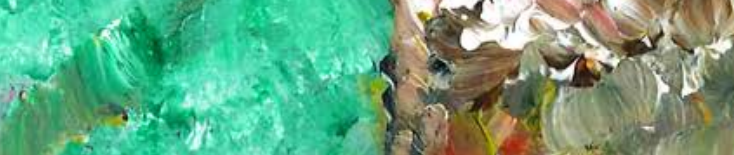

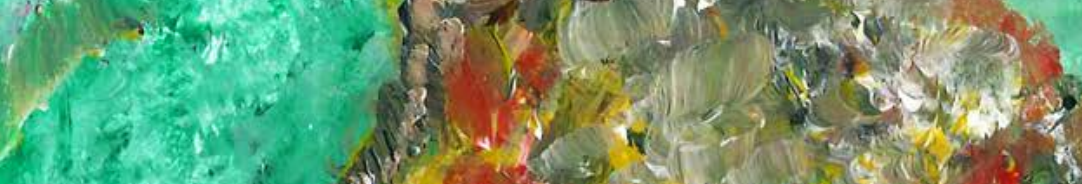

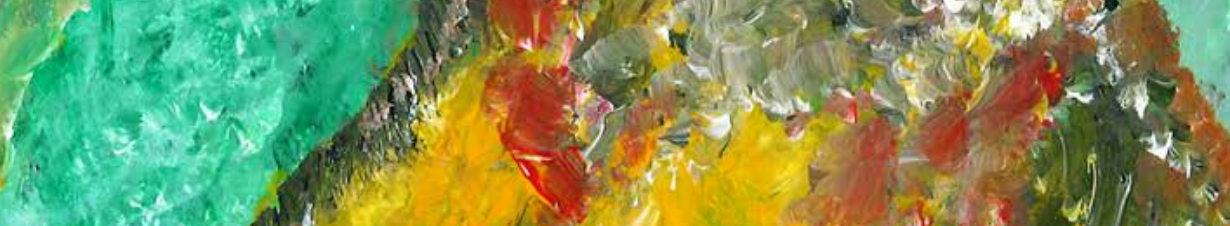

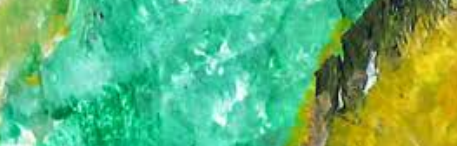

)

Q) $=\int_{2}=0$

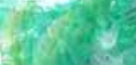

$\lim _{-\infty}$

$3 x^{2}+2$

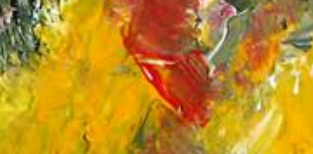

$\cos ^{2} \times$

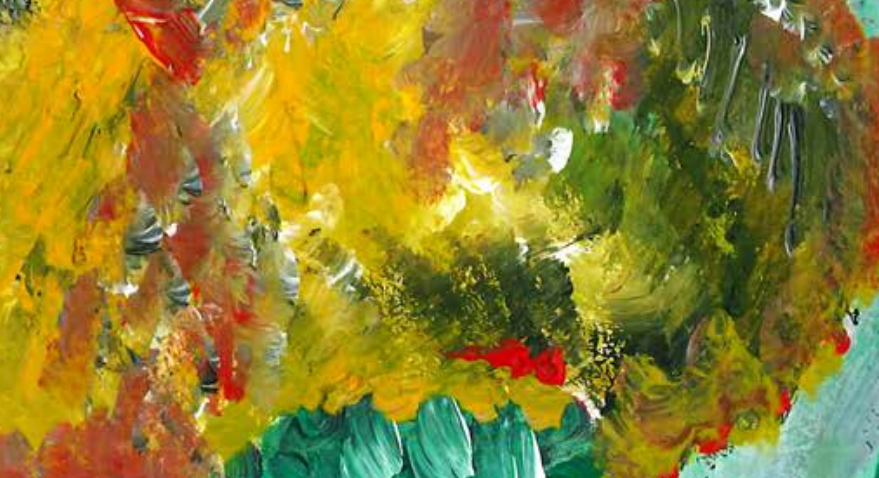

- in 2010 Q. Pregnancy derived products for
4reatment of perinatal brain injuries 2. Pregnancy derived products for
4reatment of perinatal brain injuries

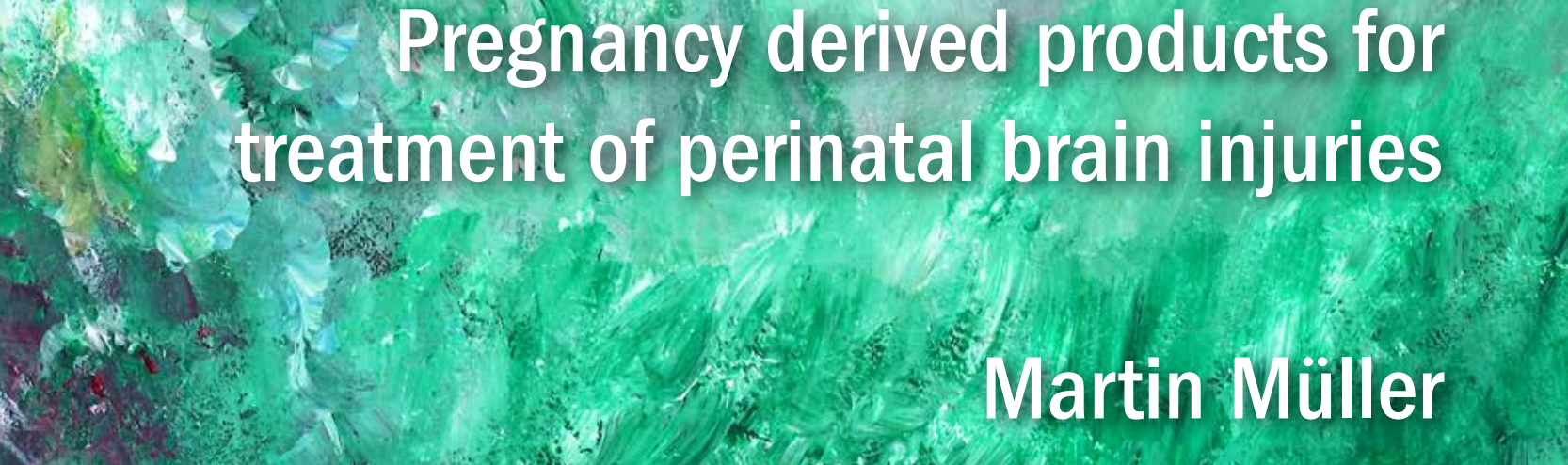

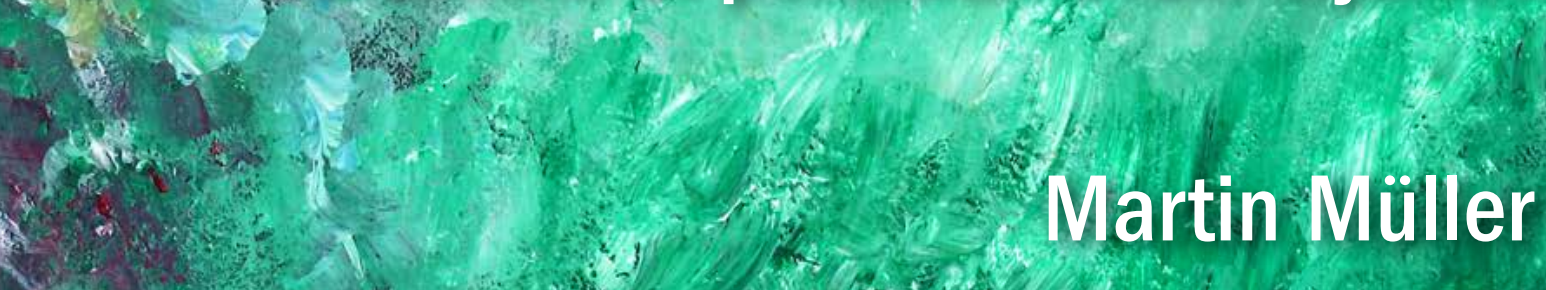


Cover image Plazentarknospe 2017, Martin Müller

Copyright M Müller, Maastricht 2017

ISBN 9789461596666

Financial support for the publication of this thesis was kindly provided by:

Stichting Kindergeneeskunde Maastricht 
Pregnancy derived products for treatment of perinatal brain injuries

\section{PROEFSCHRIFT}

Ter verkrijging van de graad van doctor

aan de Universiteit Maastricht,

op gezag van de Rector Magnificus

Prof. dr. Rianne M. Letschert

volgens het besluit van het College van Decanen,

in het openbaar te verdedigen

Op vrijdag 24 februari 2017 om 12.00 uur

Door

Martin Müller

geboren op 05.12.1976 te Wroclaw, Poland 


\section{Promotores}

Prof. dr. Boris W.W. Kramer

Prof. dr. Daniel Surbek (Universitätsklinik für Frauenheilkunde, Bern, Switzerland)

\section{Copromotores}

Dr. Antonio W.D. Gavilanes

Dr. Tim G.A. Wolfs

\section{Beoordelingscommissie}

Prof. dr. Marc Spaanderman (voorzitter)

Prof. dr. Richard Berger (MHK, Neuwied, Germany)

Prof. dr. Donald Peebles (UCL, London, United Kingdom)

Prof. dr. Harry Steinbusch

Prof. dr. Luc J.I. Zimmermann 


\section{Contents}

Abbreviations: $\quad 7$

Chapter $1 \quad$ General introduction and aims 9

Chapter 2 Homing of placenta-derived mesenchymal stem cells after perinatal intracerebral transplantation in a rat model

Chapter 3 Wharton`s jelly Mesenchymal Stem Cells protect the immature brain in rats and modulate cell fate

Chapter $4 \quad 17 \beta$-Estradiol protects 7-day old rats from acute brain injury and reduces the number of apoptotic cells.

Chapter 5 PreImplantation factor (PIF) promotes neuroprotection by targeting microRNA let-7

Chapter 6 PreImplantation Factor bolsters neuroprotection via modulating Protein Kinase A and Protein Kinase C signaling

Chapter 7 General discussion

Chapter 8 Summary

Chapter $9 \quad$ Nederlandse samenvatting

Dankwoord (Acknowledgments)

Publications

Curriculum Vitae 

Abbreviations:

AA

Akt

ATM/ATR

BAD

BAX

BDNF

$\mathrm{BM}$

CASP-3

CBP

CKD

CNS

CP

CREB

CT

CHX

EAE

PKA

PKC

FACS

FCS

FDA

FGF

GA

GAP-43

GFAP

GVHD

HI

HUCB

IBA-1

IFN- $\gamma$

ip

KSRP

LPS

MBP

MHC

MSCs

NeuN

NOD

PBS

PIF

ROI

RT

s.c.

scr

sPIF

TLRs

TNF- $\alpha$

Tx

VLGA

WJ

WJ-MSCs (antibiotics/antimycotics)

(Protein kinase B)

(ataxia-telangiectasia-mutated/ATM- and Rad3-related)

(BCL2 antagonist of cell death)

(BCL2-associated X protein)

(brain-derived neurotrophic factor)

bone marrow

(Caspase-3)

(CREB-binding protein)

(cyklin-dependent kinases)

(central nervous system)

(cerebral palsy)

(cAMP-responsive element-binding protein)

(cortical thickness)

(cycloheximide)

(experimental autoimmune encephalomyelitis)

(cyclic AMP dependent protein kinase)

(calcium-dependent protein kinase)

(fluorescence-activated cell sorting)

(fetal calf serum)

(Food and Drug Administration)

(fibroblast growth factor)

(gestational age)

(Growth associated protein 43)

(glial fibrillary acidic protein)

(graft vs. host disease)

(hypoxia-ischemia)

(human umbilical cord blood)

(ionized calcium binding-adaptor molecule 1)

(interferon gamma)

(intraperitoneal)

(KH-type splicing regulatory protein)

(lipopolysaccharide)

(myelin basic protein)

(major histocompatibility complex)

(mesenchymal stem/stromal cells)

(neuronal nuclear)

(non-obese diabetic disease)

(phosphate buffered saline)

(PreImplantation Factor)

(region of interest)

(room temperature)

(subcutaneouse)

(scrambled)

(synthetic PIF)

(Toll-like Receptors)

(tumor necrosis factor alpha)

(transplantation)

(very low gestational age)

(Wharton`s Jelly)

(Wharton`s Jelly derived MSCs) 

Chapter 1

General introduction and aims 


\section{Development of the Brain}

When sperm and egg successfully interact, a fully formed mammal emerges with the capacity to live outside the uterus after delivery and throughout its life. From the two cells that create the zygote, post-fertilization embryo development proceeds until the embryoblast and trophoblast swiftly become distinct from each other ${ }^{5}$. Embryonic programming is characterized by an order leading to emerging properties and yielding 287 different cell types and segmented organs ${ }^{5}$. Once differentiated, cells specific to each organ will not usually be found elsewhere in the body, only in that specific organ. Thus, the embryo's emerging properties will effectively transpose structure to function.

The development of mammalian brain is a complex and long-lasting process which follows specific time and space dependent sequences (Figure 1). Not surprisingly the "adult" brain configuration takes about four decades ${ }^{6}$. The neural tube starts to develop early in the pregnancy and once the neural tube is closed specific proliferation areas are formed in the ventricular and subventricular zones, which give rise to neurons and glial cells ${ }^{1,5}$.

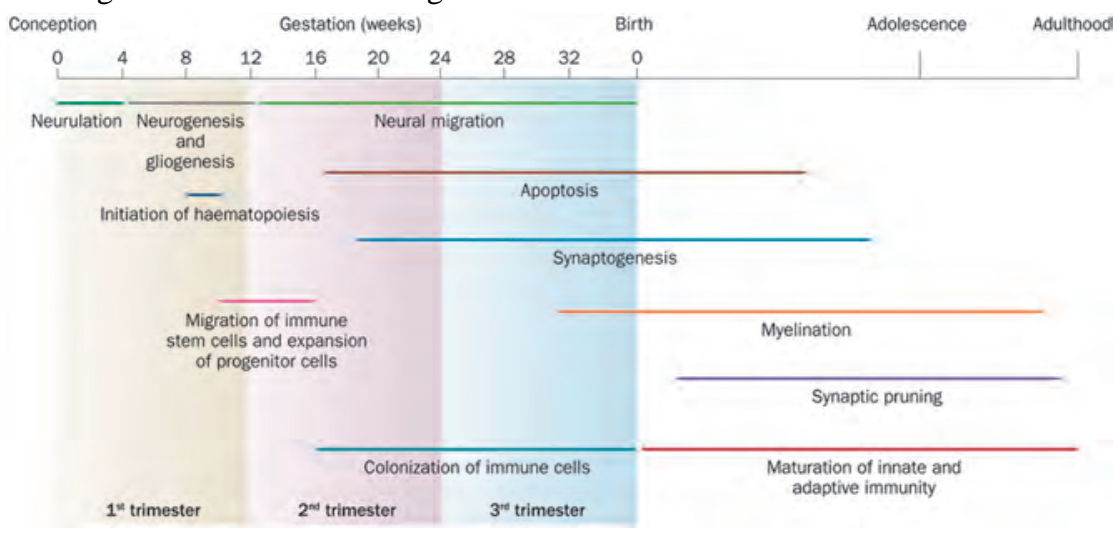

\section{Figure 1. The timeline of development of a human brain (adopted from ${ }^{1}$ )}

The steps of human brain and immune system development from gestation to early postnatal life are highly orchestrated. Short-term and long-term effects of maternal immune activation depend on genetic predisposition, time window of fetal or postnatal brain development, and strength of insult neurons.

Neurons are born and the complex process of neuronal migration begins (Figure 1 and 2). This process is regulated by molecular interactions between neuronal and glial cells along radial glial scaffold ${ }^{7}$. This radial scaffolding regulates the characteristic columnar distribution of neurons forming the six layered human cortex ${ }^{8}$. The six-layered structure is comprised primarily of pyramidal neurons and of remaining inhibitory interneurons ${ }^{9}$. The pyramidal neurons are generated in a well-defined inside-out fashion in which cortical layer VI and V (deep-layers) neurons arise and migrate first and layer IV-II (upper-layers) neurons are born and migrate later ${ }^{9}$. In humans neuronal migration peeks about 28 weeks of gestational age (GA) and is completed about 36 weeks of GA $^{10}$. In parallel neuronal differentiation begins with the major axonal sprouting occurring once neurons reach the final destination. This complex process is under control of the subplate, which is thickest around the 30 week of GA ${ }^{11}$. Young neurons form axons and the growth cones of the developing axon navigate to their final targets by 
interacting with a variety of molecular targets. In contrast, dendritic growth and branching, which starts early during fetal life, is a result of a complex molecular orchestration $^{12}$. In line with neuronal migration, dendritic trees of the deepest cortical layers mature earlier than those of the superficial cortical layers ${ }^{13}$. Dendritic growth continues till early years of the neonatal period ${ }^{14}$.

While neuron`s function is primarily information transfer, surrounding glial cells interact with them and support their development and function. Microglia are the CNS resident macrophages, which derive from immature erythromyeloid before the blood-brain barrier develops ${ }^{15}$. During fetal development microglia are present in the amoeboid morphology and a transition toward a ramified morphology during early postnatal development is made. In the immature brain, amoeboid microglia is involved in phagocytosis of apoptotic neurons, promotion of programmed cell death, and pruning of synapses ${ }^{16}$. This is an important process as in the developing brain more than the necessary neurons and synapses are generated. Additional functions of microglia are surveillance of the environment and respond to stimuli such as infection and injury. Once microglia

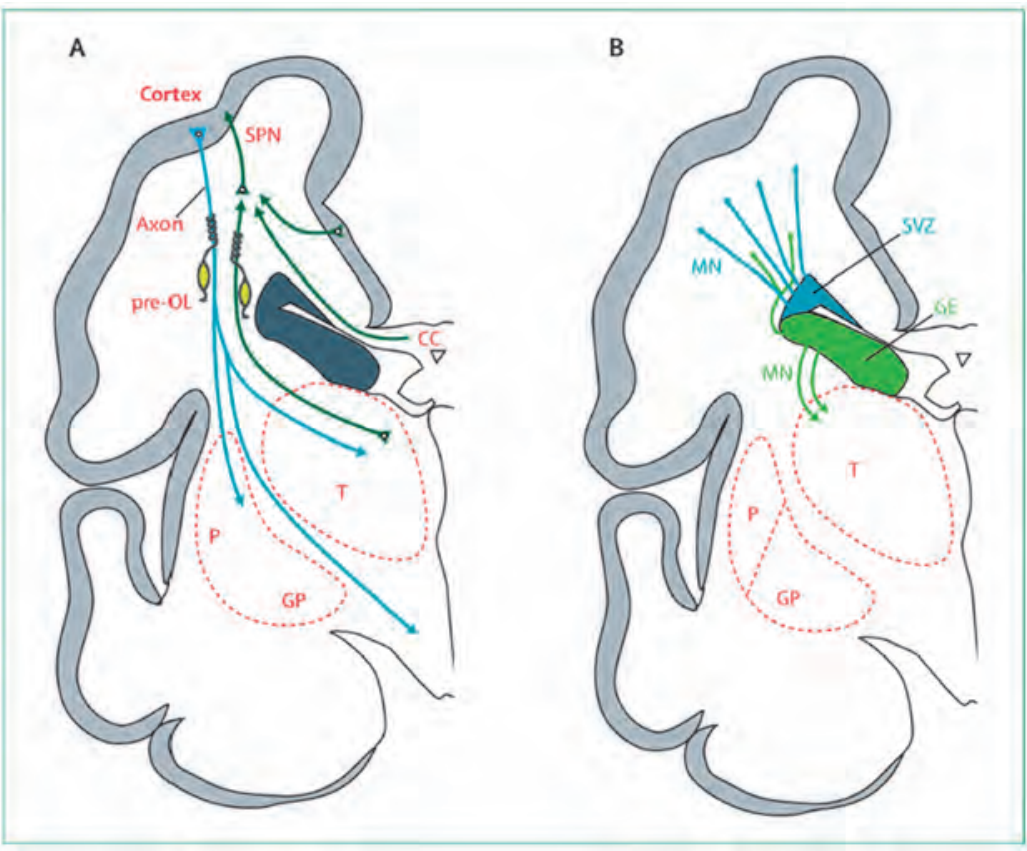

Figure 2. Cerebrum in coronal section at 28 weeks' gestation showing critical events in cortical development (adopted from ${ }^{2}$ )

(A) The axons (green) emanate from the thalamus (T; projection fibres), corpus callosum (CC; commissural fibres), and cortex (association fibres), which synapse initially on subplate neurons (SPNs). SPNs send axons to the cortex and promote cortical development before the thalamo-cortical and cortico-cortical fibres enter the cortex. From the cortex, axons (blue) descend to the thalamus, basal ganglia, and corticospinal (and corticopontine) tracts. Premyelinating oligodendrocytes (pre-OLs; yellow) ensheath axons before full differentiation to mature myelin-producing oligodendrocytes. (B) The proliferation and migration of GABAergic interneurons from the subventricular zone (SVZ) and ventral germinative epithelium of the ganglionic eminence (GE) are shown. Neurons from the SVZ (blue) migrate radially to the cortex and from the GE (green), tangentially and then radially, to the cortex. The migrating stream of interneurons from the GE to the dorsal thalamus is also shown. $\mathrm{GP}=$ globus pallidus. $\mathrm{MN}=$ migrating neurons. $\mathrm{P}=$ putamen. 
is activated production of pro-inflammatory cytokines, chemokines, reactive oxygen species, and nitric oxide is initiated. Thus, microglia activation is aimed at protecting neurons from stimuli such as infections. However it can also trigger neuroinflammation contributing to neurodegenerative disorders ${ }^{17}$.

Macroglial cells, such as oligodendrocytes and astrocytes, derive from common precursors cells as neurons. The function of macroglial cells is diverse. Oligodendrocytes produce myelin, a fatty insulating sheath surrounding axons and promoting efficient impulse conduction to the presynaptic terminals. Oligodendrocytes and myelin provide trophic support to axons and promote their integrity and survival. Central nervous system myelination occurs late in brain development with the majority of myelination occurring during the first two decades of life. Notably, oligodendrocytes are the last cells to be generated during development and derive from oligodendrocyte precursor cells, which are particularly susceptible to perinatal brain injury. Astrocytes, the most numerous cells in the mammalian brain, compose the extracellular environment, regulate the excess of neurotransmitters, and modulate synaptic connections ${ }^{16}$. They are key mediators of brain development, function, and plasticity. For example astrocytes release trophic factors and extracellular matrix proteins leading neurite outgrowths, allowing for neuronal survival, and controlling synapse formation and function ${ }^{16}$. Thus, astrocytes play a major role in the maturation, function, and maintenance of the blood-brain barrier of the developing brain and together with microglia regulate neuroinflammatory responses ${ }^{18}$.

Together brain development is a complex evolving process depending on interactions of various cell types throughout a determined time line (Figure 1). Therefore, the effect of an injury in a developing brain strongly depends on the point in time at which the lesion occurred. Many factors have to be considered: the age at insult, the site and size of the lesion, species, sex, exposure to chemical substances prior to and after the insult, and environmentally induced experience. Not surprisingly, injury to an immature brain results in a divergent pathophysiology compared to term born infant.

\section{Pathophysiology of the Brain Injury}

Perinatal brain injury affects both term and preterm born infants. Depending on the timing of injury and/or delivery, infants need to cope with different challenges. In term born infants, perinatal insults such as birth asphyxia or perinatal stroke, affect 1 to 3 newborns out of $100{ }^{19,20}$. In contrast, in preterm born infants morbidity and mortality strongly relate to the gestational age. While preterm birth before 37 weeks gestation occurs in 5-8\% of all pregnancies, very low gestational age (VLGA) before 32 weeks gestation in about $1 \%$ of singletons and $9 \%$ of twin pregnancies ${ }^{21}$. Mortality of VLGA infants ranges between 7.3 and $21.4 \%$ at 30 days and 9.0 and $22.7 \%$ at one year ${ }^{22}$. Additionally, 25\% of VLGA infants are confronted with long-lasting consequences such as cerebral palsy (CP), epilepsy, increased hyperactivity and developmental disorders ${ }^{23}$. For example the risk to develop CP is 30 times higher in infants born before 33 weeks gestation compared to term-born infants ${ }^{24}$. Moreover, injury in these infants is frequently exacerbated by fetal inflammation and preferentially affects cerebral white matter resulting in periventricular leukomalacia and germinal matrix hemorrhage ${ }^{2}$. The spectrum of injury suggests that the underlying pathophysiology is not due to a single lesion, but consists of complex white and grey matter disturbances ${ }^{2}$. 
Experimental studies identified different phases of perinatally induced neuronal death. Primary neuronal death is related to depletion of tissue energy reserves with primary energy failure. The secondary and tertiary phases are related to excitotoxicity, mitochondrial dysfunction and free radical accumulation leading to cell necrosis or apoptosis with impaired myelination and/or axonal function ${ }^{25}$. The secondary and tertiary phases may cause persistent inflammation and gliosis, sensitization to further injury, and impaired oligodendrocyte maturation and myelination ${ }^{26}$. Interestingly inflammation is increasingly recognized as being a critical contributor to both normal development and outcome after injury particularly in the immature brain (Figure 3) ${ }^{3,27}$. Maternal infection/inflammation is not only a major risk for preterm birth but is linked to systemic fetal inflammatory response which, in turn may elicit injury in the fetus. Perinatal inflammation modulates vulnerability to and development of brain injury ${ }^{28}$ and influences critical phases of myelination and cortical plasticity ${ }^{27}$. Several studies suggest that inflammation may play a critical role in autism and schizophrenia ${ }^{29}$. Together, brain development, myelination, vascularization, and apoptosis are

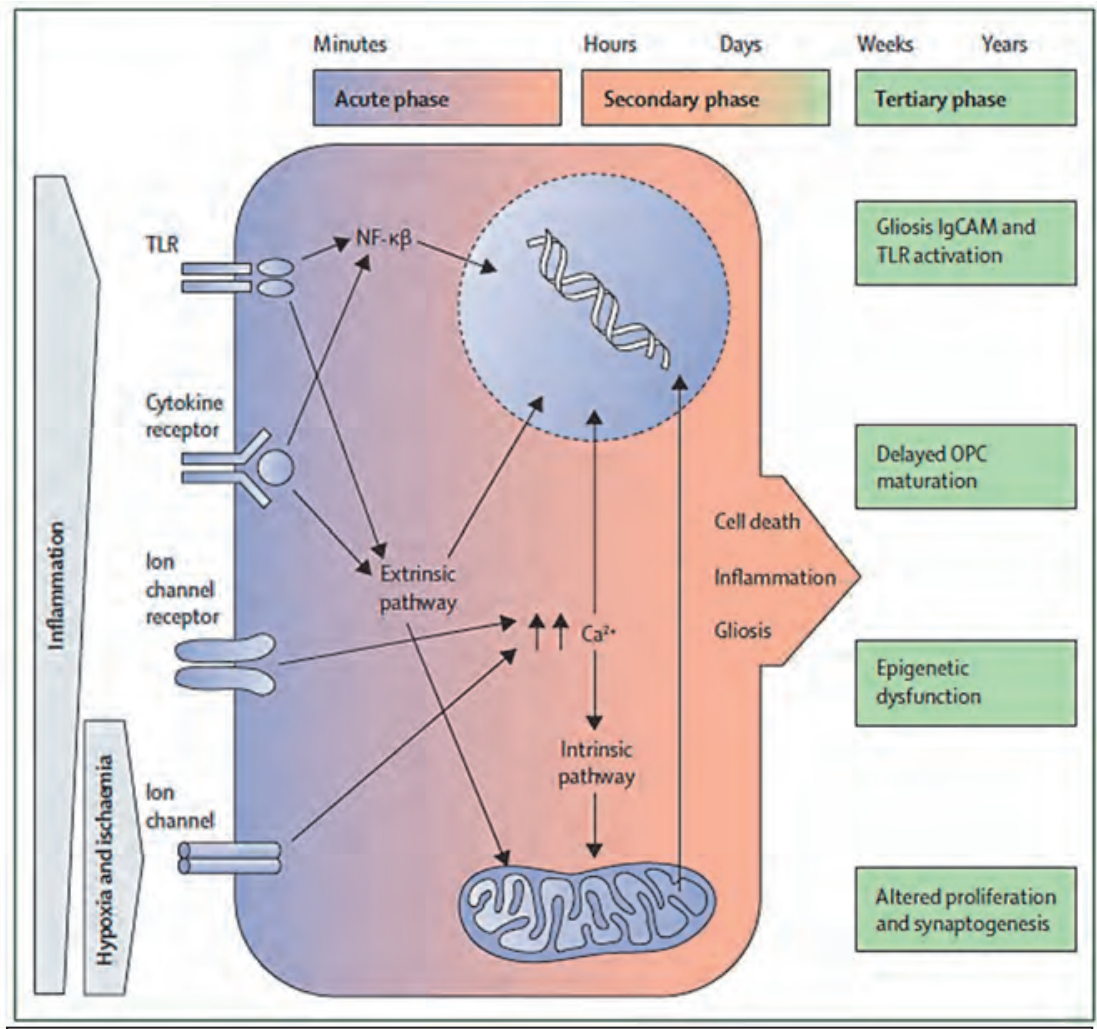

Figure 3: Outline of the acute, secondary, and tertiary damage phases in cerebral palsy (adopted from ${ }^{3}$ )

Activation of an array of receptors and ion channels leads to NF- $\kappa \beta$ activation, intrinsic and extrinsic apoptotic cascades, and an increase in intracellular calcium, which in combination affect cell death, perpetuate inflammation, and induce gliosis. Selected tertiary-phase mechanisms are also shown, including persisting effects on glia, the epigenome, and neurogenesis. NF- $\kappa \beta=$ nuclear factor- $\kappa \beta$. TLR=toll-like receptor. IgCAM=immunoglobulin cell adhesion molecule. $\mathrm{OPC}=$ oligodendrocyte precursor cell. 
strongly influenced by inflammatory responses in both physiologic and pathophysiologic conditions ${ }^{27,30}$.

Pivotal regulators of inflammatory responses in the brain are glial cells which orchestrate the release of pro- and anti-inflammatory cytokines ${ }^{31}, 32$. Proinflammatory cytokines such as tumor necrosis factor (TNF)- $\alpha$ and interferon gamma (IFN- $\gamma$ ) are cytotoxic to oligodendrocytes ${ }^{33}$. However, glial cells may produce anti-inflammatory cytokines (e.g., IL-10), which suppress expansion of IL-1 $\beta$ and TNF- $\alpha$ and contribute to resolving inflammation and repair processes 32 . Further, astrogliotic scar formation installs a barrier around tissue lesions to restrict the crossing of inflammatory cells into surrounding healthy areas ${ }^{31}$. The regulation of the inflammatory responses in the newborn appears to be a link that may explain some of the common features of peripheral and central organ injuries in infants or even persisting inflammation in adult survivors of premature birth ${ }^{3 \text {, }}$ 27, 29 .

Given the importance of inflammatory responses after brain injury in the immature brain (Figure 3), pivotal contributing factors need to be addressed. Recent evidence suggest the dual importance of pattern recognition receptors (Toll-like Receptors: TLRs). TLRs initiate innate immune responses including cytokine release and inflammation ${ }^{3}$. However, aberrant TLR activation during the perinatal period sensitizes the brain to further injury ${ }^{34}$ and reprograms the adult neuroimmune responses such as age-related cognitive decline and increasing susceptibility to seizures ${ }^{3}$. Also, exposure to the TLR4 agonist lipopolysaccharide (LPS) in the neonatal mouse disrupts fate determination in cells of the subgranular zone. Interestingly, arrest of oligodendrocyte maturation is modulated by TLR2 mediated product of the glial scar ${ }^{35}$. In line with this notion miroRNA let-7 released from injured cells to the extracellular environment during CNS damage activates TLR7 in neuronal cells, leading to neurodegeneration in the mouse ${ }^{36}$. Likewise, intracerebroventricular injection of an antagomir to let-7 significantly reduces both cortical and striatal infarcts in a rat ischemic stroke model ${ }^{37}$. Notably, let-7 alteration occurs due to sensing of bacterial LPS by TLR $4^{38}$. Other TLR4 downstream factors contribute to cerebral injury and/or development as well. For example, cyclic AMP dependent protein kinase (PKA) and calciumdependent protein kinase (PKC) ${ }^{39},{ }^{40}$. PKA/PKC are important signaling molecules and modulate a variety of cellular functions such as cellular response to hypoxia-ischemia, cell growth and differentiation, and neuronal plasticity 41, 42, 43, 44. Generally the delicate balance of cellular proliferation/differentiation and apoptosis/necrosis in an immature brain is important. In response to DNA damage the cell cycle transition/progression through G1/S and G2/M may stop to repair the damaged genetic material or the cells will die in case of irreparable DNA damage ${ }^{45}$. The key regulators of responses to DNA damaging agents are not only PKA/PKC but include cyklin-dependent kinases (CDK), 14-3-3 binding protein partners, ataxia-telangiectasia-mutated/ATM- and Rad3-related (ATM/ATR) substrates, and Protein kinase B (Akt) ${ }^{46,47,48,49,50,51}$.

Taken together, perinatal inflammation is a strong modulator of both physiologic and pathophysiologic development of the brain. The fetal inflammatory response to certain cues such as LPS ${ }^{52}$ can be detected not only in the brain, but in remote tissues not directly exposed to LPS as the lung, gut, spleen, liver, and mediastinal lymph nodes $53,54,55$. In case of LPS exposure in the amniotic fluid the gut and lungs will be exposed to LPS first. Thus, protective strategies to counteract the cascades leading to injury should therefore not focus on one organ or system but 
rather treat perinatally acquired injury globally in which not only the immune system plays a key role.

\section{Therapeutic approaches to counteract Perinatal Brain Injury}

Despite advances in obstetrics and neonatology both preterm and term born infants continue to face serious risks during pregnancy, parturition and adaptation after birth. The clinical presentation after perinatal complications or preterm birth in an individual child is complex. This complexity results from multiple potential causal pathways, signs and symptoms of injury depending on the gestational age. Not surprisingly, a comprehensive multidimensional assessment of potential contributing factors such as maternal medical history, obstetric antecedents, intrapartum factors (including fetal heart rate monitoring results and issues related to the delivery itself) and placental pathology is recommended ${ }^{56}$. Currently, the only intervention known to reduce the burden of brain injury in the term population is hypothermia. Several large clinical trials confirmed that hypothermia in infants with neonatal hypoxic-ischemic encephalopathy is associated with a significant reduction in death and disability ${ }^{57}$. However, 40$50 \%$ of infants treated with hypothermia still die or develop significant neurological disability ${ }^{58}$. In the preterm population therapeutic options are lacking as hypothermia is contra-productive. Antenatal magnesium sulfate prior to birth at less than 30 weeks of gestation reduces CP and combined CP and mortality rate at 2-years of age. However, randomized control trials do not demonstrate long term neurological benefits 59 60. Together, therapeutic approaches to counteract the consequences of perinatal brain injury are sparse and new measures are desperately needed ${ }^{2,61,62,63}$.

In the last decade, new therapeutic strategies have emerged for perinatal brain injuries ${ }^{64}$. The approach of pregnancy derived products in treating the injured brain may be especially suitable as pregnancy provides a unique milieu, which enables a development of such a complex organ as the brain. Moreover, pregnancy needs to be considered an embryo-centric rather than materno-centric endeavor with the embryo and later the fetal/placental unit condition the maternal adaptation and fetal development ${ }^{5}$. Several protential factors were identified and include mesenchymal stem/stromal cells (MSCs), 17- $\beta$ Estradiol, and PreImplantation Factor (PIF). Given the neuroprotective potential of these factors, the aim of this thesis is to explore these embryo and placental derived products as attractive candidates for brain therapy in perinatal medicine.

\section{Mesenchymal stem/stromal Cells}

Stem cells are broadly defined as cells with self-renewing and differentiation capacity. Although stem cells derived from embryonic tissue were identified first, the clinical use is limited due to ethical concerns and tumorigenic potential ${ }^{65,66}$. Clinical and animal stem cell-based studies to prevent or repair perinatal brain injury have emerged during recent years with MSCs being particularly promising. These cells are considered somatic stem cells as they originate from stem cell niches such as bone marrow (BM), skin, adipose tissue, umbilical cord, and placental tissue ${ }^{67}$. More specific, MSCs can be isolated from placental membranes and tissue ${ }^{68,69}$, amniotic fluid ${ }^{70,71,72}$, umbilical cord blood ${ }^{73,74}$ and umbilical cord`s connective tissue (Wharton`s Jelly; WJ) ${ }^{75,76}$. Although all of these cell are MSCs, specific considerations with respect to clinical use, time of application, application route, availability and ethical aspects need to be made. 
MSCs based therapies are an attractive strategy since the pathophysiology of perinatally acquired injuries is heterogeneous and MSCs have the capacity to adapt to the microenvironment of the injured organs ${ }^{64}$. The strategy may be either or both replacement/restoration of lost tissue and/or protection/salvage of injured cells. In term born infants at risk for hypoxic-ischemic injury or neonatal ischemic stroke, MSCs could exert a neuroprotective effect starting at the acute phase of injury. The timing and presentation of the injury are usually well defined. MSCs could provide trophic support and/or amelioration of the inflammatory responses leading to repair or reduced cell death. However, the different cell types, transplantation routes and the timing need to be accounted for. In contrast, in the preterm population, the timing of the injury is often unclear and the pathophysiology is more complex. The clinical diagnosis of infants at risk is challenging as symptoms such as $\mathrm{CP}$ are diagnosed in early childhood years. Thus, the injury may be considered more chronic as extensive atrophy and gliosis of the white matter tract occur. MSCs could not only modulate the inflammatory response after delivery but also the degree and magnitude of the injured white and gray matter.

The approach of MSCs as a therapy for perinatal injury is based on several crucial properties of MSCs, including delivery of the cells "homing" to the site of injury (Figure 4). Migration and homing to the tissue of injury is influenced by multiple

A

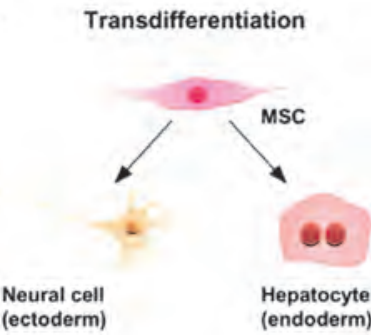

C

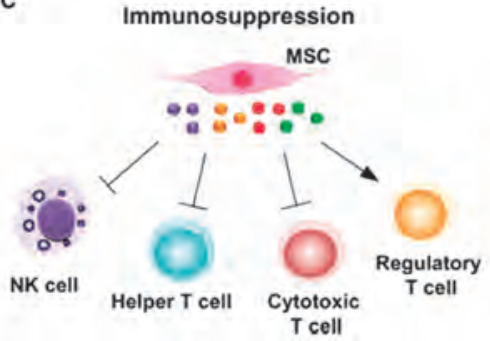

B Homing to injured sites

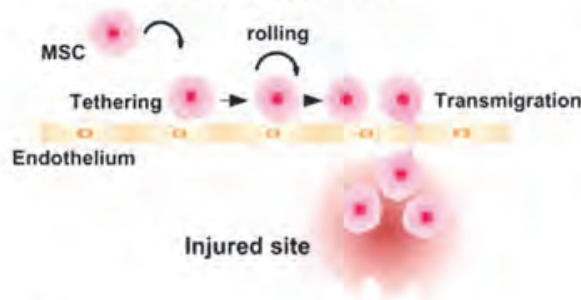

D

Trophic effects on tissue repair

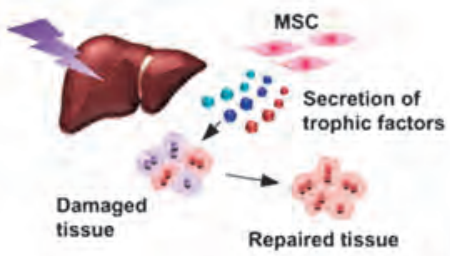

Figure 4: Various therapeutic effects of MSCs (adopted from ${ }^{4}$ )

(A) MSCs can transdifferentiate into cells of non-mesodermal origin including neurons (ectoderm) and hepatocytes (endoderm). (B) MSCs are capable of homing to injured tissues. The mechanism by which MSCs home to tissues and migrate across endothelium still remains unclear, but it is likely that injured tissue expresses specific receptors or ligands that facilitate trafficking, adhesion, and infiltration of MSCs to the site of injury in a manner similar to that in which leukocytes are recruited to sites of inflammation. (C) MSCs exhibit immunosuppressive activity through secretion of several cytokines that inhibit the activity of natural killer cells, helper $\mathrm{T}$ cells, and cytotoxic $\mathrm{T}$ cells while activating the generation of regulatory T cells. (D) MSCs produce trophic factors that promote repair of damaged tissue. 
factors including source, age, passage, and number of cells, culture conditions, and delivery method ${ }^{77}$. The apparent migration and homing abilities of MSCs without tumorigenic potential, was described by several groups and in different disease models ${ }^{78,79,80}$. Experimental studies identified factors such as stromal cell-derived factor-1 $\alpha$ and chemokines as major molecules responsible for cell homing with chemokines receptors CXCR3, CXCR4 and CXCR6 being particularly important ${ }^{81,82,83}$. Interestingly, the phenotype of MSCs is an important criteria as well. For example CD9 (high) positive MSCs display improved engraftment compared to the CD9 (low) positive population in a murine ischemic hind limb model ${ }^{84}$. This observation highlights the rather heterogeneous MSC population and the importance of proper MSCs characterization and definition for future studies.

Currently, MSCs characterization is based on a set of minimal criteria ${ }^{85}$ and they display a cell surface repertoire and gene expression pattern which differs among MSCs from various tissues of origin and culture conditions used ${ }^{86,87,88}$. For example MSC derived from amniotic fluid express many cell surface markers characteristic for BM-derived MSCs including CD73, CD90, CD105 and major histocompatibility complex (MHC) class I ${ }^{72}$. The lack of MHC class II, CD40, CD80, and CD86 molecules suggest a low immunogenic phenotype of MSCs, when compared to other stem cell sources ${ }^{89}$. In contrast, WJ-MSCs express cellsurface markers CD29, CD44, CD73, CD90, CD105, CD146 and CD166 ${ }^{90,91}$ and are considered more primitive cell population relative to BM-derived MSCs ${ }^{92}$. As a result, WJ-MSCs differentiate more efficiently into neural progenitors compared to BM-derived MSC ${ }^{93}$. In addition, the underlying clinical condition may also affect the phenotype of MSCs.

While MSCs have a proven restorative capacity in response to injury cues, the question of potential protective mechanisms remains unclear. Most of the available data comes from adult neurodegenerative diseases or in-vitro studies. Studies identified paracrine effects such as the modulation of cytokines, interleukins, and trophic factors predominately involved in neurogenesis, angiogenesis, hematopoiesis, and cardiovascular regeneration ${ }^{82,}{ }^{94}$. For example, WJ-MSCs' secretome triggers neuronal survival and differentiation in vitro and in vivo ${ }^{95,96}$. Secreted factors such as vascular endothelial growth factor A, angiopoietin-1, fibroblast growth factor (FGF)-I, hepatocyte growth factor, FGFII, brain-derived neurotrophic factor (BDNF), glial cell line-derived neurotrophic factor, and platelet-derived growth factor AB were identified 97, 98, 99, 100 . Importantly, MSCs' secretome alters both adaptive and innate immune responses 101. MSCs inhibit autoreactive $\mathrm{T}$ cell responses in animal models of multiple sclerosis and hypoxic-ischemic brain injury ${ }^{102,103,104}$. The shifting from the M1 (pro-inflammatory) to a M2 (protective) phenotype and promoting regulatory Tcells is a function unique to MSCs ${ }^{105}$. Besides T-cell modulation, MSCs inhibit B cell proliferation, neutrophils and monocytes function, and NK toxicity ${ }^{106,107,108,}$ 109 . Although these modulatory effects are partially understood, direct cell to cell contact and soluble factors may be relevant ${ }^{110}$.

Besides MSCs' immunomodulatory capacities, their multipotency, and selfrenewal properties make them valid candidates for providing brain cell regeneration/replacement. Although, this strategy for repair carries risks such as tumorigenic potential ${ }^{65,66}$, MSCs were successfully differentiated into various types of cells including cardiomyocytes, myocytes, epidermal and endothelial 
cells ${ }^{80,111,112,113}$. Importantly, MSCs express neuro-glial commitment ${ }^{114,} 115$ and are currently tested in various animal models and clinical trials for brain regeneration 116, 117, 118 . Although this line of investigation is particularly intriguing, MSCs potential to replace injured cells is not proven and a matter of constant debate 116, ${ }^{117}$. For example intravenously injected MSCs improve myocardial infarction without permanent replacement of injured cells ${ }^{118}$. In the lung, MSCs embolize causing endothelial damage and are cleared in a matter of hours ${ }^{118}$. Taken together, the MSCs' low rate of in vivo engraftment and differentiation suggests that transplanted cells affect tissue injury and repair through paracrine factors. Whether the factors released by the MSCs or the cells themselves are more promising for the therapy of perinatal injuries in the newborn remains still an open question ${ }^{119}$.

Given the wide array of regenerative/protective MSCs` mechanisms in perinatal medicine, therapeutic applications can be envisioned in the near future ${ }^{64}$. The mechanism span antiapoptotic/pro-mitotic capacities leading to neovascularization by the stimulation of angiogenesis and anti-inflammatory responses. Further stimulation of neuro- and gliogenesis, synaptogenesis, neurite outgrowth and also immunomodulation are crucial ${ }^{119,64}$. Available data clearly demonstrates that MSC and secreted factors are beneficial to treat a variety of neurodegenerative disorders ${ }^{120}$.

\section{Estradiol}

The steroid hormones estradiol and progesterone have a well-recognized role in the growth, differentiation, and function of the reproductive system. However, the function of these hormones expands beyond the reproductive system as the ubiquitous distribution of relevant estrogen and progesterone receptors in the peripheral and central nervous system shows ${ }^{121} 122$. This is especially evident in the third trimester of pregnancy, where the maternal serum concentration of estradiol and progesterone (produced by the placenta) increases significantly and brain development peaks ${ }^{16}$. Estradiol induces axonal and dendritic growth and promotes the development of synapses as well as the integration of the cerebral cortex ${ }^{123}$. This effect is partially mediated by BDNF. The neuroprotective effects of estradiol can be imparted receptor-dependent (genomic and non-genomic) or receptor independent resulting in antioxidative properties and modulation of the neurotransmission and excitability of the neuronal membrane ${ }^{124}$. The classical receptor-mediated effects affect the neuroaxonal growth and formation of dendrites, the creation of synapses, the expression of neurotropic factors, and finally increased acetylcholine synthesis. Broadly, effects of the estradiol receptor- $\alpha$ result in antiapoptotic properties and a rapid induction of the neuroprotective IGF-1 pathway ${ }^{125,126}$. Further evidence from animal experiments confirmed the neuroprotective effects of estradiol in hypoxic-ischemic brain injury. For example estradiol attenuated hypoxic-ischemic and oxidative injury to developing oligodendrocytes ${ }^{127}$ and injury to hippocampus, basal ganglia, and amygdala ${ }^{128}$. Progesterone`s role in neuroprotection has been addressed as well 129. Progesterone affects the blood-brain-barrier by reducing postischemic cellular edema and increasing expressions of claudin5 and occludin1, both involved in creation of tight junctions ${ }^{130}$. Progesterone imparts the expression of MMP-3 and MMP-9 involved in extracellular tissue degradation, inhibits postischemic 
apoptosis, and induces the release of the growth factor BNDF 131 132. Finally, inflammatory response is reduced after progesterone administration as well ${ }^{133}$.

Together, neonatal substitution/replacement of estrogen and/or progesterone in scenarios of neonatal steroid deprivation such as preterm birth has to be addressed but sufficient clinical data is lacking ${ }^{134135}$.

\section{PreImplantation Factor (PIF)}

PreImplantation factor (PIF) is a conserved, embryo-derived peptide that can be detected in the maternal circulation of human, mouse and bovine during pregnancy ${ }^{136,137}$. PIF is secreted at the two-cell stage in the mouse, four-cell stage in the human, and six-cell in bovine embryos, reflecting possible involvement in maternal signaling ${ }^{5}$. Furthermore, PIF presence in maternal circulation is instrumental in regulating maternal milieu both locally (endometrium, trophoblast) as well as systemically, acting on the maternal immune system. For example, the presence of PIF in the maternal circulation has been correlated with live birth in murine and bovine models $137,138,139$. Thus, embryo implantation, immune tolerance, fetus support, and protection can be considered all elements involved in PIF action and which could be instrumental in preventing several placenta mediated complications ${ }^{140}$.

Failure to maintain immune tolerance at the utero-placental interface can lead to pregnancy complications such as fetal loss, preterm labor, preeclampsia and poor fetal development ${ }^{140}{ }^{141}$. In this context, PIF was recognized to regulate systemic immune response, with a minimal effect on basal immunity (CD14+ cells) and a robust effect following immune activation ( $\mathrm{T}$ and $\mathrm{B}$ cells). A significantly increased binding to CD3+ cells during gestation has also been demonstrated ${ }^{142}$. Additionally, PIF decreased NK cytotoxicity in patients with a history of recurrent pregnancy loss ${ }^{143}$. A further action on the trophoblast was observed, where PIF promoted HLA-G expression, thus supporting a pro-

A

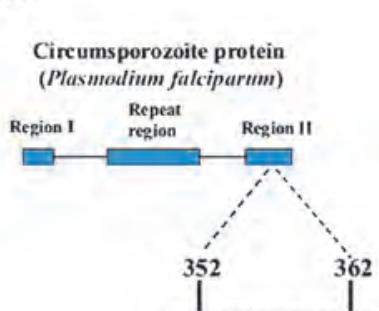

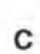

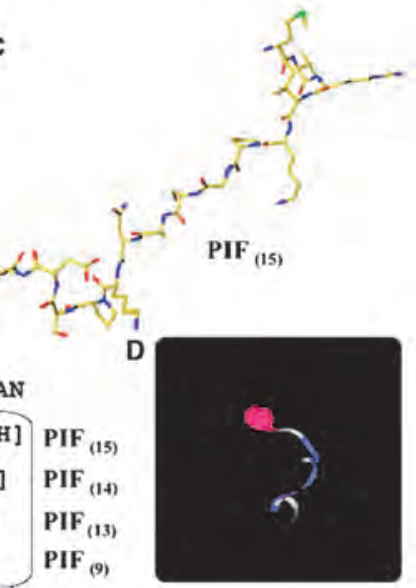

Figure 5: PIF predicted structure (adopted from ${ }^{5}$ )

(A). Circumsporozoite protein (CS) P. falciparum (protein accession SO5428) PIF peptides are identical to region II. (B). PIF amino acid sequence has 4 peptides (9-15 amino acids); a common sequencematches 11 amino acids region II, CS. (C). Predicted PIF 3-dimensional structure has charged residues. D. Predicted 3-dimensional PIF (15aa) image. 
tolerance role. In the embryo, PIF binds protein disulfide isomerases and heat shock proteins which are known to play critical roles in protecting against oxidative stress and protein misfolding ${ }^{144}$. Consistent with these modes of action, a synthetic PIF analog (sPIF) of 15-amino acids (MVRIKPGSANKPSDD) (Figure $5 \mathrm{C}$ and $\mathrm{D}$ ) was successfully tested in murine models of graft vs. host disease (GVHD) ${ }^{145}$ and non-obese diabetic disease (NOD) ${ }^{146}$.

Despite the long-standing implication of PIF in promoting immune tolerance and embryo implantation 137, 147, 148, 149, 150, the mechanism of PIF on neuronal development and protection has remained under-investigated (Figure 6) ${ }^{5}$. Recently, sPIF was reported to elicit neuroprotective effects in a murine model of experimental autoimmune encephalomyelitis (EAE) ${ }^{151}$. Subcutaneously administrated, sPIF was shown to inhibit neuroinflammation, promote neural repair, and prevent paralysis ${ }^{151}$. Analysis of cytokines combined with genomic and proteomic approaches revealed global alterations in gene expression, suggesting coordinated central and systemic multi-targeted effects induced by sPIF ${ }^{151}$. For example, sPIF decreased IL-1, a pro-inflammatory cytokine that promotes $\mathrm{T}_{\mathrm{H}} 1$ and possibly $\mathrm{T}_{\mathrm{H}} 17$ activities, and increased IL-1 inhibitors 152 153. SPIF also blocked macrophage activators, major EAE and multiple sclerosis targets, and inflammatory chemokines, principally CCL8 which promotes inflammatory cells' access to the spinal cord 154. Finally, canonical proteome analysis demonstrated that SPIF affects oxido-reduction 151 and vesicle trafficking cyklin dependent kinase PIF acts on multiple mechanisms of CNS damage

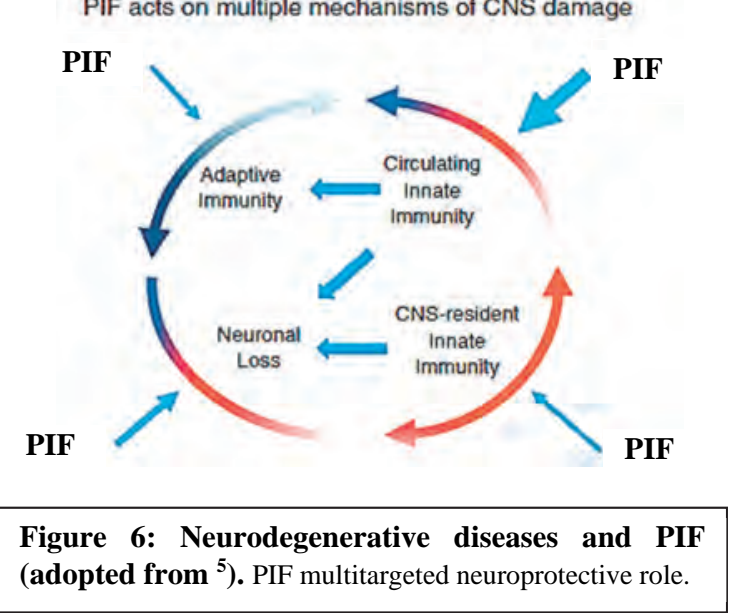
5, a kinase implicated in several neurodegenerative diseases including Alzheimer's 155

Together PIF has a determining regulatory role in maternal recognition of pregnancy and which promotes implantation and trophoblast invasion by viable embryos. sPIF regulates immunity, inflammation and transplant acceptance. sPIF is neuroprotective in adult neurodegenerative diseases. In terms of clinical application sPIF high safety profile led to a FAST-TRACK approval by the FDA to initiate clinical trials for autoimmune hepatitis.

\section{Research questions and hypotheses:}

In the last decade, new therapeutic strategies have emerged for perinatal brain injuries ${ }^{64}$. Embryo and placental derived products such as MSCs, Estradiol, and PreImplantation Factor are attractive candidates but crucial information on feasibility and mechanism are still lacking. 
Previous studies identified MSCs in perinatal sources, such as the Wharton's jelly, and turned them into promising stem cell grafts for the application in perinatal medicine ${ }^{156}$. As stated above MSCs possess several crucial properties including delivery of the cells "migration and homing" to the site of injury. Further advantages of WJ-MSC over adult MSC, such as bone marrow-derived MSC, include their minimally invasive isolation procedure, their more primitive cell character without being tumorigenic, their low immunogenicity, and their potential autologous application. As a result, WJ-MSCs differentiate more efficiently into neural progenitors compared to adult MSC. Together, MSCs potential including homing and neuroglial differentiation is influenced by multiple factors such as source, age, phenotype, and delivery method ${ }^{77,93,156}$.

These findings formed the basis for the research hypothesis and as the question of homing and differentiation potential in WJ-MSCs was not assessed. The research question were:

1. Do WJ-MSCs possess migration and "homing” capacity after intracerebral transplantation?

2. Do WJ-MSCs protect the immature brain and which mechanisms are involved?

To answer the questions 1, we used a murine animal model and assessed intraventricular stem cell transplantation in neonatal rats. We hypothesized that we can successfully deliver MSCs into the recipient's lateral ventricle and that these cells will migrate and home.

To answer question 2, we used a murine a model of preterm brain injury and tested WJ-MSCs' protective effects after hypoxic-ischemic brain injury in neonatal rats. Further we dissected the underlying protective mechanisms. We anticipated that WJ-MSCs will protect the immature brain by targeting crucial cell cycle kinases.

These general hypotheses lead to the following outline of the thesis:

\section{Chapter 2}

Migration and Homing of WJ-MSCs

In chapter 2, we tested the intracerebral transplantation of WJ-MSCs in healthy neonatal rats. Time course experiments would evaluate successful transplantation and migration of the donor cells throughout the ventricular system and periventricular white matter. We hypothesized that only a few donor cells should survive 4 weeks after transplantation suggesting WJ-MSCs' safety "clearance from the brain" and possible mechanism of action "paracrine effects".

\section{Chapter 3}

\section{Perinatal Brain Injury and WJ-MSCs}

In chapter 3, we studied WJ-MSCs ' potential to protect against immature brain injury. Using a well established hypoxic-ischemic brain injury model, we anticipated that intraventricular WJ-MSCs transplantation to reduce myelin loss and astrogliosis in the cortex while preserving proper functional behavior. We anticipated that WJ-MSCs would target crucial cell cycle signaling. 
The potential neuroprotective effect of $17 \beta$-Estradiol in infants at risk of hypoxicischemic brain injury emerged recently ${ }^{157}$. However, substitution/replacement of estrogen in scenarios of steroid deprivation such as preterm birth has not been addressed sufficiently ${ }^{134}$. There is still much controversy regarding the differing doses, time, treatment schedules, or the effect of estrogen in a neonatal brain after injury ${ }^{127} 128$. These findings formed the basis for the research hypothesis whether $17 \beta$-Estradiol protects the immature rat brain from hypoxic-ischemic brain injury.

3. Does $17 \beta$-Estradiol protect the rat brain from hypoxic-ischemic brain injury and which potential mechanism is involved?

To answer the question 3 we have used a murine model of hypoxic-ischemic brain injury. We hypothesized that repeated substitution of low-dose 17- $\beta$ Estradiol will provide neuroprotective activity in neonatal rats. These general hypotheses lead to the following outline of the thesis:

\section{Chapter 4}

\section{Perinatal Brain Injury and Estradiol}

In chapter 4, we assessed whether repeated injections of 17- $\beta$ Estradiol protects the neonatal rat brain from hypoxic-ischemic brain injury. Thus, we assessed the neuroprotective activity quantitatively by a macroscopic and microscopic score for structural damage, hemisphere volumes, and immunohistochemistry for cleaved-caspase-3 as a marker for apoptotic cells.

Finally, we anticipated to test the neuroprotective capacity of sPIF in a murine model of preterm brain injury and dissect the underlying mechanisms. As stated above SPIF`s immune modulatory capacities are well documented ${ }^{5}$ and the neuroprotective potential was tested in an adult neurodegenerative disease model 151. Given the importance of inflammatory responses after brain injury in the immature brain (Figure 3) 27,3 , we hypothesized that SPIF would exert strong neuroprotective effects. Additionally, we decided to focus on TLR4 signaling pathways as TLR4 is involved in inflammatory responses and neuroprotective effects ${ }^{158}$.

These findings formed the basis for the research hypotheses as the question of sPIF`s neuroprotective effects was not assessed after immature brain injury. The research question were:

4. Does sPIF protect the immature rat brain from hypoxic-ischemic brain injury and impact let-7 mediated alterations?

5. Does sPIF protect the immature rat brain from hypoxic-ischemic brain injury and impact PKA/PKC signaling?

To answer the questions 4 and 5 we have used both in-vivo and in-vitro studies. We hypothesized that SPIF will protect the immature rat brain from hypoxicischemic brain injury. Secondly, we anticipated that these effects will be TLR4dependent. Finally, we hypothesized that both let-7 repression and activation of PKA/PKC signaling will be involved.

These general hypotheses lead to the following outline of the thesis: 


\section{Chapter 5}

Perinatal Brain Injury and PreImplantation Factor (microRNA let-7)

In chapter 5, we studied (in-vitro) whether sPIF imparts let-7 repression in neuronal, microglial and macrophage cells. We anticipated significant changes for let-7 expression by destabilizing the key microRNA processing protein KSRP in a TLR4-dependent manner. Finally, we hypothesized that our in-vitro results will be confirmed in a rat hypoxic-ischemic brain injury model by attenuation of neuronal death and microglial activation. Importantly sPIF should inhibit let-7 biogenesis in-vivo as well.

\section{Chapter 6}

Perinatal Brain Injury and PreImplantation Factor (PKA/PKC)

In chapter 6, we studied (in-vitro) whether sPIF induces PKA/PKC activation in neuronal cells. We anticipated significant changes for PKA/PKC activity and PKA/PKC neuroprotective targets. Again, we hypothesized that these effects will be TLR4-dependent. To underline the importance of sPIF`s mediated changes, we used a rat hypoxic-ischemic brain injury model. We anticipated reduced cell death, reversed neuronal loss and restored proper cortical architecture. Importantly sPIF should activate PKA/PKC signaling, leading to increased phosphorylation of major neuroprotective substrates such as GAP-43, BAD, and CREB.

\section{Chapter 7}

\section{General discussion}

The overall results of this thesis and its implication for clinical research are discussed in chapter 7 . 


\section{Chapter 1}

\section{References:}

1. Knuesel I, Chicha L, Britschgi M, Schobel SA, Bodmer M, Hellings JA, et al. Maternal immune activation and abnormal brain development across CNS disorders. Nat Rev Neurol 2014, 10: 643660 .

2. Volpe JJ. Brain injury in premature infants: a complex amalgam of destructive and developmental disturbances. Lancet neurology 2009, 8(1): 110-124

3. Fleiss B, Gressens P. Tertiary mechanisms of brain damage: a new hope for treatment of cerebral palsy? Lancet neurology 2012, 11(6): 556-566.

4. Katsuda T, Kosaka N, Takeshita F, Ochiya T. The therapeutic potential of mesenchymal stem cell-derived extracellular vesicles. Proteomics 2013, 13(10-11): 1637-1653.

5. Barnea ER, Almogi-Hazan O, Or R, Mueller M, Ria F, Weiss L, et al. Immune regulatory and neuroprotective properties of preimplantation factor: From newborn to adult. Pharmacology \& therapeutics 2015, 156: 10-25.

6. de Graaf-Peters VB, Hadders-Algra M. Ontogeny of the human central nervous system: what is happening when? Early human development 2006, 82(4): 257-266.

7. Gressens P. Mechanisms and disturbances of neuronal migration. Pediatric research 2000, 48(6): 725-730.

8. Schmahl W, Knoedlseder M, Favor J, Davidson D. Defects of neuronal migration and the pathogenesis of cortical malformations are associated with Small eye (Sey) in the mouse, a point mutation at the Pax-6-locus. Acta neuropathologica 1993, 86(2): 126-135.

9. Molyneaux BJ, Arlotta P, Menezes JR, Macklis JD. Neuronal subtype specification in the cerebral cortex. Nature reviews Neuroscience 2007, 8(6): 427-437.

10. Gupta RK, Hasan KM, Trivedi R, Pradhan M, Das V, Parikh NA, et al. Diffusion tensor imaging of the developing human cerebrum. Journal of neuroscience research 2005, 81(2): 172178.

11. Kostovic I, Judas M, Rados M, Hrabac P. Laminar organization of the human fetal cerebrum revealed by histochemical markers and magnetic resonance imaging. Cereb Cortex 2002, 12(5): 536-544.

12. Metzger F. Molecular and cellular control of dendrite maturation during brain development. Current molecular pharmacology 2010, 3(1): 1-11.

13. Kostovic I, Judas M. Correlation between the sequential ingrowth of afferents and transient patterns of cortical lamination in preterm infants. The Anatomical record 2002, 267(1): 1-6.

14. Koenderink MJ, Uylings HB. Postnatal maturation of layer V pyramidal neurons in the human prefrontal cortex. A quantitative Golgi analysis. Brain research 1995, 678(1-2): 233-243.

15. Ginhoux F, Lim S, Hoeffel G, Low D, Huber T. Origin and differentiation of microglia. Frontiers in cellular neuroscience 2013, 7: 45.

16. Guizzetti M, Zhang X, Goeke C, Gavin DP. Glia and Neurodevelopment: Focus on Fetal Alcohol Spectrum Disorders. Frontiers in pediatrics 2014, 2: 123.

17. Benarroch EE. Microglia: Multiple roles in surveillance, circuit shaping, and response to injury. Neurology 2013, 81(12): 1079-1088.

18. Falsig J, Porzgen P, Lund S, Schrattenholz A, Leist M. The inflammatory transcriptome of reactive murine astrocytes and implications for their innate immune function. Journal of neurochemistry 2006, 96(3): 893-907. 
19. Graham EM, Ruis KA, Hartman AL, Northington FJ, Fox HE. A systematic review of the role of intrapartum hypoxia-ischemia in the causation of neonatal encephalopathy. American journal of obstetrics and gynecology 2008, 199(6): 587-595.

20. Cowan FM, Mercuri E, Rutherford MA. Perinatal stroke in term infants with neonatal encephalopathy. Neurology 2005, 64(3): 579; author reply 579.

21. Schaaf JM, Mol BW, Abu-Hanna A, Ravelli AC. Trends in preterm birth: singleton and multiple pregnancies in the Netherlands, 2000-2007. BJOG 2011, 118(10): 1196-1204.

22. Numerato D, Fattore G, Tediosi F, Zanini R, Peltola M, Banks H, et al. Mortality and Length of Stay of Very Low Birth Weight and Very Preterm Infants: A EuroHOPE Study. PLoS One 2015, 10(6): e0131685.

23. Robertson CM, Watt MJ, Yasui Y. Changes in the prevalence of cerebral palsy for children born very prematurely within a population-based program over 30 years. JAMA 2007, 297(24): 2733-2740.

24. MacLennan AH, Thompson SC, Gecz J. Cerebral palsy: causes, pathways, and the role of genetic variants. Am J Obstet Gynecol 2015.

25. Pleasure D, Soulika A, Singh SK, Gallo V, Bannerman P. Inflammation in white matter: clinical and pathophysiological aspects. Mental retardation and developmental disabilities research reviews 2006, 12(2): 141-146.

26. Favrais G, van de Looij Y, Fleiss B, Ramanantsoa N, Bonnin P, Stoltenburg-Didinger G, et al. Systemic inflammation disrupts the developmental program of white matter. Annals of neurology 2011, 70(4): 550-565.

27. Hagberg H, Mallard C, Ferriero DM, Vannucci SJ, Levison SW, Vexler ZS, et al. The role of inflammation in perinatal brain injury. Nature reviews Neurology 2015, 11(4): 192-208.

28. Eklind S, Mallard C, Leverin AL, Gilland E, Blomgren K, Mattsby-Baltzer I, et al. Bacterial endotoxin sensitizes the immature brain to hypoxic--ischaemic injury. The European journal of neuroscience 2001, 13(6): 1101-1106.

29. Meyer U, Feldon J, Dammann O. Schizophrenia and autism: both shared and disorder-specific pathogenesis via perinatal inflammation? Pediatric research 2011, 69(5 Pt 2): 26R-33R.

30. Shrivastava K, Chertoff M, Llovera G, Recasens M, Acarin L. Short and long-term analysis and comparison of neurodegeneration and inflammatory cell response in the ipsilateral and contralateral hemisphere of the neonatal mouse brain after hypoxia/ischemia. Neurology research international 2012, 2012: 781512.

31. Sofroniew MV. Astrocyte barriers to neurotoxic inflammation. Nature reviews Neuroscience 2015, 16(5): 249-263.

32. Brown GC, Neher JJ. Inflammatory neurodegeneration and mechanisms of microglial killing of neurons. Molecular neurobiology 2010, 41(2-3): 242-247.

33. Buntinx M, Moreels M, Vandenabeele F, Lambrichts I, Raus J, Steels P, et al. Cytokineinduced cell death in human oligodendroglial cell lines: I. Synergistic effects of IFN-gamma and TNF-alpha on apoptosis. Journal of neuroscience research 2004, 76(6): 834-845.

34. Aden U, Favrais G, Plaisant F, Winerdal M, Felderhoff-Mueser U, Lampa J, et al. Systemic inflammation sensitizes the neonatal brain to excitotoxicity through a pro-/anti-inflammatory imbalance: key role of TNFalpha pathway and protection by etanercept. Brain Behav Immun 2010, 24(5): 747-758.

35. Sloane JA, Batt C, Ma Y, Harris ZM, Trapp B, Vartanian T. Hyaluronan blocks oligodendrocyte progenitor maturation and remyelination through TLR2. Proceedings of the National Academy of Sciences of the United States of America 2010, 107(25): 11555-11560. 


\section{Chapter 1}

36. Lehmann SM, Kruger C, Park B, Derkow K, Rosenberger K, Baumgart J, et al. An unconventional role for miRNA: let-7 activates Toll-like receptor 7 and causes neurodegeneration. Nat Neurosci 2012, 15(6): 827-835.

37. Selvamani A, Sathyan P, Miranda RC, Sohrabji F. An antagomir to microRNA Let7f promotes neuroprotection in an ischemic stroke model. PLoS One 2012, 7(2): e32662.

38. Schulte LN, Eulalio A, Mollenkopf H-J, Reinhardt R, Vogel J. Analysis of the host microRNA response to Salmonella uncovers the control of major cytokines by the let-7 family. The EMBO journal 2011, 30(10): 1977-1989.

39. Hou L, Wang X. PKC and PKA, but not PKG mediate LPS-induced CGRP release and $[\mathrm{Ca}(2+)](\mathrm{i})$ elevation in DRG neurons of neonatal rats. Journal of neuroscience research 2001, 66(4): 592-600.

40. Tse KH, Chow KB, Leung WK, Wong YH, Wise H. Primary sensory neurons regulate Tolllike receptor-4-dependent activity of glial cells in dorsal root ganglia. Neuroscience 2014, 279: 1022.

41. Leenders AG, Sheng ZH. Modulation of neurotransmitter release by the second messengeractivated protein kinases: implications for presynaptic plasticity. Pharmacology \& therapeutics 2005, 105(1): 69-84.

42. Libien J, Sacktor TC, Kass IS. Magnesium blocks the loss of protein kinase C, leads to a transient translocation of PKC(alpha) and PKC(epsilon), and improves recovery after anoxia in rat hippocampal slices. Brain research Molecular brain research 2005, 136(1-2): 104-111.

43. Raval AP, Dave KR, Mochly-Rosen D, Sick TJ, Perez-Pinzon MA. Epsilon PKC is required for the induction of tolerance by ischemic and NMDA-mediated preconditioning in the organotypic hippocampal slice. The Journal of neuroscience : the official journal of the Society for Neuroscience 2003, 23(2): 384-391.

44. Selvatici R, Melloni E, Ferrati M, Piubello C, Marincola FC, Gandini E. Adaptative value of a PKC-PKI55 feedback loop of inhibition that prevents the kinase's deregulation. Journal of molecular evolution 2003, 57(2): 131-139.

45. Osuga H, Osuga S, Wang F, Fetni R, Hogan MJ, Slack RS, et al. Cyclin-dependent kinases as a therapeutic target for stroke. Proceedings of the National Academy of Sciences of the United States of America 2000, 97(18): 10254-10259.

46. Miras-Portugal MT, Gomez-Villafuertes R, Gualix J, Diaz-Hernandez JI, Artalejo AR, Ortega F, et al. Nucleotides in neuroregeneration and neuroprotection. Neuropharmacology 2015.

47. Mueller M, Schoeberlein A, Zhou J, Joerger-Messerli M, Oppliger B, Reinhart U, et al. PreImplantation Factor bolsters neuroprotection via modulating Protein Kinase A and Protein Kinase C signaling. Cell Death Differ. 2015 Dec;22(12):2078-86

48. Kim HH, Abdelmohsen K, Gorospe M. Regulation of HuR by DNA Damage Response Kinases. J Nucleic Acids 2010, 2010.

49. Meng S, Arbit T, Veeriah S, Mellinghoff IK, Fang F, Vivanco I, et al. 14-3-3sigma and p21 synergize to determine DNA damage response following Chk2 inhibition. Cell Cycle 2009, 8(14): 2238-2246.

50. Hermeking H, Benzinger A. 14-3-3 proteins in cell cycle regulation. Semin Cancer Biol 2006, 16(3): 183-192.

51. Xu N, Lao Y, Zhang Y, Gillespie DA. Akt: a double-edged sword in cell proliferation and genome stability. J Oncol 2012, 2012: 951724. 
52. Martinez-Lopez DG, Funderburg NT, Cerissi A, Rifaie R, Aviles-Medina L, Llorens-Bonilla $\mathrm{BJ}$, et al. Lipopolysaccharide and soluble CD14 in cord blood plasma are associated with prematurity and chorioamnionitis. Pediatric research 2014, 75(1-1): 67-74.

53. Maneenil G, Kemp MW, Kannan PS, Kramer BW, Saito M, Newnham JP, et al. Oral, nasal and pharyngeal exposure to lipopolysaccharide causes a fetal inflammatory response in sheep. PLoS One 2015, 10(3): e0119281.

54. Strackx E, Sparnaaij MA, Vlassaks E, Jellema R, Kuypers E, Vles JS, et al. Lipopolysaccharide-induced chorioamnionitis causes acute inflammatory changes in the ovine central nervous system. CNS Neurol Disord Drug Targets 2015, 14(1): 77-84.

55. Kuypers E, Willems MG, Jellema RK, Kemp MW, Newnham JP, Delhaas T, et al. Responses of the spleen to intraamniotic lipopolysaccharide exposure in fetal sheep. Pediatric research 2015, 77(1-1): 29-35.

56. Executive summary: Neonatal encephalopathy and neurologic outcome, second edition. Report of the American College of Obstetricians and Gynecologists' Task Force on Neonatal Encephalopathy. Obstet Gynecol 2014, 123(4): 896-901.

57. Higgins RD, Raju T, Edwards AD, Azzopardi DV, Bose CL, Clark RH, et al. Hypothermia and other treatment options for neonatal encephalopathy: an executive summary of the Eunice Kennedy Shriver NICHD workshop. The Journal of pediatrics 2011, 159(5): 851-858 e851.

58. Edwards AD, Brocklehurst P, Gunn AJ, Halliday H, Juszczak E, Levene M, et al. Neurological outcomes at 18 months of age after moderate hypothermia for perinatal hypoxic ischaemic encephalopathy: synthesis and meta-analysis of trial data. BMJ 2010, 340: c363.

59. Cahill AG, Stout MJ, Caughey AB. Intrapartum magnesium for prevention of cerebral palsy: continuing controversy? Current opinion in obstetrics \& gynecology 2010, 22(2): 122-127.

60. Doyle LW, Anderson PJ, Haslam R, Lee KJ, Crowther C, Australasian Collaborative Trial of Magnesium Sulphate Study G. School-age outcomes of very preterm infants after antenatal treatment with magnesium sulfate vs placebo. JAMA 2014, 312(11): 1105-1113.

61. Hassell KJ, Ezzati M, Alonso-Alconada D, Hausenloy DJ, Robertson NJ. New horizons for newborn brain protection: enhancing endogenous neuroprotection. Arch Dis Child Fetal Neonatal Ed 2015.

62. Donohue PK, Gilmore MM, Cristofalo E, Wilson RF, Weiner JZ, Lau BD, et al. Inhaled nitric oxide in preterm infants: a systematic review. Pediatrics 2011, 127(2): e414-422.

63. Buonocore G, Turrisi G, Kramer BW, Balduini W, Perrone S. New Pharmacological Approaches in Infants with Hypoxic-Ischemic Encephalopathy. Curr Pharm Des 2012.

64. Mueller M, Wolfs TG, Schoeberlein A, Gavilanes AW, Surbek D, Kramer BW. Mesenchymal stem/stromal cells-a key mediator for regeneration after perinatal morbidity? Mol Cell Pediatr 2016, 3(1): 6 .

65. Ramalho-Santos M, Willenbring H. On the origin of the term "stem cell". Cell Stem Cell 2007, 1(1): $35-38$.

66. Caplan AI. Mesenchymal stem cells. J Orthop Res 1991, 9(5): 641-650.

67. Zuk PA, Zhu M, Mizuno H, Huang J, Futrell JW, Katz AJ, et al. Multilineage cells from human adipose tissue: implications for cell-based therapies. Tissue Eng 2001, 7(2): 211-228.

68. In 't Anker PS, Scherjon SA, Kleijburg-van der Keur C, de Groot-Swings GM, Claas FH, Fibbe WE, et al. Isolation of mesenchymal stem cells of fetal or maternal origin from human placenta. Stem Cells 2004, 22(7): 1338-1345. 


\section{Chapter 1}

69. Igura K, Zhang X, Takahashi K, Mitsuru A, Yamaguchi S, Takashi TA. Isolation and characterization of mesenchymal progenitor cells from chorionic villi of human placenta. Cytotherapy 2004, 6(6): 543-553.

70. Stefanidis K, Loutradis D, Anastasiadou V, Bletsa R, Kiapekou E, Drakakis P, et al. Oxytocin receptor- and Oct-4-expressing cells in human amniotic fluid. Gynecol Endocrinol 2008, 24(5): 280-284.

71. Prusa AR, Marton E, Rosner M, Bernaschek G, Hengstschlager M. Oct-4-expressing cells in human amniotic fluid: a new source for stem cell research? Hum Reprod 2003, 18(7): 1489-1493.

72. In 't Anker PS, Scherjon SA, Kleijburg-van der Keur C, Noort WA, Claas FH, Willemze R, et al. Amniotic fluid as a novel source of mesenchymal stem cells for therapeutic transplantation. Blood 2003, 102(4): 1548-1549.

73. Wang JF, Wang LJ, Wu YF, Xiang Y, Xie CG, Jia BB, et al. Mesenchymal stem/progenitor cells in human umbilical cord blood as support for ex vivo expansion of CD34(+) hematopoietic stem cells and for chondrogenic differentiation. Haematologica 2004, 89(7): 837-844.

74. Erices A, Conget P, Minguell JJ. Mesenchymal progenitor cells in human umbilical cord blood. Br J Haematol 2000, 109(1): 235-242.

75. Ma L, Feng XY, Cui BL, Law F, Jiang XW, Yang LY, et al. Human umbilical cord Wharton's Jelly-derived mesenchymal stem cells differentiation into nerve-like cells. Chin Med J (Engl) 2005, 118(23): 1987-1993.

76. Wang HS, Hung SC, Peng ST, Huang CC, Wei HM, Guo YJ, et al. Mesenchymal stem cells in the Wharton's jelly of the human umbilical cord. Stem Cells 2004, 22(7): 1330-1337.

77. Sohni A, Verfaillie CM. Mesenchymal stem cells migration homing and tracking. Stem Cells Int 2013, 2013: 130763.

78. Prasad VK, Kurtzberg J. Umbilical cord blood transplantation for non-malignant diseases. Bone Marrow Transplant 2009, 44(10): 643-651.

79. Yang WZ, Zhang Y, Wu F, Min WP, Minev B, Zhang M, et al. Safety evaluation of allogeneic umbilical cord blood mononuclear cell therapy for degenerative conditions. J Transl Med 2010, 8: 75.

80. De Coppi P, Bartsch G, Jr., Siddiqui MM, Xu T, Santos CC, Perin L, et al. Isolation of amniotic stem cell lines with potential for therapy. Nat Biotechnol 2007, 25(1): 100-106.

81. Jaerve A, Muller HW. Chemokines in CNS injury and repair. Cell Tissue Res 2012, 349(1): 229-248.

82. Gao LR, Zhang NK, Ding QA, Chen HY, Hu X, Jiang S, et al. Common expression of stemness molecular markers and early cardiac transcription factors in human Wharton's jellyderived mesenchymal stem cells and embryonic stem cells. Cell Transplant 2013, 22(10): 18831900.

83. Yang DY, Sheu ML, Su HL, Cheng FC, Chen YJ, Chen CJ, et al. Dual regeneration of muscle and nerve by intravenous administration of human amniotic fluid-derived mesenchymal stem cells regulated by stromal cell-derived factor-1alpha in a sciatic nerve injury model. J Neurosurg 2012, 116(6): 1357-1367.

84. Kim YJ, Yu JM, Joo HJ, Kim HK, Cho HH, Bae YC, et al. Role of CD9 in proliferation and proangiogenic action of human adipose-derived mesenchymal stem cells. Pflugers Arch 2007, 455(2): 283-296.

85. Dominici M, Le Blanc K, Mueller I, Slaper-Cortenbach I, Marini F, Krause D, et al. Minimal criteria for defining multipotent mesenchymal stromal cells. The International Society for Cellular Therapy position statement. Cytotherapy 2006, 8(4): 315-317. 
86. Roobrouck VD, Vanuytsel K, Verfaillie CM. Concise review: culture mediated changes in fate and/or potency of stem cells. Stem Cells 2011, 29(4): 583-589.

87. Brooke G, Tong H, Levesque JP, Atkinson K. Molecular trafficking mechanisms of multipotent mesenchymal stem cells derived from human bone marrow and placenta. Stem Cells Dev 2008, 17(5): 929-940.

88. Mariotti E, Mirabelli P, Abate G, Schiattarella M, Martinelli P, Fortunato G, et al. Comparative characteristics of mesenchymal stem cells from human bone marrow and placenta: CD10, CD49d, and CD56 make a difference. Stem Cells Dev 2008, 17(6): 1039-1041.

89. Moorefield EC, McKee EE, Solchaga L, Orlando G, Yoo JJ, Walker S, et al. Cloned, CD117 selected human amniotic fluid stem cells are capable of modulating the immune response. PLoS One 2011, 6(10): e26535.

90. Fong CY, Chak LL, Biswas A, Tan JH, Gauthaman K, Chan WK, et al. Human Wharton's jelly stem cells have unique transcriptome profiles compared to human embryonic stem cells and other mesenchymal stem cells. Stem Cell Rev 2011, 7(1): 1-16.

91. Subramanian A, Fong CY, Biswas A, Bongso A. Comparative Characterization of Cells from the Various Compartments of the Human Umbilical Cord Shows that the Wharton's Jelly Compartment Provides the Best Source of Clinically Utilizable Mesenchymal Stem Cells. PLoS One 2015, 10(6): e0127992.

92. Troyer DL, Weiss ML. Wharton's jelly-derived cells are a primitive stromal cell population. Stem Cells 2008, 26(3): 591-599.

93. Balasubramanian S, Thej C, Venugopal P, Priya N, Zakaria Z, Sundarraj S, et al. Higher propensity of Wharton's jelly derived mesenchymal stromal cells towards neuronal lineage in comparison to those derived from adipose and bone marrow. Cell Biol Int 2013, 37(5): 507-515.

94. Hsieh JY, Wang HW, Chang SJ, Liao KH, Lee IH, Lin WS, et al. Mesenchymal stem cells from human umbilical cord express preferentially secreted factors related to neuroprotection, neurogenesis, and angiogenesis. PLoS One 2013, 8(8): e72604.

95. Pires AO, Neves-Carvalho A, Sousa N, Salgado AJ. The Secretome of Bone Marrow and Wharton Jelly Derived Mesenchymal Stem Cells Induces Differentiation and Neurite Outgrowth in SH-SY5Y Cells. Stem Cells Int 2014, 2014: 438352.

96. Teixeira FG, Carvalho MM, Neves-Carvalho A, Panchalingam KM, Behie LA, Pinto L, et al. Secretome of mesenchymal progenitors from the umbilical cord acts as modulator of neural/glial proliferation and differentiation. Stem Cell Rev 2015, 11(2): 288-297.

97. Constantin G, Marconi S, Rossi B, Angiari S, Calderan L, Anghileri E, et al. Adipose-derived mesenchymal stem cells ameliorate chronic experimental autoimmune encephalomyelitis. Stem Cells 2009, 27(10): 2624-2635.

98. Bai L, Lennon DP, Caplan AI, DeChant A, Hecker J, Kranso J, et al. Hepatocyte growth factor mediates mesenchymal stem cell-induced recovery in multiple sclerosis models. Nat Neurosci 2012, 15(6): 862-870.

99. Voulgari-Kokota A, Fairless R, Karamita M, Kyrargyri V, Tseveleki V, Evangelidou M, et al. Mesenchymal stem cells protect CNS neurons against glutamate excitotoxicity by inhibiting glutamate receptor expression and function. Experimental neurology 2012, 236(1): 161-170.

100. Gu W, Zhang F, Xue Q, Ma Z, Lu P, Yu B. Transplantation of bone marrow mesenchymal stem cells reduces lesion volume and induces axonal regrowth of injured spinal cord. Neuropathology 2010, 30(3): 205-217.

101. Bruno S, Deregibus MC, Camussi G. The secretome of mesenchymal stromal cells: Role of extracellular vesicles in immunomodulation. Immunol Lett 2015. 


\section{Chapter 1}

102. Gerdoni E, Gallo B, Casazza S, Musio S, Bonanni I, Pedemonte E, et al. Mesenchymal stem cells effectively modulate pathogenic immune response in experimental autoimmune encephalomyelitis. Ann Neurol 2007, 61(3): 219-227.

103. Jellema RK, Wolfs TG, Lima Passos V, Zwanenburg A, Ophelders DR, Kuypers E, et al. Mesenchymal stem cells induce T-cell tolerance and protect the preterm brain after global hypoxia-ischemia. PLoS One 2013, 8(8): e73031.

104. Duffy MM, Ritter T, Ceredig R, Griffin MD. Mesenchymal stem cell effects on T-cell effector pathways. Stem Cell Res Ther 2011, 2(4): 34.

105. Di Nicola M, Carlo-Stella C, Magni M, Milanesi M, Longoni PD, Matteucci P, et al. Human bone marrow stromal cells suppress T-lymphocyte proliferation induced by cellular or nonspecific mitogenic stimuli. Blood 2002, 99(10): 3838-3843.

106. Franquesa M, Hoogduijn MJ, Bestard O, Grinyo JM. Immunomodulatory effect of mesenchymal stem cells on B cells. Front Immunol 2012, 3: 212.

107. Raffaghello L, Bianchi G, Bertolotto M, Montecucco F, Busca A, Dallegri F, et al. Human mesenchymal stem cells inhibit neutrophil apoptosis: a model for neutrophil preservation in the bone marrow niche. Stem Cells 2008, 26(1): 151-162.

108. Ivanova-Todorova E, Bochev I, Mourdjeva M, Dimitrov R, Bukarev D, Kyurkchiev S, et al. Adipose tissue-derived mesenchymal stem cells are more potent suppressors of dendritic cells differentiation compared to bone marrow-derived mesenchymal stem cells. Immunol Lett 2009, 126(1-2): 37-42.

109. Spaggiari GM, Capobianco A, Abdelrazik H, Becchetti F, Mingari MC, Moretta L. Mesenchymal stem cells inhibit natural killer-cell proliferation, cytotoxicity, and cytokine production: role of indoleamine 2,3-dioxygenase and prostaglandin E2. Blood 2008, 111(3): 13271333.

110. Rahmat Z, Jose S, Ramasamy R, Vidyadaran S. Reciprocal interactions of mouse bone marrow-derived mesenchymal stem cells and BV2 microglia after lipopolysaccharide stimulation. Stem Cell Res Ther 2013, 4(1): 12.

111. Nartprayut K, Y UP, Kheolamai P, Manochantr S, Chayosumrit M, Issaragrisil S, et al. Cardiomyocyte differentiation of perinatallyderived mesenchymal stem cells. Mol Med Rep 2013, 7(5): 1465-1469.

112. Li D, Chai J, Shen C, Han Y, Sun T. Human umbilical cord-derived mesenchymal stem cells differentiate into epidermal-like cells using a novel co-culture technique. Cytotechnology 2014, 66(4): 699-708.

113. Wu KH, Zhou B, Lu SH, Feng B, Yang SG, Du WT, et al. In vitro and in vivo differentiation of human umbilical cord derived stem cells into endothelial cells. J Cell Biochem 2007, 100(3): 608-616.

114. Leite C, Silva NT, Mendes S, Ribeiro A, de Faria JP, Lourenco T, et al. Differentiation of human umbilical cord matrix mesenchymal stem cells into neural-like progenitor cells and maturation into an oligodendroglial-like lineage. PLoS One 2014, 9(10): e111059.

115. Yan ZJ, Hu YQ, Zhang HT, Zhang P, Xiao ZY, Sun XL, et al. Comparison of the neural differentiation potential of human mesenchymal stem cells from amniotic fluid and adult bone marrow. Cell Mol Neurobiol 2013, 33(4): 465-475.

116. Uccelli A, Benvenuto F, Laroni A, Giunti D. Neuroprotective features of mesenchymal stem cells. Best Pract Res Clin Haematol 2011, 24(1): 59-64. 
117. Bianco P, Cao X, Frenette PS, Mao JJ, Robey PG, Simmons PJ, et al. The meaning, the sense and the significance: translating the science of mesenchymal stem cells into medicine. Nat Med 2013, 19(1): 35-42.

118. Lee RH, Pulin AA, Seo MJ, Kota DJ, Ylostalo J, Larson BL, et al. Intravenous hMSCs improve myocardial infarction in mice because cells embolized in lung are activated to secrete the anti-inflammatory protein TSG-6. Cell Stem Cell 2009, 5(1): 54-63.

119. Fischbach MA, JA Bluestone and WA Lim. (2013). Cell-based therapeutics: the next pillar of medicine. Sci Transl Med 5:179ps7.

120. Merino-González C, Zuñiga FA, Escudero C, Ormazabal V, Reyes C, Nova-Lamperti E, et al. Mesenchymal Stem Cell-Derived Extracellular Vesicles Promote Angiogenesis: Potencial Clinical Application. Front. Physiol. 2016, 7:24.

121. Laflamme N, Nappi RE, Drolet G, Labrie C, Rivest S. Expression and neuropeptidergic characterization of estrogen receptors (ERalpha and ERbeta) throughout the rat brain: anatomical evidence of distinct roles of each subtype. J Neurobiol 1998, 36(3): 357-378.

122. Zuloaga DG, Yahn SL, Pang Y, Quihuis AM, Oyola MG, Reyna A, et al. Distribution and estrogen regulation of membrane progesterone receptor-beta in the female rat brain. Endocrinology 2012, 153(9): 4432-4443.

123. Haraguchi S, Sasahara K, Shikimi H, Honda S, Harada N, Tsutsui K. Estradiol promotes purkinje dendritic growth, spinogenesis, and synaptogenesis during neonatal life by inducing the expression of BDNF. Cerebellum 2012, 11(2): 416-417.

124. Brann DW, Dhandapani K, Wakade C, Mahesh VB, Khan MM. Neurotrophic and neuroprotective actions of estrogen: basic mechanisms and clinical implications. Steroids 2007, 72(5): 381-405.

125. Zhang Y, Tounekti O, Akerman B, Goodyer CG, LeBlanc A. 17-beta-estradiol induces an inhibitor of active caspases. The Journal of neuroscience : the official journal of the Society for Neuroscience 2001, 21(20): RC176.

126. Brywe KG, Mallard C, Gustavsson M, Hedtjarn M, Leverin AL, Wang X, et al. IGF-I neuroprotection in the immature brain after hypoxia-ischemia, involvement of Akt and GSK3beta? The European journal of neuroscience 2005, 21(6): 1489-1502.

127. Gerstner B, Lee J, DeSilva TM, Jensen FE, Volpe JJ, Rosenberg PA. 17beta-estradiol protects against hypoxic/ischemic white matter damage in the neonatal rat brain. Journal of neuroscience research 2009, 87(9): 2078-2086.

128. Nunez J, Yang Z, Jiang Y, Grandys T, Mark I, Levison SW. 17beta-estradiol protects the neonatal brain from hypoxia-ischemia. Experimental neurology 2007, 208(2): 269-276.

129. Deutsch ER, Espinoza TR, Atif F, Woodall E, Kaylor J, Wright DW. Progesterone's role in neuroprotection, a review of the evidence. Brain research 2013, 1530: 82-105.

130. Ishrat T, Sayeed I, Atif F, Hua F, Stein DG. Progesterone and allopregnanolone attenuate blood-brain barrier dysfunction following permanent focal ischemia by regulating the expression of matrix metalloproteinases. Experimental neurology 2010, 226(1): 183-190.

131. Xu CY, Li S, Li XQ, Li DL. [Effect of progesterone on MMP-3 expression in neonatal rat brain after hypoxic-ischemia]. Zhongguo Ying Yong Sheng Li Xue Za Zhi 2010, 26(3): 370-373.

132. Ishrat T, Sayeed I, Atif F, Hua F, Stein DG. Progesterone is neuroprotective against ischemic brain injury through its effects on the phosphoinositide 3-kinase/protein kinase B signaling pathway. Neuroscience 2012, 210: 442-450. 


\section{Chapter 1}

133. Wang J, Zhao Y, Liu C, Jiang C, Zhao C, Zhu Z. Progesterone inhibits inflammatory response pathways after permanent middle cerebral artery occlusion in rats. Mol Med Rep 2011, 4(2): 319-324.

134. Trotter A, Maier L, Pohlandt F. Management of the extremely preterm infant: is the replacement of estradiol and progesterone beneficial? Paediatr Drugs 2001, 3(9): 629-637.

135. Hunt R, Davis PG, Inder T. Replacement of estrogens and progestins to prevent morbidity and mortality in preterm infants. Cochrane Database Syst Rev 2004(4): CD003848.

136. Barnea ER. Insight into early pregnancy events: the emerging role of the embryo. Am $J$ Reprod Immunol 2004, 51: 319.

137. Barnea ER, Kirk D, Ramu S, Rivnay B, Roussev R, Paidas MJ. PreImplantation Factor (PIF) orchestrates systemic antiinflammatory response by immune cells: effect on peripheral blood mononuclear cells. Am J Obstet Gynecol 2012, 207: 313.

138. Stamatkin CW, Roussev RG, Stout M, Absalon-Medina V, Ramu S, Goodman C, et al. PreImplantation Factor (PIF) correlates with early mammalian embryo development-bovine and murine models. Reproductive Biology and Endocrinology 2011, 9: 63.

139. Ramu S, Stamatkin C, Timms L, Ruble M, Roussev RG, Barnea ER. PreImplantation factor (PIF) detection in maternal circulation in early pregnancy correlates with live birth (bovine model). Reprod Biol Endocrinol 2013, 11: 105.

140. Ornaghi S, Mueller M, Barnea ER, Paidas MJ. Thrombosis during pregnancy: Risks, prevention, and treatment for mother and fetus--harvesting the power of omic technology, biomarkers and in vitro or in vivo models to facilitate the treatment of thrombosis. Birth Defects Res C Embryo Today 2015, 105(3): 209-225.

141. Arck PC, Hecher K. Fetomaternal immune cross-talk and its consequences for maternal and offspring's health. Nature medicine 2013, 19(5): 548-556.

142. Barnea ER, Kirk D, Ramu S, Rivnay B, Roussev R, Paidas MJ. PreImplantation Factor (PIF) orchestrates systemic antiinflammatory response by immune cells: effect on peripheral blood mononuclear cells. American journal of obstetrics and gynecology 2012, 207(4): 313.e311-311.

143. Roussev RG, Dons'koi BV, Stamatkin C, Ramu S, Chernyshov VP, Coulam CB, et al. Preimplantation factor inhibits circulating natural killer cell cytotoxicity and reduces CD69 expression: implications for recurrent pregnancy loss therapy. Reproductive biomedicine online 2013, 26(1): 79-87.

144. Barnea ER, Lubman DM, Liu YH, Absalon-Medina V, Hayrabedyan S, Todorova K, et al. Insight into PreImplantation Factor (PIF*) mechanism for embryo protection and development: target oxidative stress and protein misfolding (PDI and HSP) through essential RIPK binding site. PloS one 2014, 9(7): e100263.

145. Azar Y, Shainer R, Almogi-Hazan O, Bringer R, Compton SR, Paidas MJ, et al. Preimplantation factor reduces graft-versus-host disease by regulating immune response and lowering oxidative stress (murine model). Biol Blood Marrow Transplant 2013, 19(4): 519-528. 146. Weiss L, Bernstein S, Jones R, Amunugama R, Krizman D, Jebailey L, et al. Preimplantation factor (PIF) analog prevents type I diabetes mellitus (TIDM) development by preserving pancreatic function in NOD mice. Endocrine 2011, 40(1): 41-54.

147. Duzyj CM, Barnea ER, Li M, Huang SJ, Krikun G, Paidas MJ. Preimplantation factor promotes first trimester trophoblast invasion. Am J Obstet Gynecol 2010, 203: 402.

148. Paidas MJ, Krikun G, Huang SJ, Jones R, Romano M, Annunziato J, et al. A genomic and proteomic investigation of the impact of preimplantation factor on human decidual cells. Am $J$ Obstet Gynecol 2010, 202: 459. 
149. Barnea ER, Kirk D, Paidas MJ. Preimplantation factor (PIF) promoting role in embryo implantation: increases endometrial integrin- $\alpha 2 \beta 3$, amphiregulin and epiregulin while reducing betacellulin expression via MAPK in decidua. Reprod Biol Endocrinol 2012, 10.

150. Roussev RG, Dons'koi BV, Stamatkin C, Ramu S, Chernyshov VP, Coulam CB, et al. Preimplantation factor inhibits circulating natural killer cell cytotoxicity and reduces CD69 expression: implications for recurrent pregnancy loss therapy. Reprod Biomed Online 2013, 26(1): 79-87.

151. Weiss L, Or R, Jones RC, Amunugama R, JeBailey L, Ramu S, et al. Preimplantation factor (PIF*) reverses neuroinflammation while promoting neural repair in EAE model. Journal of the neurological sciences 2012, 312(1-2): 146-157.

152. Basu A, Krady JK, Levison SW. Interleukin-1: a master regulator of neuroinflammation. Journal of neuroscience research 2004, 78(2): 151-156.

153. Komiyama Y, Nakae S, Matsuki T, Nambu A, Ishigame H, Kakuta S, et al. IL-17 plays an important role in the development of experimental autoimmune encephalomyelitis. $J$ Immunol 2006, 177(1): 566-573.

154. Mahad DJ, Ransohoff RM. The role of MCP-1 (CCL2) and CCR2 in multiple sclerosis and experimental autoimmune encephalomyelitis (EAE). Semin Immunol 2003, 15(1): 23-32.

155. Engmann O, Giese KP. Crosstalk between Cdk5 and GSK3beta: Implications for Alzheimer's Disease. Front Mol Neurosci 2009, 2: 2.

156. Joerger-Messerli MS, Marx C, Oppliger B, Mueller M, Surbek DV, Schoeberlein A. Mesenchymal Stem Cells from Wharton's Jelly and Amniotic Fluid. Best Pract Res Clin Obstet Gynaecol 2015.

157. Berger R, Soder S. Neuroprotection in preterm infants. Biomed Res Int 2015, 2015: 257139.

158. Dhillon SK, Gunn AJ, Jung Y, Mathai S, Bennet L, Fraser M. Lipopolysaccharide-Induced Preconditioning Attenuates Apoptosis and Differentially Regulates TLR4 and TLR7 Gene Expression after Ischemia in the Preterm Ovine Fetal Brain. Dev Neurosci 2015, 37(6): 497-514. 



\section{Chapter 2}

\section{Homing of placenta-derived mesenchymal stem cells after perinatal intracerebral transplantation in a rat model}

Published as: Schoeberlein A*, Mueller M*, Reinhart U, Sager R, Messerli M, Surbek D. Homing of placenta-derived mesenchymal stem cells after perinatal intracerebral transplantation in a rat model. Am J Obstet Gynecol. 2011 Sep;205(3):277.e1-6. PubMed PMID: 22071064. *both authors contributed equally to this work 


\begin{abstract}
Objective: The aim of this study is to assess early homing of placenta- derived stem cells after perinatal intracerebral transplantation in rats.

Study Design: Neonatal Wistar rats (2-4 days old) were anesthetized, and 250,000 human placenta- derived mesenchymal stem cells (MSC) injected into the lateral ventricle or the paraventricular white matter using a stereotactic frame. Donor MSC were detected by immunohistochemistry using an antihuman HLA-ABC antibody.
\end{abstract}

Results: In all, $84 \%$ of the animals survived the transplantation. Donor cells were detected in the brain ventricle 1-2 hours posttransplantation. After 4 hours, donor cells migrated throughout the ventricular system. At 1-4 weeks after transplantation, some cells had migrated into the periventricular white matter.

Conclusion: Human placenta- derived MSC were successfully transplanted into the lateral ventricles of neonatal rats. Donor cells survived, homed, and migrated in the recipient brains. Proliferation and differentiation analysis and functional tests will assess the therapeutic effects of stem cell transplantation. 


\section{Introduction}

Preterm delivery is one of the major causes of neonatal morbidity and mortality ${ }^{1}$. Despite enormous efforts, brain injury accounts for a major part of the clinical problems in survivors of premature birth. Approximately 63,000 infants are born with a very low birthweight $(<1500 \mathrm{~g})$ in the United States, and this group represents $1-5 \%$ of all live births ${ }^{2}$. The enormity of the problems is indicated by occurrence of cognitive, behavioral, attentional, or socialization deficits in 25$50 \%$ and of major motor deficits in $5-10 \%$ of cases in this group ${ }^{3-5}$. Several pathologies, such as severe intraventricular hemorrhage, periventricular hemorrhagic infarction, hydrocephalus, or cerebellar disease, occur in premature infants, but cerebral white matter injury, due to the unique maturation process of the brain, seems to be predominant.

Hypoxia-ischemia (HI) and inflammation during preterm intrauterine and extrauterine life frequently coexist and are an acquired form of neuronal injury. Several studies indicate that fetal inflammatory response as a consequence of maternal infection contributes to the extent of prenatal brain damage ${ }^{6}$. Several animal models have been established using lipopolysaccharide application followed by induction of HI damage, but most of them inflict damage on postnatal day 7 (P7) rats, ${ }^{7}$ which, in terms of brain development, is rather equivalent to a late human preterm ${ }^{8}$. To understand the effect of such a double-hit insult in very premature infants, animal models with inflammation and HI on postnatal day 2 (P2) rats have to be established. Few studies have been published, and most of them investigate the effect of this double hit to characterize the synergistic effect on perinatal damage, ${ }^{9}$ but no data on possible route of treatment are available. Stem cells are a promising source for targeted cell therapy for brain injury. A number of transplantation experiments in animal models of neonatal encephalopathy have been described ${ }^{10}$. Human neural stem cells transplanted intracerebrally into P7 mice after HI injury migrated into the injured hemisphere. Human neural stem cells integrated into the damaged tissue, survived, and were shown to differentiate into neurons and astrocytes ${ }^{11}$. Behavioral sensorimotor tests confirmed functional improvement. Progenitor cells derived from human adult white matter differentiated into oligodendrocytes within demyelinated lesions in the rat ${ }^{12}$. Human neural progenitor cells transplanted into the striatum, hippocampus, and the subventricular zone of the developing rat brain migrated, integrated, and differentiated extensively into the corresponding cell types ${ }^{13}$. Other cell types, such as mesenchymal stem cells (MSC), ${ }^{14}$ glial progenitor cells, ${ }^{15}$ or human umbilical cord blood (HUCB) ${ }^{16}$ cells have been used as grafts. Placental MSC, either derived from the deciduas or the chorionic villi, have been transplanted intravenously in a rat model of experimental stroke and resulted in some improvement of the outcome for the decidua group ${ }^{17}$. In a similar model, intravenous transplantation of placental MSC stimulated the proliferation of stem and progenitor cells in the host and migration of these to the site of injury ${ }^{18}$.

Intraperitoneal (ip) transplantation of HUCBcells in a neonatal rat model of HI brain damage resulted in amelioration of developmental sensorimotor reflexes, a neuroprotective effect in the striatum, and a decrease in microglial activation ${ }^{16}$. In similar experiments, intravenous injection of HUCB cells did not improve spatial memory deficits and volumometric decrease of the hemisphere ipsilateral to the arterial occlusion ${ }^{19}$. Amniotic membrane-derived stem cells transplanted into the 
telencephalic rat ventricles at embryonic day 15.5 migrated into a number of brain regions and were present into adulthood. No signs of immunorejection or tumor formation were found ${ }^{20}$.

Different routes of application, such as ip, intraventricular, intracerebral, intravenous, or intracardiac, have been reported ${ }^{10}$. Intracerebral route seems to be promising, due to exclusion of peripheral immunoreactions affecting the outcome of an experiment. A possible paracrine effect was also demonstrated in a recent study. Intravenously injected HUCB cells reduced HI-induced deficits in motor asymmetry and motor coordination. Treated animals displayed increased levels of nerve growth factor, glial cell-derived neurotrophic factor, and brain-derived neurotrophic factor in their brains after the transplant, suggesting a paracrine effect. Since only few cells were found in the brain after the treatment, the entry of neutrophic factors from the circulation into the brain parenchyma seems possible ${ }^{21}$. Since HUCB cells produce several neutrophic factors ${ }^{22}$ and cytokines $^{23}$, and grafting of the transplant is often lacking, it is possible that the paracrine effect results in neuroprotection and antiinflammation ${ }^{10}$.

There are several well-established models of HI in newborn animals. ${ }^{24}$ Unilateral or bilateral carotid artery occlusion, eventually followed by reduced oxygen tension, ${ }^{25,26}$ umbilical cord occlusion, or uterine or fetoplacental ischemia ${ }^{27}$ results in HI injury of the fetuses. Studies with stem cell grafts in HI brain injury models were exclusively done with rats age $\leq \mathrm{P} 7$, which corresponds to human neonates born at term regarding the brain development. Since the majority of cases of neonatal encephalopathy are found in infants of very low birthweight and include both HI and inflammation, we conducted a study to investigate neuroprotective effects of MSC on P2 Wistar rats.

The aim of the study was to develop a method of intracranial application of placenta-derived MSC into the lateral ventricle or into the paraventricular white matter zone using a stereotactic frame to prove that the transplantation of placental stem cells is possible and leads to their survival and homing in neonatal brains.

\section{Materials and Methods}

\section{Isolation and expansion of MSC from placental tissue}

MSC were isolated and expanded from stromal layer of third-trimester (34-39 weeks of gestation) chorion, as described earlier ${ }^{28-30}$ and from the umbilical cord connective tissue (Wharton jelly). Freshly collected umbilical cords were briefly washed in ethanol $70 \%$ and in phosphate buffered saline (PBS) containing antibiotics/antimycotics (AA) (Invitrogen, Carlsbad, CA). The vessels were flushed with PBS using a syringe and removed with forceps. The Wharton jelly was dissected into small pieces using scalpels. The tissue was incubated for 3 hours in collagenase type 2 (Worthington Biochemical Corp, Lakewood, NJ) (270 $\mathrm{U} / \mathrm{mL}, 25 \mathrm{~mL}$ in PBS-AA) at $37^{\circ} \mathrm{C}$. The suspension was diluted with the same volume of PBS, and filtered (100- $\mu$ m pore size) to remove tissue fragments. The filtered cell suspension was further diluted in 8x volume PBS and centrifuged for 10 minutes at $1500 \mathrm{rpm}$. The resulting cell pellet was resuspended in complete culture medium (Dulbecco's Modified Eagle's Medium/F12, fetal calf serum $10 \%$, AA 1x, glutamax $1 \mathrm{x}$ [Invitrogen]), and expanded at $37^{\circ} \mathrm{C}, 5 \%$ carbon 
dioxide. To confirm the stem cell character, isolated cells were analyzed by flow cytometry for the cell surface expression of MSC markers (CD73, CD90, CD105) and absence of hematopoietic and major histocompatibility complex markers (CD34, CD45, CD14, HLA-DR), as described earlier ${ }^{28-30}$. Placentas and umbilical cords were collected after caesarean sections of healthy donors after obtaining written informed consent. Tissue sampling and experiments were approved by the local institutional review board (Ethics Committee of the Canton of Berne, Switzerland).

\section{Intracerebral injection of the cell graft}

To set up transplantation techniques into the neonatal rat brain, we performed stem cell injections into the brain of noninjured, 2- to 4- (mean 2.56) day old rat pups $(\mathrm{n}=44)$. Animals were anesthetized with ketamine $(40 \mathrm{mg} / \mathrm{kg}$ body weight [BW], ip) and medetomidine $(0.4 \mathrm{mg} / \mathrm{kg} \mathrm{BW}$, ip). The BW of the neonates was in the range of $4.8-10.8 \mathrm{~g}$ (median, $8.5 \mathrm{~g}$ ). Proper dosage of the anesthetics is critical in neonates. Anesthetized animals were fixed on a block heated to $36^{\circ} \mathrm{C}$ in a small animal stereotaxic frame (Kopf Instruments, Tujunga, CA) equipped with soft tissue zygoma ear cups and a neonatal rat adaptor. Proper coordinates for lateral ventricle injection were adapted from a rat brain atlas ${ }^{31}$ by comparison of size and shape between the atlas and coronal sections of age-matched freshly euthanized neonatal rats. Bregma and lambda were adjusted to the same horizontal plane. Coordinates determined in the pilot experiments for P2 were $0.18 \mathrm{~mm}$ posterior from the bregma, $1.2 \mathrm{~mm}$ from the midline, and $1.8 \mathrm{~mm}$ below dura. Injections were made using a laboratory animal studies injector (Hamilton Co., Bonaduz, Switzerland) with a 32-gauge needle. A volume of $5 \mu \mathrm{L}$ was injected over approximately 6 minutes into the left lateral ventricle. To inject at the slowest possible rate, 36 steps of 0.1 or $0.2 \mu \mathrm{L}$ of suspension were injected, with a delay of 10 seconds between each step. The needle was left in place after injection for 2 minutes and then withdrawn slowly. A total number of 250,000 either human umbilical cord Wharton jelly- $(n=19)$ or chorion- $(n=252)$ derived MSC were injected. In all, $200 \mu \mathrm{L}$ of PBS (prewarmed to $37^{\circ} \mathrm{C}$, subcutaneously) and ceftriaxone (75 mg/kg BW, ip) were applied directly after termination of the transplantation, and atipamezole (2 $\mathrm{mg} / \mathrm{kg} \mathrm{BW}$, subcutaneously) was applied 60 minutes after the induction of anesthesia. The animals were euthanized after 3-4 hours, or 1 , 2, or 4 weeks, respectively. Approval for all animal experimentation was obtained from the Veterinary Office of the Canton of Berne, Switzerland.

\section{Analysis of homing and engraftment}

Brains were fixed in formaldehyde solution (4\%; Merck, Whitehouse Station, NJ) for 2-4 hours at room temperature (RT) followed by $4^{\circ} \mathrm{C}$ for a total time of 24-48 hours. Fixed brains were embedded in paraffin, sectioned into 7- $\mu \mathrm{m}$ coronal slices, deparaffinized, and stained with hematoxylin-eosin or cresyl violet/Nissl ( $0.1 \%$ in distilled water; Merck). After deparaffinization of the slides, the target was retrieved in citrate buffer $(10 \mathrm{mmol} / \mathrm{L})$ in a microwave oven for 15 minutes, slides were washed in PBS $0.1 \%$ and Tween 20, and slides were blocked (goat serum $10 \%$, bovine serum album in $1 \%$ in PBS). Human MSC were detected with a mouse antihuman HLA class I ABC antibody (Abcam EMR8-5; Abcam, Cambridge, UK) and the Dako Cytomation EnVision_ System-HRP (DAKO, Glostrup, Denmark). The slides were washed in PBS 0.1\% and Tween 20 (2x5 minutes) and incubated with the endogenous peroxidase block solution for 15 minutes, RT. Peroxidase-labeled polymer was applied to the slides for 30 minutes 
at RT, followed by 3 washes in PBS (5 minutes each) and the addition of 3,3 diaminobenzidine in chromogen solution in buffer substrate for 10-30 minutes, according to the manufacturer's instructions. Slides were rinsed in $\mathrm{H}^{2} \mathrm{O}$ and counterstained with cresyl violet $(0.1 \%$ in $\mathrm{H} 2 \mathrm{O})$, dehydrated in a series of ethanol baths $(95 \%, 100 \%)$ and xylene, and mounted with Eukitt (Sigma-Aldrich, St. Louis, MO). Alternatively, HLAABC expression was detected using a fluorescent setup: the peroxidase blocking was followed by incubation with a fluorescein isothiocyanate-labeled secondary antibody (goat antimouse IgG, 1:100; Sigma-Aldrich) for 1 hour at RT. After 3 washes (5 minutes each) in PBS, the brain slices were counterstained for cell nuclei with DAPI (0.01 mg/mL in PBS, 10 minutes, RT; Fluka, Sigma-Aldrich),

washed again, and mounted with Mowiol solution (Mowiol 4-88 $8.33 \%$ $\mathrm{wt} / \mathrm{vol}$, Calbiochem, Merck; polyvinyl alcohol $0.83 \%$ wt/vol, SigmaAldrich; glycerin 25\% $\mathrm{vol} / \mathrm{vol}$, SigmaAldrich; $\mathrm{H}^{2} \mathrm{O} \quad 25 \%$ vol/vol; $12 \mathrm{~mL}$ Tris$\begin{array}{llll}\text { HCL } & \text { pH } & 8.0 & 25\end{array}$ $\mathrm{mmol} / \mathrm{L})$.

\section{Results}

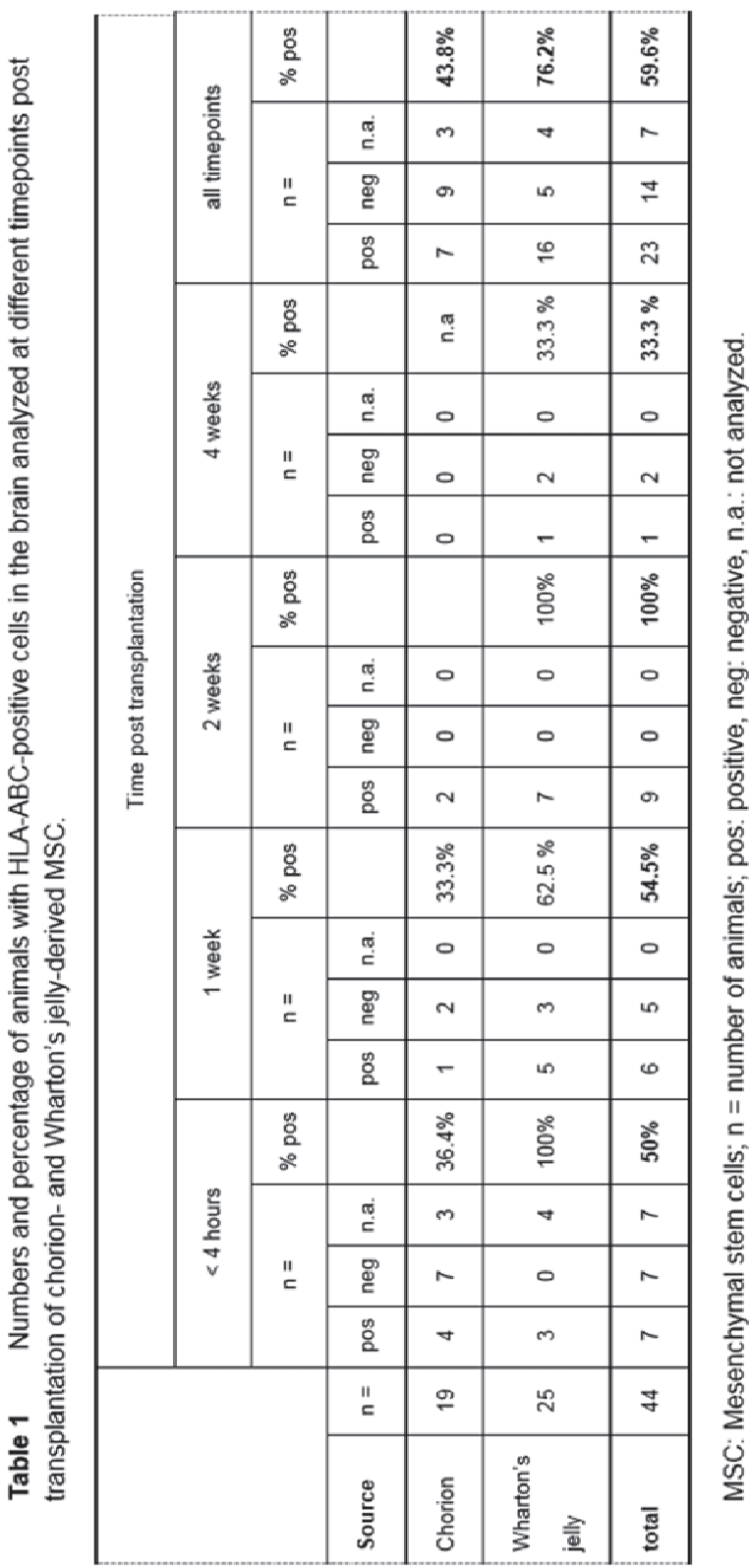

\section{Survival of the animals}

During the optimization period of the experiment, some of the animals died during stem cell transplantation due to respiratory distress. As a consequence, the dosage of anesthetics was adapted as described. After optimization of the anesthesia protocol, all animals were alive at the end of the procedure. Two 
animals died 2 hours 15 minutes or 4 hours later, while an additional 3 animals died within the first 18 hours after the procedure. The overall survival was $84 \%$. The brains of animals that had died shortly after the procedure were analyzed as described, while the pups that had died during the night following the procedure were not available for analysis.

\section{Homing and engraftment of transplanted cells}

For the analysis of the cell fate, animals were euthanized at 3-4 hours, or 1, 2, or 4 weeks after transplantation. The brains of the animals that had died or were sacrificed within 12 hours after the procedure $(n=6)$ were fixed immediately and analyzed for the presence of human cells. The results of short-term homing and engraftment for the transplantation of chorion- and Wharton jelly- derived MSC analyzed at different time points are summarized in the Table. Overall, human HLA-ABC-positive cells were found in the brains of 23 (59\% of animals analyzed) transplanted animals. Cells injected into the left lateral ventricle distributed over the ventricular system within 4 hours after transplantation (Figure $1, \mathrm{~A}$ and B). At 1, 2, and 4 weeks after transplantation, human cells were found to have emigrated from the ventricles and integrated into the surrounding tissue (Figure 1, C-H). Human donor cells were mainly found in paraventricular areas of the lateral ventricle of the ipsilateral hemisphere (2/3 of animals) and the third or fourth ventricle (1/3 of animals), namely the cortex and the striatum. In 1 animal, analyzed 1 week posttransplantation, donor-derived cells were found in the contralateral hemisphere. The predominance of the presence of donor-derived cells in the ipsilateral hemisphere was consistent for all time points, including 4 hours posttransplantation. Once they had integrated in the host's brain tissue, the morphology of the human HLA-ABC-positive cells was similar to the host cells surrounding them. They were not evenly distributed throughout the tissue: some areas of higher densities of single cells were detected, while there were very few to no cells in adjacent regions. When unintentionally injected into the cortex, donor cells remained as an aggregate of cells in the cortex or were subject to reflux through the injection channel (Figure 2, C).

\section{Comments}

We demonstrated that we can precisely target a given area, such as the lateral ventricles, successfully deliver cell suspensions in the brain of recipient rat pups, and specifically detect transplanted human cells in the brain. Donor cells migrated through the ventricular system, and their integration into the host's brain tissue was observed as soon as 1 week posttransplantation. Survival of the cell graft was shown at 4 weeks after its injection into the left lateral ventricle.

Donor cells preferentially integrated into the hemisphere ipsilateral to the injection site. The observation that this holds true for all time points, even at 4 hours posttransplantation, leads to the implication that the migration through the ventricular system is an event that is terminated within hours posttransplantation. The predominant integration into the tissue ipsilateral to the injection site and its time course gives valuable information for the targeting of affected brain regions in future applications. Only a small number of the transplanted cells were detected at the later time points. Their total number, however, was not accessed, as this was not the primary target of the study. 

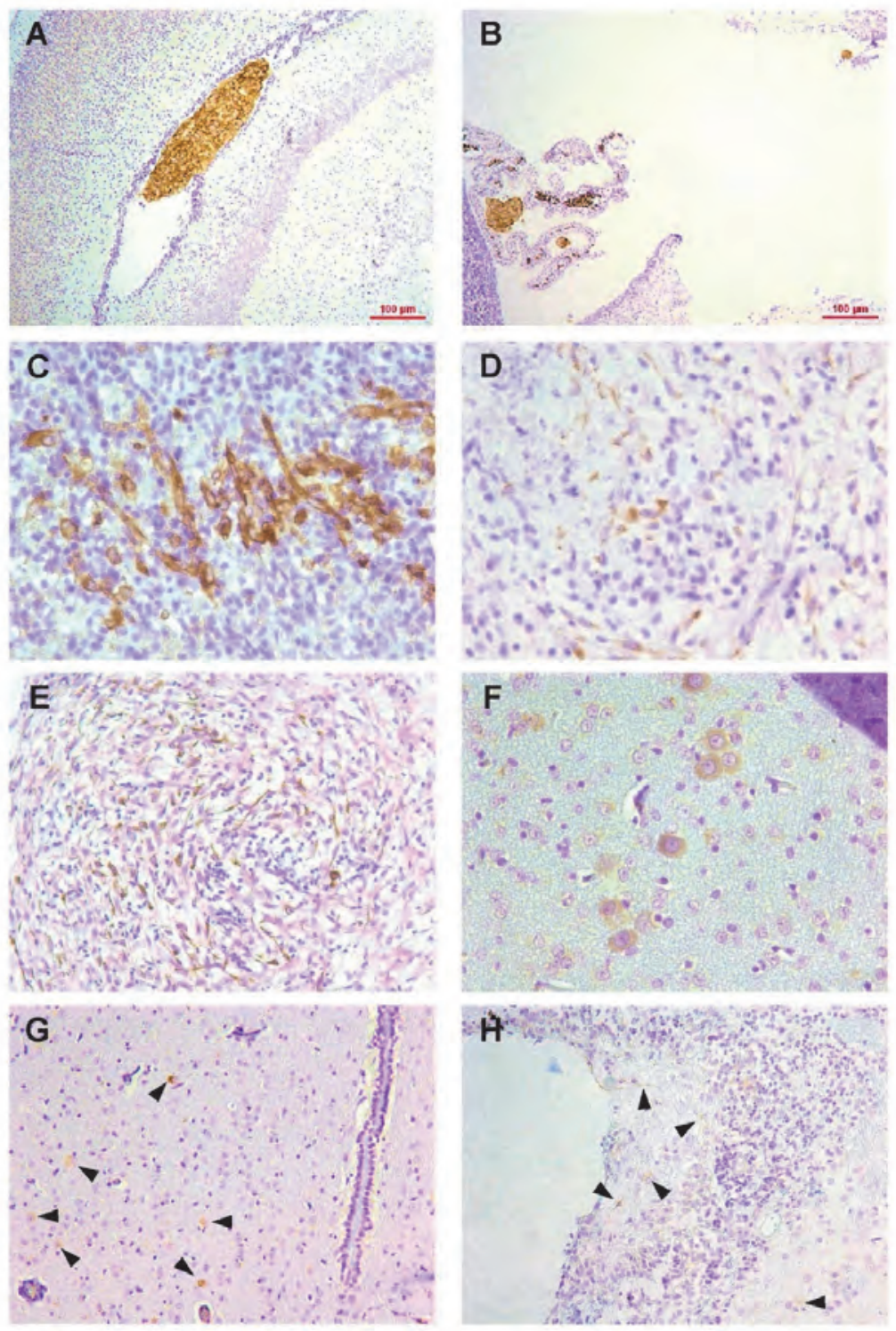

Figure 1. Cresyl violet-stained (blue/purple) coronal sections of postnatal day 2 rat brains and detection of transplanted human MSC with a horseradish peroxidase-labeled anti-human HLAABC antibody (brown stain). A) Cell graft in the left lateral ventricle $1 \mathrm{~h}$ after transplantation (Tx). B) 4h post Tx, the transplanted cells are distributed throughout the ventricular system. CD) 1 week post Tx, human cells are detected in the cortex close to the lateral ventricle (VL). E) 1 week post Tx, human cells were stained paraventricular to the left VL. F) 1 week post Tx, human cells were found in the epithelium of paraventricular to the $3^{\text {rd }}(\mathrm{V} 3)$ and $4^{\text {th }}$ ventricle (V4). G) 2 weeks post Tx, single human cells (arrow heads) were distrubuted throughout the paraventricular area of V3 and V4. H) 4 weeks post Tx, human cells were detected close to the left VL. 
Immunohistochemistry, the method chosen for analysis of the detection of donor-derived cells, is not suitable for their quantification. Further quantitative methods will be used in the future, such as real-time polymerase chain reaction of genomic DNA. In P2 rats, the establishment of the proper protocols for anesthesia and stereotaxic injection of a cell graft into specific brain regions is crucial for the outcome. While there is comprehensive information for adult rats, the availability of data for neonatal rats is very limited. Once the proper protocol was established, the transplantation of human MSC into the lateral ventricles of neonatal rats resulted in good survival and a reliable engraftment. With growing experience, both the animal survival and cell engraftment rate increased. The setup of the experiments was done with short intervals between transplantation and brain analysis. During optimization of both the anesthesia and the stereotaxic injections, the interval was extended gradually. The effect that the engraftment was higher 2 weeks posttransplantation than after shorter periods of time is most likely related to this learning curve. The same is true for the slightly better engraftment of the Wharton jelly-derived compared to chorion-derived MSC, as the former were used predominantly in the later experiments (Table).

Although the brain is believed to be a relatively immune-privileged organ, it cannot be excluded that the use of a xenogeneic, human donor in the rat host induced an immune response and had an adverse effect on the engraftment, particularly in the animals analyzed at 2-4 weeks. Our aim was to assess the potential of human placental stem cells as an autologous cell graft for their future clinical use. This could not have been accomplished with an allogeneic cell graft.
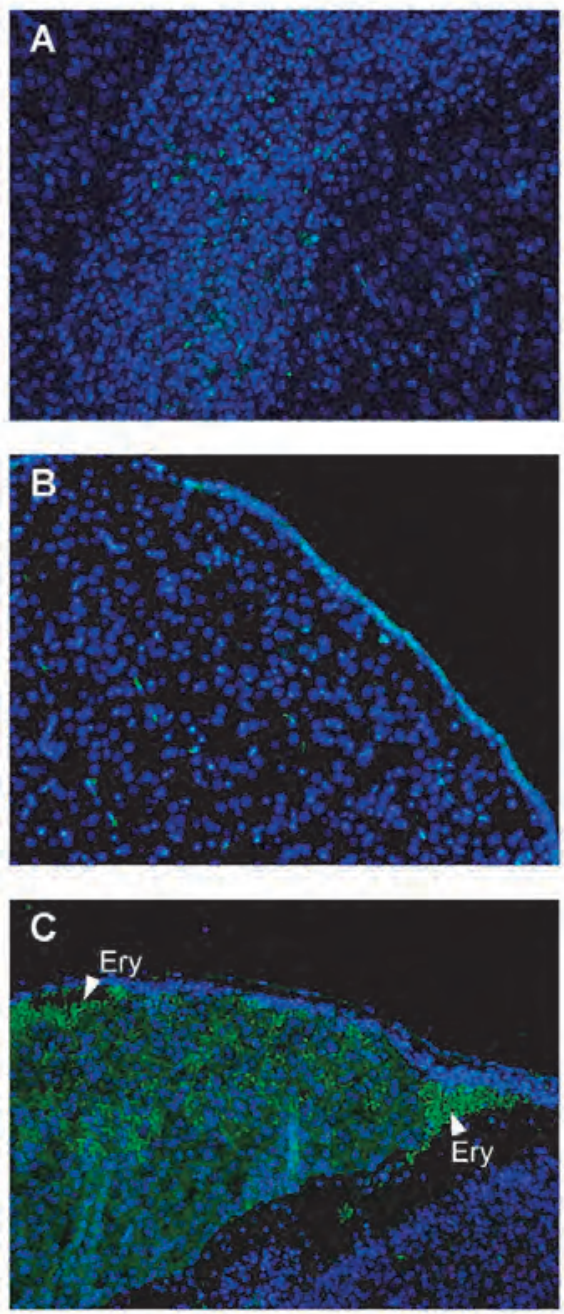

Figure 2. Coronal sections of postnatal day 2 rat brains stained for human donor cells (HLA-ABC-FITC, green) and counterstained with DAPI for cell nuclei. A) 1 week post Tx, single donor-derived cells were detected in the cortex. B) 1 week post $\mathrm{Tx}$, donor cells were found in the paraventricular tissue of the lateral ventricle. C) Donor cell injection into the cortex resulted in a reflow into the submeningal space (4h post Tx, green cell bodies + blue nuclei). Aggregates of small, bright-green cells without the nuclear (blue) stain are erythrocytes (arrowheads, Ery) that are stained unspecifically. 
The data presented here provide valuable information for the setup of planned transplantation experiments of human placental stem cells in a neonatal rat model of perinatal brain damage. Stem cell therapy for the treatment of demyelinating diseases in the adult is within the reach of clinical application within the next couple of years. First clinical trials have been approved or are in preparation now. Prenatal/perinatal injury occurring in the developing brain is a complex disease involving many factors and mechanisms. The treatment of fetuses or neonates poses ethical questions that go beyond those for most therapies in adult patients. Therefore, enhanced measures of safety, efficacy, and longterm outcome have to be respected. This evokes the need for extensive studies in animal models before clinical applications might be envisaged. Future studies will need to focus on perinatal brain injury models to address the questions of the functional improvement and of the mechanisms involved in stem cell therapy. Mechanisms might include, but are not limited to, the attenuation of the inflammatory response, apoptosis, microglial activation, and demyelination. These aspects will have to be addressed in further studies.

\section{Clinical implications}

- Stem cell transplantation including the precise targeting of brain areas is feasible in neonatal rats and leads to the integration and survival of donor cells in the host brain.

- Mesenchymal stem cells derived from placenta and the Wharton's jelly of the umbilical cord have the potential to be used as an autologous cell graft for the therapy of perinatal brain damage.

- Stem cell therapy for the treatment of demyelinating diseases in the adult is within the reach of clinical application within the next couple of years.

- Before clinical applications might be envisaged, there is a need for extensive studies in animal models of perinatal brain injury models to address the functional improvement and the mechanisms involved in stem cell therapy. 


\section{References}

1. Editorial. Preterm birth: crisis and opportunity. Lancet 2006;368:339.

2. Martin JA, Kung HC, Mathews TJ, Hoyert DL, Strobino DM, Guyer B et al. Annual summary of vital statistics: 2006. Pediatrics 2008;121:788-801.

3. Platt MJ, Cans C, Johnson A, Surman G, Topp M, Torrioli MG et al. Trends in cerebral palsy among infants of very low birthweight ( $<1500 \mathrm{~g}$ ) or born prematurely ( $<32$ weeks) in 16 European centres: a database study. Lancet 2007;369:43-50.

4. Larroque B, Ancel PY, Marret S, Marchand L, Andre M, Arnaud C et al. Neurodevelopmental disabilities and special care of 5-year-old children born before 33 weeks of gestation (the EPIPAGE study): a longitudinal cohort study. Lancet 2008;371:813-20.

5. Volpe J. Neurology of the newborn. Saunders Elsevier, Philadelphia PA, USA, 2008.

6. Bracci R, Buonocore G. Chorioamnionitis: a risk factor for fetal and neonatal morbidity. Biol Neonate 2003;83:85-96.

7. Eklind S, Mallard C, Leverin AL, Gilland E, Blomgren K, Mattsby-Baltzer I et al. Bacterial endotoxin sensitizes the immature brain to hypoxic--ischaemic injury. Eur $J$ Neurosci 2001;13:1101-06.

8. Vannucci RC, Connor JR, Mauger DT, Palmer C, Smith MB, Towfighi J et al. Rat model of perinatal hypoxic-ischemic brain damage. J Neurosci Res 1999;55:158-63.

9. Girard S, Kadhim H, Beaudet N, Sarret P, Sebire G. Developmental motor deficits induced by combined fetal exposure to lipopolysaccharide and early neonatal hypoxia/ischemia: A novel animal model for cerebral palsy in very premature infants. Neuroscience 2009;158:673-82.

10. Pimentel-Coelho PM, Mendez-Otero R. Cell therapy for neonatal hypoxic-ischemic encephalopathy. Stem Cells Dev 2010;19:299-310.

11. Daadi MM, Davis AS, Arac A, Li Z, Maag AL, Bhatnagar R et al. Human neural stem cell grafts modify microglial response and enhance axonal sprouting in neonatal hypoxic-ischemic brain injury. Stroke 2010;41:516-23.

12. Windrem MS, Roy NS, Wang J, Nunes M, Benraiss A, Goodman R et al. Progenitor cells derived from the adult human subcortical white matter disperse and differentiate as oligodendrocytes within demyelinated lesions of the rat brain. J Neurosci Res 2002;69:966-75.

13. Englund U, Fricker-Gates RA, Lundberg C, Bjorklund A, Wictorin K. Transplantation of human neural progenitor cells into the neonatal rat brain: extensive migration and differentiation with long-distance axonal projections. Exp Neurol 2002;173:1-21.

14. Lee JA, Kim BI, Jo HC, Choi CW, Kim EK, Kim HS et al. Mesenchymal stem cell transplantation for hypoxic-ischemic brain injury in neonatal rat model. Pediatr Res 2010;67:42-6.

15. Windrem MS, Schanz SJ, Guo M, Tian GF, Washco V, Stanwood N et al. Neonatal chimerization with human glial progenitor cells can both remyelinate and rescue the otherwise lethally hypomyelinated shiverer mouse. Cell Stem Cell 2008;2:553-65.

16. Pimentel-Coelho PM, Magalhaes ES, Lopes LM, Deazevedo LC, Santiago MF, Mendez-Otero R. Human cord blood transplantation in a neonatal rat model of hypoxic-ischemic brain damage: functional outcome related to neuroprotection in the striatum. Stem Cells Dev 2010;19:351-58.

17. Kranz A, Wagner DC, Kamprad M, Scholz M, Schmidt UR, Nitzsche F et al. Transplantation of placenta-derived mesenchymal stromal cells upon experimental stroke in rats. Brain Res 2010;1315:128-36. 


\section{Chapter 2}

18. Yarygin, K. N., Kholodenko, I. V., Konieva, A. A., Burunova, V. V., Tairova, R. T., Gubsky, L. V., Cheglakov, I. B., Pirogov, Y. U., Yarigin, V. N., and Skvortsova, V. I. Mechanisms of beneficial effects of human placenta MSC transplantation in rats with experimental ischemic stroke. Bull Exp Biol Med 2009;148:862-8.

19. de Paula S, Vitola A, Greggio S, de Paula D, Mello P, Lubianca J et al. Hemispheric Brain Injury and Behavioral Deficits Induced by Severe Neonatal Hypoxia-Ischemia in Rats Are Not Attenuated by Intravenous Administration of Human Umbilical Cord Blood Cells. Pediatr Res 2009;65:631-35.

20. Marcus AJ, Coyne TM, Black IB, Woodbury D. Fate of amnion-derived stem cells transplanted to the fetal rat brain: migration, survival and differentiation. J Cell Mol Med 2008;12:1256-64.

21. Yasuhara T, Hara K, Maki M, Xu L, Yu G, Ali MM et al. Mannitol facilitates neurotrophic factor up-regulation and behavioural recovery in neonatal hypoxic-ischaemic rats with human umbilical cord blood grafts. J Cell Mol Med 2010;14:914-21.

22. Fan CG, Zhang QJ, Tang FW, Han ZB, Wang GS, Han ZC. Human umbilical cord blood cells express neurotrophic factors. Neurosci Lett 2005;380:322-25.

23. Newman MB, Willing AE, Manresa JJ, Sanberg CD, Sanberg PR. Cytokines produced by cultured human umbilical cord blood (HUCB) cells: implications for brain repair. Exp Neurol 2006;199:201-08.

24. Hagberg H, Peebles D, Mallard C. Models of white matter injury: comparison of infectious, hypoxic-ischemic, and excitotoxic insults. Ment Retard Dev Disabil Res Rev 2002;8:30-38.

25. Back SA, Han BH, Luo NL, Chricton CA, Xanthoudakis S, Tam J et al. Selective vulnerability of late oligodendrocyte progenitors to hypoxia-ischemia. J Neurosci 2002;22:455-63.

26. Ten VS, Bradley-Moore M, Gingrich JA, Stark RI, Pinsky DJ. Brain injury and neurofunctional deficit in neonatal mice with hypoxic-ischemic encephalopathy. Behav Brain Res 2003;145:209-19.

27. Derrick M, Luo NL, Bregman JC, Jilling T, Ji X, Fisher K et al. Preterm fetal hypoxiaischemia causes hypertonia and motor deficits in the neonatal rabbit: a model for human cerebral palsy? J Neurosci 2004;24:24-34.

28. Portmann-Lanz CB, Schoeberlein A, Huber A, Sager R, Malek A, Holzgreve W et al. Placental mesenchymal stem cells as potential autologous graft for pre- and perinatal neuroregeneration. $\mathrm{Am}$ J Obstet Gynecol 2006;194:664-73.

29. Portmann-Lanz CB, Schoeberlein A, Portmann R, Mohr S, Rollini P, Sager R et al. Turning placenta into brain: placental mesenchymal stem cells differentiate into neurons and oligodendrocytes. Am J Obstet Gynecol 2010;202:294.e1-294.e11.

30. Portmann-Lanz CB, Baumann MU, Mueller M, Wagner AM, Weiss S, Haller O et al. Neurogenic characteristics of placental stem cells in preeclampsia. Am J Obstet Gynecol 2010;203:399.e1-7.

31. Paxinos G, Watson C. The rat brain in stereotaxic coordinates. San Diego: Academic Press, 1998. 


\section{Chapter 3}

\section{Wharton`s jelly Mesenchymal Stem Cells protect the immature}

brain in rats and modulate cell fate

Published as: Mueller M, Oppliger B, Joerger-Messerli M, Reinhart U, Barnea E, Paidas M, Kramer BW, Surbek DV, Schoeberlein A. Wharton`s jelly Mesenchymal Stem Cells protect the immature brain in rats and modulate cell fate. Stem Cells Dev. 2016 Nov 14; PubMed PMID: 27842457. 


\begin{abstract}
The development of a mammalian brain is a complex and long-lasting process. Not surprisingly, preterm birth is the leading cause of death in newborns and children. Advances in perinatal care reduced mortality, but morbidity still represents a major burden. New therapeutic approaches are thus desperately needed. Given that mesenchymal stem/stromal cells (MSCs) emerged as a promising candidate for cell therapy, we transplanted MSCs derived from the Wharton's Jelly (WJ-MSCs) to reduce the burden of immature brain injury in a murine animal model. WJ-MSCs transplantation resulted in protective activity characterized by reduced myelin loss and astroglial activation. WJ-MSCs improved locomotor behavior as well. To address the underlying mechanisms, we tested the key regulators of responses to DNA-damaging agents, such as cyclic AMP-dependent protein kinase/calcium-dependent protein kinase (PKA/PKC), cyclin-dependent kinase (CDK), ataxia-telangiectasia-mutated/ATM- and Rad3-related (ATM/ATR) substrates, protein kinase B (Akt), and 14-3-3 binding protein partners. We characterized WJ-MSCs using a specific profiler polymerase chain reaction array. We provide evidence that WJMSCs target pivotal regulators of the cell fate such as CDK/14-3-3/Akt signaling. We identified leukemia inhibitory factor as a potential candidate of WJ-MSCs' induced modifications as well. We hypothesize that WJ-MSCs may exert adaptive responses depending on the type of injury they are facing, making them prominent candidates for cell therapy in perinatal injuries.
\end{abstract}




\section{Introduction}

Preterm birth is a complex multifactorial syndrome and together with intrapartumrelated complications the leading cause of death in newborns and children ${ }^{1,2}$. This is especially evident in very low gestational age infants $(<32$ weeks gestation), where advances in perinatal care reduced mortality, but morbidity still represents a major burden ${ }^{3,4}$. The magnitude of this medical and socioeconomic burden is enormous. Depending on the degree of prematurity, up to $20 \%$ of infants will develop spastic cerebral palsy (CP) and up to 50\% demonstrate cognitive, behavioral, motor and sensory deficits, or higher incidence of psychiatric disorders ${ }^{5,6}$.

In immature infants at risk, no individual protective agent has proven safe and effective so far $^{7-9}$. Magnesium sulfate reduces the incidence of CP in the preterm population, but identification of pregnant mothers with anticipated preterm labor is difficult ${ }^{10}$. New therapeutic approaches are thus desperately needed. In recent years, mesenchymal stem/stromal cells (MSCs) emerged as a promising candidate for cell therapy targeted against perinatal brain injury ${ }^{11}$. MSCs isolated from the stroma of the umbilical cord (Wharton's Jelly [WJ]-MSCs) ${ }^{12,13}$ are of special interest as they are easy available around the time of birth, an autologous source, and pose no ethical concerns ${ }^{14},{ }^{15}$. In addition, WJMSCs possess a low immunogenic capacity and a multipotent differentiation potential ${ }^{13}$. MSCs were shown to modulate innate and adaptive immune responses, to have antiapoptotic effects, to decrease inflammation, and to enhance tissue repair, mostly through the release of paracrine factors ${ }^{16,17}$.

The development of a mammalian brain is a complex and long-lasting process which follows specific time- and space-dependent sequences with interactions of various cell types. One of the common denominators is the dynamic equilibrium of cellular proliferation/differentiation and apoptosis/necrosis, which is especially evident in responses to aggressors in the immature brain. Not surprisingly, both inflammation and hypoxia ischemia result in the predilection for white matter injury due to aggressors ranging from oxidative stress to excitotoxicity ${ }^{14,18}$. Generally, in response to DNA damage, the cell cycle checkpoints' activation at the G1/S and G2/M transitions may stop cell cycle progression to repair the damaged genetic material. In case of irreparable DNA damage, the cells will induce apoptosis ${ }^{19}$. The key regulators of responses to DNA damaging agents are cyclic AMP-dependent protein kinase/calciumdependent protein kinase (PKA/PKC), cyclin-dependent kinase (CDK), ataxia-telangiectasiamutated/ATM- and Rad3-related (ATM/ATR) substrates, protein kinase B (Akt), and 14-3-3 binding protein partners ${ }^{20-26}$. For example, activation of PKA/PKC signaling results in the protection of an immature brain ${ }^{21}$ and CDK inhibition proved to be protective in stroke ${ }^{19}$. Activation of ATM/ATR signaling results in neuronal apoptosis ${ }^{26}$, and Akt signaling is a well-defined prosurvival pathway ${ }^{20}$. Furthermore, 14-3-3 proteins have been shown to be neuroprotective in a variety of neurological disorders ${ }^{27,28}$. 14-3-3 proteins represent a homologous family, which bind their substrates through an amphipathic binding cleft leading to a variety of effects, including stress response, apoptosis, transcriptional regulation, and cell cycle regulation ${ }^{24}$. Together, targeting these cell fate pathways represent a potential neuroprotective strategy in an immature brain. 
In this report, we show the effect of WJ-MSCs in a clinically relevant murine model of immature brain injury. WJ-MSCs transplantation exerts protective effects at both histological and behavioral levels. We provide evidence that WJMSCs target pivotal regulators of the cell fate as well. Our result supports the notion of WJ-MSCs as an attractive cell graft in immature infants at risk.

\section{Methods}

All procedures have been approved by the local institutional review board (Ethics Committee and Veterinary Department of the Canton of Berne, Switzerland). We obtained a written informed consent from all umbilical cord donors.

\section{Cell graft: Wharton's jelly-derived MSCs}

Human WJ-MSCs were isolated and characterized as previously published ${ }^{12,} 29$. Briefly, umbilical cords were chopped, digested in $270 \mathrm{U} / \mathrm{mL}$ collagenase II (Worthington Biochemical Corporation, Lakewood, NJ, USA) at $37^{\circ} \mathrm{C} / 5 \% \mathrm{CO} 2$, and cultured in DMEM/F12 10\% containing fetal calf serum (FCS), $2 \mathrm{mmol} / \mathrm{L}$ glutamax, and 100 units/mL penicillin / $100 \mathrm{mg} / \mathrm{mL}$ streptomycin / $250 \mathrm{ng} / \mathrm{mL}$ amphotericin B (Thermo Fisher Scientific, Waltham, MA). The WJ-MSC were characterized by fluorescence-activated cell sorting (FACS) as follows: Antibody stainings were performed for 30 minutes at $4^{\circ} \mathrm{C}$. Antibodies were diluted in $1 \mathrm{x}$ phosphate-buffered saline (PBS), 1\% fetal calf serum (FCS). FITC-conjugated mouse monoclonal antibodies against the following markers were used: human CD105 (AbD Serotec, Oxford, UK), human CD90 (Acris Antibodies, San Diego, CA), human CD45 (BD Pharmingen, Franklin Lakes, NJ), human CD34 (BD Pharmingen), human CD14 (Millipore, Billerica, MA) and human HLA-DR (BD Pharmingen). The unconjugated mouse monoclonal antibodies against human CD73 (BD Pharmingen) and CD19 (Millipore) were detected with Alexa-Fluor 594-conjugated anti-mouse IgG antibody (Thermo Fisher Scientific). After staining, cells were fixed in 1\% paraformaldehyde (PFA) and 10'000 events were acquired on a LSR II flow cytometer (BD Biosciences, Franklin Lakes, NJ). Analysis was done using the FlowJo software (Tree Star, Inc., Ashland, OR).

\section{Animal Model: Perinatal Brain Injury}

We induced immature brain injury as we had previously described ${ }^{21,30}$. Briefly, neonatal Wistar rats were randomly divided into three groups (Sham, Injury, and Injury+WJ-MSCs; $\mathrm{n}=19$ ). The Injury and Injury+WJ-MSCs groups received lipopolysaccharides (LPS: $0.1 \mathrm{mg} / \mathrm{kg}$ BW, i.p.) at postnatal day 3 (P3). On the following day, the left common carotid artery was doubly ligated using a stereomicroscope and animals were subjected to mild hypoxia (8\% $\mathrm{O}_{2} / 92 \% \mathrm{~N}_{2} ; 40$ min). The Sham Group $(n=6)$ consisted of uninjured animals $(0.9 \% \mathrm{NaCl}$ instead of LPS i.p., exposure of carotid artery without ligation, no hypoxia and no further treatment). The Injury+WJ-MSCs Group $(n=7)$ received a single cell graft transplantation into the lateral ventricle. We transplanted 250,000 of WJ-MSCs into the left ventricle at postnatal day 11 as published previously ${ }^{29}$. Briefly, anesthetized animals were fixed on a block heated to $37^{\circ} \mathrm{C}$ in a small animal stereotaxic frame (David

Kopf Instruments, Tujunga, CA). We injected a volume of $5 \mathrm{~mL}$ over approximately 6 min into the lateral ventricle using a Laboratory Animal Studies Injector (Hamilton, Bonaduz, Switzerland) with a 32G needle. The needle was left 
in place for 2 min after injection and then withdrawn slowly. The Injury Group (n = 6) received no WJ-MSCs treatment, but the needle was placed into the ventricle without vehicle injection.

\section{Functional tests}

To assess the functional outcome after brain injury, we performed a walking pattern analysis ${ }^{31}$. Briefly, rats with stained hind paws were placed on an inclining gangway and walked up the gangway and into a dark box. Paper strips with footprints were scanned and stride length (the distance between steps of the same side) and toe distance (distance between the 1st and 5th toe) were measured for the left and right hind paw.

\section{Perioperative Care of the Animals}

See Supplementary Data (Supplementary Data are available online at www.liebertpub.com/scd) for details.

\section{Tissue Harvesting and Immunohistochemistry}

We performed brain harvesting on P39 ( $n=19$; Fig. 1C). Briefly, we deeply anesthetized animals with sodium thiopental $(100 \mathrm{mg} / \mathrm{kg}$ body weight i.p., Inresa, Freiburg, Germany) and sacrificed by cardiac perfusion with PBS followed by formaldehyde (4\%; Merck, Darmstadt, Germany). Animals were decapitated and we removed brains surgically and fixed in formaldehyde solution (4\%) for 2-4 hours at room temperature (RT) followed by $4^{\circ} \mathrm{C}$ for a total time of $24-48$ hours. Fixed brains were embedded in paraffin and sectioned into $7 \mu \mathrm{m}$ slices.

For further details on tissue immunohistochemistry see Supplementary Information

\section{Tissue Harvesting and Western Blots}

To dissect WJ-MSCs protective mechanisms in the brain tissue ( $\mathrm{n}=3$ each group), we induced brain injury as described above with following changes (see Supplementary Data for details). Whole brain lysates for kinome profiling were isolated following a protocol developed by Cell Signaling Technology (Danvers, MA). Briefly, tissue or cells were homogenized (lysate was passed through 20G needles 10 times for each sample) in a lysis buffer (20mMHEPES pH8.0, 9M urea, $1 \mathrm{mM}$ sodium orthovanadate, $2.5 \mathrm{mM}$ sodium pyrophosphate, and $1 \mathrm{mM} \beta$ glycerophosphate), sonicated, and cleared by centrifugation. Protein concentration was measured using theBradford assay and a total of $30 \mathrm{mg}$ protein was loaded for each lane. Protein bands on western blots were quantified using ImageJ using bactin as control ${ }^{32}$. The following antibodies were used: phospho-PKA/PKC substrate, No. 9624, 6967; phospho-CDK/tXR substrate, No. 9477, 8139; phospho-ATM/ATR substrate, No. 9607, 6966; phospho-Akt substrate, No. 9614, 10001; 14-3-3 binding partners, No. 9442; all from Cell Signaling Technology. For leukemia inhibitory factor (LIF) detection, we used an antibody from Millipore (No. MAB4306; CA).

\section{Induction of WJ-MSCs into neural progenitor cells and gene array}

To further characterize WJ-MSCs, we differentiated them at cell culture passage 5 (WJ-MSC derived from preterm birth: gestational week $<37$ weeks) into neurospheres ${ }^{12}$. Briefly, after an immediate differentiation step in DMEM/F12 medium containing 1x N2 supplement (Life Technologies), $10 \mathrm{ng} / \mathrm{mL}$ epidermal growth factor (EGF; R\&D Systems, Minneapolis, MN), 2mM GlutaMAX, and 
$100 \mathrm{U} / \mathrm{mL}$ penicillin/100 $\mathrm{mg} / \mathrm{mL}$ streptomycin/250 $\mathrm{ng} / \mathrm{mL}$ amphotericin $\mathrm{B}$, the cells were cultured in suspension in neurobasal medium (Life Technologies) containing 1x B27 supplement (Life Technologies), 20 ng/mL EGF, 20 ng/mL basic fetal growth factor (bFGF; PeproTech, Rocky Hill, NJ), 2mM GlutaMAX, and $100 \mathrm{U} / \mathrm{mL}$ penicillin/100 mg/mL streptomycin/250 ng/mL amphotericin B to induce neurosphere-like bodies. We extracted RNA and proteins from cell culture (WJ-MSC at passage 5 and neurospheres) using the QIAshredder and the RNeasy Plus Mini Kit from Qiagen (Hilden, Germany: according to the protocol), and proteins as previously performed ${ }^{12}$. RNA concentration was measured by NanoDrop spectrometry (Thermo Scientific, Wilmington, DE). Up to $5 \mu \mathrm{g}$ of RNA were reverse transcribed using the RT2 First-Strand cDNA (Qiagen). The neurotrophins and receptors RT2 profiler PCR array (Qiagen) was used to measure the transcription of genes related to neurotrophic signaling. The plates were supplied precoated with forward and reverse primers. For one 96-well plate, $102 \mu \mathrm{L}$ cDNA was mixed with 1,350 $\mu \mathrm{L} 2 \cdot$ RT2 SYBR Green ROX qPCR mastermix and $1,248 \mu \mathrm{L}$ nuclease-free water. Twenty-five

microliters of the PCR component cocktail were pipetted into each well. The following cycling program was used to run the PCR on a 7300 Real-Time PCR System (Life Technologies): $10 \mathrm{~min}$ at $95^{\circ} \mathrm{C}$, followed by 40 cycles of $15 \mathrm{~s}$ at $95^{\circ} \mathrm{C}$ and 1 min at $60^{\circ} \mathrm{C}$.

\section{Quantitative Assessment of the Brain}

We performed quantitative assessments in the region of interest (ROI) defined as deep cerebral cortex (cortical layers V and VI in Figure 108 according to a neonatal rat brain atlas) ${ }^{33}$ and in each hemisphere independently. Notably, ROI is the expected area of injury and hypoxia ischemia was reported to cause distinctive neuropathological alterations in these regions of the parieto-occipital cortex and white matter tracts 21, 30, 34. We acquired images using a BX51 microscope (Olympus, Tokyo, Japan) with a 40x objective and equipped with a digital camera. An independent observer acquired six consecutive ROI sections visual field by visual field without overlapping per hemisphere and animal for each specific immunostaining blinded to the experimental conditions. To asses myelin loss (myelin basic protein [MBP] immunostaining) and astrogliosis (glial fibrillary acidic protein [GFAP] immunostaining), we measured the percentage of positive MBP and GFAP staining (area) in the ROI in each hemisphere as described previously ${ }^{35,36}$. We determined the difference between contralateral (undamaged) and ipsilateral (damaged) hemispheres using Image ${ }^{32}$.

\section{Data analysis}

We avoided variability resulting from tissue handling and staining, and interanimal developmental variations by using a ratio of left (ipsilateral to carotid occlusion) to right hemisphere ${ }^{37,38}$. Data are represented as mean \pm SEM. Single comparisons to control were made using two-tailed Student's t-test or MannWhitney test. We used one-way repeated measures ANOVA followed by Bonferroni's Multiple Comparison Test for multigroup design. $\mathrm{P}<0.05$ was considered to be statistically significant. No statistically significant differences were detected between the contralateral (uninjured hemispheres) in all groups. For gene array, data analysis was performed by the delta-delta $\mathrm{Ct}$ method using the company's software provided on their webpage and expressed as fold change in 
WJ-MSC derived from preterm delivery $(\mathrm{n}=3)$ relative to neurospheres from preterm birth $(n=3)$. Data handling and statistical processing was performed using Microsoft Excel and GraphPad Prism Software.

\section{Results}

\section{WJ-MSCs as a cell graft}

We decided to use WJ-MSCs as a cell transplant as they are considered an attractive source for perinatal transplantation ${ }^{11,39}$. The isolated WJ-MSCs were adherent to plastic and displayed a fibroblast-like phenotype (Fig. 1A) ${ }^{12}$. Furthermore, after five passages, we detected characteristic MSCs cell surface markers (Fig. 1B) ${ }^{40}$. To test our hypothesis that our cell graft protects the immature brain, we used a well-established murine model (Fig. 1C) ${ }^{21,30}$. We evaluated the migration of WJ-MSCs by staining for HLA-ABC-positive cells at P39. In line with previous studies, we detected only few positive cells (Fig. 1D) ${ }^{41}$ in the cortex cerebri, hippocampus, and striatum ${ }^{29}$. We did not detect any signs of differentiation in line with previous studies ${ }^{42,43}$.

A.

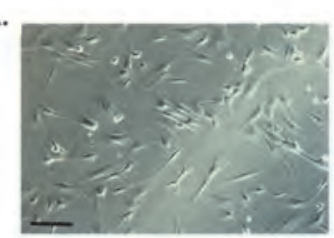

C.

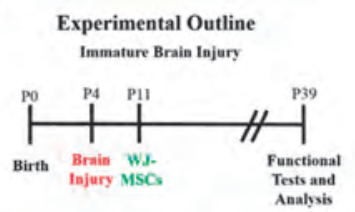

D.

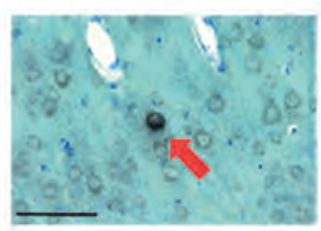

B.
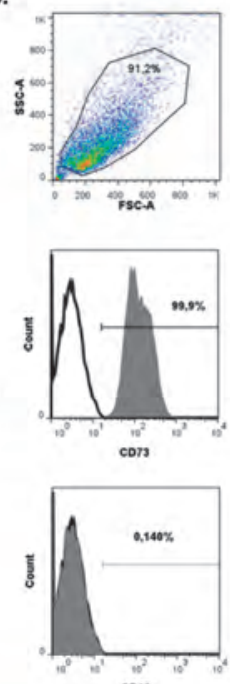
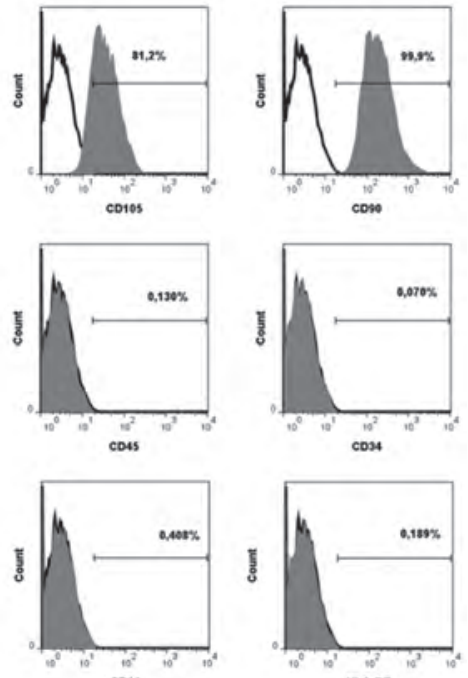

$\cos 4$

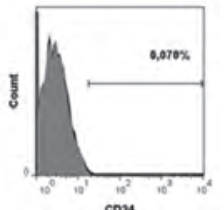

$\cos 4$

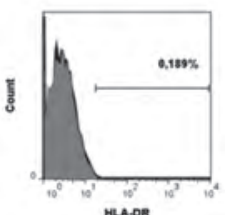

Figure 1. WJ-MSCs as a cell transplant. A: WJ-MSCs show unaltered morphology and (B) express typical MSCs markers. C: WJ-MSCs transplantation in immature brain injury model. D: WJ-MSCs (arrow: HLA-ABC positive cells) were detected in the brain cortex (Cresyl Violet staining) at P39. Scale bar represents $100 \mu \mathrm{m}$. WJ-MSCs, Wharton's Jelly derived mesenchvmal stem/stromal cells.

\section{WJ-MSCs protect against immature brain injury}

To test the effectiveness of WJ-MSCs treatment in immature brain injury, we evaluated the locomotor behavior first (Fig. 2A). In line with previous reports, we detected abnormal walking behavior after the brain insult, namely a significant change of step length and toe distance (Fig. 2A; compare left to right hind paws' step length and toe distance of Injury vs. Sham groups) ${ }^{31}$. WJ-MSCs transplantation resulted in the alleviation of spastic paresis and restored motor symmetry (Fig. 2A; compare left to right hind paws' step length and toe distance 
of Injury vs. Injury+WJ-MSCs groups). To determine the underlying pathophysiology, we focused on the motor cortex with emphasis on the

A.

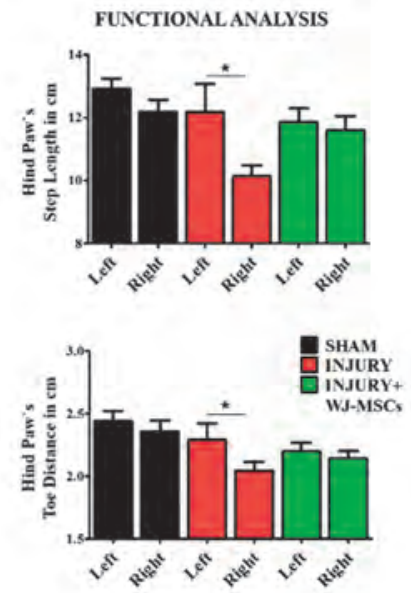

C.

MYELIN LOSS
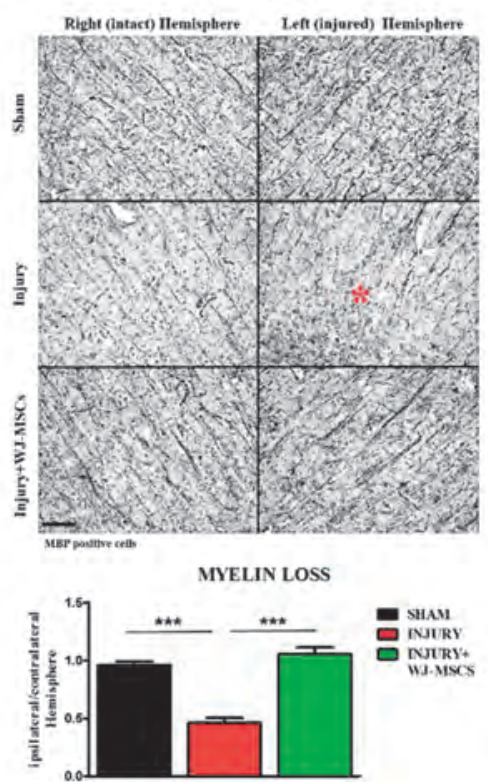

B.

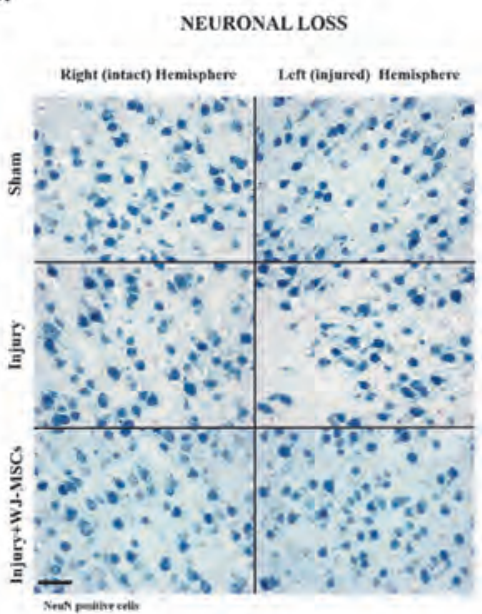

D.
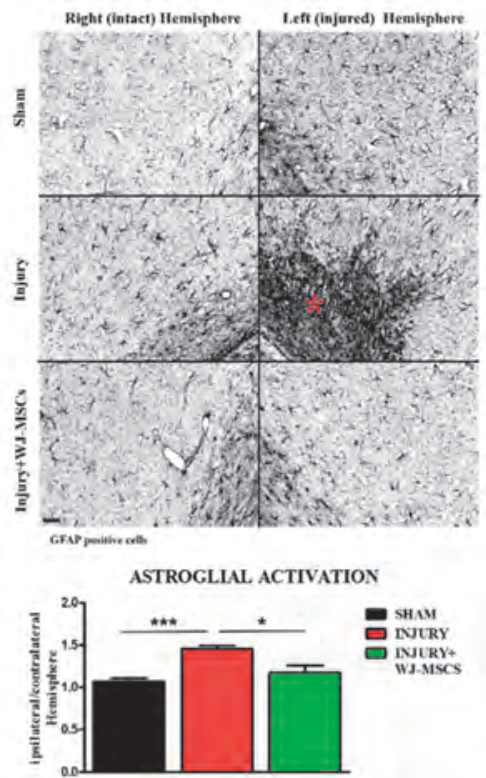

Figure 2. WJ-MSCs protect the immature brain. Quantification of locomotor behavior (A). Representative immunohistochemistry images of neuronal loss (B), myelin loss (C, upper panel), and astroglial activation (D, upper panel) in deep cortical sections of both hemispheres. Quantification of myelin loss (C, lower panel), and astroglial activation (D, lower panel). Red asterisk marks myelin loss (C) and astroglial activation (D) in injured hemisphere. Data are presented as mean \pm SEM ( $\mathrm{n}=19$, two-tailed Student`s t-test). Scale bar, $50 \mu \mathrm{m}$. ${ }^{*} \mathrm{p}<0.05$; ${ }^{* * *} \mathrm{p}<0.001$. NeuN (nuclearspecific nuclear protein) marker for neurons; MBP marker for myelin; GFAP marker for astrogliosis. GFAP, glial fibrillary acidic protein; MBP, myelin basic protein. 
characteristic deep cortical layers as these regions are altered as a consequence of immature brain injury ${ }^{34,44}$ and associated with impaired locomotor behavior ${ }^{31}$.

We evaluated the number of NeuN-positive cells (mature neurons) in deep cortical layers first as injury, and hypoxia ischemia at this time point were reported to cause distinctive neuropathological alterations in these regions ${ }^{21,30,34}$. We did not detect neuronal loss (Fig. 2B; compare ipsilateral injured to contralateral intact hemisphere Sham vs. Injury) ${ }^{35,45}$. However, we need to consider that in contrast to our previous studies ${ }^{21,30}$, we induced a mild injury (hypoxia reduced to 40 min). Additionally, the most common neuropathology in premature infants is not focal necrosis, but diffuse noncystic alterations ${ }^{14,18}$. As these alterations evolve over time to glial scars characterized by microgliosis and astrogliosis, we tested them next.

Given that the hallmark of immature brain injury is the degeneration of immature oligodendrocytes and a resulting loss of mature oligodendrocyte markers like MBP, we tested for myelin loss ${ }^{46-48}$. We detected a significant myelin loss after injury (Fig. 2C: compare ipsilateral injured to contralateral intact hemisphere Injury vs. Sham groups) ${ }^{38,49}$. Importantly, transplantation of WJ-MSCs resulted in an amelioration of the induced MBP loss (Fig. 2C: compare ipsilateral to contralateral hemisphere Injury vs. Injury+WJ-MSCs groups). Besides demyelination, glial activation is another prominent event after immature brain injury, so we tested astroglial activation next ${ }^{34,50}$. We detected increased astroglial activation in the cortex following injury (Fig. 2D: compare ipsilateral to contralateral hemisphere Injury vs. Sham groups). In line with myelin protection, WJ-MSCs reduced astroglial activation significantly (Fig. 2D: compare ipsilateral to contralateral hemisphere Injury vs. Injury+WJ-MSCs groups). Collectively, our results support the notion that WJ-MSCs attenuate the induced injury in an immature brain characterized by cortical changes such as myelin loss and astroglial activation, which underlie the resulting locomotor behavioral changes ${ }^{35}$, 45 .

\section{WJ-MSCs modulate PKA/PKC, CDK, Akt signaling, and 14-3-3 binding in the immature brain}

Our results indicate that transplantation of WJ-MSCs protects the immature brain against injury (Fig. 2 compare Injury vs. Injury+WJ-MSCs groups). However, the underlying mechanisms remain unclear. To investigate these mechanisms, we chose a global screening approach to detect key regulators of responses to DNA damage and probed the brain tissues against well-characterized motif-specific antibodies ${ }^{21}$. These antibodies detect specific posttranslational modifications in the context of specific binding motif or substrate. Thus, we assess not a single target, but rather have a global overview.

We tested PKA/PKC first as they are important signaling molecules in a variety of cellular functions, including cellular response to hypoxia ischemia or oxidative stress ${ }^{21,51,52}$. In line with previous reports, injury to an immature brain resulted in the activation of PKA/PKC signaling (Fig. 3A) ${ }^{21}$. Surprisingly, WJ-MSCs did not further activate PKA/PKC, but rather decreased it significantly (Fig. 3A). 
In search for other potential mechanisms and given the emerging importance of CDK inhibitors in oncology and their potential use in stroke, we tested for CDK substrates ${ }^{19}$. In stroke, ischemic brain injury results in an activation of CDK signaling and CDK inhibition is protective ${ }^{19}$. Immature brain injury did not affect CDK signaling and we detected CDK activation after cell graft transplantation

A.

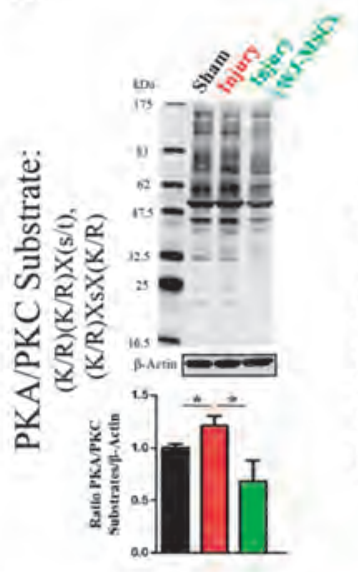

D.

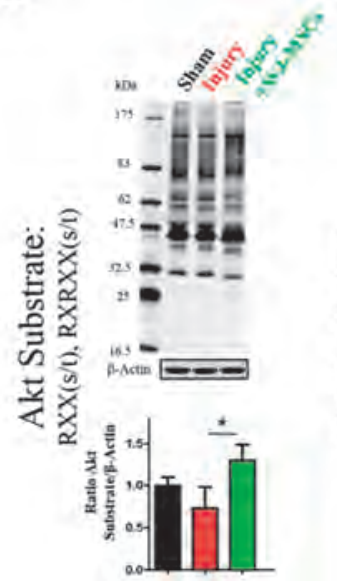

B.

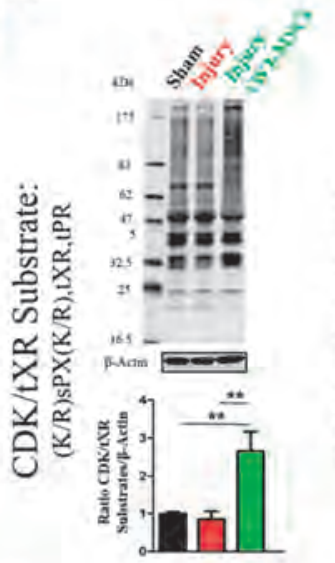

E.

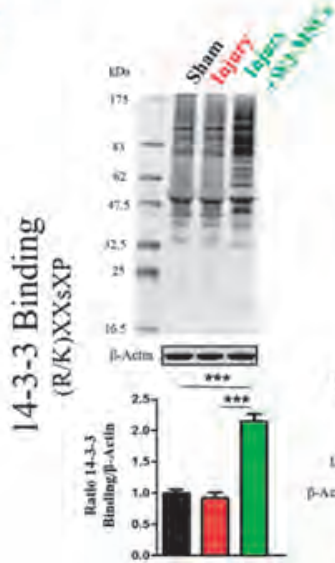

C.

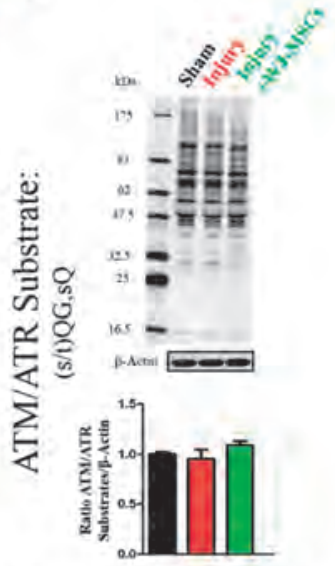

F.

IMMATURE BRAIN INJURY

G.
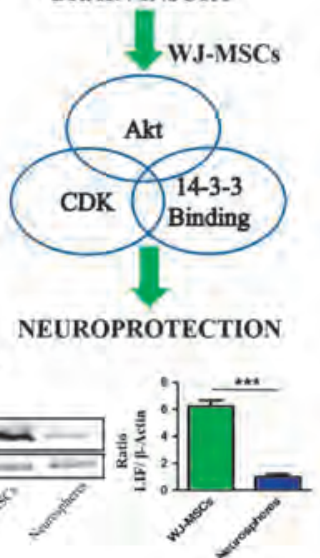

Figure 3. WJ-MSCs modulate crucial cell fate pathways. Proteins were extracted from frozen brain tissues ( $\mathrm{n}=3$ each group) and analyzed by western blot. In upper panels representative western blots and in lower panels quantification of cyclic AMPdependent protein kinase/calcium-dependent protein kinase (PKA/PKC) (A), cyclin-dependent kinase (CDK) (B), ataxia-telangiectasiamutated/ATM- and Rad3-related (ATM/ATR) substrates (C), protein kinase B (Akt) (D), and 14-3-3 binding protein partners (E). (F) Hypothesis: WJMSCs protect the immature brain and modulate cell fate signaling pathways. (G) Representative western blots (three independent experiments) of LIF identified in the gene array (Table 1) as one of the factors highly upregulated in WJ-MSCs. Protein levels are shown after normalization against beta actin. Data are presented as mean \pm SEM (two-tailed Student`s t-test). ${ }^{*} \mathrm{p}<0.05 ;{ }^{* *} \mathrm{p}<0.01 ;{ }^{* * *} \mathrm{p}<0.001$. LIF, leukemia inhibitory factor.

(Fig. 3B). To further elucidate the graft response, we tested ATM/ATR signaling 
as ATM is upstream of CDK in cell cycle arrest ${ }^{26,53,54}$. We did not detect any significant changes (Fig. 3C), which suggests that the observed cell graftmediated CDK activation is ATM/ATR independent. Next, we tested phosphorylated Akt substrates and 14-3-3 binding partners as they modulate the cell cycle progression, are crucial CDK partners, and reported neuroprotective targets $20,24,55,56$. In line with CDK activation, WJ-MSCs treatment increased phosphorylation of Akt substrates and 14-3-3 binding partners (Fig. 3D, E). Together, our results provide evidence that WJ-MSCs protect the immature brain and modulate cell fate signaling pathways (Fig. 3F) involved in brain protection.

\section{WJ-MSCs express neurotrophic factors}

Given the modifications after transplantation of WJMSCs (Fig. 3) and WJ-MSCs' protective effects (Fig. 2), we aimed to further characterize the cell graft using a gene array ${ }^{12}$. We decided to compare WJ-MSCs to differentiated neurospheres derived from WJ-MSCs as WJ-MSCs have a multi-differentiated potential. It is the potential to express factors from other tissues before any differentiation. Thus, we aimed to detect changes unique to the relatively heterogeneous cell population of WJ-MSCs ${ }^{12}$. In line with this potential, we detected increased expression of neurotrophic factors and receptors involved in brain development and response to injury such as nerve growth factor receptor (NGFR) and GDNF family receptor alpha 3 (GFRA3) ${ }^{57,58}$ (all genes summarized in Table 1). We detected increased expression of prostaglandin E receptor 2 (PTGER2), which in stroke protects against oxidative stress in a PKA-dependent manner ${ }^{59}$. Interestingly, we detected increased expression of LIF as well. LIF is an important factor contributing to a variety of cellular processes such as neuronal development, astroglial responses to injury, and oligodendrocyte survival ${ }^{60-63}$. Importantly, LIF exerts its biological effects partially through Akt, CDK, and 14-3-3 signaling pathways ${ }^{61,64,65}$, which makes it a potential candidate of the WJ-MSCs' induced modifications (Fig. 3). We confirmed increased LIF expression in WJ-MSCs on protein level as well (Fig. 3G). Together, we hypothesize that WJ-MSCs may exert adaptive

Table 1. Gene Expression Profle of WJ-MSCs and Differentiated Neurospheres in Culture

\begin{tabular}{|c|c|c|c|c|c|c|}
\hline \multirow[b]{2}{*}{ RefSeq } & \multirow[b]{2}{*}{ Symbol } & \multirow[b]{2}{*}{ Description } & \multicolumn{2}{|c|}{$2^{-4 C t}$} & \multirow{2}{*}{$\begin{array}{c}\text { Fold upregulation } \\
\text { or downregulation } \\
\text { WJ-MSCs/Neurospheres }\end{array}$} & \multirow[b]{2}{*}{$\mathrm{P}$} \\
\hline & & & W.J-MSCS & Neuro-spheres & & \\
\hline NM_001709 & BDNF & $\begin{array}{l}\text { Brain-derived neurotrophic } \\
\text { factor }\end{array}$ & $1.1 \mathrm{E}-02$ & $5.0 \mathrm{E}-02$ & -4.72 & 0.0305 \\
\hline $\mathrm{NM} 0001882$ & CRHBP & $\begin{array}{l}\text { Corticotropin-releasing } \\
\text { hormone-binding protein }\end{array}$ & $2.6 \mathrm{E}-05$ & $3.9 \mathrm{E}-06$ & 6.66 & 0.0046 \\
\hline NM_002010 & FGF9 & $\begin{array}{l}\text { Fibroblast growth factor } 9 \\
\text { (glia-activating factor) }\end{array}$ & $9.2 \mathrm{E}-06$ & $1.4 \mathrm{E}-04$ & -15.57 & 0.0355 \\
\hline NM_004960 & FUS & Fused in sarcoma & $3.8 \mathrm{E}-02$ & $1.0 \mathrm{E}-01$ & -2.62 & 0.0367 \\
\hline NM_005264 & GFRAl & GDNF family receptor alpha I & $9.6 \mathrm{E}-04$ & $1.7 \mathrm{E}-02$ & -17.56 & 0.0465 \\
\hline NM_001496 & GFRA3 & GDNF family receptor alpha 3 & $3.0 \mathrm{E}-05$ & $5.4 \mathrm{E}-06$ & 5.58 & 0.0001 \\
\hline NM_001540 & HSPBI & Heat shock 27 kDa protein 1 & $5.5 \mathrm{E}-01$ & $1.5 \mathrm{E}+00$ & -2.80 & 0.0065 \\
\hline NM_000565 & IL6R & Interleukin 6 receptor & $4.7 \mathrm{E}-04$ & $1.6 \mathrm{E}-03$ & -3.42 & 0.0034 \\
\hline NM_002309 & LIF & Leukemia inhibitory factor & $2.2 \mathrm{E}-01$ & $4.2 \mathrm{E}-02$ & 5.36 & 0.0021 \\
\hline NM_002507 & NGFR & Nerve growth factor receptor & $4.7 \mathrm{E}-04$ & $4.7 \mathrm{E}-05$ & 9.94 & 0.0035 \\
\hline NM_002527 & NTF3 & Neurotrophin 3 & $1.1 \mathrm{E}-03$ & $9.9 \mathrm{E}-03$ & -8.98 & 0.0001 \\
\hline NM_000956 & PTGER2 & $\begin{array}{l}\text { Prostaglandin E receptor } \\
2 \text { (subtype EP2) }\end{array}$ & $1.9 \mathrm{E}-02$ & $7.0 \mathrm{E}-03$ & 2.67 & 0.0455 \\
\hline
\end{tabular}

Table 1. We examined gene expression using specific profiler polymerase chain reaction array. The table shows significantly expressed genes of WJ-MSCs compared with neurospheres derived from WJ-MSCs in culture. We used an arbitrary cutoff of more than twofold change and $\mathrm{P}<0.05$. WJ-MSCs, Wharton`s Jelly derived mesenchymal stem/stromal cells.

responses depending on the type of injury they are facing, making them prominent candidates for cell therapy in perinatal injuries. 


\section{Discussion:}

This report documents that WJ-MSCs transplantation exerts protective effects against immature brain injury. Using a clinically relevant model, we demonstrate that our cell graft (Fig. 1) is able to ameliorate myelination loss and astroglial activation while preserving proper functional behavior (Fig. 2). Most importantly, we are the first to report that WJ-MSCs target crucial signaling pathways involved in cell cycle regulation and apoptosis (Fig. 3F), while expressing growth and differentiation factors (Table 1). Together, we provide evidence that WJ-MSCs are potential candidates for treatment of immature infants at risk.

MSCs and MSC-derived therapies emerged in the last decades as a potential paradigm shift for complex multifactorial diseases, such as immature brain injuries ${ }^{66}$. As the preterm infant faces multiple risk factors, including inflammation/infection, ischemia/reperfusion, and deprivation of placental protective factors, an optimal therapeutic should target the injuries globally (several organs) and locally (response to signals of local injury) ${ }^{11}$. In our study, WJ-MSCs protect the immature brain and modulate different signaling pathways. This is particularly interesting as it fuels the constant debate whether MSCs or MSC-derived products such as conditioned media or exosomes are the optimal choice for treating perinatal injuries. We hypothesize that the WJ-MSCs' ability to locally respond to signals after injury is an advantage, but the direct comparison between WJ-MSCs and their products in perinatal injury models needs to be assessed in future studies ${ }^{66}$. From a clinical point of view, precautions and longterm adverse consequences need to be considered as in the immunocompromised developing preterm infant, stem cells have the theoretical potential to enhance tumor growth ${ }^{67}$.

Another important consideration is the route of stem cell transplantation and the animal model. We tested WJ-MSCs in a well-established model of immature brain injury ${ }^{21,30,35}$. We induced injury at P3/4, a time point that corresponds to a highrisk period of human preterm infants with immature oligodendrocyte development peak ${ }^{45}$. Expectantly, we detected myelin loss with motor and sensory deficits (Fig. 2A, C) ${ }^{35}$, 45. However, preterm survivors demonstrate cognitive and behavioral deficits with higher incidence of psychiatric disorders as well ${ }^{5,6}$. Thus, studies identifying MSC's effects after P3/4 injury are needed, especially, as injury at P4 may result in postnatal maturation and affective disorders ${ }^{68}$. Multiple transplantation routes for brain injuries, including intracerebral, intraperitoneal, intranasal, or intravenous, were introduced ${ }^{67}$. Indeed, we chose an invasive route, but a straightforward approach, as we aimed to determine direct effects on the immature brain. Given that the graft preparation and optimal administration route remains unclear ${ }^{69}$, further noninvasive studies are warranted, but beyond the scope of this article ${ }^{29,70}$. From a clinical point of view, evaluation of the optimal cell transplant is obligatory. Although we did not detect morphological changes of the cell graft over time

(Fig. 1D), longitudinal assessment of the cell graft fate are still needed, especially as we used a xenograft. Additionally, preparation of the graft before transplantation such as removal of fetal bovine serum needs to be assessed before clinical utilization. 
Numerous studies postulate that MSCs protective effects after perinatal injury are based on paracrine effects and immunomodulation ${ }^{11}$. In contrast to upcoming novel immunomodulation therapies such as PreImplantation factor, WJ-MSCs did not impact PKA/PKC signaling after injury ${ }^{21}$. Given the diverse modes of action, a combined therapeutic approach may provide superior protection due to synergistic effects. Another surprising finding is that WJ-MSCs activate CDK signaling in the brain, whereas CDK inhibition protects neurons in stroke or traumatic brain injury ${ }^{19,71}$. However, when considering this opposite effect, the distinct pathophysiology of an immature brain and time point of the evaluation need to be accounted for. For example, in an immature brain, cell proliferation and differentiation, especially in the case of oligodendrocyte progenitors, depend on proper CDK activity ${ }^{53,72}$. Furthermore, in stroke CDK activation was detected up to $24 \mathrm{~h}$ of reperfusion injury only ${ }^{19}$. Given that CDK modulation was not detected after injury (Fig. 3B: compare Injury vs. Sham) and neuroprotective inhibition of CDKs is present in adult animals only ${ }^{73}$, suggest an age-dependent role of CDKs. Together, we provide evidence that WJ-MSCs modulate crucial cell fate pathways in an immature brain injury setting. We hypothesize that targeting these pathways impacts the regeneration capacity of a developing brain. Additional studies will dissect which specific pathways such as AKT/CDK/14-3-3 binding and factors such as LIF may produce beneficial effects. Furthermore, studies addressing the direct comparison of different cell transplants, including adipose-derived stem cells and bone marrow mononuclear cells, will determine whether the documented effects (Fig. 3) are WJ-MSC specific as well.

In conclusion, disease-specific and age-specific considerations are necessary when assessing therapeutics for immature infants. Additional studies identifying WJMSCs' optimal formulation and preparation (live cells vs. cell products), transplantation routes (invasive vs. non-invasive), and design (alone vs. synergistic additives) need to be addressed before clinical translation. We hypothesize that WJMSCs may exert adaptive responses depending on the type of injury they are facing, making them prominent candidates for cell therapy in perinatal injuries.

Acknowledgments: This study was supported by: Cryo-Save AG, Switzerland, Mobiliar Jubiläumsstiftung, Switzerland, and Forschungs-Grant Inselspital Bern, Switzerland

Author Disclosure Statement: No competing financial interests exist. 


\section{References:}

1. Phillips JB, P Abbot and A Rokas. Is preterm birth a human-specific syndrome? Evol Med Public Health 2015:136-48.

2. Liu L, S Oza, D Hogan, J Perin, I Rudan, JE Lawn, S Cousens, C Mathers and RE Black. Global, regional, and national causes of child mortality in 2000-13, with projections to inform post-2015 priorities: an updated systematic analysis. Lancet 2015 385:430-40.

3. Numerato D, G Fattore, F Tediosi, R Zanini, M Peltola, H Banks, P Mihalicza, L Lehtonen, S Svereus, R Heijink, ST Klitkou, E Fletcher, A Heijden, F Lundberg, E Over, U Hakkinen and TT Seppala. Mortality and Length of Stay of Very Low Birth Weight and Very Preterm Infants: A EuroHOPE Study. PLoS One 2015 10:e0131685.

4. Schaaf JM, BW Mol, A Abu-Hanna and AC Ravelli. Trends in preterm birth: singleton and multiple pregnancies in the Netherlands, 2000-2007. BJOG 2011 118:1196-204.

5. Hamrick SE, SP Miller, C Leonard, DV Glidden, R Goldstein, V Ramaswamy, R Piecuch and DM Ferriero. Trends in severe brain injury and neurodevelopmental outcome in premature newborn infants: the role of cystic periventricular leukomalacia. J Pediatr 2004 145:593-9.

6. Marret S, L Marchand-Martin, JC Picaud, JM Hascoet, C Arnaud, JC Roze, P Truffert, B Larroque, M Kaminski, PY Ancel and ES Group. Brain injury in very preterm children and neurosensory and cognitive disabilities during childhood: the EPIPAGE cohort study. PLoS One 2013 8:e62683.

7. Lobo N, B Yang, M Rizvi and D Ma. Hypothermia and xenon: novel noble guardians in hypoxic-ischemic encephalopathy? J Neurosci Res 2013 91:473-8.

8. Titomanlio L, A Kavelaars, J Dalous, S Mani, V El Ghouzzi, C Heijnen, O Baud and P Gressens. Stem cell therapy for neonatal brain injury: perspectives and challenges. Ann Neurol 2011 70:698-712.

9. Higgins RD, T Raju, AD Edwards, DV Azzopardi, CL Bose, RH Clark, DM Ferriero, R Guillet, AJ Gunn, H Hagberg, D Hirtz, TE Inder, SE Jacobs, D Jenkins, S Juul, AR Laptook, JF Lucey, M Maze, C Palmer, L Papile, RH Pfister, NJ Robertson, M Rutherford, S Shankaran, FS Silverstein, RF Soll, M Thoresen and WF Walsh. Hypothermia and other treatment options for neonatal encephalopathy: an executive summary of the Eunice Kennedy Shriver NICHD workshop. $J$ Pediatr 2011 159:851-858 e1.

10. Cahill AG, MJ Stout and AB Caughey. Intrapartum magnesium for prevention of cerebral palsy: continuing controversy? Curr Opin Obstet Gynecol 2010 22:122-7.

11. Mueller M, TG Wolfs, A Schoeberlein, AW Gavilanes, D Surbek and BW Kramer. Mesenchymal stem/stromal cells-a key mediator for regeneration after perinatal morbidity? Mol Cell Pediatr 2016 3:6.

12. Messerli M, A Wagner, R Sager, M Mueller, M Baumann, DV Surbek and A Schoeberlein. Stem Cells From Umbilical Cord Wharton's Jelly From Preterm Birth Have Neuroglial Differentiation Potential. Reprod Sci. 2013

13. Castillo-Melendez M, T Yawno, G Jenkin and SL Miller. Stem cell therapy to protect and repair the developing brain: a review of mechanisms of action of cord blood and amnion epithelial derived cells. Front Neurosci 2013 7:194.

14. Volpe JJ. Brain injury in premature infants: a complex amalgam of destructive and developmental disturbances. Lancet Neurol 2009 8:110-24.

15. Hass R, C Kasper, S Bohm and R Jacobs. Different populations and sources of human mesenchymal stem cells (MSC): A comparison of adult and neonatal tissue-derived MSC. Cell Commun Signal 2011 9:12.

16. Lee JW, X Fang, A Krasnodembskaya, JP Howard and MA Matthay. Concise review: Mesenchymal stem cells for acute lung injury: role of paracrine soluble factors. Stem Cells 2011 29:913-9.

17. Phillips AW, MV Johnston and A Fatemi. The potential for cell-based therapy in perinatal brain injuries. Transl Stroke Res 20134:137-48. 
18. Back SA and PA Rosenberg. (2014). Pathophysiology of glia in perinatal white matter injury. Glia 62:1790-1815.

19. Osuga H, S Osuga, F Wang, R Fetni, MJ Hogan, RS Slack, AM Hakim, JE Ikeda and DS Park. Cyclin-dependent kinases as a therapeutic target for stroke. Proc Natl Acad Sci U S A 2000 97:10254-9.

20. Miras-Portugal MT, R Gomez-Villafuertes, J Gualix, JI Diaz-Hernandez, AR Artalejo, F Ortega, EG Delicado and R Perez-Sen. Nucleotides in neuroregeneration and neuroprotection. Neuropharmacology 2015.

21. Mueller M, A Schoeberlein, J Zhou, M Joerger-Messerli, B Oppliger, U Reinhart, A Bordey, D Surbek, E Barnea, Y Huang and M Paidas. PreImplantation Factor bolsters neuroprotection via modulating Protein Kinase A and Protein Kinase C signaling. Cell Death Differ. 2015 Dec;22(12):2078-86

22. Kim HH, K Abdelmohsen and M Gorospe. Regulation of HuR by DNA Damage Response Kinases. J Nucleic Acids 2010.

23. Meng S, T Arbit, S Veeriah, IK Mellinghoff, F Fang, I Vivanco, D Rohle and TA Chan. 14-33sigma and p21 synergize to determine DNA damage response following Chk2 inhibition. Cell Cycle 2009 8:2238-46.

24. Hermeking H and A Benzinger. 14-3-3 proteins in cell cycle regulation. Semin Cancer Biol 2006 16:183-92.

25. Xu N, Y Lao, Y Zhang and DA Gillespie. Akt: a double-edged sword in cell proliferation and genome stability. J Oncol 2012:951724.

26. Verdaguer E, A Susana Gde, A Clemens, M Pallas and A Camins. Implication of the transcription factor E2F-1 in the modulation of neuronal apoptosis. Biomed Pharmacother 2007 61:390-9.

27. Foote M and Y Zhou. 14-3-3 proteins in neurological disorders. Int J Biochem Mol Biol 2012 3:152-64.

28. Shimada T, AE Fournier and K Yamagata. Neuroprotective function of 14-3-3 proteins in neurodegeneration. Biomed Res Int. 2013:564534.

29. Schoeberlein A, M Mueller, U Reinhart, R Sager, M Messerli and DV Surbek. Homing of placenta-derived mesenchymal stem cells after perinatal intracerebral transplantation in a rat model. Am J Obstet Gynecol 2011 205:277 e1-6.

30. Mueller M, J Zhou, L Yang, Y Gao, F Wu, A Schoeberlein, D Surbek, ER Barnea, M Paidas and Y Huang. PreImplantation factor promotes neuroprotection by targeting microRNA let-7. Proc Natl Acad Sci U S A 2014 111:13882-7.

31. Meier C, J Middelanis, B Wasielewski, S Neuhoff, A Roth-Haerer, M Gantert, HR Dinse, R Dermietzel and A Jensen. Spastic paresis after perinatal brain damage in rats is reduced by human cord blood mononuclear cells. Pediatr Res 2006 59:244-9.

32. Schneider CA, WS Rasband and KW Eliceiri. NIH Image to ImageJ: 25 years of image analysis. Nat Methods 2012 9:671-5.

33. Ramachandra R ST. Atlas of the Neonatal Rat Brain. Boca Raton, Fl, USA 2011.

34. Sizonenko SV, JZ Kiss, T Inder, PD Gluckman and CE Williams. Distinctive neuropathologic alterations in the deep layers of the parietal cortex after moderate ischemic-hypoxic injury in the P3 immature rat brain. Pediatr Res 2005 57:865-72.

35. Oppliger B, M Jorger-Messerli, M Mueller, U Reinhart, P Schneider, D Surbek and A Schoeberlein. (2016). Intranasal delivery of umbilical cord-derived mesenchymal stem cells preserves myelination in perinatal brain damage. Stem Cells Dev 25:1234-1242.

36. Donega V, CT van Velthoven, CH Nijboer, F van Bel, MJ Kas, A Kavelaars and CJ Heijnen. Intranasal mesenchymal stem cell treatment for neonatal brain damage: long-term cognitive and sensorimotor improvement. PLoS One 2013 8:e51253.

37. Jellema RK, V Lima Passos, A Zwanenburg, DR Ophelders, S De Munter, J Vanderlocht, WT Germeraad, E Kuypers, JJ Collins, JP Cleutjens, W Jennekens, AW Gavilanes, M Seehase, HJ Vles, H Steinbusch, P Andriessen, TG Wolfs and BW Kramer. Cerebral inflammation and 
mobilization of the peripheral immune system following global hypoxia-ischemia in preterm sheep. J Neuroinflammation 2013 10:13.

38. Sizonenko SV, E Sirimanne, Y Mayall, PD Gluckman, T Inder and C Williams. Selective cortical alteration after hypoxic-ischemic injury in the very immature rat brain. Pediatr Res 2003 54:263-269.

39. Joerger-Messerli MS, C Marx, B Oppliger, M Mueller, DV Surbek and A Schoeberlein. Mesenchymal Stem Cells from Wharton's Jelly and Amniotic Fluid. Best Pract Res Clin Obstet Gynaecol. 2015

40. Dominici M, K Le Blanc, I Mueller, I Slaper-Cortenbach, F Marini, D Krause, R Deans, A Keating, D Prockop and E Horwitz. Minimal criteria for defining multipotent mesenchymal stromal cells. The International Society for Cellular Therapy position statement. Cytotherapy 2006 8:315-7.

41. van Velthoven CT, A Kavelaars, F van Bel and CJ Heijnen. Mesenchymal stem cell transplantation changes the gene expression profile of the neonatal ischemic brain. Brain Behav Immun 2011 25:1342-8.

42. Lee JA, BI Kim, CH Jo, CW Choi, EK Kim, HS Kim, KS Yoon and JH Choi. (2010). Mesenchymal stem-cell transplantation for hypoxic-ischemic brain injury in neonatal rat model. Pediatr Res 67:42-46.

43. van Velthoven CT, A Kavelaars, F van Bel and CJ Heijnen. (2010). Nasal administration of stem cells: a promising novel route to treat neonatal ischemic brain damage. Pediatr Res 68:419422.

44. Ortinau $\mathrm{C}$ and $\mathrm{J}$ Neil. The neuroanatomy of prematurity: Normal brain development and the impact of preterm birth. Clin Anat. 2014

45. Misumi S, Y Ueda, R Nishigaki, M Suzuki, A Ishida, CG Jung and H Hida. (2016). Dysfunction in motor coordination in neonatal white matter injury model without apparent neuron loss. Cell Transplant 25:1381-1393.

46. Follett PL, PA Rosenberg, JJ Volpe and FE Jensen. NBQX attenuates excitotoxic injury in developing white matter. J Neurosci 2000 20:9235-41.

47. Craig A, N Ling Luo, DJ Beardsley, N Wingate-Pearse, DW Walker, AR Hohimer and SA Back. Quantitative analysis of perinatal rodent oligodendrocyte lineage progression and its correlation with human. Exp Neurol 2003 181:231-40.

48. Liu Y, FS Silverstein, R Skoff and JD Barks. Hypoxic-ischemic oligodendroglial injury in neonatal rat brain. Pediatr Res 2002 51:25-33.

49. Manning SM, DM Talos, C Zhou, DB Selip, HK Park, CJ Park, JJ Volpe and FE Jensen. NMDA receptor blockade with memantine attenuates white matter injury in a rat model of periventricular leukomalacia. J Neurosci 2008 28:6670-8.

50. McQuillen PS, RA Sheldon, CJ Shatz and DM Ferriero. Selective vulnerability of subplate neurons after early neonatal hypoxia-ischemia. J Neurosci 2003 23:3308-15.

51. Leenders AG and ZH Sheng. Modulation of neurotransmitter release by the second messengeractivated protein kinases: implications for presynaptic plasticity. Pharmacol Ther 2005 105:69-84.

52. Libien J, TC Sacktor and IS Kass. Magnesium blocks the loss of protein kinase C, leads to a transient translocation of PKC(alpha) and PKC(epsilon), and improves recovery after anoxia in rat hippocampal slices. Brain Res Mol Brain Res 2005 136:104-11.

53. Ozgen H, N Kahya, JC de Jonge, GS Smith, G Harauz, D Hoekstra and W Baron. Regulation of cell proliferation by nucleocytoplasmic dynamics of postnatal and embryonic exon-IIcontaining MBP isoforms. Biochim Biophys Acta 2014 1843:517-30.

54. Kulkarni A and KC Das. Differential roles of ATR and ATM in p53, Chk1, and histone H2AX phosphorylation in response to hyperoxia: ATR-dependent ATM activation. Am J Physiol Lung Cell Mol Physiol 2008 294:L998-L1006.

55. Li A, J Wang, M Wu, X Zhang and H Zhang. The inhibition of activated hepatic stellate cells proliferation by arctigenin through G0/G1 phase cell cycle arrest: persistent p27(Kip1) induction by interfering with PI3K/Akt/FOXO3a signaling pathway. Eur J Pharmacol 2015 747:71-87. 
56. Jang SW, X Liu, H Fu, H Rees, M Yepes, A Levey and K Ye. Interaction of Aktphosphorylated SRPK2 with 14-3-3 mediates cell cycle and cell death in neurons. $J$ Biol Chem 2009 284:24512-25.

57. Bradshaw RA, J Pundavela, J Biarc, RJ Chalkley, AL Burlingame and H Hondermarck. (2015). NGF and ProNGF: regulation of neuronal and neoplastic responses through receptor signaling. Adv Biol Regul 58:16-27.

58. Wang X, RH Baloh, J Milbrandt and KC Garcia. (2006). Structure of artemin complexed with its receptor GFRalpha3: convergent recognition of glial cell line-derived neurotrophic factors. Structure 14:1083-1092.

59. Carrasco E, P Werner and D Casper. (2008). Prostaglandin receptorEP2 protects dopaminergic neurons against 6-OHDAmediated low oxidative stress. Neurosci Lett 441:44-49.

60. Yue X, L Wu and W Hu. (2015). The regulation of leukemia inhibitory factor. Cancer Cell Microenviron 2:pii:e877.

61. Rowe DD, LA Collier, HA Seifert, CB Chapman, CC Leonardo, AE Willing and KR Pennypacker. (2014). Leukemia inhibitor factor promotes functional recovery and oligodendrocyte survival in rat models of focal ischemia. Eur J Neurosci 40:3111-3119.

62. Davis SM, LA Collier, CC Leonardo, HA Seifert, CT Ajmo, Jr. and KR Pennypacker. (2016). Leukemia inhibitory factor protects neurons from ischemic damage via upregulation of superoxide dismutase 3. Mol Neurobiol. [Epub ahead of print]; DOI:10.1007/s12035-015-9887-2.

63. Fan YY, JM Zhang, H Wang, XY Liu and FH Yang. (2013). Leukemia inhibitory factor inhibits the proliferation of primary rat astrocytes induced by oxygen-glucose deprivation. Acta Neurobiol Exp (Wars) 73:485-494.

64. Slaets H, D Dumont, J Vanderlocht, JP Noben, P Leprince, J Robben, J Hendriks, P Stinissen and N Hellings. (2008). Leukemia inhibitory factor induces an antiapoptotic response in oligodendrocytes through Akt-phosphorylation and up-regulation of 14-3-3. Proteomics 8:12371247.

65. Liu X, SC Tseng, MC Zhang, SY Chen, S Tighe, WJ Lu and YT Zhu. (2015). LIF-JAK1STAT3 signaling delays contact inhibition of human corneal endothelial cells. Cell Cycle 14:1197-1206.

66. Fischbach MA, JA Bluestone and WA Lim. Cell-based therapeutics: the next pillar of medicine. Sci Transl Med 2013 5:179ps7.

67. Mitsialis SA and S Kourembanas. Stem cell-based therapies for the newborn lung and brain: Possibilities and challenges. Semin Perinatol. 2016

68. Ouhaz Z, S Ba-M'hamed, AS Mitchell, A Elidrissi and M Bennis. (2015). Behavioral and cognitive changes after early postnatal lesions of the rat mediodorsal thalamus. Behav Brain Res 292:219-232.

69. Rossetti T, F Nicholls and M Modo. Intracerebral Cell Implantation: Preparation and Characterization of Cell Suspensions. Cell Transplant 2016 25:645-64.

70. Chen A, B Siow, AM Blamire, M Lako and GJ Clowry. Transplantation of magnetically labeled mesenchymal stem cells in a model of perinatal brain injury. Stem Cell Res 2010 5:255-66.

71. Kabadi SV and AI Faden. Selective CDK inhibitors: promising candidates for future clinical traumatic brain injury trials. Neural Regen Res 2014 9:1578-80.

72. See WL, JP Miller, M Squatrito, E Holland, MD Resh and A Koff. Defective DNA doublestrand break repair underlies enhanced tumorigenesis and chromosomal instability in p27-deficient mice with growth factor-induced oligodendrogliomas. Oncogene 2010 29:1720-31.

73. Cowper-Smith CD, GJ Anger, E Magal, MH Norman and GS Robertson. Delayed administration of a potent cyclin dependent kinase and glycogen synthase kinase 3 beta inhibitor produces long-term neuroprotection in a hypoxia-ischemia model of brain injury. Neuroscience 2008 155:864-75. 


\section{Supplementary Information}

Wharton`s jelly Mesenchymal Stem Cells protect the immature brain in rats and modulate cell fate

\section{Supplementary Methods}

\section{Perioperative Care of the Animals}

Perioperative care was performed in accordance with the Ethics Committee and Veterinary Department of the Canton of Berne, Switzerland guidelines. Acclimatization of animals to the laboratory environment was allowed before surgery. Aseptic rodent survival surgery guidelines were followed. We injected buprenorphine $(0.1 \mathrm{mg} / \mathrm{kg}$ body weight) subcutaneously (s.c.) $30 \mathrm{~min}$ before incision. Carprofen was used for postoperative analgesia $(5 \mathrm{mg} / \mathrm{kg}$, s.c., starting 4-6 h postsurgery, every $24 \mathrm{~h}$ for 3 days). We used Isoflurane as an anesthetic (induction with $4 \%$ and maintenance with $1 \%-1.5 \%$ in $\mathrm{O}_{2} ; 3 \mathrm{l} / \mathrm{min}$ ). Adequate depth of anesthesia was confirmed. After surgery, animals were placed back to the mother as soon as they were awake, able to right themselves and able to move about. We monitored several parameters, including anesthetic depth (persistence), clinical signs, and condition. We monitored the pups every hour for at least 6-8 h postoperation with special attention to breathing pattern and mobility, as well as signs of seepage or bleeding from the incision. When neonates have reached the age of interest, animals were sacrificed by Sodium Pentothal $(100 \mathrm{mg} / \mathrm{kg}$ body weight i.p.), cardiac perfusion and decapitation.

\section{Tissue Immunohistochemistry}

After deparaffinization of the slides, the target was retrieved in citrate buffer (10 $\mathrm{mM}$; $\mathrm{pH}$ 6.0) in a pressure cooker for $15 \mathrm{~min}$. Slides were washed in $0.1 \%$ Tween20/phosphate-buffered saline (PBS) and blocked in 10\% goat serum/1\% bovine albumin/PBS. Wharton's Jelly-derived mesenchymal stem/stromal cells (WJMSCs) were detected with a mouse anti-human HLA class I ABC antibody (EMR8-5; Abcam, Cambridge, United Kingdom) and the DakoCytomation EnVision+ System-HRP (K4006; DAKO, Glostrup, Denmark). Neurons were detected by a mouse monoclonal antibody specific for the neuronal nuclear antigen (NeuN, MAB377, 1:100; Merck Millipore). Myelin was detected by an antibody against myelin basic protein (MBP, mouse anti human monoclonal antibody, LS-B2231, 1:100; LifeSpan Biosciences LSBio, Seattle, WA). Astrogliosis was detected with an antibody against glial fibrillary acidic protein (GFAP, mouse monoclonal anti-GFAP, Merck Millipore MAB360, 1:500 in DAKO antibody diluent). Following the first antibody incubation, slides were washed in $0.1 \%$ Tween-20/PBS (2 x 5min) and incubated in endogenous peroxidase blocking solution at RT for 15 min. Peroxidase-labeled polymer (DAKO anti-mouse or anti-rabbit) was applied to the slides for $30 \mathrm{~min}$ at RT. Slides were washed in PBS ( $3 x, 5 \mathrm{~min}$ ), followed by the application of $\mathrm{DAB}+$ chromogen in buffer substrate for 10-30 min, according to the manufacturer's instructions (DAKO EnVision+ System-HRP (DAB), K4007). Slides were rinsed in $\mathrm{ddH}_{2} \mathrm{O}$, counterstained in Cresyl Violet (Nissl body staining for neuronal structure and gross brain morphology), dehydrated in a series of ethanol baths (95\%> 100\%) and xylene, and mounted with Eukitt (Sigma-Aldrich, St. Louis, MO). 


\section{Tissue Harvesting}

The western blots using antibody-specific motifs were performed as we had described previously ${ }^{21}$. To dissect WJ-MSCs' protective mechanisms in the brain tissue ( $\mathrm{n}=3$ each group), we induced brain injury as previously described ${ }^{21,} 30$. Injury and Injury+WJ-MSCs groups received lipopolysaccharides (LPS $0.1 \mathrm{mg} / \mathrm{kg}$ BW, i.p.) at postnatal day 2 (P2). On the following day, left common carotid artery was double ligated using a stereomicroscope and animals were subjected to hypoxia ( $\left.8 \% \mathrm{O}_{2} / 92 \% \mathrm{~N}_{2} ; 65 \mathrm{~min}\right)$. The Sham Group consisted of uninjured animals $(0.9 \% \mathrm{NaCl}$ instead of LPS i.p., exposure of carotid artery without ligation, no hypoxia, and received no treatment. The Injury Group received no further treatment, but needle was placed into the ventricle. The Injury+WJ-MSCs Group received single cell graft transplantation into the lateral ventricle. We transplanted 250,000 of WJ-MSCs into the ventricle at postnatal day 4 as published previously ${ }^{29}$. We harvested the brain tissue at P11 and evaluated specific motif antibodies as previously performed ${ }^{30}$. 



\section{Chapter 4}

17 $\beta$-Estradiol protects 7-day old rats from acute brain injury and reduces the number of apoptotic cells.

Published as: Mueller M, Middelanis J, Meier C, Surbek D, Berger R. 17 $\beta$-estradiol protects 7-day old rats from acute brain injury and reduces the number of apoptotic cells. Reprod Sci. 2013 Mar;20(3):253-61. PubMed PMID: 22875845 


\begin{abstract}
Objective: To test a possible neuroprotective activity of $17 \beta$-estradiol in the neonatal rat brain exposed to hypoxic-ischemia (controlled hypoxia after unilateral carotid artery ligation).

Methods: Seven-day-old Wistar rats underwent ligation of the left common carotid artery followed by 80 minutes hypoxia in $8 \%$ oxygen inducing an ipsilateral brain damage. Seven days later (d14), brains were analyzed quantitatively using a macroscopic and microscopic score for structural damage, hemisphere volumes were calculated, and immunohistochemistry for cleavedcaspase-3 (marker for apoptotic cells) was performed. Animals from the study group $(\mathrm{n}=19)$ received $17 \beta$-estradiol $(0.05 \mathrm{mg} / \mathrm{g}$ body weight intraperitoneally) before ( $-64,-40$, and -16 hours) and after (+3 hours) the hypoxia (hour 0 : start of the hypoxia) and the control group $(n=21)$ received mock treatment.
\end{abstract}

Results: Of the 21 pups, 13 in the $\mathrm{NaCl}$ group had macroscopically a severe brain damage and 7 of 19 animals in the study group encountered only discrete to mild lesions. Microscopic brain damage in the study group was significantly lower (score $1.5+0.7$ vs $2.8+0.8, \mathrm{P}<.05$ ). The determined volumes of the affected hemisphere were significantly lower in the $\mathrm{NaCl}$ group than in the treatment group. The numbers of apoptotic cells in both hemispheres was equal in the estradiol group, but in the control group, there were significantly more apoptotic cells in the affected hemisphere (control group: ipsilateral: $1435+653$ vs contralateral: $143+57$ cells, $\mathrm{P}<.05)$.

Discussion: 17 $\beta$-Estradiol protects newborn rat brains from hypoxic-ischemic injury, in terms of both microscopic cell injury and apoptosis. 


\section{Introduction}

Encephalopathy in premature infants is of enormous public health importance due to the large number of affected infants and its major cause for cerebral palsy. The 2007 preterm birth rate in the United States was $12.7 \%$ and the low birth weight reached $8.2 \%$. The subsequent occurrence of altered brain development resulting in long-term physical, cognitive, and behavioral deficits in $25 \%$ to $50 \%$ and major motor deficits in $1 \%$ to $5 \%$ in this group underlines the importance of this event 1,2 . The evolving process of brain injury starting during intrapartum hypoxiaischemia and reaching into the first postnatal days is a complex amalgam of destructive and developmental disturbances. It involves white and gray matter injury to varying degrees, depending on the gestational and developmental stage.

The immature brain seems to sustain less damage when exposed to lack of oxygen or nutrient, as compared to an adult brain. To induce profound brain damage, immature mice or rats are typically exposed to hypoxia-ischemia for 70 minutes ${ }^{3}$. In contrast, only 25 minutes are necessary to induce a similar brain damage in the adult mice brains ${ }^{4}$. This observation may indicate that some specific factor or group of factors are present in an immature brain and figure as neuroprotective agents.

Of potential interest are steroids, especially $17 \beta$-estradiol. At the end of physiological pregnancy, estrogens reach high levels $(15 \mathrm{ng} / \mathrm{mL})$ and after birth, this high placental estrogen is no longer available ${ }^{5,6}$. $17 \beta$-estradiol serum levels are reduced 1000 -fold $(5-35 \mathrm{pg} / \mathrm{mL})$ and may lead to a higher rate of brain damage ${ }^{7}$. Gonads, adrenal glands of the fetus, the mother, the placenta, de novo synthesis in fetal brain, or conversion of precursor enzymes are possible sources of $17 \beta$-estradiol ${ }^{8}$. The neuroprotective mode of action is believed to occur via receptor-dependent (genomic or nongenomic) or receptor-independent mechanisms ${ }^{9}$.

The potential neuroprotective activity of $17 \beta$-estradiol has been demonstrated in vivo and in vitro ${ }^{10}$. Various clinical studies proposed the prevention or delay of the onset of neurodegenerative diseases by estradiol ${ }^{11}$. In stroke, seizures, oxygen-glucose deprivation, and oxidative stress, $17 \beta$-estradiol attenuates injury in the central nervous system ${ }^{12,13}$.

In vitro studies with primary neuronal cell cultures or clonal neuronal cell lines have shown the neuroprotective effect of estrogen against a large number of substances such as the excitatory neurotransmitter L-glutamate, the viral protein gp120, apoptosis inducers such as staurosporine, or the amyloid $\beta$ peptide ${ }^{14}$.

Other potential therapeutics target perinatal brain damage but the use in clinical trials is still limited ${ }^{15}$. So far, the only clinically used neuroprotective measure is cooling down the newborn at risk ${ }^{16}$. A recent meta-analysis of moderate hypothermia after hypoxic-ischemic encephalopathy in neonates showed in an 18 months follow-up a consistent reduction in death and neurological impairment ${ }^{17}$. However, the efficacy remains limited, and long-term effects are yet unknown ${ }^{18}$.

Human nervous system develops in a complex process of proliferation and apoptosis during pregnancy and first months of life ${ }^{19}$. Contrary in rodent, this process occurs much more rapidly during a period of days in final part of 
gestation and first 3 weeks of neonatal life. Mimicking injury of a neonate human brain has been established in numerous animal models ${ }^{20}$. Mechanisms underlying disease and consequently therapeutic interventions have been explored. The developmental stage of the rat brain on postnatal day 7 is similar to the term human infant and it is also similarly susceptible to hypoxic-ischemic injury ${ }^{20}$. The combination of ischemia, obtained by unilateral carotid artery ligation, and subsequent exposure to hypoxia in 7-day-old rat pups is the most accepted animal model of perinatal asphyxia 21,22. Pathological progressive cascade of consequences in the ipsilateral hemisphere to the occlusion are observed in cerebral cortex, subcortical and periventricular white matter, striatum, and hippocampus. Excito-oxidative events take the form of selective neuronal necrosis (glia and blood vessels spared) or infarction (all elements destroyed) ${ }^{22}$.

Nunez et al applied this animal model and administered $17 \beta$-estradiol using either single or repeated dosing paradigm prior to the hypoxia ${ }^{23}$. Repeated administration showed a neuroprotective effect. Gerstner et al reported that a single dose of $17 \beta$-estradiol 12 hours prior to the injury on postnatal day 6 protects against hypoxic-ischemic white matter damage. Furthermore, 17 $\beta$ estradiol produced significant protection against oxygen-glucose deprivation induced cell death in primary oligodendrocytes ${ }^{24}$.

So there is still much controversy regarding the differing doses, time, treatment schedules, or the effect of estrogen in a neonatal brain after a hypoxic-ischemic injury. Despite the encouraging data, in vivo studies testing $17 \beta$-estradiol as a neuroprotective agent on hypoxic-ischemic insults in an immature brain are rather few. Prior to clinical trials, further investigation is necessary to assess and confirm the possible use of $17 \beta$-estradiol. The experiments that we herein report was designed to test the neuroprotective action of $17 \beta$-estradiol in the immature 7-dayold rat brain after hypoxic-ischemic injury.

\section{Materials and Methods}

\section{Animals Groups and Treatment}

The experiments were performed on 7-day-old neonatal Wistar rats (Charles River, Sulzfeld, Germany) of either sex taken randomly from their litters. Because day 7 in rat life is considered equivalent to term in humans as far as brain development is concerned, day 7 was chosen for the day of the hypoxic insult ${ }^{20}$. Three groups of animals were treated or studied at time point $-64,-40,-16,-1$ hour (carotid artery ligation; day 7 of life), 0 hour (onset of 80 minute-induced hypoxia), +3 hours, and day 14 of life.

Group 1 (9 animals) received different amounts of $17 \beta$-estradiol intraperitoneally (at $-64,-40$, and -16 hours), no ligation or hypoxia, but were sacrificed at -1 hour to measure $17 \beta$-estradiol serum levels.

Group 2 (control group; $\mathrm{n}=25$ ) received $\mathrm{NaCl}$ intraperitoneally (at $-64,-40,-16$, and +3 hours), left carotid ligation, and hypoxia and were sacrificed on day 14 .

Group 3 (study group; $\mathrm{n}=23$ ) received $0.05 \mathrm{mg} / \mathrm{g}$ body weight $17 \beta$-estradiol intraperitoneally (at $-64,-40,-16$, and +3 hours) but were otherwise treated identical to group 2 . 
The animals stayed with their dams and controlled conditions were assured. On day 14, all rats were anesthetized with opioid intraperitoneally and, using thoracotomy and cardiac cannulation, and, for non immunohistochemistry experiments, $4 \%$ formaldehyde was used to perfusion-fix the animals. The brains were extracted surgically and macroscopic inspection of the induced damage was performed immediately. The brains were then stored in formaldehyde for at least 3 days and embedded in paraffin wax. Coronal slices (5 $\mu \mathrm{m}$ thick) were sectioned every $500 \mu \mathrm{m}$ and stained with cresyl violet and fuchsin.

\section{7ß-estradiol Treatment}

The study group animals (group 3 ) received $0.05 \mu \mathrm{g} / \mathrm{g}$ body weight $17 \beta$-estradiol by intraperitoneal injection before ( $-64,-40$, and -16 hours) and after ( +3 hours) the hypoxic-ischemic insult (0 hour corresponding to the start of hypoxia). The injection volume did not exceed $500 \mu \mathrm{L}$ and the measurements of body weight were taken before each injection. Animals from the control group received equivalent volumes of $0.9 \% \mathrm{NaCl}$.

\section{Brain Studies}

From groups 2 and 3, the brains of 40 animals (21 and 19 animals, respectively) were studied. The induced damage was assessed using macroscopic and microscopic scores and for brain volume of each hemisphere in the control group (group 2) and study group (group 3). The brains of the remaining 8 animals (4 from both groups) were studied by immunohistochemistry for apoptosis (number of caspase-3 positive cells per high-power field, 400x). Both hemispheres, ipsilateral or contralateral to the ligated carotid artery, were assessed separately. All evaluations were performed by 1 observer blinded to the groups of the animals.

Macroscopic detectable damage. Macroscopic detectable damage was assessed directly after harvesting the brain from cranial cavity using a 4-point scale. Briefly, the scores indicate: $0=$ no macroscopically detectable damage; $1=$ discrete, delineated, superficial pigmentation of the ipsilateral hemisphere; 2 = moderate cystic infarction of the ipsilateral hemisphere $(\leq 4 \mathrm{~mm})$, and $3=$ severe cystic infarction of the ipsilateral hemisphere ( $\geq 4 \mathrm{~mm}$; Figure 1$)$.

Microscopic neuronal damage. Brown and Brierley criteria were used to assess the neuronal cell damage in 2 general regions of the brain, the cortex and the hippocampus ${ }^{25}$. Coronal cortex sections of both hemisphere were assessed at 5 levels anterior (A) to bregma (A 1.0, A 2.0, A 3.0, A 4.0, A $5.0 \mathrm{~mm}$ ), which is the reference plane at the middle of the dorsal hippocampus ${ }^{26}$. The cortex cerebri was evaluated at 250x magnification visual field by visual field without overlapping. According to the proportion of damaged cells, each visual field received a microscopic score: score $1=0 \%$ to $4 \%$ damage, score $2=5 \%$ to $49 \%$ damage, score $3=50 \%$ to $94 \%$ damage, score $4=95 \%$ to $99 \%$ damage, and score $5=$ $100 \%$ damage. The average scores of all 5 visual fields per hemisphere were calculated (Figure 1). Four hippocampal structures (dentate gyrus, CA 4, CA 3, CA 1/2) in both hemispheres of these samples were scored analogously.

Brain volume studies. Coronal sections of both hemispheres per animal were studied semiquantitatively for brain volume. Using an Olympus BH-2 microscope mounted with a DP10-Videocamera, at 10x magnification, coronal sections were 
chosen chronologically, fronto-occipital with a 1-mm interval each. The perimeter of both hemispheres was traced, and after appropriate calibration, the volume was calculated by multiplying the coronal slice areas with the slices distances $(1 \mathrm{~mm})$. The NIH Image program (version 1.61, US National Institute of Health, Bethseda, Maryland) was used for area measurement. Volumes of each hemisphere in relation to the intact hemisphere were calculated to assess the relative brain volume loss due to the induced damage.

\section{Immunohistochemistry}

Cleaved caspase-3 (Asp175)-positive (CC+) cells were used as a marker of apoptosis. The brains of 4 animals each from groups 2 and 3 were extracted surgically, the brain surfaces covered with tissue-freezing medium (Leica, Nussloch, Germany), and immediately frozen in 8\% methylcyclohexane in 2methylbutan ( $\mathrm{vol} / \mathrm{vol})$ at $-80^{\circ} \mathrm{C}$. Immunohistochemistry was performed on cryosections (12 $\mu \mathrm{m}$ thick) mounted on Superfrost Plus slides (BDH, London, United Kingdom) and heat dried for 1 hour at $40^{\circ} \mathrm{C}$ before fixation.

The primary antibody anti-cleaved caspase-3 (Asp175; Antibody \# 9661, Cell Signalling Technology, Danvers) was used at a dilution of 1:250. After incubation with the primary antibody, the detection antibody (Alexa Fluor 488 goat antirabbit IgG $(\mathrm{H}+\mathrm{L})$, highly cross-adsorbed; Molecular Probes, Oregon) was applied according to the manufacturer's instructions.

The evaluation was performed in 4 standard planes (planes 7, 11, 20, 31; referred to as planes A-D in results) of the neonatal rat brain according to a rat brain atlas 26. For each cortical plane, CC+ cells were counted in 6 visual fields at 250x magnification using a Axiovert 200M Zeiss-microscope mounted with an Axiocam.

\section{7 $\beta$-Estradiol dosage}

To determine the effect of different $17 \beta$-estradiol dosages, group 1 received either $\mathrm{NaCl}$ or $17 \beta$-estradiol at 3 different dosages $(0.01 ; 0.05$ or $0.1 \mathrm{mg} / \mathrm{g}$ body weight) at the same time points as the ligated animals. For serum level detection of $17 \beta-$ estradiol, blood samples were taken from the left heart ventricle at the time of the ligation procedure and serum levels were measured using a $17 \beta$-estradiol Elisa test from IBL Hamburg following user’s manual.

\section{Surgical Procedure and Induced Hypoxia}

For carotid artery ligation on day 7, halothane (4\%) inhalation anesthesia was used for introduction and anesthesia was maintained with $1.5 \%$ halothane in $50 \%$ $\mathrm{N}_{2} \mathrm{O}$ and $50 \% \mathrm{O}_{2}$. Within 10 minutes, the left common carotid artery was exposed surgically, ligated, and cut. This standard protocol makes the hemisphere ipsilateral to the ligation susceptible to the following exposure to hypoxia, preserving the contralateral hemisphere as internal control ${ }^{20}$. One hour later, the pups were exposed to a hypoxic gas mixture (8\% oxygen and $92 \%$ nitrogen) for a period of 80 minutes in an incubator. A constant environmental temperature of $36^{\circ} \mathrm{C}$ was maintained strictly. The animal experimental protocol was approved by the regional review committee (Landesamt fur Natur, Umwelt und Verbraucherschutz NRW, Germany).

\section{Statistics}


All data are given as means \pm standard deviation. Statistical differences in macroscopic score, microscopic score, volume measurement, and immunohistochemistry were evaluated by 2-factor analysis of variance and post hoc Scheffe F test, and gender differences were calculated by unpaired $\mathrm{t}$ test. $\mathrm{P}<$ .05 was considered significant.

\section{Results}

All 48 animals survived the injections, ligation, and hypoxia. Mean body weight was $27.3 \pm 3.4 \mathrm{~g}$ on postnatal day 7 . There were no significant differences in body weight between both groups and sex. Treatment of the pups by the mother in both groups appeared equal between the groups. To study the effect of different dosages of $17 \beta$-estradiol, blood levels in 9 animals with different regimens were studied. At the time corresponding to carotid artery ligation in groups 2 and $3(-1$ hour), in the group having received $\mathrm{NaCl}$, the $17 \beta$-estradiol plasma concentration was $53.4 \pm 6.25 \mathrm{pg} / \mathrm{mL}$. After repeated injections of $0.01 \mathrm{mg} / \mathrm{g}$ body weight, $17 \beta-$ estradiol levels were $53.7 \pm 12.88 \mathrm{pg} / \mathrm{mL}$ ( 2 animals), after $0.05 \mathrm{mg} / \mathrm{g} 88.7 \pm$ $12.97 \mathrm{pg} / \mathrm{mL}$ ( 3 animals), and after $0.1 \mathrm{mg} / \mathrm{g}$ body weight $91.7 \pm 1.15 \mathrm{pg} / \mathrm{mL}$.

For groups 2 and 3, it was decided to use a dosage of $0.05 \mathrm{mg} / \mathrm{g}$ as it seemed to increase levels significantly above the untreated animal. The effect of controlled hypoxia after unilateral carotid artery ligation was studied macroscopically and microscopically in rat brains on day 14 that had been exposed to hypoxia on day 7.
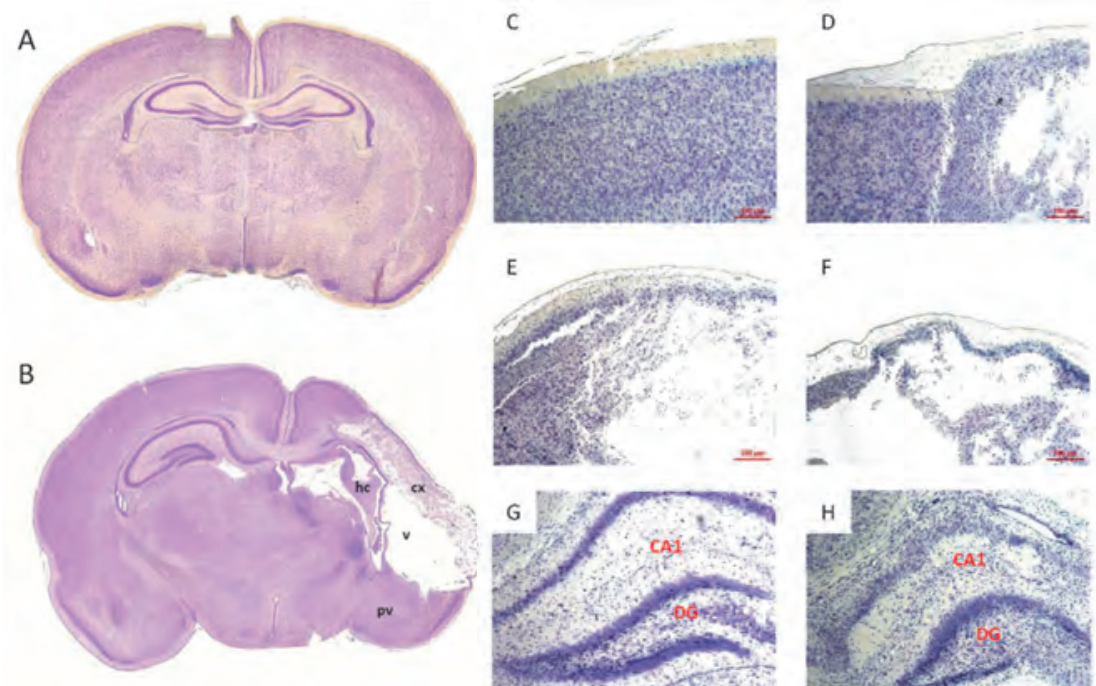

$\mathrm{F}$
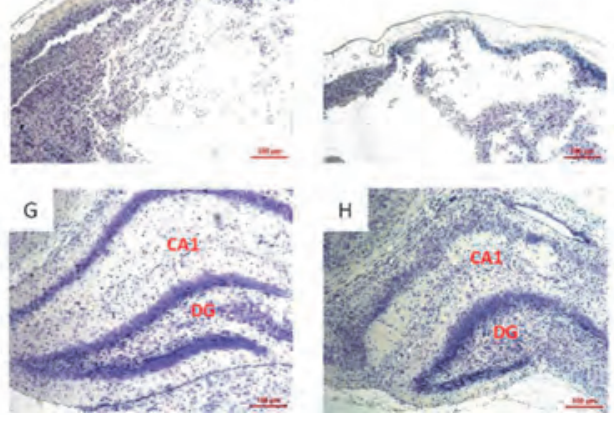

Figure 1. Macroscopically and microscopically evaluated hypoxic-ischemic brain injury in neonatal rats. Histology of the hypoxic-ischemic brain lesion showing (A) a macroscopic score 0 and (B) a macroscopic score 3 in the ipsilateral hemisphere affected by the hypoxicischemic damage. The lesion affects the hippocampus (hc), parietal and temporal cortex (cx), periventricular areas (pv), and results in an enlarged lateral ventricle (v). The induced damage was evaluated using a microscopic score of the cerebral cortex $(\mathrm{C}=$ score $1 ; \mathrm{D}=$ score 2 ; $\mathrm{E}=$ score $4 ; \mathrm{F}=$ score 5 ). The hippocampal subregions CA1/2, CA3, CA 4, and dentate gyrus (DG) were evaluated using identical technique $(\mathrm{G}=$ score $1 ; \mathrm{H}=$ score 3$)$. 


\section{Macroscopically Detectable Damage}

Figure 1 shows a normal and a score 3 rat brain. In the control group (group 2), all animals had a brain damage. Thirteen pups had a severe and 7 had a moderate damage, as described by the macroscopic scores. Brain injury was significantly less severe in group 3 treated by estradiol (Table 1). Twelve animals receiving intraperitoneal application of $17 \beta$-estradiol showed macroscopically no brain damage. Further 4 pups suffered only a discrete and 3 a moderate damage. The analysis of macroscopic scores by gender in each group revealed no statistical differences.

\begin{tabular}{ccccc}
\hline & 0 & 1 & 2 & 3 \\
\hline $\mathrm{NaCl}(n=21)$ & 0 & 1 & 7 & 13 \\
$\mathrm{~F}(\mathrm{n}=11)$ & 0 & 1 & 4 & 6 \\
$\mathrm{M}(\mathrm{n}=10)$ & 0 & 0 & 3 & 7 \\
$\mathrm{E}(\mathrm{n}=19)$ & 12 & 4 & 3 & $0^{b}$ \\
$\mathrm{~F}(\mathrm{n}=09)$ & 7 & 1 & 1 & $0^{\mathrm{c}}$ \\
$\mathrm{M}(\mathrm{n}=10)$ & 5 & 3 & 2 & $0^{b}$ \\
\hline
\end{tabular}

Table 1. Macroscopically Evaluated Hypoxic-Ischemic Brain Injury in Neonatal Rats Abbreviations: E2: estradiol; M: male; F: Female. The induced damage in the ipsilateral hemispheres was macroscopically assessed directly after brain removal using a 4-point scale. No statistically significant gender differences were detected in $\mathrm{NaCl}$ and $\mathrm{E} 2$ groups. ${ }^{\mathrm{b}} \mathrm{P}<.001$. c $\mathrm{P}<.01$.

\section{Microscopic Neuronal Damage}

Figure 1 shows microscopic scores in cortex cerebri and hippocampus. The microscopic evaluation of the cortex cerebri in group 2 showed a microscopic score $2.8 \pm 0.8$. As shown in Figure 2, animals treated with 17 $\beta$-estradiol (group 3) showed a significant lower microscore $1.5 \pm 0.7(\mathrm{P}<.001)$. This was detected

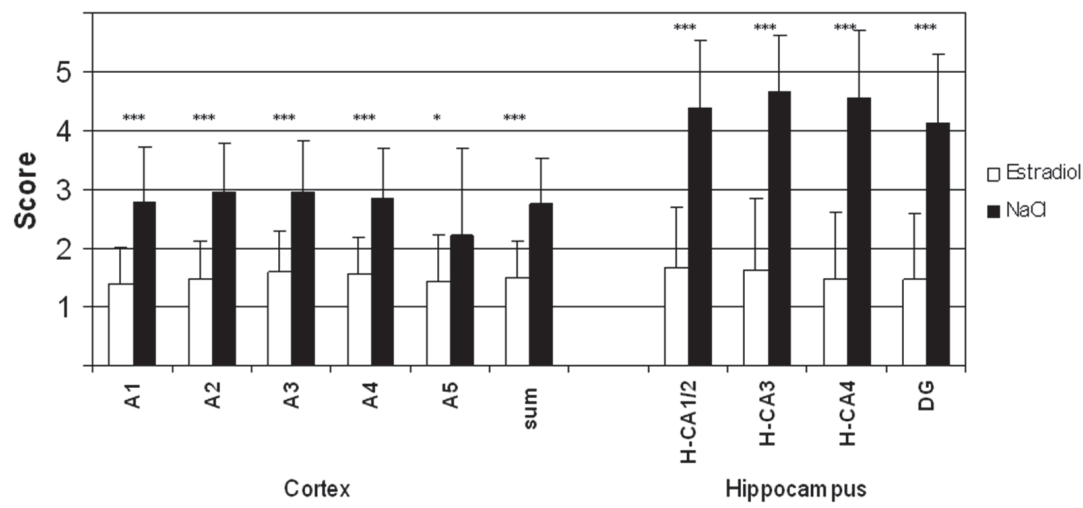

Figure 2. Microscopically evaluated hypoxic-ischemic brain injury in neonatal rat. The microscopic score was used in 5 levels of cortex cerebri (A1-A5) and in 4 hippocampal structures to evaluate the neuronal cell damage. Values are given as means \pm standard deviation and statistically significant differences between control and study group were assessed. $* * * \mathrm{P}<.001$ (17ß-estradiol vs $\mathrm{NaCl}$ ).

in all examined areas, however, the neuronal lesions were more pronounced in the 
area of the frontal cortex. This area is supplied by the arteria cerebri media. Furthermore, damage was also detected in the hippocampus and was observed not only in CA4 but also in CA3, CA $1 / 2$, and the dentate gyrus. Again, the significant lower microscore was detected in the $17 \beta$-estradiol-treated group. The analysis of microscopic scores in cortex cerebri by gender revealed several statistical differences. Female pups treated by $\mathrm{NaCl}$ (group 2) showed a significant lower microscopic score in cortex cerebri compared with male pups $(2.58 \pm 0.8$ vs $2.97 \pm 0.73 ; \mathrm{P}<.05)$. Furthermore, female animals of the control group had a significantly higher microscopic score compared with female animals of treatment group $(2.58 \pm 0.8$ vs $1.45 \pm 0.57 ; \mathrm{P}<.01)$. This difference was also detected in male pups $(2.97+0.73$ vs $1.56+0.74$; $\mathrm{P}<.001)$. The analysis of the cortex cerebri by gender in treatment group (group 3) revealed no statistical differences. Analysis of CA 1/2, CA3, CA4, and the dentate gyrus by gender in groups 2 and 3 showed no statistical differences.

\section{Brain Volume Studies}

In the control group, the determined volume of the afflicted ipsilateral hemispheres was 108+22 mL. In group 3, the measured volume of the ipsilateral hemisphere was $153 \pm 39 \mathrm{~mL}$ after injections of $17 \beta$-estradiol. The measured volume was significantly lower in group $3(\mathrm{P}<.001)$. Furthermore, the volumes of the contralateral intact hemispheres were not significantly different between both groups (159 \pm 15 in control group vs $174 \pm 33$ in treated group in microliters; $\mathrm{P}>$.05). The volume (\%) between both hemispheres [(cH - iH/cH)x 100], which was taken as a parameter for the induced hypoxic-ischemic damage, was significantly higher in group 2 than in group $3(32 \%+10 \%$ vs $12 \% \pm 13 \%$; $\mathrm{P}<$ .001; cH: contralateral hemisphere; iH: ipsilateral hemisphere; Table 2). The analysis of the volume (\%) between both hemispheres by gender in both groups showed no statistical differences.

\begin{tabular}{|c|c|c|c|}
\hline & Ipsilateral & Contralateral & $\begin{array}{c}\text { Relation lpsilateral/ } \\
\text { Contralateral in } \\
\text { Percentage }\end{array}$ \\
\hline $\begin{array}{l}\mathrm{NaCl}(n=21) \\
\mathrm{E} 2(\mathrm{n}=19)\end{array}$ & $\begin{array}{l}108 \pm 22 \\
153 \pm 39\end{array}$ & $\begin{array}{l}159 \pm 15 \\
174 \pm 33\end{array}$ & $\begin{array}{l}68 \pm 10 \\
88 \pm 13^{b}\end{array}$ \\
\hline \multicolumn{4}{|c|}{$\begin{array}{l}\text { Table 2. Volumes in Microliter of the Hemispheres in Neonatal Rats Subjected to a } \\
\text { Hypoxic-Ischemic Insult }{ }^{\mathrm{a}} \text {. } \\
\text { Abbreviation: E2, estradiol. }{ }^{\text {a }} \text { Volume measurements and the difference between the } \\
\text { volumes of both hemispheres in relation to the intact hemisphere of the neonatal } \\
\text { brain. }{ }^{b} \mathrm{P}<.001 \text { (17ß-estradiol vs NaCl). }\end{array}$} \\
\hline
\end{tabular}

\section{Immunohistochemic Studies}

In another 8 animals (4 each in groups 2 and 3), the brains were harvested at postnatal day 14 and studied successfully for the marker of apoptosis. The measured number of $\mathrm{CC}+$ cells in the $\mathrm{NaCl}$ group varied in both hemispheres (Figure 3). We detected significantly more caspase-3-positive cells in the ipsilateral damaged hemisphere (ipsilateral: $1435 \pm 653$ vs contralateral: $143 \pm 57$ cells; $\mathrm{P}<.01$; Figure 3 ). In contrast, in group 3 treated with $17 \beta$-estradiol, no significant differences between both hemispheres were detected (ipsilateral: $114 \pm$ 
70 vs contralateral: $96 \pm 52$ cells; $\mathrm{P}>.05)$. A significant difference between the ipsilateral hemispheres of groups 2 and 3 was also detected $(\mathrm{P}<.01)$. The analysis of contralateral intact hemispheres in both groups showed no statistical differences. Analysis by gender could not be performed due to an insufficient number of male animals (one in each group).
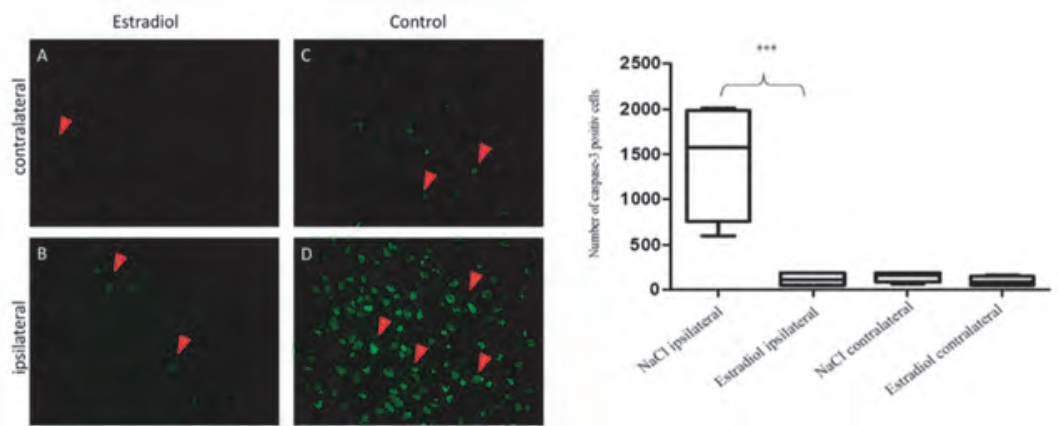

Figure 3. Immunohistochemial assessment of cleaved caspase-3 (Asp175) positive cells in hypoxic-ischemic brain injury in neonatal rats. Activated apoptotic neuronal cells (cleavedcaspase-3) in the cortex cerebri of the neonatal brain (green). Immunohistochemistry is presented for the estradiol group (A and B) and for the control group ( $C$ and $D$ ) in the contralateral and ipsilateral affected hemispheres. The measured number of cleaved-caspase-3 positive cells in both hemispheres of the estradiol group was identical. By contrast, the animals of the $\mathrm{NaCl}$ group had significantly more positive cells in the affected ipsilateral hemisphere. ${ }^{* * *} \mathrm{P}<.001$ (17 $\beta$-estradiol vs $\mathrm{NaCl}$ ).

\section{Discussion}

Our study indicates a neuroprotective effect of $17 \beta$-estradiol in a neonatal rat brain model of hypoxic-ischemic injury. Macroscopic, histological, and immunohistochemical results show clear morphologic changes indicative for neuroprotection. Perinatal hypoxia-ischemia contributes majorly to developmental disabilities in children and its incidence increased in previous years due to a higher number of prematurely born infants ${ }^{27}$. Although many potential neuroprotective measures have been identified, their clinical use is still limited, mainly due to possible adverse effects.

Several epidemiological studies indicate that estrogen therapy in proper condition may lead to health benefits such as reduction of the risk of cardiovascular diseases, neurodegenerative diseases, or cataract and also possibly increase cognitive performance in adults ${ }^{28}$. Still there is much controversy regarding the differing doses, time, treatment schedules, or the effect of estrogen and further investigation is necessary ${ }^{29}$. It also needs to be considered that results obtained from studies with adults are hardly comparable with data from studies in newborns because of different physiology. Further variability in brain function such as neuronal survival, axonal projections, dendritic branching, and synaptic patterning can be dramatically influenced by our neuroprotective effort.

To manage hypoxic-ischemic injury in preterm infants, it is required to early identify the infant at high risk. In case of acute brain injury, cellular energy failure, acidosis, glutamate release, lipid peroxidation, intracellular calcium 
accumulation, and nitric oxide toxicity lead to cell death ${ }^{30}$. It may involve mitochondrial dysfunction and be influenced by inflammatory mediators ${ }^{31}$.

During the third trimester of pregnancy, the human fetus is exposed to high levels of estrogen. Thus, in premature delivery, newborns had a deprivation of estrogen and progesterone. Similarly in rats, the hormones are decreasing slowly at the end of the first postnatal week. Several authors indicate equivalent developmental stage of 6 to 14-day-old rats brain to the human newborn at term with major growth spurt occurring postnatally in the rodent brain ${ }^{20,32}$. Investigating neuroprotective effect of estrogen and hypoxic-ischemic injury with pups at day 7 , we established a model without physiologically decreased levels of $17 \beta-$ estradiol at the time of the planned injury. In our study, repeated administrations of $17 \beta$-estradiol prior to the insult could maintain high levels of this hormone at the time of hypoxic-ischemic injury. The fourth application of $17 \beta$-estradiol mimics postnatal treatment. Human serum levels of $17 \beta$-estradiol in infants strongly depend on the gestational week of delivery. Application of $17 \beta$-estradiol and maintenance of high physiological or therapeutic serum levels could be achieved by dose-tailored estradiol administrations based on cord blood or serum levels measurements.

Recently, Nunez et al observed that repeated administration of $17 \beta$-estradiol exerts a neuroprotective effect in a neonatal rat brain after a hypoxic-ischemic injury ${ }^{23}$. In contrast, single administration of $17 \beta$-estradiol 24 hours prior to hypoxia-ischemia conferred little protection. He hypothesized that the relatively short pretreatment activates rather the rapid, nongenomic actions of $17 \beta$-estradiol and multiple injections initiate long-term, genomic mode of protection. In his study, all administrations were done prior to the insult, which makes it rather impossible to translate it to clinical use because the identification of fetuses at risk at term prior to birth is hardly possible and elevated levels of $17 \beta$-estradiol are physiologically present. In our experiment, we not only used repeated administration of $17 \beta$-estradiol prior to the induced damage but also a fourth administration after the damage was afflicted. Consensual to his results, we observed a significant reduction of the induced lesion (Table 1). It also needs to be considered that the dose of $17 \beta$-estradiol used in our experiment was 10 -fold lower than the single or repeated administrated doses in Nunez's study and still we observed a significant neuroprotective activity.

Another recent study investigated the role of $17 \beta$-estradiol on white matter injury in rats on postnatal day $6{ }^{24}$. In vivo, they observed that a single dose of 0.3 or 0.6 $\mathrm{mg} / \mathrm{g}$ body weight of $17 \beta$-estradiol applied 12 hours prior to the injury protects against hypoxic-ischemic white matter damage in the neonatal rat brain. Furthermore, $17 \beta$-estradiol produced significant protection against oxygenglucose deprivation-induced cell death in primary oligodendrocytes. Again the dose paradigm and dosage are the main difference to our study. Both of the single administered doses in Gerstner's study were higher than in our regime. All injections were applied prior to the injury, and second, in contrast to our work, the experiment was designed to investigate a relatively selective white matter injury with minimal neuronal damage in male pups only (day 6). In our experiment, both sexes were investigated and several differences detected. Animal and human studies had been published concerning sex differences in neonates after brain injury ${ }^{33}$. Equivalent brain damage produces a far greater damage in male compared with female animals and also a poorer functional recovery. In our study, 
microscopically evaluated damage in cortex cerebri ( $\mathrm{NaCl}$ group) was significantly greater in male than in female pups. No statistical differences were detected in the therapy group. Interestingly, the evaluation of hippocampus showed no statistical differences between both sexes indicating a higher sensitivity to hypoxic-ischemic brain damage of hippocampus than cortex cerebri. Furthermore, both male and female neonates were sensitive to $17 \beta$-estradiol therapy.

So there is still much controversy regarding the differing doses, time, treatment schedules, or the effect of estrogen in a neonatal brain after a hypoxic-ischemic injury. It seems that a certain balanced level of $17 \beta$-estradiol is needed to exert the neuroprotective effect and it may be attained by long-term administrations. 17 $\beta$ estradiol application starting during the first 24 hours of neonatal period could prevent the physiological decrease of the hormone. Information concerning a possible "window of opportunity" or a secondary increase of estradiol serum levels during the postnatal period is still missing and should be addressed in future studies.

Apoptosis is an important factor influencing estrogen-mediated neuroprotection. The balance between pro-apoptotic and anti-apoptotic factors is very delicate. BAD (BCL2 antagonist of cell death) or BAX (BCL2-associated X protein) is the inducer of apoptosis. In contrast, BCL2 and BCLXL are inhibitors of apoptosis. The neuronal vulnerability is determined by the fragile balance between those factors and influencing apoptosis ${ }^{34}$. Gene promoters of BCL2 and BCLXL contain estrogen response elements and their transcription is induced by estrogen in vitro. Further in vivo experiments confirmed that estradiol exerts neuroprotection after focal cerebral ischemia and there was an increased level of BCL2 in the peri-infarct region ${ }^{35}$. Apoptotic cascade reaction is regulated by caspase inhibitors and can be influenced by estradiol ${ }^{36}$. Caspase- 3 is a critical executioner of apoptosis. It is either partially or totally responsible for the proteolytic cleavage of many key proteins. Caspase activation is by far the most specific indicator of cell suicide mechanism and a prolonged role of apoptosis in hypoxic-ischemic brain damage has been reported ${ }^{37,38}$. In our experiments, we determined the number of CC+ (executioner) cells in different parts of the cortex (Figure 3). Animals of the control group had significantly more CC+ cells in the affected ipsilateral hemisphere compared with the contralateral side. In group 3 , there were no significant differences between both hemispheres (Figure 3). It still needs to be considered than we did not differentiate if these cells were neuronal or glial cells and the chosen planes represent a part of the brain. On the other hand, the planes were selected according to the expected insult site and neuroprotective effect of $17 \beta$-estradiol should similarly affect both types of cells. The measured hemisphere volumes and the volume difference between both hemispheres additionally indicate a protective effect of $17 \beta$-estradiol (Table 2). In group 2, there was a $32 \%$ volume reduction of the affected hemisphere after the induced damage. In contrast, the application of $17 \beta$-estradiol resulted in a reduction of only $12 \%$. A negative aspect of the measurement is that we measured the volume of the entire hemispheres not differentiating the hippocampus. The volume reduction of the hippocampus would also be of interest but the induced cystical lesions made it impossible to calculate a representative area.

Other studies have assessed potential neuroprotective means in animal models. These studies used different agents like magnesium sulfate, allopurinol, 
deferoxamine, calcium blockers, minocycline, or erythropoietin and showed a neuroprotective effect ${ }^{30}$. Additionally, possible interactions have to be considered. During perinatal period, high levels of $\alpha$-fetoprotein are present and may influence the neuroprotective effect of $17 \beta$-estradiol ${ }^{39,40}$.

Currently, therapeutic hypothermia is a standard of care for neonatal hypoxiaischemia (HI) brain injury. Survival and neurodevelopment in newborns withmoderate and severe HI encephalopathy is improved but newborns which are profoundly asphyxiated will not likely profit from hypothermic therapy. In addition, current evidence is limited to a 18-month follow-up and a long-term prediction is difficult ${ }^{18}$. Another recent systematic review confirmed the potential use of magnesium sulfate given to women at risk of preterm birth. The neurologic outcomes of preterm neonates exposed to antenatal magnesium sulfate were evaluated. The neonatal risk of cerebral palsy and the rate of substantial gross motor dysfunction were significantly reduced, but long-term evaluation is still lacking ${ }^{41}$. Another approach is neural regeneration. Mesenchymal stem cells have a neurogenic potential that might serve as a source for autologous stemcell graft 42,43 . Placenta-derived mesenchymal cells are potentially very promising stemcells and further animal and clinical studies are necessary to assess their potential as an autologous stem cell graft for functional neural regeneration ${ }^{44}$. Few studies investigated the supplementation of steroids in prematurely born infants. In a neurodevelopmental follow-up, Trotter et al showed normal psychomotor development in infants born less than 30 weeks of gestation and given estradiol and progesterone after a premature delivery compared with untreated infants, where a trend toward delayed development was detected ${ }^{45}$. A recent Cochrane review showed that further investigation is needed to determine whether the supplementation of estradiol or progesterone alone or in combination or in different doses represents a risk or benefit to a preterm infant ${ }^{46}$. Another important aspect is that data addressing supplementation of sex steroids in term infants are lacking. Again properly conducted randomized controlled trials are needed. Trials could include premature or term infants receiving individualized estradiol and/or progesterone supplementation and neurodevelopmental follow-up should be included.

\section{Limitations of This Study}

A limitation of the study is the use of the animal model itself. Conclusions from animal studies cannot be transferred to human neonates without intensive investigation. Generally, no single animal model can replicate the complex condition of a human brain. However, the immature rat model has gained wide acceptance in studying basic physiology, brain injury mechanisms, and therapeutic interventions after perinatal brain damage. Furthermore, therapeutic intervention in this animal setting is providing valuable information regarding the neuroprotective effect of agents like 17 $\beta$-estradiol. Extensive investigation in animal models is inevitable before clinical trials in human neonates can be initiated. Another weakness of our study is the lack of assessment of functional neurologic outcome and lack of a sham group. Nevertheless, our morphological findings are in line with other studies, showing a correlation between the outcome parameters used in our study and functional outcome. In conclusion, the results of our study show that $17 \beta$-estradiol protects the immature rat brain from hypoxicischemic damage and reduces the number of $\mathrm{CC}+$ cells significantly. Further 


\section{Chapter 4}

studies are needed to show the long term neurodevelopmental effect, before clinical studies can be initiated.

\section{Declaration of Conflicting Interests}

The author(s) declared no potential conflicts of interest with respect to the research, authorship, and/or publication of this article.

\section{Funding}

The author(s) disclosed receipt of the following financial support for the research, authorship, and/or publication of this article: DFG Be 1688 and approved by LANUV (Das Landesamt für Natur, Umwelt und Verbraucherschutz NordrheinWestfalen) Recklinghausen, Germany, Az. 50.8720 Nr. S/7 27.10.2000. 


\section{References}

1. Volpe JJ. Brain injury in premature infants: a complex amalgam of destructive and developmental disturbances. Lancet Neurol. 2009;8(1):110-124.

2. Heron M, Sutton PD, Xu J, Ventura SJ, Strobino DM, Guyer B. Annual summary of vital statistics: 2007. Pediatrics. 2010;125(1):4-15.

3. Brazel CY, Rosti RT 3rd, Boyce S, Rothstein RP, Levison SW. Perinatal hypoxia/ischemia damages and depletes progenitors from the mouse subventricular zone. Dev Neurosci. 2004;26(24):266-274.

4. Basu A, Krady JK, O’Malley M, Styren SD, DeKosky ST, Levison SW. The type 1 interleukin1 receptor is essential for the efficient activation of microglia and the induction of multiple proinflammatory mediators in response to brain injury. $J$ Neurosci. 2002;22(14):6071-6082.

5. Tulchinsky D, Hobel CJ, Yeager E, Marshall JR. Plama estradiol, estriol, and progesterone in human pregnancy. II. Clinical applications in Rh-isoimmunization disease. Am J Obstet Gynecol. 1972;113(6):766-770.

6. Wood CE. Estrogen/hypothalamus-pituitary-adrenal axis interactions in the fetus: the interplay between placenta and fetal brain. J Soc Gynecol Investig. 2005;12(2):67-76.

7. Thomas L. Labor und Diagnose. Frankfurt, Germany: TH Books Verlagsgesellschaft, 1998.

8. Amateau SK, Alt JJ, Stamps CL, McCarthy MM. Brain estradiol content in newborn rats: sex differences, regional heterogeneity, and possible de novo synthesis by the female telencephalon. Endocrinology. 2004;145(6):2906-2917.

9. Manthey D, Behl C. From structural biochemistry to expression profiling: neuroprotective activities of estrogen. Neuroscience. 2006;138(3):845-850.

10. Behl C. Oestrogen as a neuroprotective hormone. Nat Rev Neurosci. 2002;3(6):433-442.

11. Henderson VW. Action of estrogens in the aging brain: dementia and cognitive aging. Biochim Biophys Acta. 2010;1800(10):1077-1083.

12. Brown CM, Suzuki S, Jelks KA, Wise PM. Estradiol is a potent protective, restorative, and trophic factor after brain injury. Semin Reprod Med. 2009;27(3):240-249.

13. Bryant DN, Sheldahl LC, Marriott LK, Shapiro RA, Dorsa DM. Multiple pathways transmit neuroprotective effects of gonadal steroids. Endocrine. 2006;29(2):199-207.

14. Wise PM, Dubal DB, Wilson ME, Rau SW, Bottner M, Rosewell KL. Estradiol is a protective factor in the adult and aging brain: understanding of mechanisms derived from in vivo and in vitro studies. Brain Res Brain Res Rev. 2001;37(1-3):313-319.

15. Berger R, Garnier Y. Pathophysiology of perinatal brain damage. Brain Res Brain Res Rev. 1999;30(2):107-134.

16. Shankaran S, Laptook AR, Ehrenkranz RA, et al. Whole-body hypothermia for neonates with hypoxic-ischemic encephalopathy. N Engl J Med. 2005;353(15):1574-1584.

17. Edwards AD, Brocklehurst P, Gunn AJ, et al. Neurological outcomes at 18 months of age after moderate hypothermia for perinatal hypoxic ischaemic encephalopathy: synthesis and metaanalysis of trial data. BMJ. 2010;340:c363.

18. Tagin MA, Woolcott CG, Vincer MJ, Whyte RK, Stinson DA. Hypothermia for Neonatal Ischemic Encephalopathy: An Updated Systemic Review and Meta-analysis [published online February 6, 2012]. Arch Pediatr Adolesc Med.

19. Chan WY, Lorke DE, Tiu SC, Yew DT. Proliferation and apoptosis in the developing human neocortex. Anat Rec. 2002;267(4):261-276.

20. Yager JY, Ashwal S. Animal models of perinatal hypoxic-ischemic brain damage. Pediatr Neurol. 2009;40(3):156-167. 


\section{Chapter 4}

21. Rice JE, 3rd Vannucci RC, Brierley JB. The influence of immaturity on hypoxic-ischemic brain damage in the rat. Ann Neurol. 1981;9(2):131-141.

22. Vannucci RC, Vannucci SJ. Perinatal hypoxic-ischemic brain damage: evolution of an animal model. Dev Neurosci. 2005;27(2-4):81-86.

23. Nunez J, Yang Z, Jiang Y, Grandys T, Mark I, Levison SW. 17beta-estradiol protects the neonatal brain from hypoxia-ischemia. Exp Neurol. 2007;208(2):269-276.

24. Gerstner B, Lee J, DeSilva TM, Jensen FE, Volpe JJ, Rosenberg PA. 17beta-estradiol protects against hypoxic/ischemic white matter damage in the neonatal rat brain. $J$ Neurosci Res. 2009;87(9):2078-2086.

25. Brown AW, Brierley JB. Anoxic-ischaemic cell change in rat brain light microscopic and finestructural observations. J Neurol Sci. 1972;16(1):59-84.

26. Paxinos G, Watson C. The rat brain in stereotaxic coordinates. Sydney, Australia: Academic Press, 1986.

27. Jensen FE. Developmental factors regulating susceptibility to perinatal brain injury and seizures. Curr Opin Pediatr. 2006;18(6):628-633.

28. Grady D, Rubin SM, Petitti DB, et al. Hormone therapy to prevent disease and prolong life in postmenopausal women. Ann Intern Med. 1992;117(12):1016-1037.

29. Chen S, Nilsen J, Brinton RD. Dose and temporal pattern of estrogen exposure determines neuroprotective outcome in hippocampal neurons: therapeutic implications. Endocrinology. 2006;147(11):5303-5313.

30. Perlman JM. Intervention strategies for neonatal hypoxic-ischemic cerebral injury. Clin Ther. 2006;28(9):1353-1365.

31. Coumans AB, Middelanis JS, Garnier Y, et al. Intracisternal application of endotoxin enhances the susceptibility to subsequent hypoxic-ischemic brain damage in neonatal rats. Pediatr Res. 2003;53(5):770-775.

32. Dobbing J, Sands J. Comparative aspects of the brain growth spurt. Early Hum Dev. 1979;3(1):79-83.

33. Lauterbach MD, Raz S, Sander CJ. Neonatal hypoxic risk in preterm birth infants: the influence of sex and severity of respiratory distress on cognitive recovery. Neuropsychology. 2001;15(3):411-420.

34. Antonsson B. Bax and other pro-apoptotic Bcl-2 family "killerproteins" and their victim the mitochondrion. Cell Tissue Res. 2001;306(3):347-361.

35. Alkayed NJ, Goto S, Sugo N, et al. Estrogen and Bcl-2: gene induction and effect of transgene in experimental stroke. $J$ Neurosci. 2001;21(19):7543-7550.

36. Zhang Y, Tounekti O, Akerman B, Goodyer CG, LeBlanc A. 17-beta-estradiol induces an inhibitor of active caspases. J Neurosci. 2001;21(20):RC176.

37. Gown AM, Willingham MC. Improved detection of apoptotic cells in archival paraffin sections: immunohistochemistry using antibodies to cleaved caspase 3. J Histochem Cytochem. 2002;50(4):449-454.

38. Nakajima W, Ishida A, Lange MS. Et al. Apoptosis has a prolonged role in the neurodegeneration after hypoxic ischemia in the newborn rat. J Neurosci. 2000;20(21):7994-8004.

39. Aussel C, Laliberte F, Masseyeff R. Alpha-fetoprotein favours accumulation of estrone but not arachidonic acid into the fetal and new-born rat brain. Life Sci. 1985;36(5):479-484.

40. Nunez EA, Benassayag C, Vallette G, et al. The role of nonesterified fatty acids and of alpha 1-fetoprotein in estrogen-dependent endocrine systems. Ann N Y Acad Sci. 1983;417:137-148. 
41. Doyle LW, Crowther CA,Middleton P, Marret S, Rouse D. Magnesium sulphate for women at risk of preterm birth for neuroprotection of the fetus. Cochrane Database Syst Rev. 2009;(1):CD004661.

42. Portmann-Lanz CB, Schoeberlein A, Huber A, et al. Placental mesenchymal stem cells as potential autologous graft for pre- and perinatal neuroregeneration. Am J Obstet Gynecol. 2006;194(3):664-673.

43. Portmann-Lanz CB, Schoeberlein A, Portmann R, et al. Turning placenta into brain: placental mesenchymal stem cells differentiate into neurons and oligodendrocytes. Am J Obstet Gynecol. 2010;202(3):294. e1-294. e11.

44. Schoeberlein A, Mueller M, Reinhart U, Sager R, Messerli M, Surbek DV. Homing of placenta-derived mesenchymal stem cells after perinatal intracerebral transplantation in a rat model. Am J Obstet Gynecol. 2011;205(3):277. e1-6.

45. Trotter A, Maier L, Pohlandt F. Management of the extremely preterm infant: is the replacement of estradiol and progesterone beneficial? Paediatr Drugs. 2001;3(9):629-637.

46. Hunt R, Davis PG, Inder T. Replacement of estrogens and progestins to prevent morbidity and mortality in preterm infants. Cochrane Database Syst Rev. 2004;(4):CD003848. 



\section{Chapter 5}

\section{PreImplantation factor (PIF) promotes neuroprotection by targeting microRNA let-7}

Published as: Mueller M, Zhou J, Yang L, Gao Y, Wu F, , Schoeberlein A, Surbek D, Barnea E, Paidas M, Huang Y. PreImplantation factor promotes neuroprotection by targeting microRNA let-7. Proc Natl Acad Sci U S A. 2014 Sep 23;111(38):13882-7. PubMed PMID: 25205808; PubMed Central PMCID: PMC4183321. 


\begin{abstract}
Dysfunction and loss of neurons are the major characteristics of CNS disorders that include stroke, multiple sclerosis, and Alzheimer's disease. Activation of the Toll-like receptor 7 by extra-cellular micro-RNA let-7, a highly expressed microRNA in the CNS, induces neuronal cell death. Let-7 released from injured neurons and immune cells acts on neighboring cells, exacerbating CNS damage. Here we show that a synthetic peptide analogous to the mammalian PreImplantation factor (PIF) secreted by developing embryos and which is present in the maternal circulation during pregnancy inhibits the biogenesis of let-7 in both neuronal and immune cells of the mouse. The synthetic peptide, sPIF, destabilizes KH-type splicing regulatory protein (KSRP), a key microRNAprocessing protein, in a Toll-like receptor 4 (TLR4)-dependent manner, leading to decreased production of let-7. Furthermore, s.c. administration of sPIF into neonatal rats following hypoxic-ischemic brain injury robustly rescued cortical volume and number of neurons and decreased the detrimental glial response, as is consistent with diminished levels of KSRP and let-7 in sPIF-treated brains. Our results reveal a previously unexpected mechanism of action of PIF and underscore the potential clinical utility of sPIF in treating hypoxic-ischemic brain damage. The newly identified PIF/TLR4/KSRP/ let-7 regulatory axis also may operate during embryo implantation and development.
\end{abstract}




\section{Introduction}

PreImplantation factor (PIF) is a conserved, embryo-derived peptide that can be detected in human, mouse, and bovine maternal circulation during pregnancy ${ }^{1,2}$. The presence of PIF in the maternal circulation has been correlated with live births in murine and bovine models ${ }^{2-4}$. Despite the longstanding understanding that PIF is involved in promoting maternal immune tolerance and embryo implantation ${ }^{2,5-8}$, the mechanism by which PIF does so has remained poorly understood. Recently, a synthetic PIF analog (sPIF) of 15 amino acids (MVRIKPGSANKPSDD) was reported to elicit neuroprotective effects in a murine model of experimental autoimmune encephalomyelitis ${ }^{9}$. When administrated s.c., sPIF inhibited neuroinflammation, promoted neural repair, and prevented paralysis ${ }^{9}$. Analysis of cytokines combined with genomic and proteomic approaches revealed global alterations in gene expression, suggesting that sPIF induced coordinated central and systemic multi targeted effects ${ }^{9}$. However, the molecular signal transduction pathways underpinning the observed effects were not defined.

Premature birth is a major cause of neonatal morbidity and mortality ${ }^{10}$. Depending on the degree of prematurity $15-20 \%$ of affected newborns die during the postnatal period, and $\sim 25 \%$ of survivors suffer significant long-term disability including cerebral palsy, epilepsy, increased hyperactivity, and developmental disorders ${ }^{11}$. Therapeutic approaches to counteract the cascades of neonatal brain injury have been proposed. Unfortunately, thus far no individual neuroprotective agent has been proven safe and effective in immature infants ${ }^{12}$.

The developmentally regulated, imprinted H19 is among the most highly expressed genes in developing embryos ${ }^{13}$. The $\mathrm{H} 19$ gene encodes a 2.6-kb noncoding RNA H19 known to reduce the bioavailability of let-7 by acting as a microRNA sponge ${ }^{14}$. Let-7 regulates target gene expression by binding to imperfectly complementary sequences in the mRNA, inducing translational repression and mRNA destabilization ${ }^{15}$. The biogenesis of let-7 involves multiple steps. It is first synthesized as long primary transcripts (pri-let-7), which are cleaved in the nucleus by the Drosha complex, yielding a hairpin precursor (prelet-7) of $\sim 70$ nt. Prelet-7 then is exported to the cytoplasm where it is further processed into mature let-7 of 22 nt by the Dicer complex ${ }^{16}$. Regulation of microRNA processing has emerged as a major step in controlling mature microRNA levels ${ }^{17}$. The RNA-binding proteins LIN28 and hnRNP A1 act to inhibit let-7 processing ${ }^{18-20}$, whereas KH-type splicing regulatory protein (KSRP) promotes it ${ }^{21}$.

Because developing embryos secrete PIF ${ }^{3}$, and H19 is highly expressed in the embryo ${ }^{13}$, we hypothesized that PIF might regulate H19 or let-7 expression. In the current study, we show that sPIF inhibits the biogenesis of let-7 by destabilizing the microRNA-processing protein KSRP in cultured neuronal and immune cells and that this regulation depends on the expression of Toll-like receptor 4 (TLR4). We provide evidence that this novel PIF/TLR4/KSRP/let-7 regulatory pathway, combined with its induced up-regulation of the antiinflammatory cytokine IL-10, may contribute to sPIF's neuroprotective effects in vivo. We propose that this regulatory mechanism also may underlie the action of PIF in maternal immune modulation and embryo implantation and development. 


\section{Results}

sPIF Decreases Let-7 Levels in Both Neuronal and Macrophage Cells. Given the high expression level of H19 in developing embryos ${ }^{13}$, which also secrete PIF ${ }^{3}$, we set out to examine whether PIF might regulate H19 gene expression. Thus we performed experiments using murine N2a neuroblastoma cells and RAW 264.7 macrophage cells, because sPIF targets both neuronal and immune cells ${ }^{2,9}$. Although we detected only negligible levels of H19 expression, we unexpectedly noticed increased expression of Hmga2 and Dicer in cells treated with sPIF as compared with cells treated with a control scrambled peptide (PIFscr) (Fig. S1 A and B). Hmga2 and Dicer are validated targets of let-7 ${ }^{22,}{ }^{23}$. Let-7 binds to imperfectly complementary sequences in the respective mRNAs, leading to translational repression and mRNA destabilization ${ }^{22-24}$. Thus, SPIF might have a direct effect on let-7 levels. Indeed, let-7 was down-regulated in cells treated with sPIF in comparison with cells treated with PBS or PIFscr at the same concentration (Fig. S1C). Further scrutiny revealed that sPIF in both cell types down-regulated the expression of several let-7 family members in an apparently dose- and time dependent manner (Fig. 1 A-D). sPIF-induced let-7 suppression also was observed in BV-2 cells, a murine microglia cell line derived from resident macrophages of the CNS (Fig. S2A) ${ }^{25}$. These results support the notion that sPIF negatively impacts let-7 levels in both neuronal and macrophage cells.

TLR4 Expression Is Necessary for sPIF-Induced Let-7 Repression. Let-7 is down-regulated in macrophages and epithelial cells as a host defense mechanism against bacterial pathogens ${ }^{24}$. This microRNA alteration occurs by TLR4's sensing bacterial LPS ${ }^{24}$. We hypothesized that TLR4's sensing sPIF also might mediate let-7 repression. Thus, TLR4 was down-regulated using an siRNA (siTLR4) previously reported to silence TLR4 specifically and efficiently in murine cells ${ }^{26}$. Although siTLR4 led to significant suppression of TLR4 in both N2a (Fig. 1E) and RAW (Fig. 1F) cells, sPIF-induced let-7 repression was concomitantly abolished (Fig. $1 \mathrm{G}$ and $\mathrm{H}$, compare the two columns on the left with the two columns on the right). Similar results were observed in BV-2 cells (Fig. S2 B and C). These results suggested that TLR4 expression is required for sPIF-mediated let-7 repression.

KSRP Is Down-Regulated by SPIF in a TLR4-Dependent Manner. As an integrated component of both Drosha and Dicer complexes, KSRP acts to regulate the biogenesis of a cohort of microRNAs including let-7 ${ }^{21,27}$. KSRP binds with high affinity to the terminal loop of microRNA precursors and promotes their processing. Indeed, siRNA-mediated knockdown of KSRP in cultured human and mouse cells inhibits microRNA processing, leading to decreased let-7 levels ${ }^{21}$. Because the activation of TLR4 by LPS in human epithelial cells led to decreased KSRP levels ${ }^{28}$, we wished to test whether KSRP is involved in SPIF induced let-7 repression and whether this regulation is dependent on TLR4 expression. Thus, we analyzed the effects of sPIF in combination with TLR4 knockdown on KSRP expression. Although sPIF did not affect KSRP at the mRNA level, with or without TLR4 knockdown (Fig. 1 I and J), it caused a reduction of at least $50 \%$ in the KSRP protein level as compared with PIFscr-treated cells (Fig. $1 \mathrm{~K}$ and L, compare lanes 2 with lanes 1 ). This inhibition was abrogated in the siTLR4transfected cells (Fig. $1 \mathrm{~K}$ and L, compare lanes 4 with lanes 3). Similar 
observations were obtained with BV-2 cells (Fig. S2D). These results suggested that in both neuronal and immune cells KSRP was down-regulated by sPIF in a TLR4-dependent manner, and this down-regulation appeared to be at the posttranslational level.
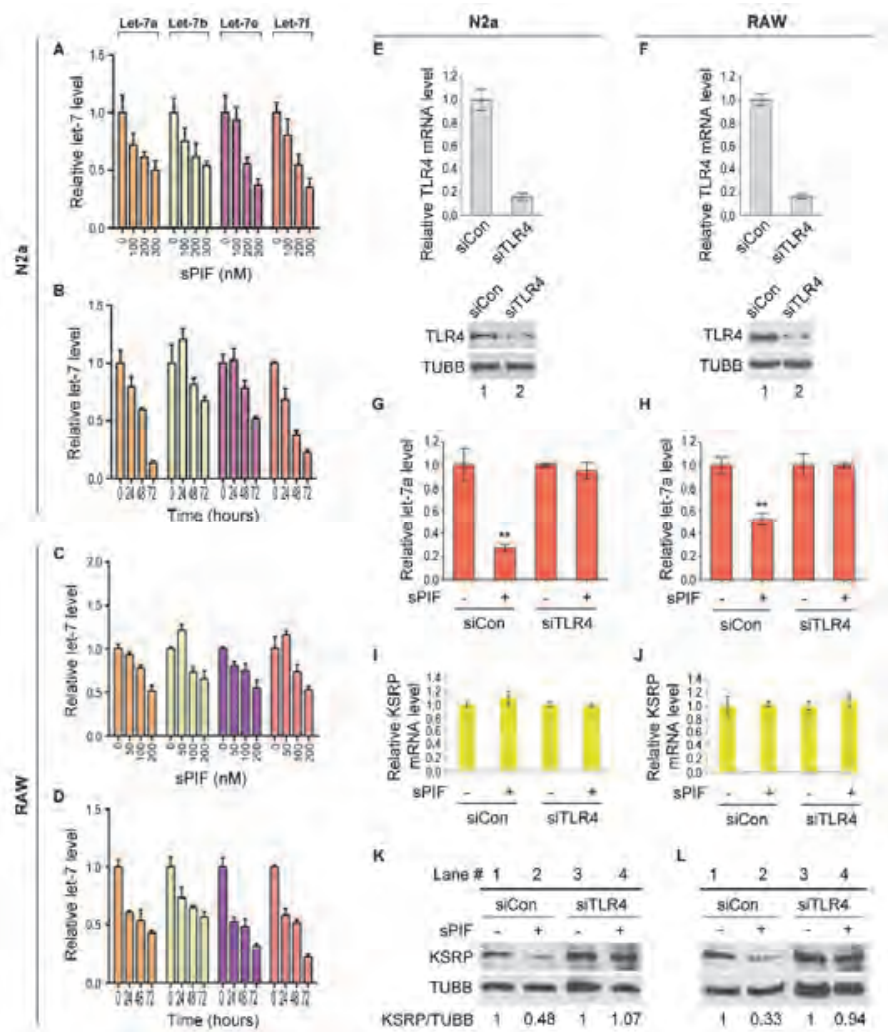

K

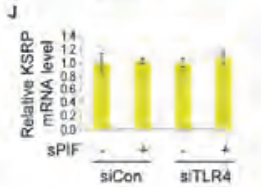
L

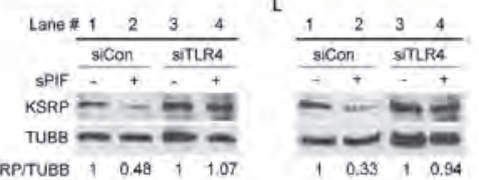

Figure 1. sPIF down-regulates let-7 in neuronal (N2a) and macrophage (RAW) cells in a TLR4-dependent manner. (A and C) Cells were incubated with sPIF or PIFscr at the indicated concentrations. RNAs were extracted $48 \mathrm{~h}$ later, and levels were determined by qRT-PCR. Let7 levels from sPIF-treated cells are presented after normalization against those from PIFscrtreated cells, which were arbitrarily set as 1. (B and D) N2a and RAW cells were incubated with sPIF or PIFscr (at $300 \mathrm{nM}$ for N2a cells and $200 \mathrm{nM}$ for RAW cells). RNAs were harvested at the indicated time points, and levels were determined. ( $E$ and F) Cells were transfected with control siRNA (siCon) or siRNA specific for TLR4 (siTLR4). RNAs and proteins were harvested $48 \mathrm{~h}$ posttransfection and were analyzed by qRT-PCR (Upper) and Western blot (Lower). (G-J) Cells were transfected with siCon or siTLR4. sPIF (+) or PIFscr ( -) was added to the cells (300 nM for N2a cells, $200 \mathrm{nM}$ for RAW cells) $48 \mathrm{~h}$ posttransfection, and cells were incubated for an additional $48 \mathrm{~h}$. RNAs were extracted, and levels were determined by qRT-PCR. Results are presented with let-7a (or KSRP mRNA) levels in PIFscrtreated cells arbitrarily set as 1 . ( $\mathrm{K}$ and L) Cells were treated as described in G-J. Proteins were harvested after 48-h incubation with PIFscr $(-)$ or sPIF (+). KSRP protein levels were determined by Western blot analysis using $\beta$-tubulin (TUBB) as a loading control. Except in K and $\mathrm{L}$, all numbers are mean $\pm \mathrm{SD}(\mathrm{n}=3)$, and are representative of three independent transfection results. $* * \mathrm{P}<0.01$. In $\mathrm{K}$ and $\mathrm{L}$, the numbers were derived from quantitation of protein bands on the presented gels representative of two independent transfection results. The levels of the KSRP protein (after normalization against $\beta$-tubulin) in the PIFscr-treated cells were arbitrarily set as 1 . 
SPIF Induces Destabilization of KSRP Protein. To test the possibility that accelerated protein decay might contribute to the observed decrease in KSRP, we carried out Western blot analyses in the presence of cycloheximide (CHX), an inhibitor of de novo protein synthesis. In both RAW and N2a cells, KSRP showed a faster decay in SPIF- than in PIFscr-treated cells (Fig. $2 \mathrm{~A}$ and F, compare lanes 1-5 with lanes 6-10). Based on a rough estimation, the KSRP protein half-life was $\sim 45$ min in PIFscr-treated RAW cells and $180 \mathrm{~min}$ in sPIF-treated RAW cells. For N2a cells, these half-lives were $\sim 60 \mathrm{~min}$ and $180 \mathrm{~min}$, respectively. Together, these results are consistent with sPIF-induced destabilization of KSRP protein.

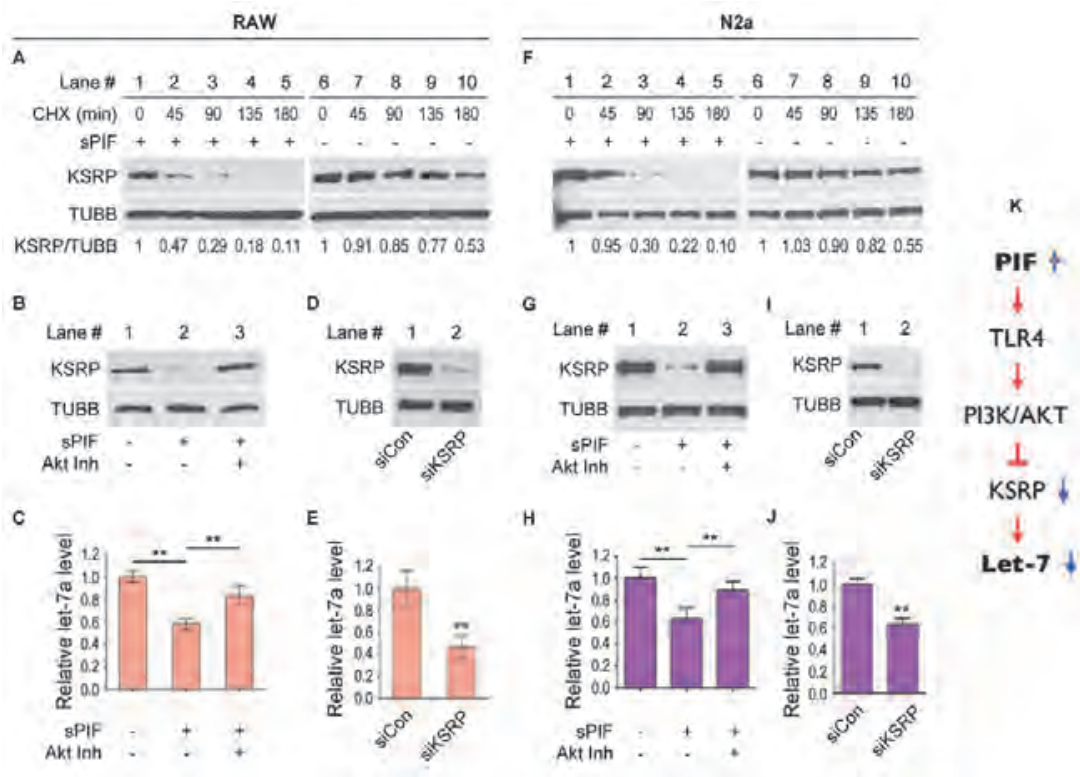

Figure 2. sPIF represses let-7 by destabilizing KSRP, which involves PI3K/AKT signaling. (A and F) Cells were incubated with sPIF $(+)$ or PIFscr $\left(^{-}\right)(200 \mathrm{nM}$ for RAW cells and 300 $\mathrm{nM}$ for N2a cells) for $24 \mathrm{~h}$, followed by the addition of CHX. Proteins were harvested at the indicated time points and were analyzed. KSRP protein levels are presented after normalization against $\beta$-tubulin, with the KSRP level at the 0 time point arbitrarily set as 1 . Results are representative of three independent experiments. (B, C, G, and H) Cells were treated with sPIF (+) or PIFscr (-) in the presence or absence of Akt Inh for $48 \mathrm{~h}$. Proteins and RNAs were isolated, and levels were determined by Western blot and qRT-PCR, respectively. (D, E, I, and J) Cells were transfected with siCon or siRNA specific for KSRP (siKSRP). Proteins and RNAs were extracted $48 \mathrm{~h}$ later and were analyzed by Western blot and qRTPCR, respectively. Except in A and F, all numbers are mean \pm SD $(n=3)$, and are representative of three independent experiments. ${ }^{* *} \mathrm{P}<0.01$. (K) Proposed model for sPIFinduced let-7 repression. PIF activates PI3K/AKT signaling through TLR4, leading to KSRP protein degradation, which in turn decreases the production of mature let-7.

The PI3K/AKT Signaling Pathway Is Involved in sPIF-Induced Destabilization of KSRP Protein. Given that KSRP is a substrate of PI3K/AKT phosphorylation ${ }^{29}$ and that stimulation of TLR4 by LPS activates the PI3K/AKT signaling pathway ${ }^{30,31}$, we hypothesized that PI3K/AKT signaling might be involved in sPIF induced KSRP protein destabilization. Thus, we inhibited PI3K/AKT signaling in RAW cells using an inhibitor specific for AKT (Akt Inh). 
Although, as expected, sPIF reduced KSRP (Fig. 2B, Upper, compare lane 2 with lane 1), such reduction was not seen in the presence of Akt Inh (Fig. 2B, Upper, compare lane 3 with lane 2). Importantly, application of the inhibitor also abolished sPIF-induced let-7 repression (Fig. 2C). Similar results were obtained in N2a cells (Fig. $2 \mathrm{G}$ and H). Furthermore, in both RAW (Fig. 2D) and N2a

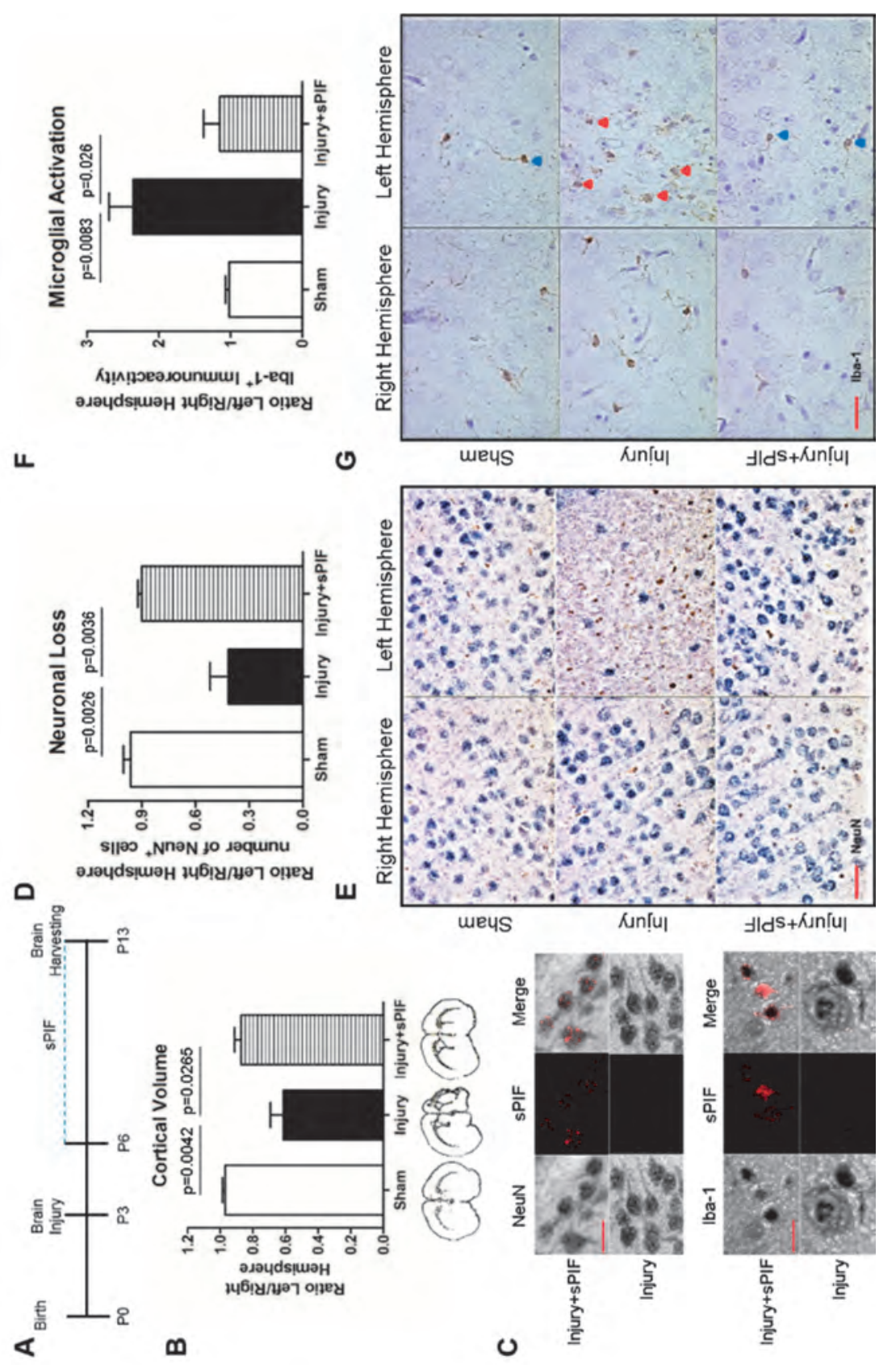


Figure 3. sPIF rescues cortical volume and neuronal loss while decreasing microglial activity in vivo. (A) Experimental outline. (B, D, and F) Quantification of cortical volume (B), neuronal loss (D), and microglial activation (F). Data are presented as mean \pm SEM $(n=4$ per group; two-tailed Student's t test). (C) Representative immunohistochemistry images of NeuN and Iba-1 staining and immunofluorescence images of sPIF (red) staining in injury $(n=4)$ and injury+sPIF $(n=4)$ cortical sections from the left hemisphere. Merged images are shown. (Scale bars, $25 \mu \mathrm{m}$.) (E and G) Representative immunohistochemistry images using cresyl violet with NeuN (for neuronal loss) (E) or Iba-1 (for microglial activation) (G) in cortical sections ( $\mathrm{n}=4$ per group). Iba- $1+$ cells display a predominantly amoeboid state (red arrowheads) and a ramified state (blue arrowheads) in the left hemisphere. (Scale bars, 50 $\mu \mathrm{m}$.).

(Fig. 2I) cells, siRNA-mediated KSRP knockdown caused a decrease in let-7 (Fig. $2 \mathrm{E}$ and $\mathrm{J}$ ). Similar results were obtained in BV-2 cells (Fig. S3). These results suggested that PI3K/AKT signaling is involved in the SPIF induced destabilization of KSRP protein, which in turn impairs let-7 biogenesis, thereby decreasing let-7 levels (Fig. 2K).

sPIF Promotes Neuroprotection in Vivo. The role of let-7 in inducing neuronal cell death and hence in the spreading of CNS damage has been firmly established through both in vivo and in vitro studies by multiple research groups. For example, Lehmann et al. ${ }^{32}$ showed that let-7 released from injured cells to the extracellular environment during CNS damage activated Toll-like receptor 7 in neuronal cells, leading to neurodegeneration in the mouse. Likewise, intracerebroventricular injection of an antagomir to let-7 significantly reduced both cortical and striatal infarcts in a rat ischemic stroke model ${ }^{33}$. Because sPIF decreases let-7 levels (Fig. $1 \mathrm{~A}-\mathrm{D}$ and Fig. S2 A and C), we surmised that sPIF might function to reduce CNS damage, in part, through decreasing let-7 levels in injured brains. Our previously reported newborn rat hypoxic-ischemic brain injury model recapitulates very preterm human infants who are highly susceptible to brain damage and postnatal infections ${ }^{34}$. Such significant damage exerts detrimental effects on both mental and motor development ${ }^{35-37}$. Preterm human infants share similarities to postnatal day 3 (P3) rats in terms of cortical neuronal and glial development. Thus, we induced brain injury at P3, followed by sPIF treatment at P6, and harvested brain samples at P13 (Fig. 3A). We observed a significant loss of cortical volume in the injured animals (Fig. 3B, compare the center and left columns), which was abolished by sPIF treatment (Fig. 3B, compare the right and center columns). The sPIF administered s.c. colocalized with both neurons (Fig. 3C, Upper) and glia (Fig. 3C, Lower). The significant neuronal loss in deep cortical layers (Fig. 3D, compare the center and left columns, and Fig. 3E, compare the center and top right panels) was reduced in sPIF-treated animals (Fig. 3D, compare the center and right columns, and Fig. 3E, compare the bottom and middle right panels). Microglia of macrophage lineage represent both the target and source of injury in CNS ${ }^{38,39}$. Decreased glial activation and a restored number of neurons have been associated with reduced cerebral response to injury ${ }^{40,41}$. We observed increased activation of microglia (Fig. 3F, compare the center and left columns, and Fig. 3G, compare the middle and top right panels), which were abrogated by sPIF treatment (Fig. 3F, compare the right and center columns, and Fig. 3G, compare the bottom and middle right panels). Further, we observed morphological changes in Iba-1+ microglia shifting from a predominantly amoeboid to a ramified state in sPIF-treated animals (Fig. $3 \mathrm{G}$, compare the cells indicated by red and blue arrowheads). Thus, our results are 
consistent with the notion that sPIF reduces inflammation and promotes neural protection by targeting neuronal and glial cells.

Decreasing Let-7 and Increasing IL-10 Together May Contribute to sPIFMediated Neuroprotection in Vivo. sPIF down-regulates let-7 in both neuronal and microglia/macrophage cells (Fig. 1 A-D and Fig. S2 A and C). Therefore, we predicted that SPIF also could decrease let-7 in the injured hemisphere, thereby contributing to the observed significant neuroprotection. Indeed, the levels of the four tested let-7 members were significantly lower in SPIF-treated than in vehicletreated brains (Fig. 4 A-D). Furthermore, there was a significant decrease in the KSRP protein levels in sPIF- as compared with vehicle-treated brains (Fig. $4 \mathrm{E}$ and F). These results provide compelling evidence that the PIF/TLR4/KSRP/Let-7 regulatory axis is active in vivo. IL-10, an anti-inflammatory cytokine, has a wellestablished role in neuroprotection ${ }^{42-45}$. In addition to acting on glia and

A
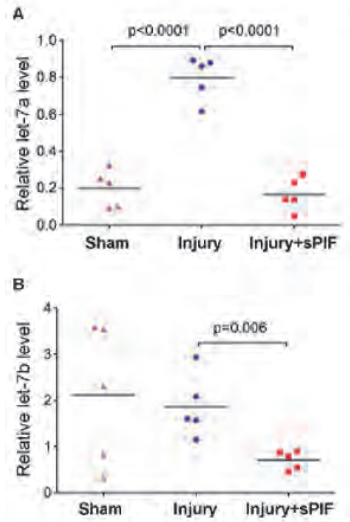

G

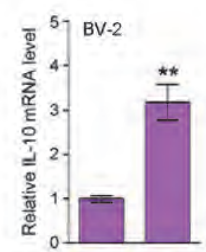

sPIF c

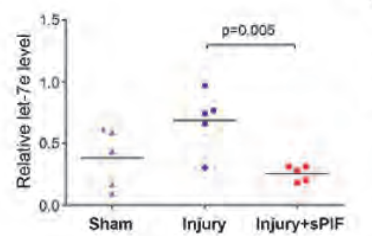

D

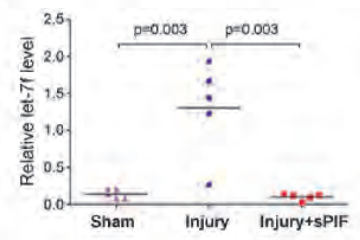

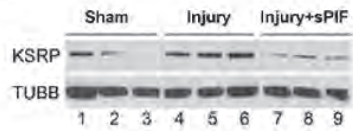

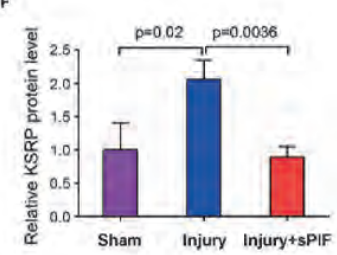

H

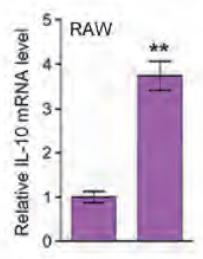

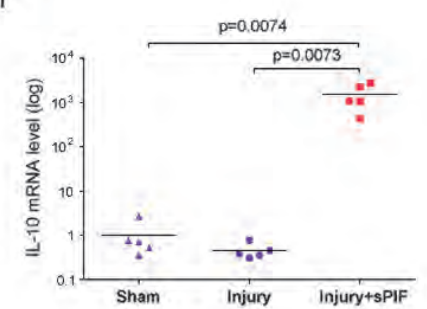

Figure 4. sPIF down-regulates KSRP and let-7 and up-regulates IL-10 in vivo. (A-D) RNAs were extracted from frozen brain tissues of sham, injury, and injury+sPIF rats ( $n=5$ animals per group). Levels of the indicated let-7 family members were determined by qRT-PCR. Results are presented after normalization against U6 RNA. (E) Proteins were extracted from frozen brain tissue of three animals in each group and were analyzed by Western blot. (F) Quantitation of E, with KSRP protein levels shown after normalization against $\beta$-tubulin. (G and $\mathrm{H}) \mathrm{BV}-2$ and RAW cells were incubated with sPIF $(+)$ or PIFscr $\left(^{-}\right)$(50 nM for BV-2 cells and $200 \mathrm{nM}$ for RAW cells) for $48 \mathrm{~h}$. RNAs were extracted, and levels were determined by qRT-PCR. IL-10 mRNA levels are presented after normalization against $\beta$-tubulin mRNA with the level in PIFscr-treated cells arbitrarily set as 1 . Numbers are mean $\pm \operatorname{SD}(n=3)$. ${ }^{* * P}$ $<0.01$. (I) RNAs were extracted from frozen brain tissues of sham, injury, and injury + sPIF rats ( $n=5$ animals per group). IL-10 mRNA levels were determined by qRT-PCR. Results are presented after normalization against $\beta$-tubulin mRNA.

endothelium to reduce inflammatory responses following ischemic brain damage, 
it directly protects cortical neurons by activating the PI3K/AKT pathway via IL10 receptors on neurons ${ }^{45}$. As is consistent with IL-10 being a known target of let-7 ${ }^{24,46}$, we observed up-regulation of IL-10 in both BV-2 and RAW cells in sPIF-treated as compared with scrPIF-treated groups (Fig. $4 \mathrm{G}$ and $\mathrm{H}$ ). Significant IL-10 up-regulation also was evident in sPIF-treated as compared with vehicletreated brains (Fig. 4I). Thus, the increasing levels of IL-10 also may contribute to sPIF's neuroprotective effects in vivo.

\section{Discussion}

This report demonstrates that sPIF inhibits the biogenesis of let-7 microRNA in both neuronal and immune cells by downregulating the expression of the key microRNA-processing factor KSRP at the posttranslational level and that this regulation is dependent on TLR4 expression. We also show that short-term s.c. administration of sPIF in a clinically relevant model of newborn brain injury leads to a significant reversal of injury. We provide evidence that this novel PIF/TLR4/KSRP/let-7 signal-transduction pathway, together with its induced IL10 up-regulation, may contribute to the observed sPIF-promoted neuroprotection in vivo. our data suggest that TLR4 has an important role in SPIF induced let-7 repression (Fig. $1 \mathrm{E}-\mathrm{H}$ and Fig. S2 B and C).

However, the exact mechanism by which sPIF interacts with TLR4 remains to be completely explained. sPIF may not bind TLR4 directly but rather may act via additional, unidentified cofactors, as is the case for LPS and the TLR4 complex ${ }^{47}$. The divergent in vivo effects of sPIF (neuroprotection; see Fig. 3) and LPS (neuroinflammation) ${ }^{48}$ suggest an association with distinct cofactors. Although LPS inhibits let-7 in vitro ${ }^{24}$, other downstream effects of LPS (likely determined by cofactors) may override this potentially beneficial effect of LPS in vivo. Because in vivo repression of both KSRP and let-7 coincides with sPIF-induced neuroprotection (Figs. 3 and 4), its conceivable that cofactors of sPIF act in concert to elicit downstream effects that are specific to SPIF but are different from those induced by LPS. Identification of the PIF-interacting cofactors is currently underway.

Both let-7 ${ }^{49}$ and miR-27b ${ }^{28}$ target the 3 UTR of KSRP mRNA to induce mRNA degradation and translational suppression, respectively. However, regulation of ksrp gene expression at the posttranslational level via protein destabilization (Fig. $2 \mathrm{~A}$ and $\mathrm{F}$ ) has not been documented previously, nor has the involvement of PI3K/AKT signaling in regulating KSRP protein stability (Fig. 2 B and G). KSRP has important roles in both microRNA biogenesis and the regulation of mRNA stability ${ }^{29}$. AKT-mediated KSRP phosphorylation at a unique serine residue (S193) through PI3K/AKT signaling induces KSRP association with protein 14-33 and impairs KSRP's ability to promote target mRNA degradation ${ }^{50}$. S193 phosphorylation leads to the unfolding of KSRP, creating a binding site for 14-33, which drives the nuclear localization of KSRP and prevents it from destabilizing mRNA in the cytoplasm ${ }^{51}$. sPIF-induced destabilization of the KSRP protein involves proteasomes (Fig. S3D), as is the case in metformininduced c-MYC degradation ${ }^{52}$. Metformin treatment of tumor cells activates AMPK, leading to c-MYC phosphorylation at the conserved Thr58, which in turn triggers proteasomal degradation of $\mathrm{c}^{\mathrm{MYC}}{ }^{52}$. Destabilization of the KSRP protein may involve AKT-mediated phosphorylation at a specific site(s). Mapping 
the sites and determining the effects of phosphorylation will provide critical mechanistic insight into sPIF-induced KSRP destabilization, which warrants future investigation.

sPIF has a short half-life in circulation. For example, in the mouse, the circulating sPIF level peaked at $\sim 320 \mathrm{ng} / \mathrm{mL} 30 \mathrm{~min}$ after a single-dose s.c. injection of 40 $\mathrm{mg} / \mathrm{kg}$ and was mostly cleared from circulation within $2 \mathrm{~h}$ (Fig. S4A). This peak concentration of SPIF was close to that of endogenous PIF detected in the pregnant bovine serum $(\sim 227 \mathrm{ng} / \mathrm{mL}){ }^{4}$. The dosage we used in the rats was 1.5 $\mathrm{mg} / \mathrm{kg} / \mathrm{d}$ (Materials and Methods), and, as expected, the circulating sPIF was undetectable $12 \mathrm{~h}$ after injection (Fig. S4B). Despite the rapid clearance of sPIF from circulation, potent neuroprotection was observed (Fig. 3). This finding suggests that the circulating sPIF concentrations are not a good indicator of the local concentration of SPIF at its site of action, as was noted by our immunofluorescence study using anti-PIF antibody at the same time point in the brain (Fig. 3C). Such a scenario would be consistent with our need to use higher concentrations of sPIF to observe sPIF effects in our cell-culture experiments.

As shown in this report, activation of PI3K/AKT signaling by SPIF leads to the down-regulation of let-7, which in turn increases IL-10 expression. Because IL-10 promotes PI3K/AKT signaling by acting on the IL-10 receptor ${ }^{45}$, a possible positive feedback loop involving PI3K/AKT, let-7, and IL-10 may exist. Although highly speculative, such a putative feedback regulatory circuit may partially explain the dramatic increase in IL-10 expression in the sPIF-treated brain (Fig. 4I). Given the broad changes in the gene-expression profile induced by sPIF, as determined by both genomic and proteomic analyses ${ }^{9}$, it is almost certain that PIF plays pleiotropic roles in gene regulation.

Identification and characterization of the PIF/TLR4/KSRP/let-7 pathway represent critical first steps toward the mechanistic understanding of the multifunctional PIF. Despite the recent purification and characterization of PIF ${ }^{2}$, attempts to identify its gene have been unsuccessful so far. It is possible that the PIF gene resides within a highly complex and structured repetitive chromosomal region that has not yet been sequenced and annotated ${ }^{53}$. Indeed, antimicrobial peptides encoded by genes in a region flanked by repetitive elements have been reported previously in bovines ${ }^{54}$.

Several aspects of perinatal brain injury are recapitulated using rodent models with LPS-induced inflammation and/or hypoxia-ischemia ${ }^{48}$. Activation of microglia and innate immunity is considered a major component contributing to immature brain injury 55, 56. SPIF treatment resulted in reduced microglial activation (Fig. $3 \mathrm{~F}$ and G). Neuroprotective effects were detected despite the late starting point (P6) of the therapy. This finding is of particular importance, because in premature infants the precise timing of the injury (whether it occurs before or during labor or in the postnatal period) is often unclear ${ }^{56}$. The currently available delayed immune-modulatory treatment options often result in no benefit or even in the development of adverse effects ${ }^{56}$. Our results strongly suggest that even a significantly delayed initiation of therapy with SPIF is effective in reversing advanced neural damage. The current and previously reported neuroprotective data ${ }^{9}$ combined with the recent Food and Drug Administration's fast-track approval for clinical trials support sPIF's potential clinical application. 
Let-7 repression in blastocysts facilitates embryo implantation in the mouse ${ }^{57,58}$. Proper regulation of expression of IL-10 in trophoblasts and uterine immune cells has been implicated in placental health and fetal development ${ }^{59}$. We propose that our newly discovered PIF/TLR4/KSRP/let-7 signal transduction pathway and its mediated regulation of IL-10 expression may underlie PIF's mode of action on immune control and embryo development in the maternal-fetal interface. The demonstration that systemic sPIF administration targets the brain directly makes sPIF an attractive, minimally invasive approach to brain-injury therapy.

\section{Materials and Methods}

Details of antibodies, siRNAs, inhibitors, peptides, cell culture, siRNA knockdown, Western blot, quantitative RT-PCR, and immunohistochemistry are given in SI Materials and Methods.

sPIF Treatment of Cultured Cells, Protein Stability Analysis, Akt Inhibitor Rescue Experiments, Induction of Hypoxic-Ischemic Brain Injury, Assessment of Cortical Volume, Neuronal Loss, and Glial Activity, and Quantification and Statistical Analysis are given in SI Materials and Methods.

ACKNOWLEDGMENTS. This work was supported by funds from the Eagle Foundation, Cryo-Save AG, an Albert McKern Scholar Award, and unrestricted funds from BioIncept, LLC. 


\section{References:}

1. Barnea ER. Insight into early pregnancy events: The emerging role of the embryo. Am J Reprod Immunol 2004 51(5):319-322.

2. Barnea ER, et al. PreImplantation Factor (PIF) orchestrates systemic anti-inflammatory response by immune cells: Effect on peripheral blood mononuclear cells. Am J Obstet Gynecol 2012 207(4):e1-e11.

3. Stamatkin CW, et al. PreImplantation Factor (PIF) correlates with early mammalian embryo development-bovine and murine models. Reprod Biol Endocrinol 2011 9:63.

4. Ramu S, et al. PreImplantation factor (PIF) detection in maternal circulation in early pregnancy correlates with live birth (bovine model). Reprod Biol Endocrinol 2013 11:105.

5. Duzyj CM, et al. Preimplantation factor promotes first trimester trophoblast invasion. Am J Obstet Gynecol 2010 203(4):e1-e4.

6. Paidas MJ, et al. A genomic and proteomic investigation of the impact of preimplantation factor on human decidual cells. Am J Obstet Gynecol 2022010 (5):e1-e8.

7. Barnea ER, Kirk D, Paidas MJ. Preimplantation factor (PIF) promoting role in embryo implantation: Increases endometrial integrin- $\alpha 2 \beta 3$, amphiregulin and epiregulin while reducing betacellulin expression via MAPK in decidua. Reprod Biol Endocrinol 2012 10:50.

8. Roussev RG, et al. Preimplantation factor inhibits circulating natural killer cell cytotoxicity and reduces CD69 expression: Implications for recurrent pregnancy loss therapy. Reprod Biomed Online 2013 26(1):79-87.

9. Weiss L, et al. Preimplantation factor (PIF*) reverses neuroinflammation while promoting neural repair in EAE model. J Neurol Sci 2012 312(1-2):146-157.

10. Editorial Preterm birth: Crisis and opportunity. Lancet 2006 368(9533):339.

11. Volpe JJ. Brain injury in premature infants: A complex amalgam of destructive and developmental disturbances. Lancet Neurol 2009 8(1):110-124.

12. Higgins RD, et al. Eunice Kennedy Shriver National Institute of Child Health and Human Development Hypothermia Workshop Speakers and Moderators. Hypothermia and other treatment options for neonatal encephalopathy: An executive summary of the Eunice Kennedy Shriver NICHD workshop. J Pediatr 2011 159(5):851-858, e1.

13. Gabory A, Jammes H, Dandolo L. The H19 locus: Role of an imprinted noncoding RNA in growth and development. BioEssays 2010 32(6):473-480.

14. Kallen AN, et al. The imprinted H19 lncRNA antagonizes let-7 microRNAs. Mol Cell 2013 52(1):101-112.

15. Fabian MR, Sonenberg N. The mechanics of miRNA-mediated gene silencing: A look under the hood of miRISC. Nat Struct Mol Biol 2012 19(6):586-593.

16. Bartel DP. MicroRNAs: Target recognition and regulatory functions. Cell 2009 136(2):215233.

17. Trabucchi M, et al. How to control miRNA maturation? RNA Biol 2009 6(5):536-540.

18. Michlewski G, Cáceres JF. Antagonistic role of hnRNP A1 and KSRP in the regulation of let7a biogenesis. Nat Struct Mol Biol 2010 17(8):1011-1018.

19. Thornton JE, Gregory RI. How does Lin28 let-7 control development and disease? Trends Cell Biol 2012 22(9):474-482.

20. Huang Y. A mirror of two faces: Lin28 as a master regulator of both miRNA and mRNA. Wiley Interdiscip Rev RNA 2012 3(4):483-94. 


\section{Chapter 5}

21. Trabucchi M, et al. The RNA-binding protein KSRP promotes the biogenesis of a subset of microRNAs. Nature 2009 459(7249):1010-1014.

22. Lee YS, Dutta A. The tumor suppressor microRNA let-7 represses the HMGA2 oncogene. Genes Dev 2007 21(9):1025-1030.

23. Tokumaru S, Suzuki M, Yamada H, Nagino M, Takahashi T. let-7 regulates Dicer expression and constitutes a negative feedback loop. Carcinogenesis 2008 29(11):2073-2077.

24. Schulte LN, Eulalio A, Mollenkopf H-J, Reinhardt R, Vogel J. Analysis of the host microRNA response to Salmonella uncovers the control of major cytokines by the let-7 family. EMBO $2011 \mathrm{~J}$ 30(10):1977-1989.

25. Blasi E, Barluzzi R, Bocchini V, Mazzolla R, Bistoni F. Immortalization of murine microglial cells by a v-raf/v-myc carrying retrovirus. J Neuroimmunol 1990 27(2-3):229-237.

26. Sokolowska M, et al. Low molecular weight hyaluronan activates cytosolic phospholipase A2 $\alpha$ and eicosanoid production in monocytes and macrophages. J Biol Chem 2014 289(7):4470-4488.

27. Briata P, et al. KSRP, many functions for a single protein. (Translated from eng). Front Biosci 2011 16:1787-1796.

28. Zhou R, Gong A-Y, Eischeid AN, Chen X-M. miR-27b targets KSRP to coordinate TLR4mediated epithelial defense against Cryptosporidium parvum infection. PLoS Pathog 2012 8(5):e1002702.

29. Briata P, et al. PI3K/AKT signaling determines a dynamic switch between distinct KSRP functions favoring skeletal myogenesis. Cell Death Differ 2012 19(3):478-487.

30. Ojaniemi M, et al. Phosphatidylinositol 3-kinase is involved in Toll-like receptor 4-mediated cytokine expression in mouse macrophages. Eur J Immunol 2003 33(3):597-605.

31. Laird MHW, et al. TLR4/MyD88/PI3K interactions regulate TLR4 signaling. J Leukoc Biol 2009 85(6):966-977.

32. Lehmann SM, et al. An unconventional role for miRNA: Let-7 activates Toll-like receptor 7 and causes neurodegeneration. Nat Neurosci 2012 15(6):827-835.

33. Selvamani A, Sathyan P, Miranda RC, Sohrabji F. An antagomir to microRNA Let7f promotes neuroprotection in an ischemic stroke model. PLoS ONE 2012 7(2):e32662.

34. Müller MM, Middelanis J, Meier C, Surbek D, Berger R. 17ß-estradiol protects 7-day old rats from acute brain injury and reduces the number of apoptotic cells. Reprod Sci 2013 20(3):253261.

35. Sizonenko SV, Kiss JZ, Inder T, Gluckman PD, Williams CE. Distinctive neuropathologic alterations in the deep layers of the parietal cortex after moderate ischemic-hypoxic injury in the P3 immature rat brain. Pediatr Res 2005 57(6):865-872.

36. Sizonenko SV, Camm EJ, Dayer A, Kiss JZ. Glial responses to neonatal hypoxic-ischemic injury in the rat cerebral cortex. Int J Dev Neurosci 2008 26(1):37-45.

37. van Vliet EO, de Kieviet JF, Oosterlaan J, van Elburg RM. Perinatal infections and neurodevelopmental outcome in very preterm and very low-birth-weight infants: A meta-analysis. JAMA Pediatr 2013 167(7):662-668.

38. Hanisch UK. Microglia as a source and target of cytokines. Glia 2002 40(2):140-155.

39. Hagberg H, Gressens P, Mallard C. Inflammation during fetal and neonatal life: Implications for neurologic and neuropsychiatric disease in children and adults. Ann Neurol 2012 71(4):444457.

40. Baron JC, Yamauchi H, Fujioka M, Endres M. Selective neuronal loss in ischemic stroke and cerebrovascular disease. J Cereb Blood Flow Metab 2014 34(1):2-18. 
41. Jellema RK, et al. Cerebral inflammation and mobilization of the peripheral immune system following global hypoxia-ischemia in preterm sheep. J Neuroinflammation 2013 10:13.

42. Spera PA, Ellison JA, Feuerstein GZ, Barone FC. IL-10 reduces rat brain injury following focal stroke. Neurosci Lett 1998 251(3):189-192.

43. Grilli $\mathrm{M}$, et al. Interleukin-10 modulates neuronal threshold of vulnerability to ischaemic damage. Eur J Neurosci 2000 12(7):2265-2272.

44. Ooboshi $\mathrm{H}$, et al. Postischemic gene transfer of interleukin-10 protects against both focal and global brain ischemia. Circulation 2005 111(7):913-919.

45. Sharma S, et al. IL-10 directly protects cortical neurons by activating PI-3 kinase and STAT-3 pathways. Brain Res 2011 1373:189-194.

46. Swaminathan S, et al. Differential regulation of the Let-7 family of microRNAs in CD4+ T cells alters IL-10 expression. J Immunol 2012 188(12):6238-6246.

47. Takeuchi O, Akira S. Pattern recognition receptors and inflammation. Cell 2010 140(6):805820 .

48. Salmaso N, Jablonska B, Scafidi J, Vaccarino FM, Gallo V. Neurobiology of premature brain injury. Nat Neurosci 2014 17(3):341-346.

49. Repetto E, et al. Let-7b/c enhance the stability of a tissue-specific mRNA during mammalian organogenesis as part of a feedback loop involving KSRP. PLoS Genet 2012 8(7):e1002823.

50. Gherzi R, et al. The RNA-binding protein KSRP promotes decay of beta-catenin mRNA and is inactivated by PI3K-AKT signaling. PLoS Biol 2006 5(1):e5.

51. Díaz-Moreno I, et al. Phosphorylation-mediated unfolding of a KH domain regulates KSRP localization via 14-3-3 binding. Nat Struct Mol Biol 2009 16(3):238-246.

52. Akinyeke $\mathrm{T}$, et al. Metformin targets c-MYC oncogene to prevent prostate cancer. Carcinogenesis 2013 34(12):2823-32.

53. Huddleston J, et al. Reconstructing complex regions of genomes using long read sequencing technology. Genome Res 2014 24(4):688-696.

54. Diamond G, Jones DE, Bevins CL. Airway epithelial cells are the site of expression of a mammalian antimicrobial peptide gene. Proc Natl Acad Sci USA 1993 90(10):4596-4600.

55. Yang D, et al. Plasminogen activator inhibitor-1 mitigates brain injury in a rat model of infection-sensitized neonatal hypoxia-ischemia. Cereb Cortex 2013 23(5):1218-1229.

56. Mallard C, et al. Astrocytes and microglia in acute cerebral injury underlying cerebral palsy associated with preterm birth. Pediatr Res 2014 75(1-2):234-240.

57. Liu WM, et al. Involvement of microRNA lethal-7a in the regulation of embryo implantation in mice. PLoS ONE 2012 7(5):e37039.

58. Cheong AW, et al. MicroRNA Let-7a and dicer are important in the activation and implantation of delayed implanting mouse embryos. 2014 Hum Reprod 29(4):750-762.

59. Chatterjee P, Chiasson VL, Bounds KR, Mitchell BM. Regulation of the Anti-Inflammatory Cytokines Interleukin-4 and Interleukin-10 during Pregnancy. Front Immunol 2014 5:253.

\section{Supplementary Information}

Detection of the synthetic PreImplantation factor (sPIF) concentration in mouse plasma was part of a toxicokinetic study approved by the United States Food and Drug Administration (FDA) for a phase I clinical study (autoimmune hepatitis; University of Miami). It was performed by Covance Laboratories Inc. in 
accordance with the protocol dated September 25, 2012, Protocol Amendment Nos. 1 through 4, and Covance standard operating procedures (SOPs). The study was conducted in compliance with the FDA Good Laboratory Practice Regulations, 21 CFR 58. Thirty male and female mice [Crl:CD1(ICR)] from Charles River Laboratories received an s.c. injection of $40 \mathrm{mg} \cdot \mathrm{kg}^{-1} \cdot \mathrm{d}^{-1} \mathrm{sPIF}$, and concentrations were measured in the plasma. Blood was collected from three animals of each sex at each time point, $0.5,1,2$, 4, and $8 \mathrm{~h}$ postdose. Before blood collection animals were anesthetized by carbon dioxide inhalation, and blood was collected via cardiac puncture. Samples were transferred into prechilled tubes containing $\mathrm{K}_{2}$ EDTA and acetic acid in water $(\sim 15 \mu \mathrm{L}$ of a $20 \%$ acetic acid solution for $0.6 \pm 0.1 \mathrm{~mL}$ whole blood or $\sim 12.5 \mu \mathrm{L}$ of a $20 \%$ acetic acid solution for blood volume $<0.5 \mathrm{~mL}$ ). Tubes were inverted for $\sim 30 \mathrm{~s}$ after blood collection. Blood was maintained on wet ice before centrifugation to obtain plasma. Samples were centrifuged at a minimum of $2,560 \times \mathrm{g}$ for $15 \mathrm{~min}$ at $2-8^{\circ} \mathrm{C}$. Centrifugation began within 30 min of collection. Plasma was harvested and maintained on dry ice before storage at -60 to $-80{ }^{\circ} \mathrm{C}$. Samples were transferred to the CovanceBioanalytical Department for analysis of sPIF concentrations.

sPIF and the internal standard were extracted from samples using solid-phase extraction. After evaporation under nitrogen, the residue was reconstituted and analyzed using LC MS/MS. Samples were analyzed in accordance with Covance SOPs and the validated method. Each batch included a calibration curve, a matrix blank, a control zero (matrix blank containing internal standard), a reagent blank, and duplicate quality control samples at three concentrations within the calibration range. The samples were interspersed with calibration standards and quality control samples within the batch.

For rat samples ( $\mathrm{n}=15$; 5 per group) blood was collected via cardiac puncture at the time of tissue harvesting (postnatal day 13, $12 \mathrm{~h}$ after the last sPIF injection) and was processed according to SOP standards. Blood was drawn at room temperature, and the clot was allowed to form for $45 \mathrm{~min}$. Samples were centrifuged in a horizontal rotor for $20 \mathrm{~min}$ at $1,100-1,300 \times \mathrm{g}$ at room temperature. Serum was transferred, stored in a $-80{ }^{\circ} \mathrm{C}$ freezer, and shipped to Biosynthesis for analysis of sPIF concentrations using MS/MS.

Antibodies, siRNAs, inhibitors, and peptides. The antibodies for Toll like receptor 4 (TLR4) (ab22048; Abcam), KH-type splicing regulatory protein (KSRP) (13398s; Cell Signaling), and $\beta$-tubulin (ab6046; Abcam) were purchased. The siRNAs for TLR4 (L-008088-01; Thermo Scientific Dharmacon) and KSRP (custom synthesized by Ambion) and the negative control siRNA (D001810-10-20; Thermo Scientific Dharmacon) were purchased. The AKT inhibitor (124005) and cycloheximide (C7698-1G) were from Calbiochem and Sigma-Aldrich, respectively. sPIF (MVRIKPGSANKPSDD) and the control scrambled peptide PIFscr (GRVDPSNKSMPKDIA) with $>95 \%$ purity documented by HPLC and mass spectrometry were generated at Biosynthesis.

Cell Culture. N2a (CCL-131) and RAW 264.7 (TIB-71) cells werepurchased from ATCC. BV-2 cells (ATL03001) were purchased from Banca Biologica e Cell Factory. N2a and RAW cells were maintained in DMEM (11965-092; Gibco), and BV-2 cells were maintained in RPMI 1640 (11875-093; Gibco), both supplemented with 10\% FBS, $1 \mathrm{mM}$ L-glutamine, and 1\% penicillinstreptomycin, 
in a 5\% CO2 atmosphere at $37{ }^{\circ} \mathrm{C}$. For N2a and BV-2 cells, FBS (16140-071; Gibco) was used. For RAW cells, ES-Qualified FBS (10439024; Gibco) was used. We applied $0.25 \%$ trypsin-EDTA to detach N2a and BV-2 cells from culture plates and used cell scrapers (without trypsin) to detach RAW cells during cell passage. siRNA Knockdown of TLR4 and KSRP. Cells were transfected in a 48well plate scale. To prepare siRNA transfection solution for each well, $16 \mathrm{pmol}$ of control siRNA siCon or siRNA was diluted in $50 \mu \mathrm{L}$ Opti-MEM (Life Technologies) by gentle pipetting. In parallel, $0.5 \mu \mathrm{L}$ of Lipofectamine 2000 (Life Technologies) was diluted with $50 \mu \mathrm{L}$ Opti-MEM. Following 5 min of incubation at room temperature, the two were mixed by gentle pipetting and incubated for 20-30 min at room temperature to allow the formation of siRNA/lipid complexes. At the end of incubation, the $100-\mu \mathrm{L}$ transfection solution was used to resuspend the cell pellet ( $8 \times 104$ cells for N2a and BV-2 cells; $1 \times 105$ cells for RAW cells). After incubation at room temperature for $10 \mathrm{~min}$, regular growth medium was added at a ratio of one volume of transfection solution to five volumes of growth medium, and the cell suspension was transferred to culture plates. After 24-h incubation at $37{ }^{\circ} \mathrm{C}$ in $5 \% \mathrm{CO} 2$, the medium was replaced with fresh medium. RNA and protein were extracted and analyzed at the indicated time points following transfection.

Western Blot Analyses. Western blot analyses were used to assess TLR4 and/or KSRP protein levels in cultured cells and rat brain tissues. Briefly, cell pellets or frozen tissue samples were lysed quickly in $\sim 10$ volumes of $2 \times$ SDS-sample buffer heated at $100{ }^{\circ} \mathrm{C}$ for $5 \mathrm{~min}$. To homogenize cell pellets, occasional vortexing was performed. To homogenize brain tissues, lysate was passed through $20-\mathrm{G}$ needles 10 times for each sample. Homogenized samples $(5-10 \mu \mathrm{L})$ were loaded onto $10 \%$ SDS gel, followed by Western blot analyses. Protein bands on Western gels were quantified using Image J (US National Institutes of Health).

Quantitative Real-Time RT-PCR. Quantitative real-time PCR (qPCR) was carried out essentially as described previously ${ }^{1}$. For mRNA quantification, total RNAs were extracted from cells using PureLink RNA Mini Kit (12183018A; Ambion). cDNA was synthesized using the Bio-Rad iSCRIPT kit (1725122) in a $20-\mu \mathrm{L}$ reaction containing $500-800$ ng of total RNA. Real-time PCR was performed in a $15-\mu \mathrm{L}$ reaction containing $0.5-1 \mu \mathrm{L}$ of cDNA using iQ SYBR Green (Bio-Rad) in a Bio-Rad iCycler. PCR was performed by initial denaturation at $95^{\circ} \mathrm{C}$ for $5 \mathrm{~min}$, followed by 40 cycles of $30 \mathrm{~s}$ at $95^{\circ} \mathrm{C}, 30 \mathrm{~s}$ at $60{ }^{\circ} \mathrm{C}$, and $30 \mathrm{~s}$ at $72{ }^{\circ} \mathrm{C}$. Specificity was verified by melting curve analysis and agarose gel electrophoresis. The threshold cycle $(\mathrm{Ct})$ values of each sample were used in the post-PCR data analysis. The PCR primers for the mouse mRNAs are listed below.

Dicer forward: 5'-TAGGCATTCCTAGCACCAAG, Dicer reverse: 5'-TGAGTGGGGTAAGATCCGTA, Hmga2 forward: 5'-TCTCTGTCCCGTTCTGTCTC, Hmga2 reverse: 5'-GGAGTGAATTGTGTCCCTTG, IL-10 forward: TGGCCCAGAAATCAAGGAGC, IL-10 reverse: CAGCAGACTCAATACACACT, KSRP forward: TTATCGGGGACCCATACAAA, KSRP reverse: ACTCCGGCCAATGACTACAC, Beta-tubulin forward: 5'-CGTGTTCGGCCAGAGTGGTGC, Beta-tubulin reverse: 5'-GGGTGAGGGCATGACGCTGAA, TLR4 forward: AGACCTCAGCTTCAATGGTG, 
TLR4 reverse: GAGACTGGTCAAGCCAAGAA

For miRNA quantification, total RNAs were extracted from cells or frozen brain tissues using the PureLink RNA Mini Kit. Levels of mature miRNAs were determined by RT-qPCR using the miScript reverse transcription kit (catalog no. 218161) and the miScript SYBR Green PCR kit (catalog no. 218073) according to the manufacturers' instructions. PCR primer sets (miScript primer) specific for let-7a (MS00006482), let-7b (MS00003122), let-7c (MS00003129), let-7e (MS00031227), let-7f (MS00006489), and snRNA U6 (MS00033740) were purchased from Qiagen. The indicated miRNA levels were normalized against U6.

sPIF Treatment of Cultured Cells. Cells were seeded in 48-well plates in regular growth medium at a density of $\sim 8 \times 10^{4}$ cells per well. The next day, the medium was replaced with serum-free medium containing PBS, sPIF, or PIFscr at the indicated final concentrations, followed by incubation for the indicated time duration. The peptides (or PBS) were replenished every $24 \mathrm{~h}$ in fresh serumfree medium until RNA and protein were extracted for further analyses.

Protein Stability Analysis. N2a cells $\left(8 \times 10^{4}\right.$ per well) and RAW cells $\left(1 \times 10^{5}\right.$ per well) were seeded in 48-well plates in regular culture medium. The next day, cells were incubated in serum free medium containing SPIF $(+)$ or PIFscr $(-)$ (300 $\mathrm{nM}$ for N2a cells; $200 \mathrm{nM}$ for RAW cells). Following 24-h incubation, the medium was replaced with fresh serum-free medium in the presence of $\mathrm{CHX}$ at final concentrations of $20 \mu \mathrm{g} / \mathrm{mL}$ for RAW cells and $30 \mu \mathrm{g} / \mathrm{mL}$ for N2a cells. Cells were harvested in $2 \times$ SDS lysis buffer at the indicated time points, followed by Western blot analysis.

Akt Inhibitor Rescue Experiments. N2a cells ( $5 \times 10^{4}$ per well) and RAW cells $\left(1 \times 10^{5}\right.$ per well) were seeded in regular growth medium in 48-well plates. The next day, the medium was replaced with $200 \mu \mathrm{L}$ serum-free medium with (Akt Inh + ) or without (Akt Inh -) $10 \mu \mathrm{M}$ Akt inhibitor. After 30-min incubation, an additional $300 \mu \mathrm{L}$ of fresh serum-free medium containing sPIF (sPIF +) or PIFscr (sPIF -), with (Akt Inh +) or without (Akt Inh -) $10 \mu \mathrm{M}$ Akt inhibitor was added. The final volume of serum-free medium was $500 \mu \mathrm{L}$ per well. The final concentration of Akt Inh was $10 \mu \mathrm{M}$. The final concentrations of sPIF (or PIFscr) were $300 \mathrm{nM}$ for N2a cells and $200 \mathrm{nM}$ for RAW cells. After 24-h incubation, the medium was replaced with fresh serum-free medium with or without Akt Inh, sPIF, or PIFscr as described above. After an additional 24-h incubation, RNA and protein were extracted and analyzed.

Immunohistochemistry. We performed cardiac perfusion with PBS, followed by $4 \%$ formaldehyde solution in PBS (Merck) before brain harvesting. Brains were removed surgically and fixed in the formaldehyde solution for 2-4 h at room temperature followed by $4{ }^{\circ} \mathrm{C}$ for a total time of 24-48 h. Fixed brains were embedded in paraffin and sectioned into 7- $\mu \mathrm{m}$ slices. After deparaffinization of the slides, the target was retrieved in citrate buffer $(10 \mathrm{mM}$; $\mathrm{pH} 6.0)$ in a pressure cooker for $15 \mathrm{~min}$. Slides were washed in $0.1 \%$ Tween-20/PBS and blocked in $10 \%$ goat serum $/ 1 \%$ bovine albumin/PBS. Neurons were detected by a mouse monoclonal antibody specific for the neuronal nuclear antigen (NeuN) (1:100; nMAB377; Chemicon). A rabbit polyclonal antibody against the ionized calcium 
binding-adaptor molecule 1 (Iba-1) (1:100; ab5076; Abcam), a highly specific marker for microglia, was used to localize both resting and activated microglia (18593) ${ }^{2}$. Monoclonal antibody anti-PIF (1:150; GenWay) was used to detect sPIF. After the first antibody incubation, slides were washed twice for 5 min each washing in $0.1 \%$ Tween-20/PBS and were incubated in endogenous peroxidase blocking solution at room temperature for $15 \mathrm{~min}$. Peroxidase-labeled polymer (antimouse or anti-rabbit; DAKO) was applied to the slides for $30 \mathrm{~min}$ at room temperature. Slides were washed three times for 5 min each washing in PBS, followed by application of 3,3' - diaminobenzidine-tetrahydrochloride (DAB) + chromogen in buffer substrate (K4007; DAKO EnVision+ System-HRP) for 10$30 \mathrm{~min}$ according to the manufacturer's instructions. Slides were rinsed in doubledistilled H2O, counterstained in cresyl violet (Nissl body staining for neuronal structure and gross brain morphology), dehydrated in a series of ethanol baths $(95 \% \rightarrow 100 \%)$ and xylene, and mounted with Eukitt (Sigma-Aldrich). Additionally, sPIF expression was detected using a fluorescent setup: Slides were incubated with an FITC-labeled secondary antibody (1:100; goat anti-mouse IgG; Sigma-Aldrich) for $1 \mathrm{~h}$ at room temperature. After three washes of 5 min each in PBS, the brain slices were mounted with aqueous mounting media Immu-Mount from Thermo.

Induction of Hypoxic-Ischemic Brain Injury. All animal procedures were approved by the Ethics Committee and Veterinary Department of the Canton of Berne, Switzerland. Twenty-seven neonatal Wistar rats were randomly divided into three groups, sham, injury, and injury+sPIF, with nine rats in each group. The injury and injury+sPIF groups received LPS $(0.1 \mathrm{mg} / \mathrm{kg}$ body weight, i.p.) at P3. On the following day the left common carotid artery was double-ligated using a stereomicroscope, and animals were subjected to 65 min of hypoxia (8\% O2/92\% N2). Starting on P6, the injury group received PBS (vehicle), and the injury+ sPIF group received sPIF ( $0.75 \mathrm{mg} / \mathrm{kg}$ body weight twice daily) until brain harvesting. The sham group consisted of sham operated animals treated with $0.9 \% \mathrm{NaCl}$ instead of LPS, exposure of carotid artery without ligation, and no hypoxia. Brains were harvested on P13.

Assessment of Cortical Volume, Neuronal Loss, and Glial Activity. Cortical volume was determined in coronal sections stained with cresyl violet and calculated according to Cavalieri's principle using the following formula: $\mathrm{V}=$ $\Sigma \mathrm{A} \cdot \mathrm{P} \cdot \mathrm{T}$, where $\mathrm{V}$ is the total volume of the cortex, $\Sigma \mathrm{A}$ is the sum of the areas measured, $\mathrm{P}$ is the inverse of the sampling fraction, and $\mathrm{T}$ is the section thickness ( $n=4$ per group). The volume was measured in each hemisphere independently. Assessment of neuronal loss and glial activity was performed in the region of interest (ROI), defined as deep cerebral cortex (cortical layers V and VI in plane 118 according to a stereotactic rat atlas) ${ }^{3}$. This cortical area between the rhinal sulcus, the cingulum, contains cerebral white matter, and hypoxia-ischemia at P3 was reported to cause distinctive neuropathological alterations in this region ${ }^{4,5}$. All images of immunohistochemical staining were obtained with a BX51 microscope (Olympus) equipped with a digital camera with a $40 \times$ objective. An independent observer blinded to the experimental conditions acquired six consecutive coronal sections per hemisphere from each animal for each specific immunostaining. For sPIF colocalization, z-section images (spaced by $1-2 \mu \mathrm{m}$ ) were acquired on a laserscanning confocal microscope (OlympusFluoView 1000) with a $40 \times$ dry objective. Images were analyzed and reconstructed using Image J. 
Quantification and Statistical Analysis. All quantifications, such as manual cell counts and Iba-1 immunoreactivity, were performed in a blinded manner. Positive cell counts for NeuN and Iba-1 immunoreactivity were performed in the ROI (see above) as previously reported ${ }^{2,4,6}$. Neuronal loss was determined by unbiased counting of positive cells ${ }^{6}$. We analyzed Iba- 1 immunoreactivity with a standard threshold to determine positive staining, using Image $\mathrm{J}$ as recently reported ${ }^{2}$. We avoided variability resulting from tissue handling and staining and interanimal developmental variations by using the ratio of counts obtained from the left hemisphere (ipsilateral to the carotid injury) to counts obtained from the right hemisphere ${ }^{2,5}$. Data are represented as mean \pm SEM. Single comparisons with control were made using a two-tailed Student t test or the Mann-Whitney test. P < 0.05 was considered to be statistically significant. Data handling and statistical processing were performed using Microsoft Excel and GraphPad Prism Software. 


\section{References:}

1. Kallen AN, et al. The imprinted H19 lncRNA antagonizes let-7 microRNAs. Mol Cell 2013 52(1):101-112.

2. Jellema RK, et al. Cerebral inflammation and mobilization of the peripheral immune system following global hypoxia-ischemia in preterm sheep. J Neuroinflammation 2013 10:13.

3. Ramachandra R Atlas of the Neonatal Rat Brain (CRC, Boca Raton, FL) 2011.

4. Sizonenko SV, Kiss JZ, Inder T, Gluckman PD, Williams CE. Distinctive neuropathologic alterations in the deep layers of the parietal cortex after moderate ischemic-hypoxic injury in the P3 immature rat brain. Pediatr Res 2005 57(6):865-872.

5. Sizonenko SV, et al. Selective cortical alteration after hypoxic-ischemic injury in the very immature rat brain. Pediatr Res 2003 54(2):263-269.

6. Ofengeim D, et al. N-terminally cleaved Bcl-xL mediates ischemia-induced neuronal death. Nat Neurosci 2012 15(4):574-580.

A

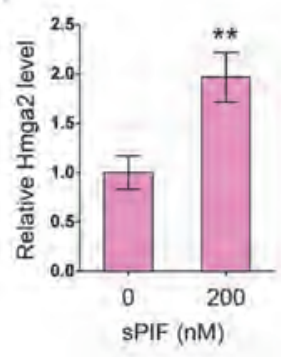

B

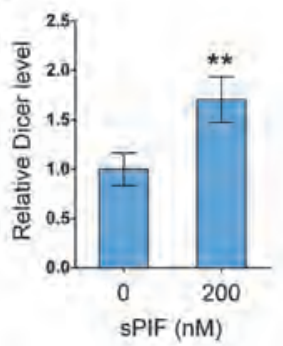

$c$

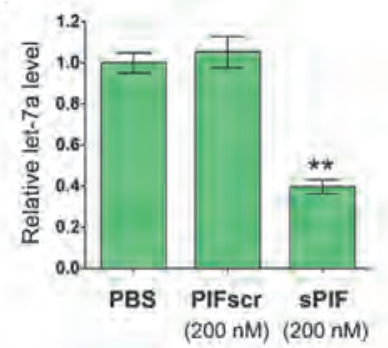

Figure S1. sPIF up-regulates let-7 targets. RAW cells were incubated with PBS, PIFscr, or sPIF at a final concentration of $200 \mathrm{nM}$ for $48 \mathrm{~h}$. RNAs were isolated, and levels were determined by RT-qPCR. (A and B) The levels of indicated mRNAs are presented after normalization against $\beta$-tubulin mRNA with those from PIFscr-treated cells arbitrarily set as 1. (C) Let-7a levels are presented after normalization against U6 RNA. The let-7a level in PBS-treated cells was arbitrarily set as 1 . All numbers are mean $\pm \mathrm{SD}(\mathrm{n}=3)$. ${ }^{* *} \mathrm{P}<0.01$. 
A

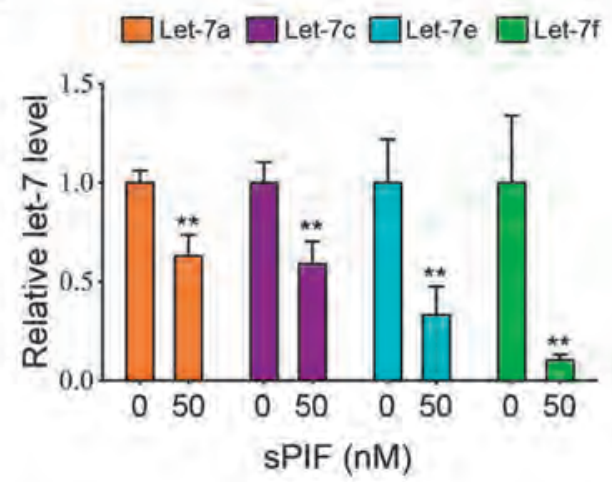

C

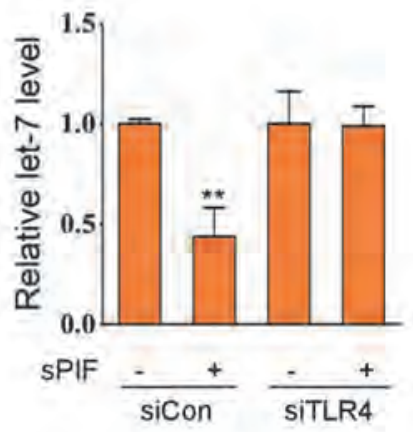

B

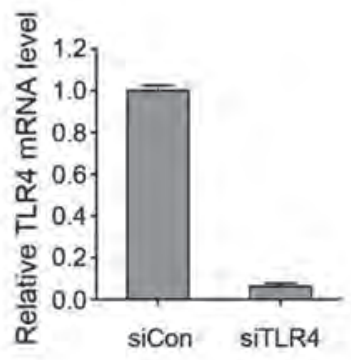

Figure S2. sPIF down-regulates let-7 in BV-2 cells in a TLR4-dependent manner.

(A) Cells were incubated with PIFscr (0) or with sPIF at a final concentration of $50 \mathrm{nM}(50)$ for $48 \mathrm{~h}$. RNAs were isolated, and levels were determined by RT-qPCR. Levels of the indicated let-7 family members are presented after normalization against U6 RNA, with the levels in PIFscr-treated cells arbitrarily set as 1. (B) Cells were transfected with siCon or siTLR4. RNAs were harvested 48 h posttransfection and analyzed by RT-qPCR. (C) Cells were transfected with siCon or siTLR4. sPIF $(50 \mathrm{nM})$ was added $(+)$ or not added $(-)$ to the cells at $48 \mathrm{~h}$ posttransfection, and cells were incubated for an additional $48 \mathrm{~h}$. RNAs were extracted and levels determined by RT-qPCR. Results are presented with let-7a levels in PIFscr-treated ( - ) cells arbitrarily set as 1 . (D) Cells were treated as described in C. Proteins were harvested following $48 \mathrm{~h}$ of incubation with PIFscr $(-)$ or SPIF (+). KSRP protein levels were determined by Western blot using $\beta$-tubulin as a loading control. Except in D, all numbers are mean $\pm \mathrm{SD}(\mathrm{n}=3)$ and are representative of two independent transfection results. ${ }^{* *} \mathrm{P}<0.01$. In $\mathrm{D}$, the numbers were derived from quantitation of protein bands on the presented gels representative of two independent transfection results. The levels of the KSRP protein (after normalization against $\beta$-tubulin) in PIFscr-treated cells were arbitrarily set as 1 . TUBB, $\beta$-tubulin. 
A

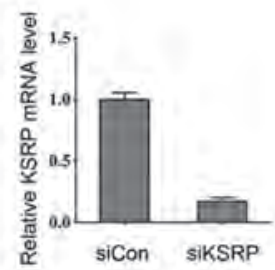

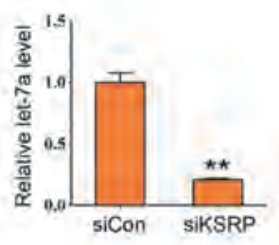

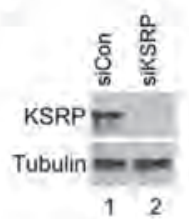

D

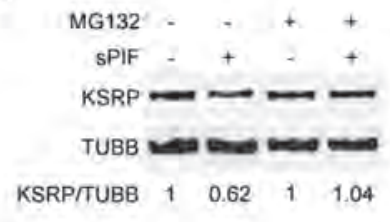

Figure S3. (A-C) KSRP siRNA knockdown decreases let-7 expression in BV-2 cells. Cells were transfected with siCon or siKSRP. RNAs and proteins were isolated $48 \mathrm{~h}$ later and analyzed by RT-qPCR (A and C) and Western blot (B), respectively. Data are shown as mean $\pm S D(n=3)$. Representative results of two independent experiments are shown. ${ }^{* *} \mathrm{P}<0.01$. (D) sPIF-induced KSRP protein destabilization is blocked by the proteasome inhibitor MG132. BV-2 cells were treated with scrPIF $(-)$ or SPIF $(+)$ at a final concentration of $50 \mathrm{nM}$ for $48 \mathrm{~h}$. Then medium was removed and replaced with fresh medium containing MG132 at a final concentration of $5 \mu \mathrm{M}$, and incubation was carried out for an additional $6 \mathrm{~h}$. Total proteins were isolated, followed by Western blot analysis. KSRP protein levels were determined using $\beta$-tubulin as a loading control. The numbers were derived from quantitation of protein bands on the presented gels representative of three independent Western blot results. The levels of the KSRP protein (after normalization against $\beta$-tubulin) in the PIFscr-treated cells were arbitrarily set as 1.
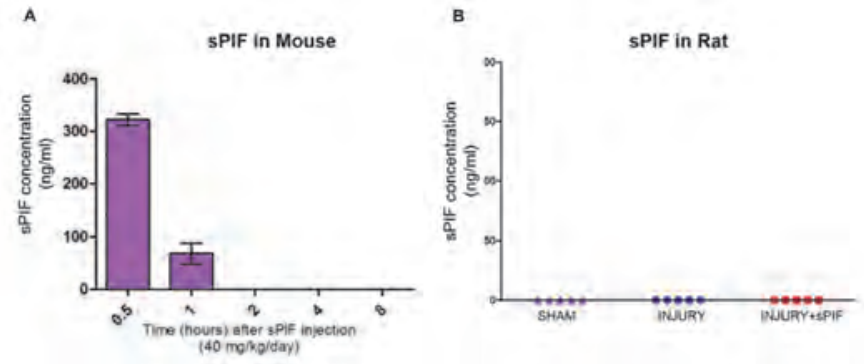

Figure S4. Circulating sPIF concentrations in mice and rats. (A) sPIF $\left(40 \mathrm{mg} \cdot \mathrm{kg}^{-1} \cdot \mathrm{d}^{-1} ; \mathrm{n}=\right.$ 30) was injected s.c., and plasma sPIF levels were measured at $0.5,1,2,4$, and $8 \mathrm{~h}$ postinjection using LC MS/MS. The sPIF concentration was detectable only at 0.5 and $1 \mathrm{~h}$ postinjection. (B) sPIF levels were measured from sham, injury, and injury+sPIF rats ( $\mathrm{n}=5$ animals per group). Samples were obtained at the time of tissue harvesting (12 $\mathrm{h}$ after the last sPIF injection); sPIF was undetectable in all three groups. 



\section{Chapter 6}

\section{PreImplantation Factor bolsters neuroprotection via modulating Protein Kinase A and Protein Kinase $\mathrm{C}$ signaling}

Published as: Mueller M, Schoeberlein A, Zhou J, Joerger-Messerli M, Oppliger B, Reinharts U, Bordey A, Surbek D, Barnea E, Huang Y, Paidas M . PreImplantation Factor bolsters neuroprotection via modulating Protein Kinase A and Protein Kinase C signaling. Cell Death Differ. 2015 Dec;22(12):2078-86. PubMed PMID: 25976303 


\begin{abstract}
:
A synthetic peptide (sPIF) analogous to the mammalian embryo-derived PreImplantation Factor (PIF) enables neuroprotection in rodent models of experimental autoimmune encephalomyelitis and perinatal brain injury. The protective effects have been attributed, in part, to SPIF's ability to inhibit the biogenesis of microRNA let-7, which is released from injured cells during central nervous system (CNS) damage and induces neuronal death. Here, we uncover another novel mechanism of sPIF-mediated neuroprotection. Using a clinically relevant rat newborn brain injury model, we demonstrate that sPIF, when subcutaneously administrated, is able to reduce cell death, reverse neuronal loss and restore proper cortical architecture. We show, both in vivo and in vitro, that sPIF activates cyclic AMP dependent protein kinase (PKA) and calciumdependent protein kinase (PKC) signaling, leading to increased phosphorylation of major neuroprotective substrates GAP-43, BAD and CREB. Phosphorylated CREB in turn facilitates expression of Gap43, Bdnf and Bcl2 known to have important roles in regulating neuronal growth, survival and remodeling. As is the case in sPIF-mediated let-7 repression, we provide evidence that sPIF-mediated PKA/PKC activation is dependent on TLR4 expression. Thus, we propose that sPIF imparts neuroprotection via multiple mechanisms at multiple levels downstream of TLR4. Given the recent FDA fast-track approval of sPIF for clinical trials, its potential clinical application for treating other CNS diseases can be envisioned.
\end{abstract}




\section{Introduction}

Perinatal brain injury in the context of premature birth is a major cause of neonatal morbidity and mortality ${ }^{1}$. Depending on the degree of prematurity, $15-$ $20 \%$ of the affected newborns die during the postnatal period and $\sim 25 \%$ of survivors suffer significant long-term disability including cerebral palsy, epilepsy and increased hyperactivity ${ }^{2}$. Therapeutic approaches to counteract the disastrous cascades of neonatal brain injury have been proposed. Unfortunately, in premature infants at risk, no neuroprotective agent has proven safe and effective so far $^{3}$.

Secreted from developing embryos, PreImplantation Factor (PIF) can be detected in the maternal circulation during pregnancy, ${ }^{4,5}$ and its presence has been correlated with live birth ${ }^{5-7}$. PIF has been implicated in promoting embryo implantation through modulating maternal immune tolerance 5, 8, 9 . Consistent with the immune function, a synthetic PIF analog (sPIF) of 15 amino acids (MVRIKPGSANKPSDD) that was subcutaneously administrated was able to both reverse and prevent paralysis through inhibiting neuroinflammation in a murine model of experimental autoimmune encephalomyelitis ${ }^{10}$. The neuroprotective property of sPIF was further underscored by its ability to mitigate neuronal loss and microglial activation in a rat model of perinatal brain injury ${ }^{11}$. The neuroprotective effects were attributed, at least in part, to sPIF's ability to downregulate microRNA let-7 in the injured brain. Abundantly expressed in the central nervous system (CNS), let-7 released from dying cells during brain injury induces neuronal death, exacerbating CNS damage ${ }^{12}$, ${ }^{13}$. sPIF inhibited the biogenesis of let-7 in both neuronal and immune cells through Toll-like Receptor 4 (TLR4) ${ }^{11}$. As PIF imparts multitargeted effects, ${ }^{10}$ it is almost certain that inhibiting let-7 is not the only mechanism of PIF action.

In search of additional mechanisms, we chose to focus on cyclic AMP-dependent protein kinase (PKA) and calciumdependent protein kinase (PKC). PKA/PKC signaling is downstream of TLR4, ${ }^{14}, 15$ and TLR4 was required for sPIFinduced neuroprotective effects ${ }^{11}$. PKA/PKC are important signaling molecules in a variety of cellular functions, including cell growth and differentiation, neuronal plasticity and cellular response to hypoxia-ischemia ${ }^{16-19}$. Mechanistically, PKA/PKC activation leads to phosphorylation of serine and threonine residues on target proteins, thereby modulating protein stability, protein-protein interactions and catalytic activity ${ }^{20}$. In the case of brain injury, activation of the PKA/PKC signaling pathways imparts neuroprotection by increasing expression of antiapoptotic and neurotrophic molecules while reducing pro-apoptotic molecules in neurons ${ }^{21-23}$. Not surprisingly, PKA/PKC pathways have been recognized as potent targets for neuroprotective strategies.

In the current study, we have examined and revealed a novel mechanism of PIF action. sPIF confers neuroprotection in a rat model of perinatal brain injury by modulating PKA/PKC signaling, which is recapitulated in vitro using neuronal cells. Overall, our data support clinical translation of sPIF treatment for hypoxicischemic brain injuries.

\section{Results}


แ่
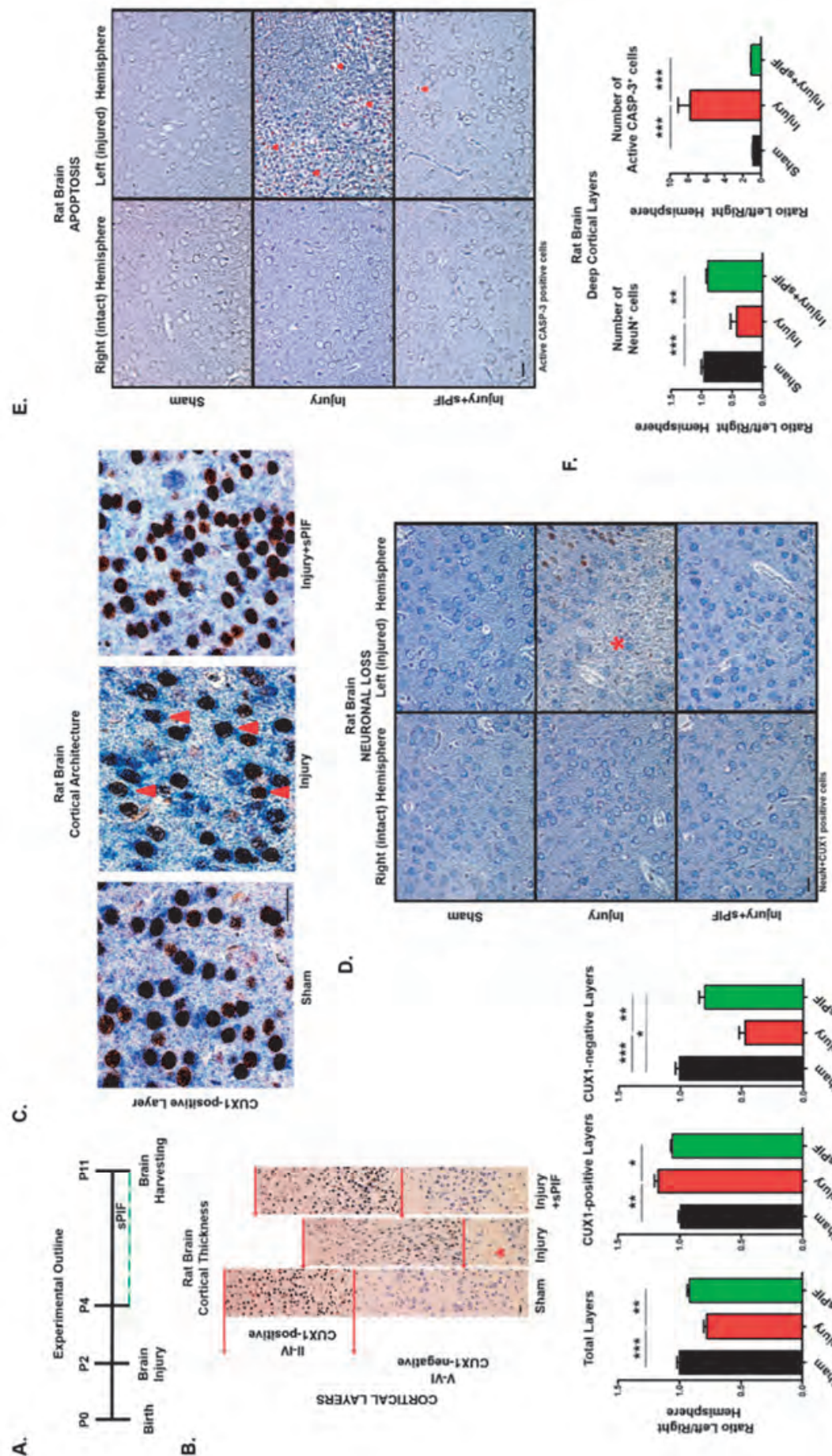

นะ
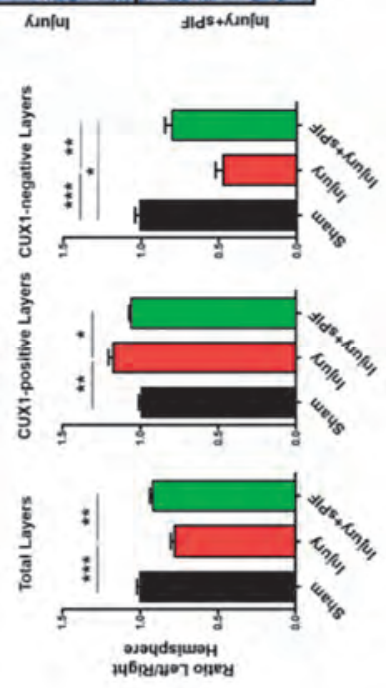
Figure 1. sPIF rescues cortical thickness and neuronal loss while decreasing active Caspase3-positive cells in vivo. (a) Experimental outline. (b) Representative immunohistochemistry images containing somatosensory cortices and quantification of cortical thickness in upper (NeuN and CUX1-positive) and deeper (NeuN-positive and CUX1-negative) cortical layers. In injured animals, reduced cortical thickness is marked with a red star. (c) Representative immunohistochemistry images of CUX1-positive layers displaying cortical architecture. In injured animals, neurons display altered soma morphology (marked with red arrows). (d and e) Representative immunohistochemistry images stained with cresyl violet and (d) NeuN+CUX1 (for neuronal loss) and (e) active CASP-3 (for cell death) in deep cortical layers. In injured animals, neuronal loss is marked with a red star and active CASP-3-positive cells with red arrows. (f) Quantification of number of NeuN and active CASP-3-positive cells in deep cortical layers. Quantification results are displayed as ratio of the left (injured) to right (uninjured) hemisphere. Scale bar, $25 \mu \mathrm{m}$. Data are resented as mean \pm S.E.M. ( $\mathrm{n}=4$ each group, one-way repeated measures ANOVA followed by Bonferroni's Multiple Comparison Test). $* \mathrm{P}<0.05, * * \mathrm{P}<0.01, * * * \mathrm{P}<0.001$

sPIF promotes neuronal survival and migration in vivo. Given that sPIF induces global alterations in gene expression, it is highly likely that sPIF facilitates neuronal survival beyond targeting microRNA let- ${ }^{9,11}$. To evaluate the neuroprotective potential of sPIF, we induced brain injury in neonatal rats at P2 (Figure 1a). This time point matches ongoing neuronal development ${ }^{24}$. The mammalian cerebral cortex is a six-layered structure comprising primarily pyramidal neurons and remaining inhibitory interneurons ${ }^{25}$. The pyramidal neurons are generated in a well-defined inside-out manner, in which layer VI and V (deep layers) neurons arise and migrate first and layer IV-II (upper layers) neurons are born and migrate later ${ }^{25}$. By birth, upper-layer neurons are still migrating until P7 whole deep-layer neurons are undergoing maturation. Thus, the major features of neuronal development and in particular deep-layer neurons may be altered as a consequence of perinatal brain injury 26,27 .

We evaluated cortical thickness (CT) first because in premature newborns reduced CT correlates with adverse neurological outcomes ${ }^{28}$. We focused on evaluating regions containing motor and somatosensory cortices, as injury in these regions between the rhinal sulcus and the cingulum causes distinctive neuropathological alterations 11, 27, 29. We examined the position of upper (CUX1-positive) and deeper (CUX1-negative) neurons in the cortex (Figure 1b). CUX1 is a welldefined molecular marker of upper-layer neurons (cortical layers II-IV) ${ }^{30}$. We detected reduced CT in deep cortical layers in the Injury compared with the Sham animals (Figure 1b). This observation confirmed previous reports that at P2 deep cortical layers are particularly susceptible to hypoxic-ischemic brain injury ${ }^{27,31}$. We also detected an expansion of the CUX1-positive layers as CUX1-positive cells were misplaced (Figure 1b). This observation suggested that hypoxicischemic injury at P2 resulted in disturbed neuronal migration of CUX1-positive cells. In addition, CUX1-positive cells displayed abnormal soma morphology as they exhibited a very thin leading process, which indicates disturbed neuronal migration (Figure 1c) ${ }^{32}$.

Next, we analyzed the number of NeuN+ (mature neurons) and active Caspase-3 (CASP-3, marker of apoptosis)-positive cells in deep cortical layers, as injury predominantly reduced the thickness of these regions (Figure 1b). Brain injury at P2 resulted in neuronal loss (Figures $1 \mathrm{~d}$ and $\mathrm{f}$ ) and increased number of active CASP-3-positive cells (Figures 1e and f). Strikingly, in sPIF-treated animals (Injury+sPIF), both the CT (Figure 1b) and number of NeuN+ neurons (Figures 
A.
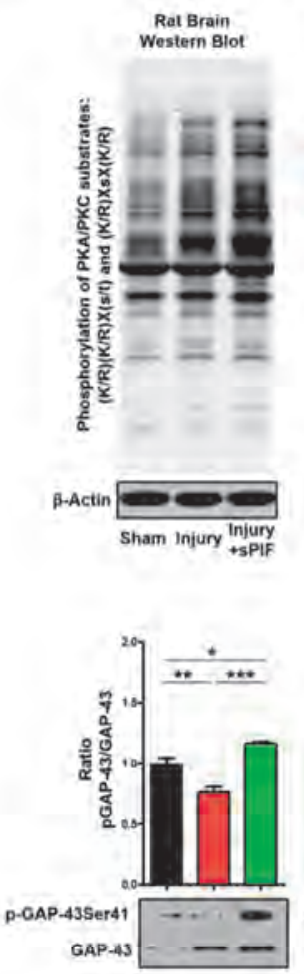

B.

Rat Brain
Western Blots
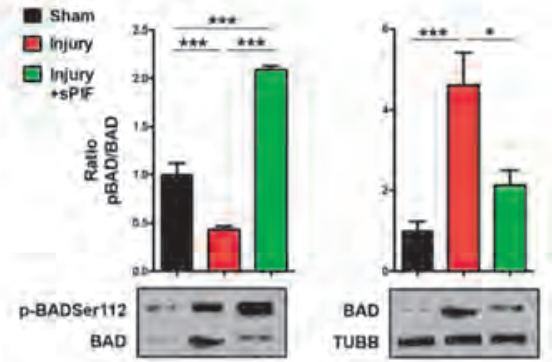

C.
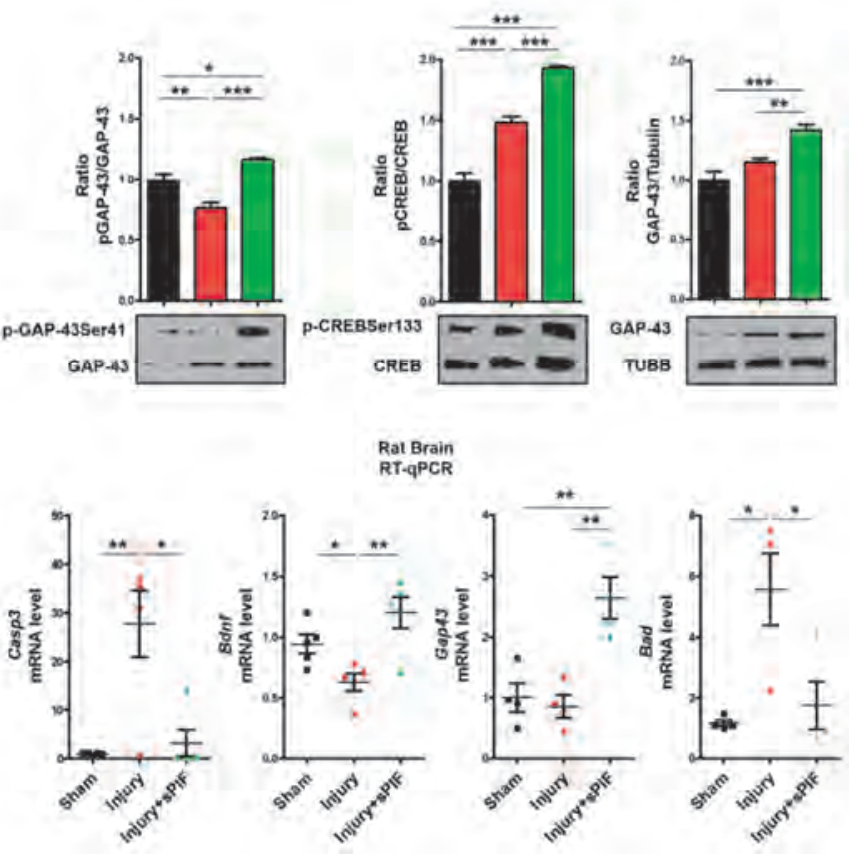

Figure 2. sPIF enhances phosphorylation of PKA/PKC substrates in vivo. (a) Representative western blots ( $\mathrm{n}=3$ each group) of brain lysates probed with antibodies against specific $(\mathrm{K} / \mathrm{R})(\mathrm{K} / \mathrm{R}) \mathrm{X}(\mathrm{s} / \mathrm{t})$ and $(\mathrm{K} / \mathrm{R}) \mathrm{XsX}(\mathrm{K} / \mathrm{R})$ phosphorylation motifs representing PKA/PKC substrates. $\beta$-Actin was used as a loading control. (b) Representative western blots ( $\mathrm{n}=5$ each group) of brain lysates probed with specific antibodies against phosphorylated and total protein levels. Protein levels were quantified using a ratio of phosphorylated/total protein level using beta-tubulin (TUBB) as a loading control. (c) RNAs were extracted from brain lysates (n =5 each group) and levels determined using RT-qPCR. Quantification results of the Sham group were arbitrarily set as 1 . Data are presented as mean \pm S.E.M. (one-way repeated measures ANOVA followed by Bonferroni's Multiple Comparison Test, two-tailed Student's t-test). $* \mathrm{P}<0.05, * * \mathrm{P}<0.01, * * * \mathrm{P}<0.001$

$1 \mathrm{~d}$ and $\mathrm{f}$ ) were restored (compare with Sham) with decreasing numbers of active CASP-3-positive cells (Figures 1e and f). Further, the cortical architecture and 
neuronal morphology in the sPIF-treated animals were comparable to those from the Sham animals (Figures $1 \mathrm{~b}$ and c). Collectively, our results support the notion that SPIF acts to promote neuronal survival and preserve proper neuronal migration, thereby preserving the cortical architecture.

sPIF modulates PKA/PKC signaling in vivo. Given the neuroprotective effects of sPIF (Figure 1), we tested whether sPIF modulates PKA/PKC signaling. Having a screening approach in mind, we tested well-characterized S/T phosphorylation motif antibodies, which detect all phosphorylated PKA/PKC substrates in brain lysates ${ }^{33}$. There is a global phosphorylation increase in the Injury compared with the Sham group (Figure 2a), which is in line with the notion that inflammatory and/or ischemic insults activate PKA/PKC signaling ${ }^{34-36}$. Importantly, we detected a further increase in phosphorylation in the Injury+sPIF compared with the Injury group, suggesting possible modulation of PKA/PKC signaling by SPIF ${ }^{35}$. Thus, we reasoned that SPIF might enhance the phosphorylation of neuroprotective PKA/PKC substrates and therefore decided to test the phosphorylation status of BADSer112, GAP-43Ser41 and CREBSer133.

Bcl-associated death protein (BAD) induces apoptosis 22, 23. However, phosphorylation of BAD at the Ser112 site (BADSer112) results in liberation of anti-apoptotic proteins blocking apoptosis in vitro ${ }^{37,38}$ and in vivo ${ }^{21,39}$. Growth associated protein 43 (GAP-43) is a well-established marker of neuronal plasticity with increased expression during neuronal recovery 40, 41. Importantly, phosphorylation at Ser41 regulates GAP-43 interaction with the cytoskeleton, promoting neurite outgrowth ${ }^{42}$ and dephosphorylation results in cytoskeleton destruction and growth cone collapse ${ }^{43}, 44$. The transcription factor cAMPresponsive element-binding protein (CREB) has been implicated in neuronal development, synaptic plasticity and in cell survival in response to ischemia ${ }^{45,46}$. Phosphorylation of CREBSer133 leads to recruitment of CREB-binding protein (CBP) at the promoter regions of cAMP-responsive genes including Gap43, Bcl2, and Bdnf 40, 47, 48 which impart neuroprotection 21, 49, 50. In summary, phosphorylation of all three proteins (BAD, GAP-43 and CREB) results in broad neuroprotective effects and represents a target for neuroprotective strategies.

Thus, we tested the three PKA/PKC substrates in our perinatal brain injury model. sPIF treatment indeed significantly enhanced phosphorylation of BADSer112, GAP-43Ser41 and CREBSer133 compared with the Injury animals (Figure 2b). The expressions of downstream genes Bcl2, Bdnf and Gap43 were expectedly increased in the sPIF-treated versus Injury animals (Figure 2c). Notably, we detected the increase in Gap43 at the RNA and protein levels (Figures 2b and c), which is consistent with PKA/PKC mediated neuronal recovery ${ }^{40,41}$. On the other hand, we detected an increase in pro-apoptotic BAD protein and the RNA levels in Injury versus Sham and Injury+sPIF groups (Figures $2 b$ and c). This is in line with the notion of increased BAD protein and RNA levels in neurodegenerative diseases, ${ }^{51,52}$ which further supports the activity of sPIF of neuroprotection. Together, these results suggested that the neuroprotective effects observed (Figure 1) were at least in part because of modulation of PKA/PKC signaling, which prompted us to carry out more in-depth dissections of the underlying mechanisms in vitro.

sPIF protects neuronal cells through a PKA/PKC-dependent mechanism in vitro. We have previously used the murine neuroblastoma cell line N2a to 
demonstrate that SPIF inhibits the biogenesis of let-7, corroborating sPIF's ability of neuronal protection in vivo ${ }^{11}$. To determine whether SPIF protects neuronal cells in part by regulating PKA/PKC signaling, N2a cells were pretreated with lipopolysaccharides (LPS; to mimic the in vivo situation ${ }^{11}$ ), and then subjected to sPIF or scrambled PIF (PIFscr, as a negative control). We detected a timedependent increase in the PKA/PKC activity in sPIF- versus PIFscr-treated cells (Figure 3a), consistent with our in vivo results (Figures 2b and c). The ability of SPIF to reduce apoptosis and promote neuronal survival in N2a was also evaluated. In line with our in vivo results (Figures $1 d-f$ and $2 c$ ), sPIF reduced the expression of the pro-apoptotic genes Bad and Casp3 while increasing that of the anti-apoptotic Bcl2 (Figure 3b). In addition, sPIF promoted neuronal survival as assessed by increased cell viability and reduced apoptosis (Figure 3c).

A.
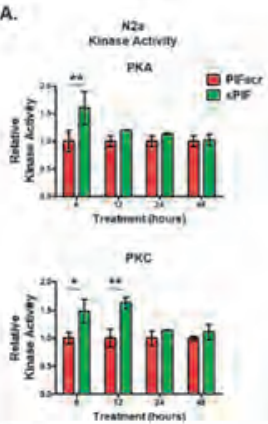

B.

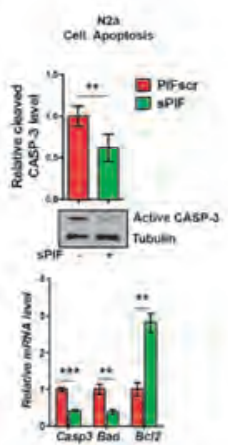

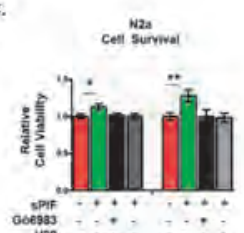

is Treatment 24.

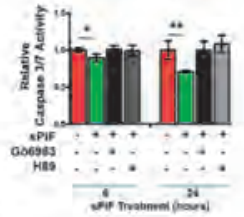

D.

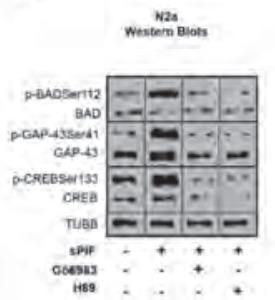

E.
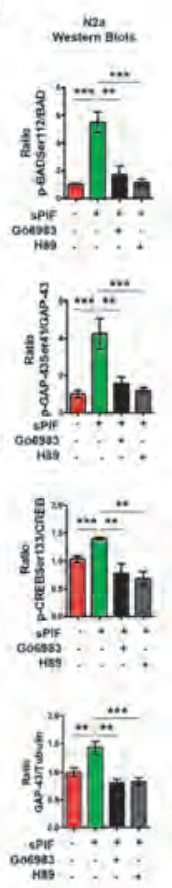

F.
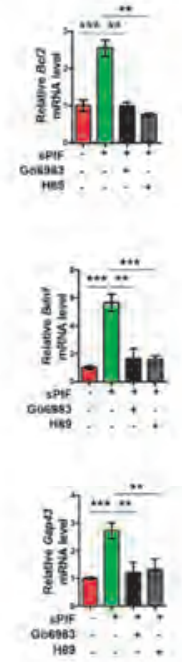

Figure 3. (a) sPIF promotes neuronal survival in a PKA/PKC-dependent manner in vitro. N2a cells were incubated in the presence of LPS and on the next day treated with sPIF $(+)$ or PIFscr $(-)$ at $200 \mathrm{nM}$ and/or in the presence of PKA (H89+) and PKC (Gö6983+) inhibitors. (a) Kinase activity assay was used to determine PKA and PKC activity at the indicated time points. (b) Protein and RNAs were extracted $24 \mathrm{~h}$ later and levels determined by western blot and RT-qPCR. (c) Cell viability and Caspase 3/7 activity were determined 6 and 24 h later. (d and e) Proteins were extracted $24 \mathrm{~h}$ later and levels determined with western blot analysis. (f) RNAs were extracted $24 \mathrm{~h}$ later and levels determined using RT-qPCR. Protein and RNA levels are presented after normalization using TUBB as loading control and against those from PIFscr-treated, which were arbitrarily set as 1 . All results are representative of three or more independent experiments. Data are presented as mean \pm S.D. (two-tailed Student's t-test). $* \mathrm{P}<0.05, * * \mathrm{P}<0.01, * * * \mathrm{P}<0.001$

To confirm whether the sPIF-induced reduction of apoptosis was dependent on PKA/PKC signaling, pharmacological inhibitors specific against PKA (H89) and PKC (Gö6983) ${ }^{53,54}$ were used. As shown in Figure 3c, sPIF-induced neuronal survival was abolished in the presence of H89 and Gö6983, consistent with a 
PKA/PKC-mediated mechanism. Expectedly, the presence of the inhibitors abrogated sPIF-induced phosphorylation increase of PKA/PKC substrates BADSer112, GAP-43Ser41 and CREBSer133 (Figures 3d and e) as well as the increase in the expression of downstream targets Bcl2, Bdnf and Gap43 (Figure 3f). Taken together, our in vitro results lend a strong support to our in vivo findings that by modulating PKA/PKC signaling sPIF enhances the expression of neuroprotective genes while decreasing pro-apoptotic gene expression, thereby promoting neuronal survival.

A.

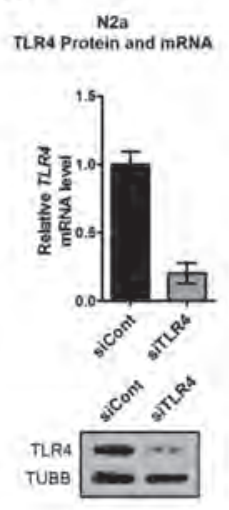

B.

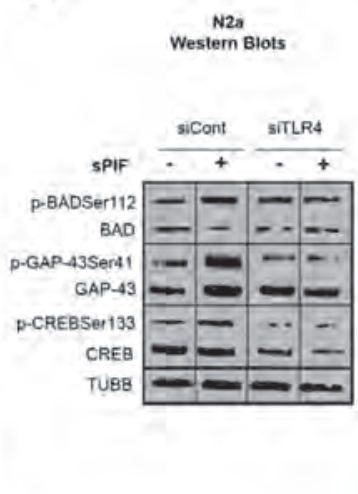

c.

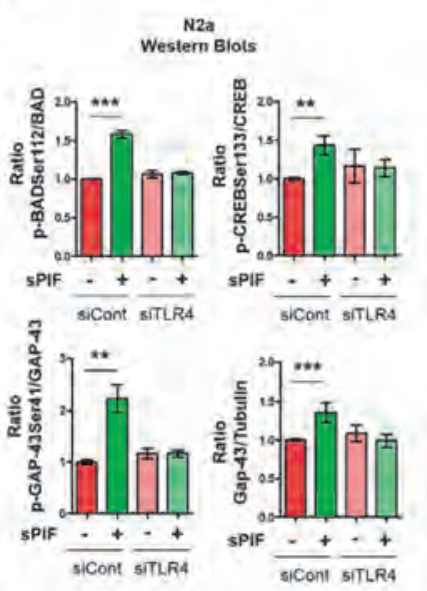

D.

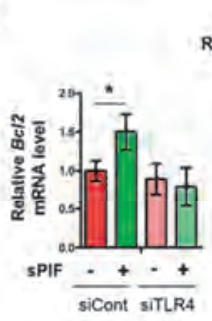

$\stackrel{\text { N2a }}{\text { RT-qPCR }}$

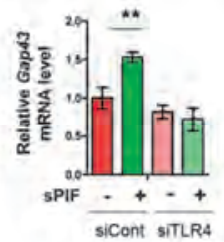

E.

Proposed Model for sPIF-Induced neuronal protection
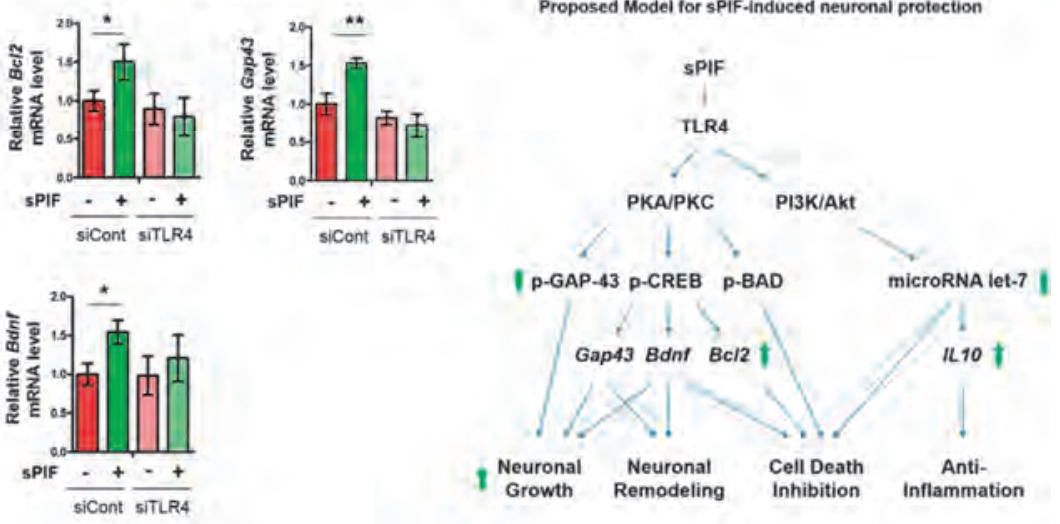

Figure 4. (a) SPIF enhances phosphorylation of PKA/PKC substrates in a TLR4-dependent manner in vitro. N2a cells were transfected with control siRNA (siCon) or siRNA specific for TLR4 (siTLR4). On the following day, cells were pretreated with LPS and treated with sPIF $(+)$ or PIFscr $(-)$ at $200 \mathrm{nM}$. (a) RNAs and proteins were harvested $12 \mathrm{~h}$ post transfection and analyzed using RT-qPCR (upper) and western blot analysis (bottom), respectively. (b and c) Proteins were extracted $24 \mathrm{~h}$ later and levels determined using western blot analysis. (d) RNAs were extracted $24 \mathrm{~h}$ later and levels determined using RT-qPCR. (e) Proposed model for sPIFinduced neuronal protection. Protein and RNA levels are presented after normalization using TUBB as loading control and against those from PIFscr-treated, which were arbitrarily set as 1 . All results are representative of three or more independent experiments. Data are presented as mean \pm S.D. (two-tailed Student's t-test). $* \mathrm{P}<0.05,{ }^{*} \mathrm{P}<0.01$, $* * * \mathrm{P}<0.001$ 
The sPIF-mediated PKA/PKC mechanism is TLR4-dependent. TLR4 is known to be upstream of PKA/PKC signaling ${ }^{14,}{ }^{15}$. We also have previously shown that TLR4 is required for sPIF-mediated let-7 inhibition in N2a cells ${ }^{11}$. To determine whether sPIF-induced alteration in PKA/PKC signaling was also dependent on TLR4, TLR4 was knocked down in N2a using a TLR4-specific siRNA (siTLR4) ${ }^{11}$ and effects on PKA/PKC substrate phosphorylation and downstream target gene expression were assessed. When TLR4 was downregulated (Figure 4a), sPIF-induced phosphorylation increase of PKA/PKC substrates BADSer112, GAP-43Ser41 and CREBSer133 was abolished (Figures $4 \mathrm{~b}$ and c). Consistently, sPIF-induced increase in the expression of downstream target genes Bcl2, Bdnf and Gap43 was also negated (Figure 4d). Collectively, these results provide evidence that TLR4 is required for sPIF-mediated modulation of PKA/PKC signaling.

\section{Discussion}

This report documents a new mechanism of sPIF-mediated neuroprotection. Using a clinically relevant newborn brain injury model, we demonstrate that subcutaneously injected sPIF was able to reduce cell death, reverse neuronal loss and restore proper cortical architecture. We provide evidence from both in vivo and in vitro studies that sPIF does so in part by modulating PKA/PKC signaling in a TLR4-dependent manner. As summarized in Figure 4e, sPIF activates PKA/PKC signaling through TLR4, resulting in phosphorylation of neuroprotective substrates GAP-43, CREB and BAD, which in turn stimulates expression of downstream genes Gap43, Bdnf and Bcl2. These genes have wellestablished roles in modulating neuronal growth, remodeling and survival ${ }^{21,49,50}$. In light of our previous findings, ${ }^{11}$ SPIF downregulates microRNA let-7 expression through PI3K/Akt signaling, also in a TLR4-dependent manner reducing neuronal death. Meanwhile, decreased let-7 levels lead to increased expression of IL10, a direct target of let-7-mediated inhibition ${ }^{55,56}$ and a potent anti-inflammatory cytokine in neuroprotection ${ }^{57-59}$. Given the potent in vivo neuroprotective effects of sPIF, ${ }^{10,11}$ we propose that the two pathways (PKA/PKC and PI3K/Akt) may work synergistically in sPIF-mediated neuroprotection.

Our current and previous ${ }^{11}$ findings highlight an important role of TLR4 in sPIFmediated neuroprotection, although the exact mechanism by which sPIF interacts with TLR4 remains to be investigated. The divergent in vivo effects of sPIF (neuroprotection, Figure 1) and LPS-induced neuroinflammation ${ }^{24}$ suggest association/synergism with distinct cofactors of TLR4 signaling ${ }^{35}$. Thus, it is conceivable that cofactors of sPIF likely act in concert to elicit/synergize downstream effects that are specific to SPIF but different from those induced by LPS. In addition, studies to determine in vivo effects of TLR4 silencing will be needed to firmly establish the role of TLR4 in sPIF-mediated neuroprotection.

With respect to potential clinical relevance and translation to human premature newborns, we decided to induce brain injury by a combination of LPS and hypoxia-ischemia at P2 and started therapy at P4 (Figure 1a) in neonatal rats. We used LPS before hypoxia-ischemia because perinatal infection/ inflammation contributes substantially to cerebral injury in immature neonates ${ }^{60}$. In neonatal rats, LPS results in time and TLR4-dependent sensitization to the following injury, ${ }^{61,} 62$ which mimics the situation in human newborns when 
infection/inflammation occurs. In addition, we induced brain injury at P2 because neonatal rats correspond to human immature infants in terms of brain development and susceptibility to injury ${ }^{24}$. It is also noteworthy that sPIF promotes neuroprotection despite the late starting point (P4) of the therapy. From a clinical point of view this late treatment is promising, as in immature infants the precise timing of the injury often remains unclear (whether it occurs pre-, during labor or during the postnatal period) and treatment options frequently result in no benefit ${ }^{63}$.

Finally, our finding that sPIF targets PKA/PKC is particularly intriguing as studies have pointed to the modulation of PKA/PKC signaling as a therapeutic approach for adult neuronal injury such as Alzheimer's Disease and cerebral ischemic/stroke ${ }^{20,64,65}$. Importantly, in our previous studies we have demonstrated that subcutaneously injected SPIF was able to reach the brain and localize to neuronal cells as assessed using immunofluorescence ${ }^{11}$. Furthermore, in this previous study, we showed that such a dosing regimen was indeed effective in rescuing brain damage in the same rat model used in this current study. Together, the current and previously reported neuroprotective evidence, ${ }^{10,11}$ combined with the FDA fast-track approval and recently started Phase I Clinical Trial for autoimmune hepatitis (https:/clinicaltrials.gov), supports the potential clinical application of sPIF for both perinatal and adult brain injuries.

\section{Materials and Methods}

Cell culture. Mouse neuroblastoma cells (N2a) were purchased from ATCC. Cells were maintained in DMEM (Gibco, Life Technologies, Carlsbad, CA, USA; 11965-092) supplemented with 10\% FBS (Gibco, 16140-071), 1 mM L-glutamine (Gibco, 25030-081) and 1\% penicillin-streptomycin (Gibco, 15140-122) in 5\% $\mathrm{CO}_{2}$ atmosphere at $37^{\circ} \mathrm{C}$. Trypsin-EDTA (0.25\%, Gibco, 25200-056) was applied to detach N2a from culture plates.

Treatment of cultured cells. Cells were seeded in 48-well plates in regular growth media at a density of $\sim 8 \times 10^{4}$ per well. The next day, media were replaced with free-serum media containing LPS $(0.5 \mu \mathrm{g} / \mathrm{ml})$ for $24 \mathrm{~h}$. The day after, media were replaced with serum-free media containing sPIF or PIFscr at $200 \mathrm{nM}$ concentration, followed by incubation for the indicated time duration. For PKA/PKC inhibitor studies after LPS pretreatment, media were replaced with serum-free media containing inhibitors for PKA (H89) or PKC (Gö6983) at $5 \mu \mathrm{M}$ concentration. After $30 \mathrm{~min}$, media were replaced with serum-free media containing PKA or PKC inhibitor and sPIF or PIFscr at $200 \mathrm{nM}$ for the indicated time duration.

Cell viability and apoptosis (Caspase 3/7) activity. Briefly, cells were seeded in 96-well plates at a density of $1 \times 10^{4}$ /well. The next day, media were replaced with serum-free media containing LPS $(0.5 \mu \mathrm{g} / \mathrm{ml})$ for $24 \mathrm{~h}$. The next day, media were replaced with serum-free media containing sPIF or PIFscr at $200 \mathrm{nM}$ concentration. Cell viability and apoptosis (caspase 3/7 activity) were measured 6 and $24 \mathrm{~h}$ post sPIF or PIFscr treatment using the Cell Titer Blue Cell Viability kit (Promega, Madison, WI, USA; no. G8081) and the Apo-ONE Homogeneous Caspase-3/7 Assay kit (Promega, no. G7791), respectively. 
PKA and PKC activity. Briefly, cells were seeded in 48-well plates at a density of $8 \times 10^{4} /$ well. The next day, media were replaced with serum-free media containing LPS $(0.5 \mu \mathrm{g} / \mathrm{ml})$ for $24 \mathrm{~h}$. The next day, media were replaced with serum free media containing sPIF or PIFscr at $200 \mathrm{nM}$ concentration. PKA and PKC activities were measured at 6, 12, 24 and $48 \mathrm{~h}$ post-sPIF and -PIFscr treatment using the PKA (Enzo Life Sciences, Farmingdale, NY, USA; ADi-EKS390 A) and PKC (Enzo Life Sciences, ADi-EKS-420 A) kinase activity kit, respectively, according to the manufacturer's protocols.

Induction of hypoxic-ischemic brain injury. All animal procedures and perioperative care were approved by the Ethics Committee and Veterinary Department of the Canton of Berne, Switzerland. Animals (36 neonatal Wistar rats) were randomly divided into three groups (Sham, Injury and Injury+sPIF; $\mathrm{n}=12$ each group). Injury and Injury+sPIF groups received LPS $(0.1 \mathrm{mg} / \mathrm{kg} \mathrm{BW}$, i.p.) at postnatal day 1 (P1). On the following day, the animals were placed on an approved thermoregulatory device $\left(37^{\circ} \mathrm{C}\right)$, anesthetized using isoflurane and a 5$\mathrm{mm}$ jugular skin incision was made (using microscissors). We exposed the left carotid artery, separated from the nervus vagus and permanently ligated (6.0 prolene suture) and cut the artery ${ }^{11,66}$. We closed the skin incision using a 6-0 prolene suture. The complete procedure did not exceed $10 \mathrm{~min}$. Animals were returned to the mother for a recovery period of $60 \mathrm{~min}$ and then placed in a gastight cylinder, which was flooded with pre-warmth and humidified gas mixture $\left(8 \% \mathrm{O}_{2}\right.$ and $\left.92 \% \mathrm{~N}_{2}\right)$ for a period of up to $65 \mathrm{~min}$, thus creating a stable $8 \% \mathrm{O}_{2}$ environment. Starting on postnatal day 4 , the Injury group received phosphatebuffered saline (Vehicle) and the Injury+sPIF group received sPIF $(0.75 \mathrm{mg} / \mathrm{kg}$ BW twice daily) until brain harvesting on postnatal day ${ }^{11}$. The Sham group consisted of sham-operated animals $(0.9 \% \mathrm{NaCl}$ instead of LPS, exposure of the carotid artery without ligation, no hypoxia).

Quantitative assessment of the brain. Assessment of neuronal loss and number of active CASP-3-positive cells was made in the region of interest (ROI) defined as the deep cerebral cortex (cortical layers V and VI in Figure. 108 according to a stereotactic rat atlas ${ }^{67}$ and in each hemisphere independently. This cortical area between the rhinal sulcus and the cingulum contains the cerebral white matter, and hypoxia-ischemia on P3 was reported to cause distinctive neuropathological alterations in these regions ${ }^{27,29}$. CT, and CUX1-positive and -negative CT were determined in coronal sections (Figure 108 according to a stereotactic rat atlas) ${ }^{67}$ containing motor and somatosensory cortices. The sections were stained with cresyl violet and evaluation performed in each hemisphere independently. Because of the variability in the thickness of the motor cortex, we drew a perpendicular line to the white matter through the six layers of the cortex to measure the thickness. All images of immunohistochemical stainings were obtained with a BX51 microscope (Olympus, Tokyo, Japan) equipped with a digital camera and images acquired using a $\times 40$ objective images for ROI evaluation and a $\times 10$ objective for CT and Neuronal Displacement evaluation. An independent observer acquired six consecutive coronal sections per hemisphere and animal for each specific immunostaining blinded to the experimental conditions. Images were analyzed and reconstructed using Image J (US National Institutes of Health, Bethesda, MD, USA).

Quantification and statistical analysis. All quantifications such as manual cell counts were performed in a blinded manner. Positive cell counts for NeuN and 
active CASP-3-positive cells were performed in the ROI (see above) as previously reported $27,68,69$. Number of cells was determined by unbiased counting of positive cells ${ }^{68}$.

Data analysis. We avoided variability resulting from tissue handling and staining, and interanimal developmental variations by using a ratio of left (ipsilateral to carotid occlusion) to the right hemisphere ${ }^{29,69}$. Data from in vivo studies are represented as mean \pm S.E.M. Data from in vitro studies are represented as mean \pm S.D. Single comparisons with control were made using two-tailed Student's ttest or Mann-Whitney test. We used one-way repeated measures ANOVA followed by Bonferroni's Multiple Comparison Test for multigroup design. $\mathrm{P}<0.05$ was considered to be statistically significant. Data handling and statistical processing were performed using the Microsoft Excel and GraphPad Prism Software.

Conflict of Interest. ERB is CSO of BioIncept, LLC, NJ, USA. The remaining authors declare no conflict of interest.

Acknowledgements. This work was supported by funds from the Eagle Foundation (Switzerland), Cryo-Save AG (Switzerland), Forschungs-Grant (University Hospital Bern, Switzerland) and unrestricted fund from BioIncept LLC. We thank Jeff Silva, Cell Signaling Technology, MA, USA for performing the PKA/PKC motif. antibodies experiments. We thank Cedric Simillion, University of Bern, for support with the statistical analysis. 


\section{Chapter 6}

\section{References}

1. Preterm birth: crisis and opportunity. Lancet 2006; 368: 339.

2. Volpe JJ. Brain injury in premature infants: a complex amalgam of destructive and developmental disturbances. Lancet Neurol 2009; 8: 110-124.

3. Higgins RD, Raju T, Edwards AD, Azzopardi DV, Bose CL, Clark RH et al. Hypothermia and other treatment options for neonatal encephalopathy: an executive summary of the Eunice Kennedy Shriver NICHD workshop. J Pediatr 2011; 159: 851-858.

4. Barnea ER. Insight into early pregnancy events: the emerging role of the embryo. Am J Reprod Immunol 2004; 51: 319.

5. Barnea ER, Kirk D, Ramu S, Rivnay B, Roussev R, Paidas MJ. PreImplantation Factor (PIF) orchestrates systemic antiinflammatory response by immune cells: effect on peripheral blood mononuclear cells. Am J Obstet Gynecol 2012; 207: 313.

6. Stamatkin CW, Roussev RG, Stout M, Absalon-Medina V, Ramu S, Goodman C et al. PreImplantation Factor (PIF) correlates with early mammalian embryo development-bovine and murine models. Reprod Biol Endocrinol 2011; 9: 63.

7. Ramu S, Stamatkin C, Timms L, Ruble M, Roussev RG, Barnea ER. PreImplantation factor (PIF) detection in maternal circulation in early pregnancy correlates with live birth (bovine model). Reprod Biol Endocrinol 2013; 11: 105.

8. Roussev RG, Dons'koi BV, Stamatkin C, Ramu S, Chernyshov VP, Coulam CB et al. Preimplantation factor inhibits circulating natural killer cell cytotoxicity and reduces CD69 expression: implications for recurrent pregnancy loss therapy. Reprod Biomed Online 2013; 26: 79-87.

9. Paidas MJ, Krikun G, Huang SJ, Jones R, Romano M, Annunziato J et al. A genomic and proteomic investigation of the impact of preimplantation factor on human decidual cells. Am $J$ Obstet Gynecol 2010; 202: 459 e451-459 e 458.

10. Weiss L, Or R, Jones RC, Amunugama R, JeBailey L, Ramu S et al. Preimplantation factor (PIF*) reverses neuroinflammation while promoting neural repair in EAE model. J Neurol Sci 2012; 312: 146-157.

11. Mueller M, Zhou J, Yang L, Gao Y, Wu F, Schoeberlein A et al. PreImplantation factor promotes neuroprotection by targeting microRNA let-7. Proc Natl Acad Sci USA 2014; 111:13882-13887.

12. Lehmann SM, Kruger C, Park B, Derkow K, Rosenberger K, Baumgart J et al. An unconventional role for miRNA: let-7 activates Toll-like receptor 7 and causes neurodegeneration. Nat Neurosci 2012; 15: 827-835.

13. Selvamani A, Sathyan P, Miranda RC, Sohrabji F. An antagomir to microRNA Let7f promotes neuroprotection in an ischemic stroke model. PLOS ONE 2012; 7: e32662.

14. Hou L, Wang X. PKC and PKA, but not PKG mediate LPS-induced CGRP release and [Ca(2+)](i) elevation in DRG neurons of neonatal rats. J Neurosci Res 2001; 66:592-600.

15. Tse KH, Chow KB, Leung WK, Wong YH, Wise H. Primary sensory neurons regulate Tolllike receptor-4-dependent activity of glial cells in dorsal root ganglia. Neuroscience 2014; 279: $10-22$.

16. Leenders AG, Sheng ZH. Modulation of neurotransmitter release by the second messenger activated protein kinases: implications for presynaptic plasticity. Pharmacol Ther 2005; 105:6984. 
17. Libien J, Sacktor TC, Kass IS. Magnesium blocks the loss of protein kinase C, leads to a transient translocation of PKC(alpha) and PKC(epsilon), and improves recovery after anoxia in rat hippocampal slices. Brain Res Mol Brain Res 2005; 136: 104-111.

18. Raval AP, Dave KR, Mochly-Rosen D, Sick TJ, Perez-Pinzon MA. Epsilon PKC is required for the induction of tolerance by ischemic and NMDA-mediated preconditioning in the organotypic hippocampal slice. J Neurosci 2003; 23: 384-391.

19. Selvatici R, Melloni E, Ferrati M, Piubello C, Marincola FC, Gandini E. Adaptative value of a PKC-PKI55 feedback loop of inhibition that prevents the kinase's deregulation. J Mol Evol 2003; 57: 131-139.

20. Sun MK, Alkon DL. Pharmacology of protein kinase C activators: cognition-enhancing and antidementic therapeutics. Pharmacol Ther 2010; 127: 66-77.

21. Chen Z, Jalabi W, Hu W, Park HJ, Gale JT, Kidd GJ et al. Microglial displacement of inhibitory synapses provides neuroprotection in the adult brain. Nat Commun 2014; 5: 4486.

22. Park HJ, Park KH, Shin KS, Lee MK. The roles of cyclic AMP-ERK-Bad signaling pathways on 6-hydroxydopamine-induced cell survival and death in PC12 cells. Toxicology 2013; 27:22332241.

23. Zhao H, Yenari MA, Cheng D, Sapolsky RM, Steinberg GK. Bcl-2 overexpression protects against neuron loss within the ischemic margin following experimental stroke and inhibits cytochrome c translocation and caspase-3 activity. J Neurochem 2003; 85: 1026-1036.

24. Salmaso N, Jablonska B, Scafidi J, Vaccarino FM, Gallo V. Neurobiology of premature brain injury. Nat Neurosci 2014; 17: 341-346.

25. Molyneaux BJ, Arlotta P, Menezes JR, Macklis JD. Neuronal subtype specification in the cerebral cortex. Nat Rev Neurosci 2007; 8: 427-437.

26. Ortinau C, Neil J. The neuroanatomy of prematurity: Normal brain development and the impact of preterm birth. Clin Anat 2014; 28: 168-183.

27. Sizonenko SV, Kiss JZ, Inder T, Gluckman PD, Williams CE. Distinctive neuropathologic alterations in the deep layers of the parietal cortex after moderate ischemic-hypoxic injury in the P3 immature rat brain. Pediatr Res 2005; 57: 865-872.

28. Bjuland KJ, Lohaugen GC, Martinussen M, Skranes J. Cortical thickness and cognition in very-low-birth-weight late teenagers. Early Hum Dev 2013; 89: 371-380.

29. Sizonenko SV, Sirimanne E, Mayall Y, Gluckman PD, Inder T, Williams C. Selective cortical alteration after hypoxic-ischemic injury in the very immature rat brain. Pediatr Res 2003; 54:263269.

30. Ferrere A, Vitalis T, Gingras H, Gaspar P, Cases O. Expression of Cux-1 and Cux-2 in the developing somatosensory cortex of normal and barrel-defective mice. Anat Rec A Discov Mol Cell Evol Biol 2006; 288: 158-165.

31. Kida H, Nomura S, Shinoyama M, Ideguchi M, Owada Y, Suzuki M. The effect of hypothermia therapy on cortical laminar disruption following ischemic injury in neonatal mice. PLOS ONE 2013; 8: e68877.

32. Reiner O, Sapir T. Cdk5 checks p27kip1 in neuronal migration. Nat Cell Biol 2006; 8: 11-13.

33. Wang IT, Allen M, Goffin D, Zhu X, Fairless AH, Brodkin ES et al. Loss of CDKL5 disrupts kinome profile and event-related potentials leading to autistic-like phenotypes in mice. Proc Natl Acad Sci USA 2012; 109: 21516-21521.

34. Kitagawa K. CREB and cAMP response element-mediated gene expression in the ischemic brain. FEBS J 2007; 274: 3210-3217. 


\section{Chapter 6}

35. Goldsmith M, Avni D, Ernst O, Glucksam Y, Levy-Rimler G, Meijler MM et al. Synergistic IL-10 induction by LPS and the ceramide-1-phosphate analog PCERA-1 is mediated by the cAMP and p38 MAP kinase pathways. Mol Immunol 2009; 46: 1979-1987.

36. Cheung HH, Teves L, Wallace MC, Gurd JW. Increased phosphorylation of the NR1 subunit of the NMDA receptor following cerebral ischemia. $J$ Neurochem 2001; 78: 1179-1182.

37. Chen J, Liu Y, Soh JW, Aguilera G. Antiapoptotic effects of vasopressin in the neuronal cell line H32 involve protein kinase Calpha and beta. J Neurochem 2009; 110: 1310-1320.

38. Harada H, Becknell B, Wilm M, Mann M, Huang LJ, Taylor SS et al. Phosphorylation and inactivation of BAD by mitochondria-anchored protein kinase A. Mol Cell 1999; 3: 413-422.

39. Li Y, Zeng M, Chen W, Liu C, Wang F, Han X et al. Dexmedetomidine reduces isoflurane induced neuroapoptosis partly by preserving PI3K/Akt pathway in the hippocampus of neonatal rats. PLoS ONE 2014; 9: e93639.

40. Lai HC, Wu MJ, Chen PY, Sheu TT, Chiu SP, Lin MH et al. Neurotrophic effect of citrus 5hydroxy-3,6,7,8,3',4'-hexamethoxyflavone: promotion of neurite outgrowth via cAMP/PKA/CREB pathway in PC12 cells. PLOS ONE 2011; 6: e28280.

41. Das KP, Freudenrich TM, Mundy WR. Assessment of PC12 cell differentiation and neurite growth: a comparison of morphological and neurochemical measures. Neurotoxicol Teratol 2004; 26: 397-406.

42. Korshunova I, Novitskaya V, Kiryushko D, Pedersen N, Kolkova K, Kropotova E et al. GAP43 regulates NCAM-180-mediated neurite outgrowth. J Neurochem 2007; 100: 1599-1612.

43. Strittmatter SM, Valenzuela D, Kennedy TE, Neer EJ, Fishman MC. G0 is a major growth cone protein subject to regulation by GAP-43. Nature 1990; 344: 836-841.

44. Huang KP, Huang FL, Chen HC. Hypoxia/ischemia induces dephosphorylation of rat brain neuromodulin/GAP-43 in vivo. J Neurochem 1999; 72: 1294-1306.

45. Finkbeiner S. CREB couples neurotrophin signals to survival messages. Neuron 2000; 25:1114.

46. Mayr BM, Canettieri G, Montminy MR. Distinct effects of cAMP and mitogenic signals on CREB-binding protein recruitment impart specificity to target gene activation via CREB. Proc Natl Acad Sci USA 2001; 98: 10936-10941.

47. Tardito D, Perez J, Tiraboschi E, Musazzi L, Racagni G, Popoli M. Signaling pathways regulating gene expression, neuroplasticity, and neurotrophic mechanisms in the action of antidepressants: a critical overview. Pharmacol Rev 2006; 58: 115-134.

48. Meller R, Minami M, Cameron JA, Impey S, Chen D, Lan JQ et al. CREB-mediated Bcl-2 protein expression after ischemic preconditioning. J Cereb Blood Flow Metab 2005; 25:234-246.

49. Zhang L, Zhao H, Zhang X, Chen L, Zhao X, Bai X et al. Nobiletin protects against cerebral ischemia via activating the p-Akt, p-CREB, BDNF and Bcl-2 pathway and ameliorating BBB permeability in rat. Brain Res Bull 2013; 96: 45-53.

50. Sist B, Fouad K, Winship IR. Plasticity beyond peri-infarct cortex: spinal up regulation of structural plasticity, neurotrophins, and inflammatory cytokines during recovery from cortical stroke. Exp Neurol 2014; 252: 47-56.

51. Kim HW, Chang YC, Chen M, Rapoport SI, Rao JS. Chronic NMDA administration to rats increases brain pro-apoptotic factors while decreasing anti-Apoptotic factors and causes cell death. BMC Neurosci 2009; 10: 123.

52. Shacka JJ, Roth KA. Bcl-2 family and the central nervous system: from rheostat to real complex. Cell Death Differ 2006; 13: 1299-1304. 
53. Kaddour H, Hamdi Y, Vaudry D, Basille M, Desrues L, Leprince J et al. The octadecaneuropeptide ODN prevents 6-hydroxydopamine-induced apoptosis of cerebellar granule neurons through a PKC-MAPK-dependent pathway. J Neurochem 2013; 125: 620-633.

54. Talman V, Amadio M, Osera C, Sorvari S, Boije Af Gennas G, Yli-Kauhaluoma J et al. The C1 domain-targeted isophthalate derivative HMI-1b11 promotes neurite outgrowth and GAP-43 expression through PKCalpha activation in SH-SY5Y cells. Pharmacol Res 2013;73: 44-54.

55. Schulte LN, Eulalio A, Mollenkopf HJ, Reinhardt R, Vogel J. Analysis of the host microRNA response to Salmonella uncovers the control of major cytokines by the let-7 family. EMBO J 2011; 30: 1977-1989.

56. Swaminathan S, Suzuki K, Seddiki N, Kaplan W, Cowley MJ, Hood CL et al. Differential regulation of the Let-7 family of microRNAs in CD4+ T cells alters IL-10 expression. J Immunol 2012; 188: 6238-6246.

57. Ooboshi H, Ibayashi S, Shichita T, Kumai Y, Takada J, Ago T et al. Postischemic gene transfer of interleukin-10 protects against both focal and global brain ischemia. Circulation 2005; 111: 913-919.

58. Sharma S, Yang B, Xi X, Grotta JC, Aronowski J, Savitz SI. IL-10 directly protects cortical neurons by activating PI-3 kinase and STAT-3 pathways. Brain Res 2011; 1373:189-194.

59. Grilli M, Barbieri I, Basudev H, Brusa R, Casati C, Lozza G et al. Interleukin-10 modulates neuronal threshold of vulnerability to ischaemic damage. Eur J Neurosci 2000; 12:2265-2272.

60. Strunk T, Inder T, Wang X, Burgner D, Mallard C, Levy O. Infection-induced inflammation and cerebral injury in preterm infants. Lancet Infect Dis 2014; 14: 751-762.

61. Eklind S, Mallard C, Arvidsson P, Hagberg H. Lipopolysaccharide induces both a primary and a secondary phase of sensitization in the developing rat brain. Pediatr Res 2005; 58:112-116.

62. Hickey E, Shi H, Van Arsdell G, Askalan R. Lipopolysaccharide-induced preconditioning against ischemic injury is associated with changes in toll-like receptor 4 expression in the rat developing brain. Pediatr Res 2011; 70: 10-14.

63. Mallard C, Davidson JO, S T, Green CR, Bennet L, Robertson NJ et al. Astrocytes and microglia in acute cerebral injury underlying cerebral palsy associated with preterm birth. Pediatr Res 2014; 75: 234-240.

64. Connelly WM, Errington AC, Di Giovanni G, Crunelli V. Metabotropic regulation of extrasynaptic GABAA receptors. Front Neural Circ 2013; 7: 171.

65. Tanaka K. Alteration of second messengers during acute cerebral ischemia - adenylate cyclase, cyclic AMP-dependent protein kinase, and cyclic AMP response element binding protein. Prog Neurobiol 2001; 65: 173-207.

66. Müller MM, Middelanis J, Meier C, Surbek D, Berger R. 17beta-estradiol protects 7- day old rats from acute brain injury and reduces the number of apoptotic cells. Reprod Sci 2013; 20:253261.

67. Ramachandra R Atlas of the Neonatal Rat Brain. CRC Press: Boca Raton, London, 2011.

68. Ofengeim D, Chen YB, Miyawaki T, Li H, Sacchetti S, Flannery RJ et al. N-terminally cleaved Bcl-xL mediates ischemia-induced neuronal death. Nat Neurosci 2012; 15:574-580.

69. Jellema RK, Lima Passos V, Zwanenburg A, Ophelders DR, De Munter S, Vanderlocht J et al. Cerebral inflammation and mobilization of the peripheral immune system following global hypoxia-ischemia in preterm sheep. J Neuroinflammation 2013; 10: 13. 


\section{Supplementary Information}

Antibodies, siRNAs, inhibitors, and peptides. The antibodies against TLR4 (Abcam, ab22048), active CASP-3 (Cell Signaling, 9661S), BAD (Cell Signaling, 9239), p-BADSer112 (Cell Signaling, 5284P), GAP-43 (Abcam, ab11136), pGAP-43Ser41 (Santa Cruz, sc-17109), CREB (Cell Signaling, 9197), pCREBSer133 (Cell Signaling, 9198), phospho-PKC Substrate (Cell Signaling, 6967), phospho-PKA Substrate (Cell Signaling, 9624), $\beta$-Actin (Cell Signaling, 4970), and $\beta$-Tubulin (Abcam, ab6046) were purchased. The siRNAs for TLR4 (Thermo Scientific Dharmacon, L-008088-01) and the negative control siRNA (Thermo Scientific Dharmacon, D-001810-10-20) were purchased. LPS (Sigma Aldrich, L6529-1MG), inhibitor H89 (EMD Millipore, 371963-1MG), and inhibitor Gö6983 (EMD Millipore, 365251) were purchased. sPIF (MVRIKPGSANKPSDD) and PIFscr (GRVDPSNKSMPKDIA) with >95\% purity documented by HPLC and mass spectrometry, were generated at Biosynthesis (Lewisville, Tx, USA).

TLR4 siRNA knockdown. Cells were transfected in a 48-well plate scale. To prepare siRNA transfection solution for each well, 16pmol of siCon or siRNA was mixed with $50 \mu \mathrm{l}$ OPTI- MEM (Gibco 31985-070) by gentle pipetting. In parallel, $0.5 \mu$ l Lipofectamine 2000 was mixed with $50 \mu$ l OPTI-MEM. Following 5 min of incubation at room temperature (RT), the two solutions were mixed by gentle pipetting and incubated for $30 \mathrm{~min}$ at RT to allow the formation of siRNA/lipid complexes. At the end of incubation, the $100 \mu \mathrm{l}$ transfection solution was used to re-suspend cell pellet $\left(8 \times 10^{4}\right.$ cells). After incubation at RT for 10 min, regular growth media was added at a ratio of 1:4 (1 volume of transfection solution / 4 volumes of growth media) and the cell suspension was transferred to the culture plate. After $24 \mathrm{~h}$ incubation at $37{ }^{\circ} \mathrm{C}$ in $5 \% \mathrm{CO}_{2}$, the medium was replaced with serum free media containing LPS $(0.5 \mu \mathrm{g} / \mathrm{ml})$ for 24 hours. RNAs and proteins were extracted and analyzed at the indicated time points following transfection and/or peptide treatment.

Western Blot analyses. These were used to assess TLR4, active CASP-3, BAD, p-BADSer112, GAP-43, p-GAP-43Ser41, CREB, and p-CREBSer133 protein levels in cultured cells and rat brain tissues. Briefly, cell pellets or frozen tissue samples were quickly lysed in $\sim 10$ volumes of $2 x$ SDS sample buffer heated at $100{ }^{\circ} \mathrm{C}$ for $5 \mathrm{~min}$. To homogenize cell pellets, occasional vortexing was performed. To homogenize brain tissues, lysate was passed through 20G needles 10 times for each sample. Five to $10 \mu \mathrm{l}$ homogenized samples were separated on a $10 \%$ SDS polyacrylamide gel, followed by Western blot analyses. Whole brain lysate for kinome profiling (Phospho-PKA/PKC Substrates) was isolated following a protocol developed by Cell Signaling Technology. Briefly, tissue was homogenized in lysis buffer (20mM HEPES pH 8.0, 9M urea, 1mM sodium orthovanadate, $2.5 \mathrm{mM}$ sodium pyrophosphate, $1 \mathrm{mM} \quad \beta$-glycerophosphate), sonicated, and cleared by centrifugation. Protein concentration was measured using the Bradford assay and a total of $30 \mu \mathrm{g}$ protein was loaded for each lane. Protein bands on Western gels were quantified using Image J (US National Institutes of Health).

qRT-PCR. These were carried out as previously described ${ }^{1}$. For mRNA quantification, total RNAs were extracted from cells using PureLink RNA Mini 
Kit (Ambion, catalog number 12183018A). cDNA was synthesized using Bio-Rad iSCRIPT kit (1725122) in a $20 \mu \mathrm{l}$ reaction containing 500-800 ng of total RNA. Real-time PCR was performed in a $15 \mu$ reaction containing $1 \mathrm{ul}$ of cDNA using iQSYBRGreen (Bio-Rad) in a Bio-Rad iCycler. PCR was performed by initial denaturation at $95^{\circ} \mathrm{C}$ for $5 \mathrm{~min}$, followed by 40 cycles of $30 \mathrm{sec}$ at $95^{\circ} \mathrm{C}, 30 \mathrm{sec}$ at $60^{\circ} \mathrm{C}$, and $30 \mathrm{sec}$ at $72^{\circ} \mathrm{C}$. Specificity was verified by melting curve analysis and agarose gel electrophoresis. The threshold cycle $(\mathrm{Ct})$ values of each sample were used in the post-PCR data analysis. The indicated mRNA levels were normalized against Tubulin. The PCR primers for the mouse and rat mRNAs are listed below. Mouse: Beta-tubulin: Forward 5'-CGTGTTCGGCCAGAGTGGTGC, Reverse 5'GGGTGAGGGCATGACGCTGAA; TLR4: Forward AGACCTCAGCTTCAATGGTG, Reverse GAGACTGGTCAAGCCAAGAA; Bad: Forward 5'- AGT CTT TCG AGG CCT TAG GA -3', Reverse 5'- CCC CAG TTA TGA CAG GAC AG -3'; Bcl2: Forward 5'- CTG GAA ACC CTC CTG ATT TT -3', Reverse 5'- AAA TAT TTC AAA CGC GTC CA -3'; Gap43: Forward 5'- AGG GAG ATG GCT CTG CTA CT -3', Reverse 5'- GAG GAC GGG GAG TTA TCA GT -3': Casp3: Forward 5'- GTC CAT GCT CAC GAA AGA AC -3', Reverse 5'- ACC TGA TGT CGA AGT TGA GG -3'; Bdnf: Forward 5'- GGT GCA GAA AAG CAA CAA GT -3', Reverse 5'- GCA CAA AAA GTT CCC AGA GA -3'. Rat: Beta-tubulin Forward: 5'-CGT GTT CGG CCA GAG TGG TGC, Reverse: 5'-GGG TGA GGG CAT GAC GCT GAA Bcl2: 5'- CAT CAC TCT GGG TGC ATA CC -3', Reverse 5'- TTG ACC ATT TGC CTG AAT GT -3', Bdnf: Forward 5'- CAT TTC ATG ACA CTC GTG GA -3', Reverse 5'- ATT TCA GTG GCA GTG TGG AT -3'; Gap43: Forward 5'-CAG GAA AGA TCC CAA GTC CA -3', Reverse 5'- GAA CGG AAC ATT GCA CAC AC-3'; Bad: Forward Primer 5'- CCT TGC TTT GGA GTT TTC AA -3', Reverse Primer 5'-AAA GCA CGT TTC TTG ACC TG -3'.

Perioperative Care of the animals. Perioperative care was performed in accordance with Ethics Committee and Veterinary Department of the Canton of Berne, Switzerland guidelines. Acclimatization of animals to the laboratory environment was allowed prior to surgery. Aseptic rodent survival surgery guidelines were followed. We injected Buprenorphine $(0.01-0.1 \mathrm{mg} / \mathrm{kg}$ body weight) subcutaneously $30 \mathrm{~min}$ prior incision as a pre-operative procedure once prior to surgery. Buprenorphine was used as postoperative analgesia (starting 4-6 hours post-surgery, every 8-12 hours for 2-3 days) as well. We used Isoflurane as anesthetic (Induction with $4 \%$ and continuation with $1.5-2 \%$; $31 / \mathrm{min}$ ). Adequate depth of anesthesia was confirmed. After surgery, animals were placed back to the mother as soon as they were awake, able to right themselves and able to move about. We monitored several parameters including anesthetic depth (persistence), clinical signs and condition. We monitored the pups every hours for at least 6-8 hours post operation with special attention to breathing pattern and mobility, as well as signs of seepage or bleeding from the incision. Once completely recovered, the dam was transferred back to the room where the rats are housed. When neonates have reached the age of interest animals were sacrificed by Natrium-Pentothal (100mg/kg body weight i.p.), cardiac perfusion, and decapitation.

Immunohistochemistry. We performed cardiac perfusion with PBS followed by formaldehyde (4\%; Merck, Whitehouse Station, NJ) before brain harvesting. Brains were removed surgically and fixed in formaldehyde solution (4\%) for 2-4 
hours at room temperature (RT) followed by $4^{\circ} \mathrm{C}$ for a total time of $24-48$ hours. Fixed brains were embedded in paraffin and sectioned into $7 \mu \mathrm{m}$ slices. After deparaffinization of the slides, the target was retrieved in citrate buffer $(10 \mathrm{mM}$; $\mathrm{pH}$ 6.0) in a pressure cooker for 15 minutes. Slides were washed in $0.1 \%$ Tween$20 / \mathrm{PBS}$ and blocked in $10 \%$ goat serum/1\% bovine albumin/PBS. Neurons were detected by a mouse monoclonal antibody specific for the neuronal nuclear antigen (NeuN, Chemicon/Millipore, MAB377, 1:100). Anti-active + pro Caspase-3 was detected by a mouse monoclonal antibody (CASP-3, Abcam, ab13847, 1:100). A rabbit polyclonal antibody against the homeobox protein cutlike 1 (CUX1, Santa Cruz Biotechnology, sc-13024, 1:100), a highly specific marker for superficial layer neurons, was used to visualize neuronal migration. Following first antibody incubation, slides were washed in $0.1 \%$ Tween-20/PBS (2x 5min) and incubated in endogenous peroxidase blocking solution at RT for 15 min. Peroxidase-labeled polymer (DAKO anti mouse or anti rabbit) was applied to the slides for $30 \mathrm{~min}$ at RT. Slides were washed in PBS ( $3 \times 5 \mathrm{~min}$ ), followed by application of $\mathrm{DAB}+$ chromogen in buffer substrate for 10-30 min, according to the manufacturer's instructions (DAKO EnVision+ System-HRP (DAB), K4007). Slides were rinsed in ddH2O, counterstained in Cresyl violet (Nissl body staining for neuronal structure and gross brain morphology) dehydrated in a series of ethanol baths (95\% > 100\%) and xylene, and mounted with Eukitt (Sigma-Aldrich, St. Louis, MO). 
Perinatal Brain Injury and Prelmplantation Factor (PKA/PKC)

\section{References}

1. Mueller M, Zhou J, Yang L, Gao Y, Wu F, Schoeberlein A et al. PreImplantation factor promotes neuroprotection by targeting microRNA let-7. Proc Natl Acad Sci USA 2014; 111:13882-13887. 

Chapter 7

General discussion 
The development of a mammalian brain is a complex and long-lasting process which follows specific time and space dependent sequences. Therefore, the effect of an injury strongly depends on the point in time at which the lesion occurred and this is especially evident in a developing brain. Brain injury may result during pregnancy, parturition and adaptation after birth and successful therapeutic options are lacking. In the last decades, new therapeutic strategies emerged for perinatal brain injuries ${ }^{1}$ with pregnancy derived products being of special interest. For this purpose, we explored embryo and placental derived products such as mesenchymal stem/stromal cells (MSCs), 17- $\beta$ Estradiol, and PreImplantation Factor (PIF) as attractive candidates to treat perinatal brain injuries.

\section{Migration and Homing of WJ-MSCs in immature rats}

Stem cell therapy for the treatment of neurodegenerative diseases in adults is in reach but injury in a developing brain is a much more complex process involving many factors and mechanisms. The treatment of fetuses or neonates poses ethical questions that go beyond those for most therapies in adult patients. This evokes the need for extensive studies in animal models before clinical applications might be envisioned.
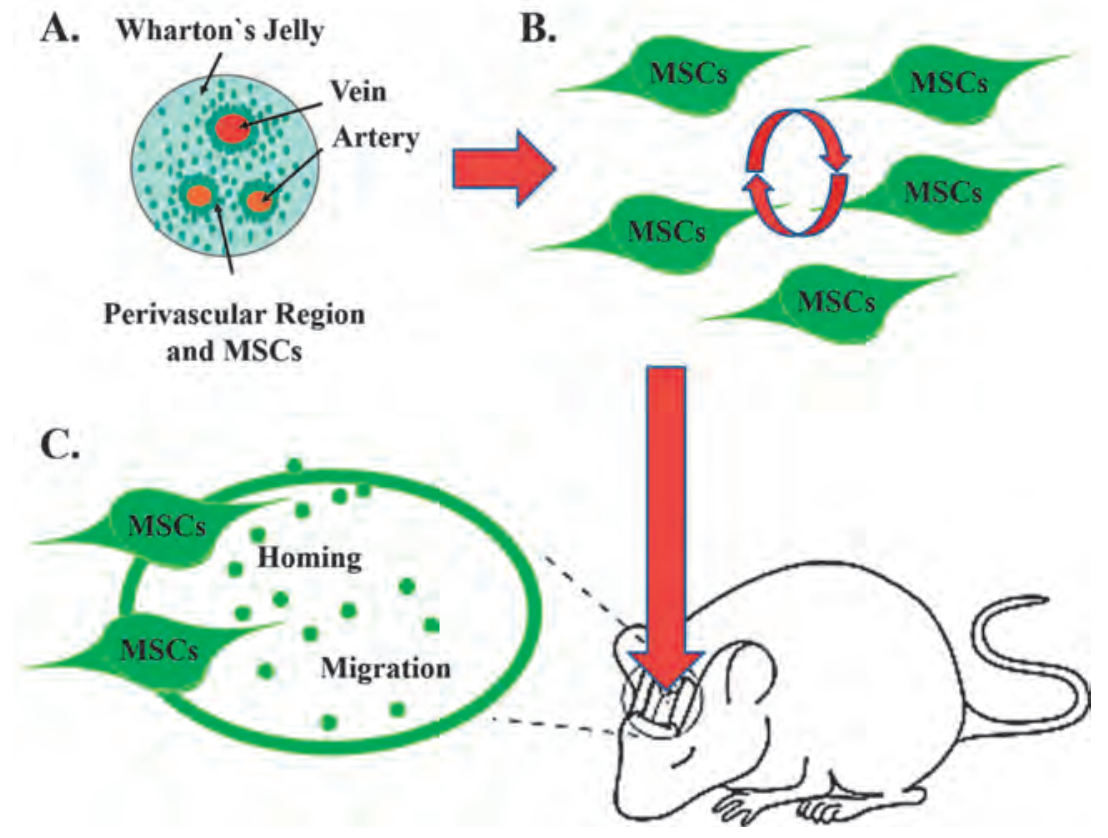

Figure 1. Mesenchymal stem cells (MSCs) derived from Wharton`s Jelly migrate and home after transplantation.

(A) Section of an umbilical cord with MSCs in the Wharton`s Jelly and perivascular region. (B) MSCs were isolated and cultured prior to transplantation. (C) MSCs display "Migration and Homing” capacity after intracerebral transplantation. See chapter 2

In chapter 2 we validated the method of intracerebral stem cell transplantation. We hypothesized that we can precisely target a given area, successfully deliver cell suspensions into the brain, and specifically detect the transplant. These hypothesizes were confirmed in our study using a newborn rat model. We decided 
to test our hypothesis in newborn rats as preterm human infants share similarities to newborn rats in terms of cortical neuronal and glial development ${ }^{2}$. We established a new model of intracerebral stem cell transplantation in newborn rats and used MSCs derived from Wharton`s Jelly (human) as a cell graft (Figure 1A). In a separate set of experiments, we gradually optimized both the anesthesia and the stereotaxic injections technique. Once a proper protocol was established, the transplantation resulted in a good survival and reliable engraftment. We detected human donor cells (injected into the left lateral ventricle) distributed over the ventricular system within 4 hours after transplantation. During the following time course experiments cells emigrated from the ventricles and integrated into the surrounding tissue. Human donor cells were mainly observed in paraventricular areas of the lateral ventricle of the ipsilateral hemisphere and the third or fourth ventricle. These include the cortex and the striatum. Interestingly, donor-derived cells were detected in the contralateral hemisphere as well and the morphology of the human HLA-ABC-positive cells was similar to the host cells surrounding them. The cells migrated and homed into the brain without apparent tumorigenic potential confirming previous results from different disease models ${ }^{3,4,5}$.

Although comprehensive information for stem cell transplantation in animals exists, the availability of data for neonatal rats is very limited. We assessed and proved the concept of WJ-MSCs transplantation in immature rats (Figure 1). Our study clearly demonstrates the feasibility of intracerebral stem cell application and forms the basis for testing cell graft transplantation in immature brain injury models.

\section{WJ-MSCs protect the immature brain against perinatal injury}

In chapter 3, we hypothesized that WJ-MSCs will protect against immature brain injury. We anticipated cerebral protection characterized by reduced myelination loss and astroglial activation while ameliorating spastic paresis. Further as the common dominator in a developing organ is the dynamic equilibrium of cellular proliferation/differentiation and apoptosis/necrosis, we anticipated WJ-MSCs to impact pivotal regulators of the cell fate. These hypothesizes were confirmed. Indeed using a clinically relevant immature brain injury model we demonstrated the protective capacity of our cell graft. We used the previously established stereotactic intracerebral transplantation route (chapter 2) and detected WJ-MSCs predominantly in the cortex and striatum. Further, we demonstrated that our cell graft is able to reduce injury-mediated myelination loss and astroglial activation while preserving proper functional behavior of the animals. Most importantly, these observed protective effects were mediated in part by targeting crucial signaling pathways involved in cell cycle regulation and apoptosis.

Numerous studies postulate that MSCs protective effects in the immature brain are based on paracrine effects and immunomodulation ${ }^{1}$. We showed for the first time that WJ-MSCs modulate signaling pathways in an immature brain and that these pathways are involved in cell cycle regulation and apoptosis. These are cyclic AMP dependent protein kinase / calcium-dependent protein kinase (PKA/PKC), cyklin-dependent kinase (CDK), ataxia-telangiectasia-mutated/ATM- and Rad3related (ATM/ATR) substrates, Protein kinase B (Akt), and 14-3-3 binding protein partners ${ }^{6-11}$. 
As the preterm infant faces multiple risk factors including inflammation/infection, ischemia/reperfusion, and deprivation of placental protective factors, an optimal therapeutic should target the injuries globally (several organs) and locally (response to signals of local injury) ${ }^{1}$. We demonstrated that WJ-MSCs protect the immature brain and modulate divergent signaling pathways (Figure 2). This observation is particularly interesting as it fuels the constant debate whether MSCs or MSCs derived products such as condition media or extracellular vesicles are the optimal choice for treating perinatal injuries. We concluded that WJ-MSCs ability to locally response to signals after injury may provide an advantage ${ }^{12}$.

As shown in Figure 2, WJ-MSCs impact divergent signaling pathways in the brain following injury. Interestingly, we detected other differences as well. For example WJMSCs activate CDK signaling in the immature brain but in stroke CDK inhibition is protective 13. These differences may result from distinct physiology and pathophysiology of an immature brain. In the immature brain oligodendrocyte progenitors are especially vulnerable to injury 1 and proper oligodendrocyte proliferation and differentiation is CDK-dependent ${ }^{14,}{ }^{15}$. Thus, disease-specific and age-specific considerations are necessary when assessing therapeutics for immature infants. Additionally and in contrast to upcoming novel therapies such as PreImplantation Factor (chapter 5 and 6), WJMSCs did not impact PKA/PKC activation in the brain ${ }^{7}$. We concluded that this may be an opportunity to use both WJ-MSCs and PreImplantation Factor synergistically because of the diverse mode of action.

In conclusion our data clearly demonstrates WJMSCs` potential to reduce the burden of perinatal brain injury by targeting crucial cell fate pathways.

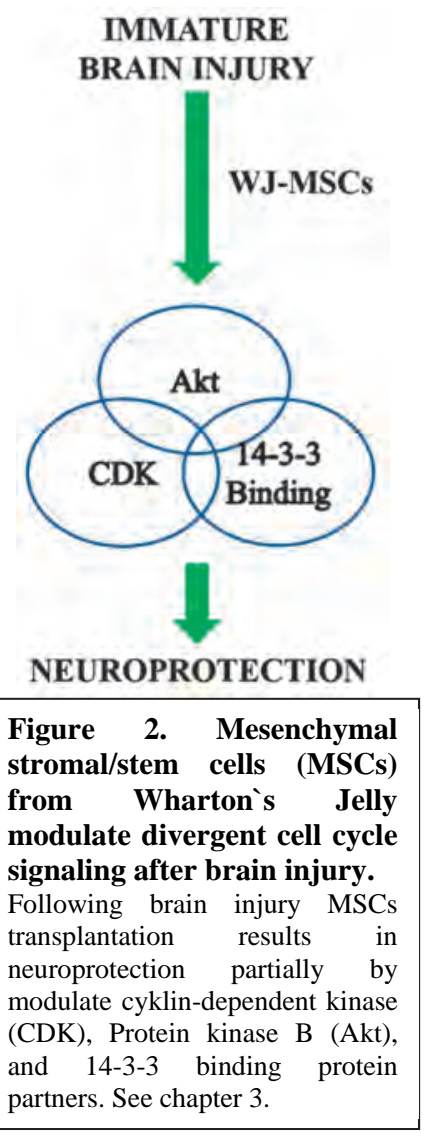

\section{BRAIN INJURY}

UROPROTECTION

Figure 2. Mesenchymal stromal/stem cells (MSCs) from Wharton's Jelly modulate divergent cell cycle signaling after brain injury. Following brain injury MSCs transplantation results in neuroprotection partially by modulate cyklin-dependent kinase (CDK), Protein kinase B (Akt), and 14-3-3 binding protein partners. See chapter 3 .

\section{$17 \beta$-Estradiol protects the immature brain against perinatal injury}

The treatment approach of pregnancy derived products in perinatal injuries expands beyond stem cells. We and others postulate that pregnancy needs to be considered an embryo-centric rather than materno-centric environment ${ }^{16}$. Given that placenta supports the growth and development of such a complex structure as a brain and produces steroid hormones, we hypothesized that $17 \beta$-Estradiol will protect the immature brain against perinatal injury (chapter 4). Using a rat model of perinatal brain injury we anticipated to detect less structural damage, restored hemisphere volumes, and reduced number of apoptotic cells after $17 \beta$-Estradiol supplementation. These hypothesizes were confirmed. We detected macroscopically and microscopically significantly less brain damage after $17 \beta$ - 
Estradiol treatment. The determined volumes of the injured hemisphere were significantly higher in the treatment group as well. Finally, the numbers of apoptotic cells was reduced. We concluded that $17 \beta$-Estradiol protected newborn rat brains against injury, in terms of both microscopic cell injury and apoptosis.

Although $17 \beta$-Estradiol therapy in scenarios of steroid deprivation such as preterm birth emerged recently ${ }^{17}$, it has not been addressed sufficiently ${ }^{18}$. Given the controversy regarding the differing doses, time, treatment schedules, route of application, or the effect of estrogen in a neonatal brain after injury ${ }^{19}{ }^{20}$, we performed a dose escalation study first. Indeed we detected increased $17 \beta$ Estradiol serum levels and the lowest dose of $0.05 \mathrm{mg} / \mathrm{g}$ was chosen. We induced injury in neonatal rats and supplemented $17 \beta$-Estradiol. In line with previous reports we detected neuroprotective activity ${ }^{19,20}$. Notably, in our experiment the $17 \beta$-Estradiol dose was up to 10 -fold lower than previously used and we observed a significant neuroprotective activity. This neuroprotection was present in both female and male pups whereas male pups suffered greater injury. This is important as animal and human studies identified sex differences in neonates after brain injury ${ }^{21}$ with far greater damage and poorer functional recovery in males.

The cerebral vulnerability is determined by the fragile balance between pro- and anti-apoptotic factors. Given that the apoptotic cascade reaction is regulated by caspase inhibitors and can be influenced by estradiol ${ }^{22}$, we stained for caspase-3 positive cells. Notably, caspase-3 is a critical executioner of apoptosis. We detected a significantly higher number of positive cells after injury and 17 $\beta$ Estradiol attenuated cell death. This observation is in line with restored cortical volume after treatment. Together, our results demonstrate $17 \beta$-Estradiol neuroprotective capacity after immature brain injury and provide further support for steroid supplementation in infants at risk ${ }^{23}$.

\section{PreImplantation Factor (PIF) protects the immature brain against perinatal injury}

Consistent with the notion of pregnancy as an embryo-centric endeavor ${ }^{16}$ we focused on yet another embryo-derived product that can be detected in the maternal circulation during pregnancy ${ }^{24,25}$. The presence of PIF in the maternal circulation has been correlated with live birth ${ }^{25,26,27}$ and recognized to regulate immune responses ${ }^{28}$. Not surprisingly, a synthetic PIF analog (sPIF) was successfully tested in murine models of graft vs. host disease ${ }^{29}$, non-obese diabetic disease ${ }^{30}$, and experimental autoimmune encephalomyelitis ${ }^{31}$.

In chapter 5 and 6 we hypothesized that SPIF would exert a strong neuroprotective effect because inflammatory responses are prominent after brain injury in the immature brain ${ }^{32}$. We tested subcutaneous injected SPIF in a murine immature brain injury model and anticipated restored cortical volume, neuronal survival and migration, and reduced glial responses. These hypothesizes were confirmed. sPIF co-localized with both neurons and glia which is a provides strong evidence that sPIF crosses the blood-brain barrier. This observation was underlined by detection of PIF in non-injured brain tissue and serum using liquid chromatography with tandem mass spectrometry as well. Further we detected abrogated neuronal loss and glial activation after SPIF treatment. This is in line with the notion that decreased glial activation and restored number of neurons lead to reduced cerebral response to injury ${ }^{33,34}$. Interestingly, parallel to the decreased glial response we 
noted morphological changes in Iba-1 positive microglia shifting from predominantly amoeboid (pro-inflammatory) to ramified (anti-inflammatory) state in SPIF- treated animals. Further we evaluated cortical thickness and morphology, because in premature infants reduced cortical thickness correlates with adverse neurological outcomes ${ }^{35}$. SPIF restored cortical architecture and neuronal morphology while reducing the number of apoptotic cells. Collectively, our results were consistent with the notion that SPIF reduces inflammation, promotes neuronal survival and preserves proper neuronal migration, thereby preserving the cortical architecture.

\section{PreImplantation Factor (PIF) targets microRNA let-7 and PKA/PKC signaling}

Approximately $93 \%$ of the human genome is transcribed, yet only about $2 \%$ of the RNA (i.e., messenger RNA or mRNA) encodes proteins, and the rest are noncoding RNAs (ncRNAs) ${ }^{36}$. As the ncRNAs including microRNAs let-7 direct and regulate biological processes during neuronal development and the developing embryos secrete PIF ${ }^{26}$ we hypothesized that sPIF neuroprotective effects will be partially attributed to let-7 modulation. We confirmed the hypothesis in vitro and in vivo. Using neuronal and immune cells we confirmed that sPIF reduces the biogenesis of let-7. Notably, let-7 function goes beyond physiological neuronal development. For example Lehmann et al ${ }^{37}$ showed that let-7 released from injured cells to the extracellular environment during brain damage leads to neurodegeneration in the mouse. Likewise, intracerebroventricular injection of an antagomir to let-7 significantly reduces both cortical and striatal infarcts in a rat ischemic stroke model ${ }^{38}$. To further elucidate sPIF-mediated neuroprotective mechanisms we focused on let-7 biogenesis. The biogenesis of let-7 involves multiple steps. It is first synthesized as long primary transcripts (pri-let-7), which are cleaved in the nucleus by the Drosha complex, yielding a hairpin precursor (pre-let-7). Pre-let-7 is then exported to the cytoplasm where it is further processed into mature let-7 ${ }^{39}$. Importantly, the regulation of microRNA processing has emerged as a major step in controlling mature microRNA levels ${ }^{40}$ and the RNA-binding proteins such as LIN28 and hnRNP A1 (inhibit) and KSRP (promote) let-7 processing 41, 42, 4344. Indeed, our results showed that SPIF mediated let-7 down-regulation was induced by KSRP inhibition and that this effect was Toll-like Receptor 4 (TLR4) dependent. TLR4 is involved in inflammatory responses and neuroprotective effects ${ }^{45}$. Together, we provided evidence that this novel PIF/TLR4/KSRP/let-7 regulatory pathway, combined with its induced upregulation of the antiinflammatory cytokine IL-10, may contribute to sPIF's neuroprotective effects in vivo. We proposed that this regulatory mechanism might also underlie the action of PIF in maternal immune modulation and embryo implantation and development.

In search of additional mechanisms we focused on cyclic AMP dependent protein kinase (PKA) and calcium-dependent protein kinase (PKC). As discussed in chapter $1 \mathrm{PKA} / \mathrm{PKC}$ are important signaling molecules in a variety of cellular functions, including cell growth and differentiation, neuronal plasticity, and cellular response to hypoxia-ischemia 46, 47, 48, 49. Additionally, PKA/PKC signaling is downstream of TLR4 ${ }^{50,51}$ and TLR4 was required for sPIF-induced neuroprotective effects ${ }^{52}$. Mechanistically, PKA/PKC modulate protein stability, protein-protein interactions, and catalytic activity activation by phosphorylation 
of serine and threonine residues on target proteins ${ }^{53}$. In the case of brain injury, activation of the PKA/PKC signaling pathways imparts neuroprotection by increasing expression of anti-apoptotic and neurotrophic molecules, while reducing pro-apoptotic molecules in neurons ${ }^{54,55,56}$. Thus, we hypothesized that sPIF mediated neuroprotective effects are partially attributed to increased PKA/PKC activity. These hypothesizes were confirmed. Using the murine model of immature brain injury and neuronal cell lines we showed that SPIF modulates PKA/PKC signaling in a TLR4-dependent fashion. In line with our hypothesis sPIF increased phosphorylation of neuroprotective substrates GAP-43, CREB, and $\mathrm{BAD}$, which in turn stimulates expression of downstream genes Gap43, Bdnf and $B c l 2$. These genes have well-established roles in modulating neuronal growth, remodeling, and survival ${ }^{54,57,58}$. Given the potent neuroprotective effects of sPIF 31, 52, we proposed that the two pathways (PKA/PKC and let-7) may work synergistically in sPIF-mediated neuroprotection (Figure 3).

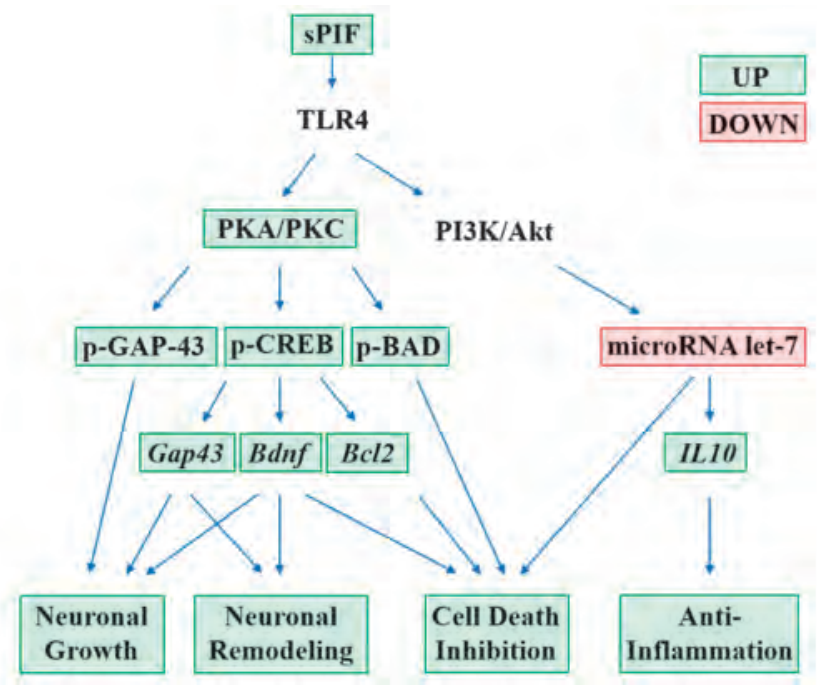

Figure 3. sPIF proposed mode of action after immature brain injury leading to neuroprotection. SPIF modulates PKA/PKC signaling in a TLR4 dependent manner. PKA/PKC phosphorylates neuroprotective substrates leading to increased expression of neuroprotective genes and neuronal growth and remodeling while inhibiting cell death. Inhibition of cell death and anti-inflammation is mediated by reduced microRNA let-7 as well. These effect are TLR4 and PI3K/Akt dependent. See chapter 5 and 6

Our results highlight an important role of TLR4 in sPIF-mediated neuroprotection, although the exact mechanism by which SPIF interacts with TLR4 remains to be investigated. The divergent in vivo effects of sPIF and LPSinduced neuroinflammation ${ }^{2}$ suggest association/synergism with distinct cofactors of TLR4 signaling. We concluded that it is conceivable that co-factors of sPIF likely act in concert to elicit/synergize downstream effects that are specific to sPIF but different from those induced by LPS. Also, studies to determine in vivo effects of TLR4 silencing will be needed to firmly establish TLR4's role in sPIFmediated neuroprotection. Finally, our finding that sPIF targets let-7 and PKA/PKC are particularly intriguing as studies have pointed to modulation of let7 and PKA/PKC signaling as a therapeutic approach for adult neuronal injury 
such as Alzheimer`s Disease and cerebral ischemic/stroke 37, 53, 59, 6038 . The use of sPIF in other diseases is underlined by its ability to cross the blood-brain barrier as well. Together, the current and previously reported neuroprotective evidence ${ }^{31}$, 52 , combined with the FDA fast track approval and recently started Phase I Clinical Trial supports sPIF's potential clinical application for both perinatal and adult brain injury.

\section{Future directions}

In this translational project, we evaluated pregnancy derived product as therapeutic options for perinatal injuries. We developed a model of intracerebral stem graft transplantation and tested the neuroprotective potential of Wharton`s Jelly derived stem cells, 17 $\beta$-Estradiol, and synthetic PreImplantation Factor in animal models mimicking the immature brain injury. However, many questions remain to be answered prior to moving from bench to bedside.

We have demonstrated that the direct route of intracerebral cell graft transplantation is feasible (Figure 1) and that our cell graft protects the immature brain against perinatal injury. Given the divergent effects on pivotal cell fate pathways (Figure 2), the question whether live cell transplants or cell`s products are the optimal choice for treatment remains open. Further studies should explore the direct comparison between cell and cell products in animal models. Additionally as new and minimally invasive transplantation routes emerged recently. The questions whether intranasal route is superior need to be addressed. Finally, the preparation of the cell transplant such as preconditioning and timing of the transplantation, need to be evaluated. These questions are underlined by the fact that in term born infants a short "window of treatment" exists and in preterm born infants the timing of an insult and treatment regime remain unclear. Thus, dose and treatment regime escalation studies will address effects of cell-based therapy for the injured brain.

Dose-effect studies of $17 \beta$-Estradiol need to be performed as well. Although compelling data on neuroprotective potential of steroids exists the question of optimal treatment in newborns remain. Given the broad effect of steroids the lowest effective dose and optimal treatment length need to be addressed. Additionally, all here proposed pregnancy derived products are effective in reducing the burden of injury but the question of additive or even synergistic effects using combination therapies is intriguing. We have demonstrated that WJMSCs and SPIF target different signaling pathways thus the combined therapy is promising.

We have tested pregnancy derived products in murine models of perinatal injuries. Although these models recapitulate the development of a human brain to a certain degree, additional studies in bigger animal models are necessary. Thus, studies confirming the neuroprotective potential of Wharton`s Jelly derived stem cells, $17 \beta$-Estradiol, and synthetic PreImplantation Factor in a translational sheep model of ischemic brain injury are warrant. For this purpose, the treatments would need to be tested in instrumented lambs with subsequent comprehensive cognitive and motoric evaluation. Efficacy, safety, and feasibility of these therapies could be demonstrated prior to becoming standard of care in infants at risk of brain injury. Finally, the results need to be confirmed in clinical trials in infants at risk. The 
safety of MSCs, 17 $\beta$-Estradiol, and PreImplantation Factor therapy for diverse diseases including cardiovascular, neurological, oncological/ hematological, and immunological are ongoing or completed ${ }^{28,61,62}$.

Our findings expend beyond neonatal brain injuries. Several of the identified neuroprotective signaling pathways are involved in various adult neurodegenerative disease as well. This implies that our proposed therapies may be tested in models of stroke, Alzheimer`s disease, Parkinson, or multiple sclerosis. Additionally, we identified micro-RNA let-7 as a potent target of sPIF. The bioavailability of let-7 is closely influenced by another non-coding RNA, namely the developmentally regulated, imprinted H19. In line with PIF presence during pregnancy, H19 is among the highest expressed genes in the developing embryos ${ }^{63}$. Given H19 involvement in endometriosis, metabolic function, or even broad epigenetic modulations, sPIF may be beneficial in these conditions as well 64, 65, 6667 .

In conclusion, we evaluated pregnancy derived products in translational animal models of perinatal brain injury. We showed that pregnancy derived therapy is effective in protecting the injured brain against the detrimental cerebral and inflammatory response. The modulated pathways were partially dissected. Our results form the basis of future preclinical work and pave the way for clinical trials to investigate the neuroprotective potential of Wharton`s Jelly derived stem cells, 17 $\beta$-Estradiol, and synthetic PreImplantation Factor in infants at risk of brain injuries. Most importantly, these efforts may tackle the enormous burden of perinatal injuries. 


\section{Chapter 7}

\section{References:}

1. Mueller M, Wolfs TG, Schoeberlein A, Gavilanes AW, Surbek D, Kramer BW. Mesenchymal stem/stromal cells-a key mediator for regeneration after perinatal morbidity? Mol Cell Pediatr 2016, 3(1): 6 .

2. Salmaso N, Jablonska B, Scafidi J, Vaccarino FM, Gallo V. Neurobiology of premature brain injury. Nat Neurosci 2014, 17(3): 341-346.

3. Prasad VK, Kurtzberg J. Umbilical cord blood transplantation for non-malignant diseases. Bone Marrow Transplant 2009, 44(10): 643-651.

4. Yang WZ, Zhang Y, Wu F, Min WP, Minev B, Zhang M, et al. Safety evaluation of allogeneic umbilical cord blood mononuclear cell therapy for degenerative conditions. J Transl Med 2010, 8: 75.

5. De Coppi P, Bartsch G, Jr., Siddiqui MM, Xu T, Santos CC, Perin L, et al. Isolation of amniotic stem cell lines with potential for therapy. Nat Biotechnol 2007, 25(1): 100-106.

6. Miras-Portugal MT, Gomez-Villafuertes R, Gualix J, Diaz-Hernandez JI, Artalejo AR, Ortega F, et al. Nucleotides in neuroregeneration and neuroprotection. Neuropharmacology 2015.

7. Mueller M, Schoeberlein A, Zhou J, Joerger-Messerli M, Oppliger B, Reinhart U, et al. PreImplantation Factor bolsters neuroprotection via modulating Protein Kinase A and Protein Kinase C signaling. Cell Death Differ. 2015 Dec;22(12):2078-86

8. Kim HH, Abdelmohsen K, Gorospe M. Regulation of HuR by DNA Damage Response Kinases. J Nucleic Acids 2010.

9. Meng S, Arbit T, Veeriah S, Mellinghoff IK, Fang F, Vivanco I, et al. 14-3-3sigma and p21 synergize to determine DNA damage response following Chk2 inhibition. Cell Cycle 2009, 8(14): 2238-2246.

10. Hermeking H, Benzinger A. 14-3-3 proteins in cell cycle regulation. Semin Cancer Biol 2006, 16(3): 183-192.

11. Xu N, Lao Y, Zhang Y, Gillespie DA. Akt: a double-edged sword in cell proliferation and genome stability. J Oncol 2012, 2012: 951724.

12. Fischbach MA, Bluestone JA, Lim WA. Cell-based therapeutics: the next pillar of medicine. Sci Transl Med 2013, 5(179): 179ps177.

13. Osuga H, Osuga S, Wang F, Fetni R, Hogan MJ, Slack RS, et al. Cyclin-dependent kinases as a therapeutic target for stroke. Proceedings of the National Academy of Sciences of the United States of America 2000, 97(18): 10254-10259.

14. Ozgen H, Kahya N, de Jonge JC, Smith GS, Harauz G, Hoekstra D, et al. Regulation of cell proliferation by nucleocytoplasmic dynamics of postnatal and embryonic exon-II-containing MBP isoforms. Biochim Biophys Acta 2014, 1843(3): 517-530.

15. See WL, Miller JP, Squatrito M, Holland E, Resh MD, Koff A. Defective DNA double-strand break repair underlies enhanced tumorigenesis and chromosomal instability in p27-deficient mice with growth factor-induced oligodendrogliomas. Oncogene 2010, 29(12): 1720-1731.

16. Barnea ER, Almogi-Hazan O, Or R, Mueller M, Ria F, Weiss L, et al. Immune regulatory and neuroprotective properties of preimplantation factor: From newborn to adult. Pharmacology \& therapeutics 2015, 156: 10-25.

17. Berger R, Soder S. Neuroprotection in preterm infants. Biomed Res Int 2015, 2015: 257139.

18. Trotter A, Maier L, Pohlandt F. Management of the extremely preterm infant: is the replacement of estradiol and progesterone beneficial? Paediatr Drugs 2001, 3(9): 629-637.

19. Gerstner B, Lee J, DeSilva TM, Jensen FE, Volpe JJ, Rosenberg PA. 17beta-estradiol protects against hypoxic/ischemic white matter damage in the neonatal rat brain. Journal of neuroscience research 2009, 87(9): 2078-2086.

20. Nunez J, Yang Z, Jiang Y, Grandys T, Mark I, Levison SW. 17beta-estradiol protects the neonatal brain from hypoxia-ischemia. Experimental neurology 2007, 208(2): 269-276 
21. Lauterbach MD, Raz S, Sander CJ. Neonatal hypoxic risk in preterm birth infants: the influence of sex and severity of respiratory distress on cognitive recovery. Neuropsychology 2001, 15(3): 411-420.

22. Zhang Y, Tounekti O, Akerman B, Goodyer CG, LeBlanc A. 17-beta-estradiol induces an inhibitor of active caspases. The Journal of neuroscience : the official journal of the Society for Neuroscience 2001, 21(20): RC176.

23.Hunt R, Davis PG, Inder T. Replacement of estrogens and progestins to prevent morbidity and mortality in preterm infants. Cochrane Database Syst Rev 2004(4): CD003848.

24. Barnea ER. Insight into early pregnancy events: the emerging role of the embryo. Am J Reprod Immunol 2004, 51: 319.

25. Barnea ER, Kirk D, Ramu S, Rivnay B, Roussev R, Paidas MJ. PreImplantation Factor (PIF) orchestrates systemic antiinflammatory response by immune cells: effect on peripheral blood mononuclear cells. Am J Obstet Gynecol 2012, 207: 313.

26. Stamatkin CW, Roussev RG, Stout M, Absalon-Medina V, Ramu S, Goodman C, et al. PreImplantation Factor (PIF) correlates with early mammalian embryo development-bovine and murine models. Reproductive Biology and Endocrinology 2011, 9: 63.

27. Ramu S, Stamatkin C, Timms L, Ruble M, Roussev RG, Barnea ER. PreImplantation factor (PIF) detection in maternal circulation in early pregnancy correlates with live birth (bovine model). Reprod Biol Endocrinol 2013, 11: 105.

28. Ornaghi S, Mueller M, Barnea ER, Paidas MJ. Thrombosis during pregnancy: Risks, prevention, and treatment for mother and fetus--harvesting the power of omic technology, biomarkers and in vitro or in vivo models to facilitate the treatment of thrombosis. Birth Defects Res C Embryo Today 2015, 105(3): 209-225.

29. Azar Y, Shainer R, Almogi-Hazan O, Bringer R, Compton SR, Paidas MJ, et al. Preimplantation factor reduces graft-versus-host disease by regulating immune response and lowering oxidative stress (murine model). Biol Blood Marrow Transplant 2013, 19(4): 519-528.

30. Weiss L, Bernstein S, Jones R, Amunugama R, Krizman D, Jebailey L, et al. Preimplantation factor (PIF) analog prevents type I diabetes mellitus (TIDM) development by preserving pancreatic function in NOD mice. Endocrine 2011, 40(1): 41-54.

31. Weiss L, Or R, Jones RC, Amunugama R, JeBailey L, Ramu S, et al. Preimplantation factor (PIF*) reverses neuroinflammation while promoting neural repair in EAE model. Journal of the neurological sciences 2012, 312(1-2): 146-157.

32. Hagberg H, Mallard C, Ferriero DM, Vannucci SJ, Levison SW, Vexler ZS, et al. The role of inflammation in perinatal brain injury. Nature reviews Neurology 2015, 11(4): 192-208.

33. Baron JC, Yamauchi H, Fujioka M, Endres M. Selective neuronal loss in ischemic stroke and cerebrovascular disease. J Cereb Blood Flow Metab 2014, 34: 2-18.

34. Jellema RK, Lima Passos V, Zwanenburg A, Ophelders DR, De Munter S, Vanderlocht J, et al. Cerebral inflammation and mobilization of the peripheral immune system following global hypoxia-ischemia in preterm sheep. J Neuroinflammation 2013, 10: 13.

35. Bjuland KJ, Lohaugen GC, Martinussen M, Skranes J. Cortical thickness and cognition in very-low-birth-weight late teenagers. Early human development 2013, 89(6): 371-380.

36. Consortium EP, Birney E, Stamatoyannopoulos JA, Dutta A, Guigo R, Gingeras TR, et al. Identification and analysis of functional elements in $1 \%$ of the human genome by the ENCODE pilot project. Nature 2007, 447(7146): 799-816.

37. Lehmann SM, Kruger C, Park B, Derkow K, Rosenberger K, Baumgart J, et al. An unconventional role for miRNA: let-7 activates Toll-like receptor 7 and causes neurodegeneration. Nat Neurosci 2012, 15(6): 827-835.

38. Selvamani A, Sathyan P, Miranda RC, Sohrabji F. An antagomir to microRNA Let7f promotes neuroprotection in an ischemic stroke model. PLoS One 2012, 7(2): e32662.

39. Bartel DP. MicroRNAs: target recognition and regulatory functions. Cell 2009, 136(2): 215233. 


\section{Chapter 7}

40. Trabucchi M, Briata P, Filipowicz W, Rosenfeld MG, Ramos A, Gherzi R. How to control miRNA maturation? RNA biology 2009, 6(5): 536-540.

41. Michlewski G, Caceres JF. Antagonistic role of hnRNP A1 and KSRP in the regulation of let7a biogenesis. Nat Struct Mol Biol 2010, 17(8): 1011-1018.

42. Thornton JE, Gregory RI. How does Lin28 let-7 control development and disease? Trends Cell Biol 2012.

43. Huang Y. A mirror of two faces: Lin28 as a master regulator of both miRNA and mRNA. Wiley Interdiscip Rev RNA 2012.

44. Trabucchi M, Briata P, Garcia-Mayoral M, Haase AD, Filipowicz W, Ramos A, et al. The RNA-binding protein KSRP promotes the biogenesis of a subset of microRNAs. Nature 2009, 459(7249): 1010-1014.

45. Dhillon SK, Gunn AJ, Jung Y, Mathai S, Bennet L, Fraser M. Lipopolysaccharide-Induced Preconditioning Attenuates Apoptosis and Differentially Regulates TLR4 and TLR7 Gene Expression after Ischemia in the Preterm Ovine Fetal Brain. Dev Neurosci 2015, 37(6): 497-514.

46. Leenders AG, Sheng ZH. Modulation of neurotransmitter release by the second messengeractivated protein kinases: implications for presynaptic plasticity. Pharmacology \& therapeutics 2005, 105(1): 69-84.

47. Libien J, Sacktor TC, Kass IS. Magnesium blocks the loss of protein kinase C, leads to a transient translocation of PKC(alpha) and PKC(epsilon), and improves recovery after anoxia in rat hippocampal slices. Brain research Molecular brain research 2005, 136(1-2): 104-111.

48. Raval AP, Dave KR, Mochly-Rosen D, Sick TJ, Perez-Pinzon MA. Epsilon PKC is required for the induction of tolerance by ischemic and NMDA-mediated preconditioning in the organotypic hippocampal slice. The Journal of neuroscience : the official journal of the Society for Neuroscience 2003, 23(2): 384-391.

49. Selvatici R, Melloni E, Ferrati M, Piubello C, Marincola FC, Gandini E. Adaptative value of a PKC-PKI55 feedback loop of inhibition that prevents the kinase's deregulation. Journal of molecular evolution 2003, 57(2): 131-139.

50. Hou L, Wang X. PKC and PKA, but not PKG mediate LPS-induced CGRP release and $[\mathrm{Ca}(2+)](\mathrm{i})$ elevation in DRG neurons of neonatal rats. Journal of neuroscience research 2001, 66(4): 592-600.

51. Tse KH, Chow KB, Leung WK, Wong YH, Wise H. Primary sensory neurons regulate Tolllike receptor-4-dependent activity of glial cells in dorsal root ganglia. Neuroscience 2014, 279: 1022.

52. Mueller M, Zhou J, Yang L, Gao Y, Wu F, Schoeberlein A, et al. PreImplantation factor promotes neuroprotection by targeting microRNA let-7. Proceedings of the National Academy of Sciences of the United States of America 2014, 111(38): 13882-13887.

53. Sun MK, Alkon DL. Pharmacology of protein kinase C activators: cognition-enhancing and antidementic therapeutics. Pharmacology \& therapeutics 2010, 127(1): 66-77.

54. Chen Z, Jalabi W, Hu W, Park HJ, Gale JT, Kidd GJ, et al. Microglial displacement of inhibitory synapses provides neuroprotection in the adult brain. Nature communications 2014, 5: 4486.

55. Park HJ, Park KH, Shin KS, Lee MK. The roles of cyclic AMP-ERK-Bad signaling pathways on 6-hydroxydopamine-induced cell survival and death in PC12 cells. Toxicology in vitro : an international journal published in association with BIBRA 2013, 27(8): 2233-2241.

56. Zhao H, Yenari MA, Cheng D, Sapolsky RM, Steinberg GK. Bcl-2 overexpression protects against neuron loss within the ischemic margin following experimental stroke and inhibits cytochrome c translocation and caspase-3 activity. Journal of neurochemistry 2003, 85(4): 10261036.

57. Zhang L, Zhao H, Zhang X, Chen L, Zhao X, Bai X, et al. Nobiletin protects against cerebral ischemia via activating the p-Akt, p-CREB, BDNF and Bcl-2 pathway and ameliorating BBB permeability in rat. Brain research bulletin 2013, 96: 45-53. 
58. Sist B, Fouad K, Winship IR. Plasticity beyond peri-infarct cortex: spinal up regulation of structural plasticity, neurotrophins, and inflammatory cytokines during recovery from cortical stroke. Experimental neurology 2014, 252: 47-56.

59. Connelly WM, Errington AC, Di Giovanni G, Crunelli V. Metabotropic regulation of extrasynaptic GABAA receptors. Frontiers in neural circuits 2013, 7: 171.

60. Tanaka K. Alteration of second messengers during acute cerebral ischemia - adenylate cyclase, cyclic AMP-dependent protein kinase, and cyclic AMP response element binding protein. Progress in neurobiology 2001, 65(2): 173-207.

61. Lalu MM, McIntyre L, Pugliese C, Fergusson D, Winston BW, Marshall JC, et al. Safety of cell therapy with mesenchymal stromal cells (SafeCell): a systematic review and meta-analysis of clinical trials. PLoS One 2012, 7(10): e47559.

62. Hubner S, Reich B, Heckmann M. Role of sex steroids and their receptors in human preterm infants: Impacts on future treatment strategies for cerebral development. Biochem Pharmacol 2015, 98(4): 556-563.

63. Gabory A, Jammes H, Dandolo L. The H19 locus: role of an imprinted non-coding RNA in growth and development. Bioessays 2010, 32(6): 473-480.

64. Gao Y, Wu F, Zhou J, Yan L, Jurczak MJ, Lee HY, et al. The H19/let-7 double-negative feedback loop contributes to glucose metabolism in muscle cells. Nucleic Acids Res 2014, 42(22): 13799-13811.

65. Ghazal S, McKinnon B, Zhou J, Mueller M, Men Y, Yang L, et al. H19 lncRNA alters stromal cell growth via IGF signaling in the endometrium of women with endometriosis. EMBO Mol Med 2015, 7(8): 996-1003.

66. Zhou J, Yang L, Zhong T, Mueller M, Men Y, Zhang N, et al. H19 lncRNA alters DNA methylation genome wide by regulating S-adenosylhomocysteine hydrolase. Nature communications 2015, 6: 10221.

67. Kallen AN, Zhou XB, Xu J, Qiao C, Ma J, Yan L, et al. The imprinted H19 lncRNA antagonizes let-7 microRNAs. Molecular cell 2013, 52(1): 101-112. 

Chapter 8

Summary 


\section{Pregnancy derived products for treatment of perinatal brain injuries}

\section{Introduction}

Perinatal brain injuries affect both preterm and term born infants and successful therapies are lacking. In the last decade, new therapeutic strategies have emerged for perinatal brain injuries with embryo and placental derived products such as mesenchymal stem/stromal cells (MSCs), Estradiol, and PreImplantation Factor (PIF) being of special interest. The objective of this translational research was to establish (1) the feasibility and protective capacity of Wharton`s Jelly derived MSCs (WJ-MSCs), (2) the potential of 17 $\beta$-Estradiol supplementation, (3) the neuroprotective effects of synthetic PreImplantation Factor (sPIF) in murine models of perinatal brain injury. The underlying mechanisms were dissected as well.

\section{Methods}

We evaluated the neuroprotective potential of embryo and placenta derived products in vitro using neuronal and immune cells and in vivo using rat models of perinatal brain injury. To test WJ-MSCs (1) potential we developed a model of stereotactic intracerebral injections in neonatal rats and subsequently tested WJMSCs in an immature brain injury model. To screen for potential signaling pathways we used well defined motif antibodies and performed Western Blots. $17 \beta$-Estradiol (2) and sPIF (3) were tested in neonatal brain injury models and the underlying mechanisms (3) were dissected in vitro. Functional tests were performed (1) and all brains were assessed by histology.

\section{Results}

WJ-MSCs (1) after stereotactic intracerebral transplantation migrate throughout the ventricle system and home in the brain. WJ-MSCs reduce injury-mediated myelination loss and astroglial activation while preserving proper functional behavior of the animals. Importantly these observed protective effects were mediated in part by targeting crucial signaling pathways involved in cell cycle regulation and apoptosis. Following brain injury WJ-MSCs modulate cyklindependent kinase (CDK), Protein kinase B (Akt), and 14-3-3 binding protein partners.

$17 \beta$-Estradiol (2) reduces macroscopically and microscopically brain damage after injury. Treatment results in restored cerebral volume and significantly reduced number of apoptotic cells.

Subcutaneously injected SPIF (3) co-localized with both neurons and glia. sPIF abrogated neuronal loss and glial activation after injury while shifting microglia anti-inflammatory state. Further, sPIF restored cortical architecture and neuronal morphology while reducing the number of apoptotic cells. Mechanistically, sPIF reduced the biogenesis of let- 7 , which in the extracellular environment causes cell death. sPIF decreased production of let-7 by destabilizing KSRP, a key microRNA processing protein, in a TLR4/PI3K/Akt-dependent manner. Additionally, in a TLR4-dependent fashion, sPIF modulated PKA/PKC signaling. sPIF increased phosphorylation of neuroprotective substrates GAP-43, CREB, and $\mathrm{BAD}$, which in turn stimulated expression of downstream genes Gap43, Bdnf and Bcl2.

\section{Conclusion}


Pregnancy derived products such as Wharton`s Jelly derived MSCs, 17ßEstradiol, and synthetic PreImplantation Factor protect the immature brain after perinatal injury. These effects are partially mediated by modulating non-coding RNAs and cell fate signaling pathways. 

Chapter 9

Nederlandse samenvatting

Summary in Dutch 


\section{Zwangerschaps afgeleide producten voor de behandeling van perinataal hersenletsel}

\section{Introductie}

Perinataal hersenletsel heeft invloed op zowel prenatale alsook a temre geboren kinderen en succesvolle therapieën ontbreken. In de laatste 10 jaar, zijn nieuwe therapeutische strategieën ontstaan voor perinataal hersenletsel bij embryo's en zijn placenta afgeleide producten als mesenchymale stam-/bindweefsel cellen (MSC's), Estradiol en PreImplantation Factor (PIF) van speciaal belang. Het doel van dit translationeel onderzoek was om de haalbaarheid en de beschermende capaciteit van Wharton Jelly afgeleide MSC's, het potentieel van $17 \beta$-Estradiol suppletie, en de neuroprotectieve effecten van synthetische PIF (sPIF) in muismodellen van perinatale hersenletsel te behalen. De onderliggende mechanismen werden ook ontleed.

\section{Methoden}

We evalueerden het neuroprotectieve vermogen van embryo en placenta afgeleide producten in vitro met behulp van neurale en immuuncellen en in vivo in ratmodellen van perinatale hersenbeschadiging. Om WJ-MSC's potentieel te testen hebben we een model van stereotactische intracerebrale injecties in neonatale ratten en vervolgens WJ-MSC's getest in onvolgroeide hersenletsel model ontwikkeld. Om te screenen op mogelijke signaalwegen gebruikten we goed gedefinieerde motief antilichamen en uitgevoerd Western Blots. 17ßEstradiol en sPIF werden getest in neonatale hersenletsel modellen en de onderliggende mechanismen werden ontleed in vitro. Functionele test werden uitgevoerd en alle hersenen werden beoordeeld door histologie.

\section{Resultaten}

WJ-MSC's na stereotactische intracerebrale transplantatie migreren gedurende de ventrikel systeem en thuis in de hersenen. WJ-MSC's verminderen letsel gemedieerde myelinisatie verlies en astrologlial actvitation met behoud van een goede functionele gedrag van de dieren. Belangrijker werden deze waargenomen beschermende effecten gedeeltelijk gemedieerd door zich te richten cruciale signaalwegen betrokken bij de regulering van de celcyclus en apoptose. $\mathrm{Na}$ hersenletsel WJ-MSC moduleren cycline-afhankelijke kinase (CDK), proteïne kinase B (Akt) en bindend 14-3-3 eiwit partners. 17 $\beta$-Estradiol vermindert macroscopisch en microscopisch hersenschade na een blessure. Behandeling leidt gerestaureerd hersenvolume en significant verminderd aantal apoptotische cellen. Subcutaan SPIF co-gelokaliseerd met zowel neuronen en glia. sPIF afgeschaft neuronaal verlies en gliacellen activering na een blessure, terwijl er verschuiving is van microglia anti-inflammatoire toestand. Verder sPIF herstelde corticale architectuur en neuronale morfologie, gedurende het verminderen van het aantal apoptotische cellen. Mechanistisch sPIF verminderde de biogenese van let-7, die in het extracellulaire milieu celdood veroorzaakt. sPIF verminderde productie van laat-7 door destabiliseren KRSP, een belangrijke microRNA processing eiwit, in een TLR4 / PI3K / Akt-afhankelijke manier. Bovendien, in een TLR4afhankelijke wijze, sPIF gemoduleerde PKA / PKC signalering, sPIF verhoogde fosforylering van neuroprotectieve substraten GAP-43, CREB en BAD, die op hun beurt de expresse stimuleerde van stroomafwaarts genen Gap43, Bdnf en Bcl2. 


\section{Conclusie}

Zwangerschap afgeleide producten, zoals Wharton's Jelly afgeleide MSC's, 17ßEstradiol, en synthetische PreImplantation Factor beschermen van de onvolgroeide hersenen na perinataal letsel. Deze effecten worden gedeeltelijk gemedieerd door modulerende niet-coderende RNA's en mobiele bestemde signaalroutes. 



\section{Dankwoord \\ Acknowledgments}

The present thesis is the result of many years of work which could not have been accomplished without continuous support of my mentors, friends, and family.

I am deeply grateful to my promoters, Professor dr. B.W. Kramer and Professor dr. D. Surbek, for their continuous guidance, support, and advice throughout my graduate and postdoctoral career. Dear Boris, thank your for the invitation and the opportunity to present this thesis. Your diligence, enthusiasm, and thirst for knowledge are a constant example to me of a dedicated scientist. Dear Daniel, thank you for demonstrating me that a successful research career and a fulfilling clinical practice in obstetrics are not mutually exclusive.

Moreover, I am deeply grateful to my teacher in science, Professor dr. Michael Paidas. Dear Michael, your amazing energy and vibrancy, broad spectrum of interests, and the love of a good challenge have guided me on the path of a successful scientist.

I am grateful to my teacher in science, Professor dr. Yingqun Huang. Dear Yingqun, thank you for stimulating my curiosity and a desire to learn more about science. You have educated me in the world of professional science.

I am also grateful to Dr. Eytan Barnea. Dear Eytan, you have been an integral part of my development from an "interested" researcher to someone who wants to walk down this career path. Thank you for your trust.

I also thank Professor dr. Richard Berger for his critical and inspiring education. Dear Richard, thank you for sparking my interest for science and obstetrics.

I would like to acknowledge the continuous support of Dr. Andreina Schoeberlein. Dear Andreina, thank you for enhancing my personal development as an independent and successful researcher.

On a personal note, I would like to thank my parents. Their patience was inexhaustible. I am very grateful to my love, Dr. Christina Bürgler. Dear Christina, whithout you this project and a great deal of happiness in my life would not have been possible. This book is dedicated to you. 

Publications 


\section{Publications}

\section{THIS THESIS}

Mueller M, Wolfs TG, Schoeberlein A, Gavilanes AW, Surbek D, Kramer BW. Mesenchymal stem/stromal cells-a key mediator for regeneration after perinatal morbidity?. Mol Cell Pediatr. 2016 Dec;3(1):6. PubMed PMID: 26869264; PubMed Central PMCID: PMC4751100.

Schoeberlein A*, Mueller M*, Reinhart U, Sager R, Messerli M, Surbek D. Homing of placenta-derived mesenchymal stem cells after perinatal intracerebral transplantation in a rat model. Am J Obstet Gynecol. 2011 Sep;205(3):277.e1-6. PubMed PMID: 22071064. *both authors contributed equally to this work

Mueller M, Oppliger B, Joerger-Messerli M, Reinhart U, Barnea E, Paidas M, Kramer BW, Surbek DV, Schoeberlein A. Wharton`s jelly Mesenchymal Stem Cells protect the immature brain in rats by modulating cell fate. Submitted to Stem Cells and Dev. 2016

Mueller M, Middelanis J, Meier C, Surbek D, Berger R. 17 $\beta$-estradiol protects 7day old rats from acute brain injury and reduces the number of apoptotic cells. Reprod Sci. 2013 Mar;20(3):253-61. PubMed PMID: 22875845

Mueller M, Zhou J, Yang L, Gao Y, Wu F, , Schoeberlein A, Surbek D, Barnea E, Paidas M, Huang Y. PreImplantation factor promotes neuroprotection by targeting microRNA let-7. Proc Natl Acad Sci U S A. 2014 Sep 23;111(38):13882-7. PubMed PMID: 25205808; PubMed Central PMCID: PMC4183321.

Mueller M, Schoeberlein A, Zhou J, Joerger-Messerli M, Oppliger B, Reinharts U, Bordey A, Surbek D, Barnea E, Huang Y, Paidas M . PreImplantation Factor bolsters neuroprotection via modulating Protein Kinase A and Protein Kinase C signaling. Cell Death Differ. 2015 Dec;22(12):2078-86. PubMed PMID: 25976303

\section{NOT INCULDED IN THIS THESIS}

\section{REGENERATIVE MEDICINE}

Joerger-Messerli MS, Marx C, Oppliger B, Mueller M, Surbek DV, Schoeberlein A. Mesenchymal Stem Cells from Wharton's Jelly and Amniotic Fluid. Best Pract Res Clin Obstet Gynaecol. 2016 Feb;31:30-44. PubMed PMID: 26482184.

Barnea E.R, Almogi-Hazan O, Or R, Mueller M, Ria F, Weiss L, Paidas MJ. Immune regulatory and neuroprotective properties of preimplantation factor: From newborn to adult. Pharmacol Ther. 2015 Dec;156:10-25. PubMed PMID: 26546485.

\section{STEM CELLS STUDIES}


Joerger-Messerli M, Brühlmann E, Bessire A, Wagner A, Mueller M, Surbek DV. Preeclampsia enhances neuroglial marker expression in umbilical cord Wharton's jelly-derived mesenchymal stem cells. J Matern Fetal Neonatal Med. 2015 Mar;28(4):464-9. PubMed PMID: 24803009.

Messerli M, Wagner A, Sager R, Mueller M, Baumann M, Surbek DV, Schoeberlein A. Stem cells from umbilical cord Wharton's jelly from preterm birth have neuroglial differentiation potential. Reprod Sci. 2013 Dec;20(12):145564. PubMed PMID: 23670950; PubMed Central PMCID: PMC3817666.

Portmann-Lanz CB, Baumann MU, Mueller M, Wagner AM, Weiss S, Haller O, Sager R, Reinhart U, Surbek DV. Neurogenic characteristics of placental stem cells in preeclampsia. Am J Obstet Gynecol. 2010 Oct;203(4):399.e1-7. PubMed PMID: 20723871.

\section{NON-CODING RNAs STUDIES}

Zhou J, Yang L, Zhong T, Mueller M, Men Y, Zhang N, Xie J, Giang K, Chung H, Sun X, Lu L, Carmichael G, Taylor H \& Huang Y. H19 lncRNA alters DNA methylation genome wide by regulating S-adenosylhomocysteine hydrolase. Nat Commun. 2015 Dec 21;6:10221. PubMed PMID: 26687445; PubMed Central PMCID: PMC4703905.

Ghazal S, McKinnon B, Zhou J, Mueller M, Men Y, Yang L, Mueller M, Flannery C, Huang Y, Taylor HS. H19 lncRNA alters stromal cell growth via IGF signaling in the endometrium of women with endometriosis. EMBO Mol Med. 2015 Jun 18;7(8):996-1003. PubMed PMID: 26089099; PubMed Central PMCID: PMC4551339.

Gao Y, Wu F, Zhou J, Yan L, Jurczak M, Lee H, Yang L, Mueller M, Zhou X, Dandolo L, Szendroedi J, Roden M, Flannery C, Taylor H. The H19/let-7 doublenegative feedback loop contributes to glucose metabolism in muscle cells. Nucleic Acids Res. 2014 Dec 16;42(22):13799-811. PubMed PMID: 25399420; PubMed Central PMCID: PMC4267628.

\section{MATERNAL HEALTH STUDIES}

Christmann-Schmid C, Raio L, Scheibner K, Mueller M, Surbek D. Back to "once a caesarean: always a caesarean"? A trend analysis in Switzerland. Arch Gynecol Obstet. 2016 Mar 15;PubMed PMID: 26980229.

Ornaghi S, Mueller M, Barnea ER, Paidas MJ. Thrombosis during pregnancy: Risks, prevention, and treatment for mother and fetus--harvesting the power of omic technology, biomarkers and in vitro or in vivo models to facilitate the treatment of thrombosis. Birth Defects Res C Embryo Today. 2015 Sep;105(3):209-25. PubMed PMID: 26403978.

Mueller M, Henle A, Droz S, Kind AB, Rohner S, Baumann M, Surbek DV. Intrapartum detection of Group B streptococci colonization by rapid PCR-test on labor ward. Eur J Obstet Gynecol Reprod Biol. 2014 May;176:137-41. PubMed PMID: 24680393. 
Fröhlicher S, Reichen-Fahrni G, Mueller M, Surbek D, Droz S, Spellerberg B, Sendi P. Serotype distribution and antimicrobial susceptibility of group B streptococci in pregnant women: results from a Swiss tertiary centre. Swiss Med Wkly. 2014 Mar 20;144:w13935. PubMed PMID: 24652673.

Mueller M, Kolly L, Bauman M, Imboden S, Surbek DV. Analysis of caesarean section rates over time in a single Swiss centre using a ten-group classification system. Swiss Med Wkly. 2014 Feb 19;144:w13921. PubMed PMID: 24554332.

\section{OTHERS}

Imboden S, Müller M, Raio L, Mueller MD, Tutschek B. Clinical significance of 3D ultrasound compared to MRI in uterine malformations. Ultraschall Med. 2014 Oct;35(5):440-4. PubMed PMID: 24557634.

Huber C, Zdanowicz JA, Mueller M, Surbek D. Factors influencing the accuracy of fetal weight estimation with a focus on preterm birth at the limit of viability: a systematic literature review. Fetal Diagn Ther. 2014;36(1):1-8. PubMed PMID: 24863502.

Mueller M, Baumann MU, Mueller MD, Kuhn A. A randomized comparison of microtip and air-charged catheter for the measurement of maximum urethral closure pressure. Ginekol Pol. 2012 Aug;83(8):586-9. PubMed PMID: 23342881.

Schmid C, Berger K, Müller M, Silke J, Mueller MD, et al. Painful bladder syndrome: management and effect on sexual function and quality of life. Ginekol Pol. 2011 Feb;82(2):96-101. PubMed PMID: 21568222. 
Curriculum Vitae 
Martin Müller was born on December $5^{\text {th }}, 1976$ in Wroclaw (Poland). He moved with his parents in early childhood to Germany. After attending graduate schools in Germany and Canada he graduated secondary school at the English High School at Boston, USA in 1996. Martin attended medical school at the University of Wroclaw (Poland) and Bochum (Germany) and received his medical degree in both countries in 2002. In 2002 (Bochum) he initiated his residency in Obstetrics and Gynecology and received his board certification in 2007. In 2008 he worked as Senior Registrar Physician in Neuwied (Germany) and in 2009 Martin joined the Department of Obstetrics and Gynecology at the University Hospital Bern (Switzerland) where he gained the subspeciality certificate for Obstetrics and Feto-Maternal Medicine in 2013. Additionally, 2014 he started his postdoctoral education in New Haven (USA) at the Yale University School of Medicine. Since his return to University of Bern in 2015, he works as Medical Director of the Outpatient Clinic (Bern) and Visiting Assistant Professor (Yale). His research carrier focused on therapeutic approaches to salvage brain neonatal brain injuries and the collaborations between Bern (Prof. Surbek), Yale (Prof. Paidas) and Maastricht (Prof. Kramer) formed the basis for this thesis. Martin recently received subspeciality certificate for operative Obstetrics and Gynecology and venia docendi (Habilitation) at University of Bern, Switzerland. 
